\title{
The feasibility of ecological taxation
}

Citation for published version (APA):

Paulus, A. T. G. (1995). The feasibility of ecological taxation. [Doctoral Thesis, Maastricht University]. Rijksuniversiteit Limburg. https://doi.org/10.26481/dis.19951109ap

Document status and date:

Published: 01/01/1995

DOI:

10.26481/dis.19951109ap

Document Version:

Publisher's PDF, also known as Version of record

\section{Please check the document version of this publication:}

- A submitted manuscript is the version of the article upon submission and before peer-review. There can be important differences between the submitted version and the official published version of record.

People interested in the research are advised to contact the author for the final version of the publication, or visit the DOI to the publisher's website.

- The final author version and the galley proof are versions of the publication after peer review.

- The final published version features the final layout of the paper including the volume, issue and page numbers.

Link to publication

\footnotetext{
General rights rights.

- You may freely distribute the URL identifying the publication in the public portal. please follow below link for the End User Agreement:

www.umlib.nl/taverne-license

Take down policy

If you believe that this document breaches copyright please contact us at:

repository@maastrichtuniversity.nl

providing details and we will investigate your claim.
}

Copyright and moral rights for the publications made accessible in the public portal are retained by the authors and/or other copyright owners and it is a condition of accessing publications that users recognise and abide by the legal requirements associated with these

- Users may download and print one copy of any publication from the public portal for the purpose of private study or research.

- You may not further distribute the material or use it for any profit-making activity or commercial gain

If the publication is distributed under the terms of Article $25 \mathrm{fa}$ of the Dutch Copyright Act, indicated by the "Taverne" license above, 


\section{THE FEASIBILITY OF ECOLOGICAL TAXATION}

Aggie Paulus 


\title{
THE FEASIBILITY \\ OF ECOLOGICAL TAXATION
}

\author{
PROEFSCHRIFT
}

Ter verkrijging van de graad van doctor aan de Rijksuniversiteit Limburg te Maastricht, op gezag van de Rector Magnificus, Prof.mr. M.J. Cohen, volgens het besluit van het College van Dekanen, in het openbaar te verdedigen op

donderdag 9 november 1995 om 14.00 uur

door

Agnes Theodora Gerarda Paulus 


\section{Promotor:}

Prof.dr. J.G. Backhaus

\section{Co-promotor:}

Dr. G. Meijer

Leden van de beoordelingscommissie:

Prof.dr. A. van Witteloostuijn (voorzitter)

Prof.dr. M.G. Faure LL.M.

Prof.dr. J. Muysken

Prof.dr. A. Nentjes (Rijksuniversiteit Groningen)

CIP DATA KONINKLIJKE BIBLIOTHEEK, DEN HAAG

Paulus, Agnes Theodora Gerarda

The Feasibility of Ecological Taxation / Agnes Theodora

Gerarda Paulus. - Ill., fig., tab.

Thesis Rijksuniversiteit Limburg Maastricht. - With index, ref. - With Summary in Dutch.

ISBN 90-9008775-3

Subject headings: environmental taxation / ecotaxes.

(C)1995 Aggie Paulus, Matastricht

Druk: Datawyse I Universitaire Pers Maastricht 
Voor Mam, Pap, Hella, John, Sander en Laura 



\section{Preface}

Within the context of the first National Research Programme on Global Air Pollution and Climate Change (NRP), a research project entitled "The Feasibility of an Ecological Tax Reform in the Netherlands" was started in August 1991 at the University of Limburg in Maastricht. On behalf of the Ministry of Housing, Physical Planning and Environment (VROM) in the Netherlands, the research project was (partly) financed and co-ordinated by the National Institute of Public Health and Environmental Protection (RIVM). Within the National Research Programme, the afore mentioned research project was part of a set of four research projects in total. Of the other three research projects, two were conducted at the Free University and the Institute for Environmental Studies in Amsterdam and one at the University of Groningen.

The research projects conducted in Amsterdam were aimed at investigating the socio-economic aspects of the greenhouse effect in terms of a Climate Fund and at constructing a general equilibrium model to supplement the macro-economic results of sectoral economic effects of environmental policy options of the Central Planning Bureau of Statistics. The research project conducted in Groningen studied the instrument of tradeable carbon dioxide emission permits as a policy instrument for reducing $\mathrm{CO}_{2}$ emissions. Within the context of the National Research Programme and the afore mentioned set of research projects, the research project conducted at the University of Limburg in Maastricht was aimed at determining the feasibility of ecological taxation. The research was embedded into a $\mathrm{Ph} . \mathrm{D}$ research project. The research results of the latter project are presented in this dissertation.

Since many have knowingly or unknowingly contributed to the effort of creating a dissertation on a topic which is constantly debated in practice, I would like to express my thanks and gratitude. First, the financial support and the opportunities provided by the RIVM to conduct research within the framework of the first NRP are gratefully acknowledged. In the same sense, I'm grateful to all the other NRP researchers and especially those with whom I held discussions and presentations on the subject during different conferences. Their remarks and suggestions are strongly appreciated. Further, since writing a dissertation is usually a guided individual effort, I would like to thank my promotor Prof. Dr. J.G. Backhaus and my co-promotor Dr. G. Meijer for their practical and constructive guidance. For their evaluation and remarks on the final version of this dissertation, thanks are also due to Prof. Dr. A. van Witteloostuijn, Prof. Dr. M.G. Faure, Prof. Dr. A. Nentjes and Prof. Dr. J. Muysken. I would also like to express my gratitude for the members of the public finance group at the University of Limburg, especially those with whom I weekly attended our so-called Brown Bag meetings. The same gratitude is expressed for colleagues and friends at the Faculty of Economics at the University of Limburg, and especially 
for those Ph.D students with whom I shared frustrations, joys, despair and happiness. Thanks are also due to those who provided comments or further starting points for particular parts of the dissertation, with special thanks for Prof. C. Powers (University of Santa Clara, California, USA), Prof. N. Tideman (Virginia Polytechnic Institute and State University, Blacksburg Virginia, USA) and Prof. B. Frey (University of Zürich, Switzerland). Last but certainly not least, I would like to thank my family for supporting me in all possible ways and manners I can think of. 'Mam, Pap, Hella, John, Sander en Laura, dit book is daorum daan auch aon uuch opgedraage.'

Maastricht, August 22, 1995. 


\section{Contents}

List of Figures $\ldots \ldots \ldots \ldots \ldots \ldots \ldots \ldots \ldots \ldots \ldots \ldots \ldots \ldots$ viii

List of Tables and Schemes $\ldots \ldots \ldots \ldots \ldots \ldots \ldots \ldots \ldots$ viii

List of Translated Terms $\ldots \ldots \ldots \ldots \ldots \ldots \ldots \ldots \ldots \ldots \ldots \ldots \ldots$

1 Introduction, background and scope $\ldots \ldots \ldots \ldots \ldots \ldots \ldots$

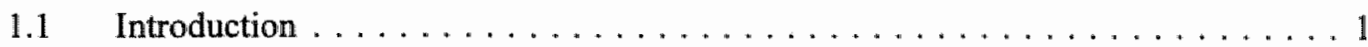

1.2 From market to government failures $\ldots \ldots \ldots \ldots \ldots \ldots \ldots \ldots$

1.2.1 The internalization of suggestions of Pigou into
environmental economics and public finance $\ldots \ldots \ldots \ldots \ldots \ldots$.

1.2 .2 Political economy . . . . . . . . . . . . . . . . 6

1.3 Background and scope: analytical framework and research questions $\ldots \ldots \ldots \ldots \ldots \ldots \ldots \ldots \ldots$

1.4 Research approach and outline of the study $\ldots \ldots \ldots \ldots \ldots \ldots$

2 Ecological taxation: origin and theoretical context $\ldots \ldots \ldots \ldots \ldots \ldots$

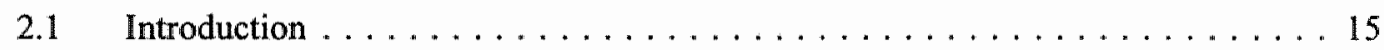

2.2 The economic approach to environmental problems and the theory of environmental policy $\ldots \ldots \ldots \ldots \ldots \ldots \ldots \ldots \ldots$

2.2.1 Relationships between ecological and economic systems . . . . . . . 15

2.2.2 Environmental economics and the theory of environmental policy ..................... 17

2.3 The idea of using taxes for ecological purposes:

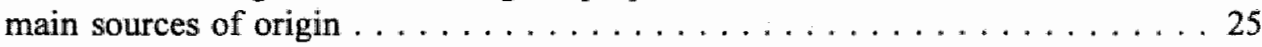

2.3 .1 Pigouvian taxes $\ldots \ldots \ldots \ldots \ldots \ldots \ldots \ldots \ldots \ldots \ldots . \ldots \ldots$

2.3.2 Possibilities to incorporate the idea of Pigouvian taxes into actual environmental policy making $\ldots \ldots \ldots \ldots \ldots \ldots \ldots$

2.3.3 The use of revenue raising taxes for ecological purposes $\ldots \ldots \ldots 34$

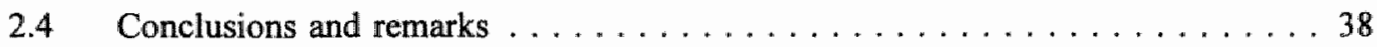




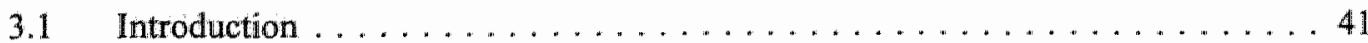

3.2 Defining taxes that are relevant

from an ecological point of view $\ldots \ldots \ldots \ldots \ldots \ldots \ldots \ldots \ldots \ldots \ldots$

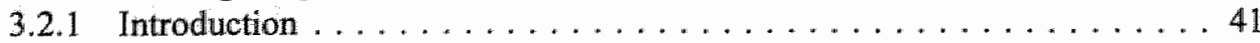

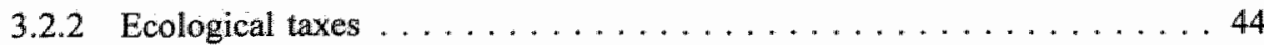

3.2.3 Ecologically relevant taxes $\ldots \ldots \ldots \ldots \ldots \ldots \ldots \ldots \ldots$

3.3 General possibilities of using taxes for ecological purposes . . . . . . . . . . . 49

3.4 General problems of using taxes for ecological purposes $\ldots \ldots \ldots \ldots 5$

3.5 Ecological taxes and ecological tax reform:

a checklist for design and implementation

4 The imposition of ecological taxes and the concept of ecological tax units . 77

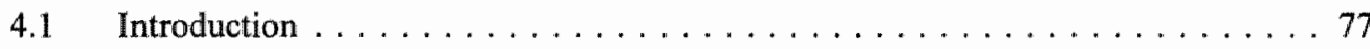

$4.2 \quad$ Ecological level and circumstances $\ldots \ldots \ldots \ldots \ldots \ldots \ldots 78$

4.3 Ecological taxation: taxing authority

and level of introduction . . . . . . . . . . . . . . . . . . . . 79

4.3.1 The theory of fiscal federalism, clubs and local expenditures . . . . . . . . . . . . . . . 79

4.3.2 Ecological taxation: economic level . . . . . . . . . . . . . 86

4.3.3 The imposition of ecological taxes: the political decision making process $\ldots \ldots \ldots \ldots \ldots \ldots 8$

4.4 Ecological tax units $\ldots \ldots \ldots \ldots \ldots \ldots \ldots \ldots \ldots \ldots \ldots \ldots \ldots$

4.5 The river Rhine: possibilities for the application of the idea of ecological tax units . . . . . . . . . . . . . . 96

4.6 From current political units to ecological tax units? . . . . . . . . . . . . 99

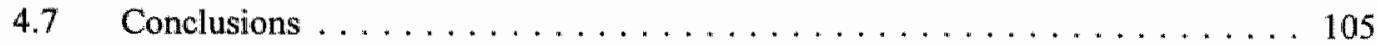

5 From theory to practice: an analytical framework $\ldots \ldots \ldots \ldots$. . .

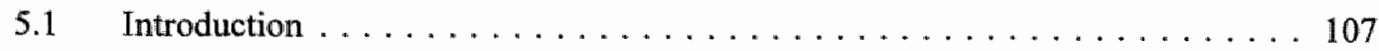


5.3 The development of ecological taxation $\ldots \ldots \ldots \ldots \ldots \ldots \ldots \ldots \ldots$

5.4 An analysis of the feasibility of ecological taxation in the Netherlands.

6 The institutional, fiscal and environmental policy

framework for ecological taxation in the Netherlands $\ldots \ldots \ldots \ldots \ldots 117$

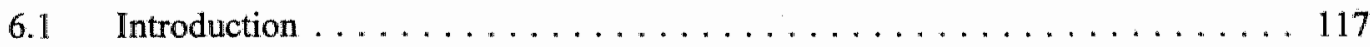

6.2 The institutional and fiscal context for ecological taxation in the Netherlands

6.2.1 Administrative and financial relationships between government bodies in the Netherlands . . . . . . . . . . . 117

6.2.2 Changing administrative and financial relationships $\ldots \ldots \ldots \ldots 123$

6.3 Taxation by sub national governmental bodies in the Netherlands . . . . . . 128

6.3.1 Taxes and related levies which can be imposed by provinces in the Netherlands . . . . . . . . . . . . 128

6.3.2 Taxes and related levies which can be imposed by municipalities in the Netherlands . . . . . . . . . . . . . 129

6.3 .3 Water boards $\ldots \ldots \ldots \ldots \ldots \ldots \ldots \ldots \ldots \ldots \ldots \ldots \ldots$

6.4 The environmental policy context for ecological taxation in the Netherlands . . . . . . . . . . . . . . . . . . . . . . . 134

6.4.1 Environmental policy in the Netherlands: general features . . . . . . 134

6.4.2 Environmental policy by sub national public bodies in the Netherlands . . . . . . . . . . . . . . . . . . . . . 139

6.4.3 Environmental policy instruments in the Netherlands . . . . . . . 143

6.5 Implications for the use of taxes for ecological purposes in the Netherlands

7 Ecological taxation in the Netherlands

7.1 Introduction . . . . . . . . . . . . . . . . . . . . . . . . . . . . 149

7.2 An overview of environmentally relevant levies in the Netherlands . . . . . . . . . . . . . . . . . . . . . . . . . . 149

7.2 .1 Environmental levies . . . . . . . . . . . . . . . . . . . . 149

7.2.2 Environmental user charges on fuels and regulatory charges on minerall oils . . . . . . . . . . . . 151 
7.2 .3 Noise charge on civil aviation $\ldots \ldots \ldots \ldots \ldots \ldots \ldots \ldots \ldots \ldots$

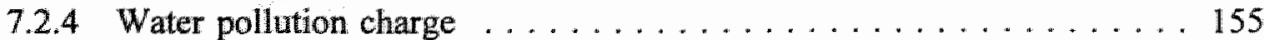

7.2.5 The charge for soil protection . . . . . . . . . . . . . 158

7.2.6 Waste disposal charges and refuse collection charges . . . . . . . 160

7.2 .7 Sewer(age) charges . . . . . . . . . . . . . . . . . . . . . . 161

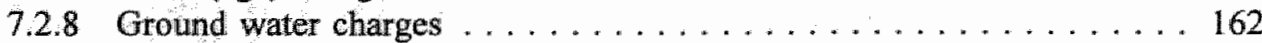

7.2.9 Charge on surplus manure $\ldots \ldots \ldots \ldots \ldots \ldots \ldots \ldots \ldots \ldots \ldots$

7.2 .10 Water quantity assessments $\ldots \ldots \ldots \ldots \ldots \ldots \ldots \ldots \ldots \ldots$

7.2.11 Environmental taxation main features . . . . . . . . . . 164

8 Ecological taxation in the Netherlands: development stages $\ldots \ldots \ldots \ldots 171$

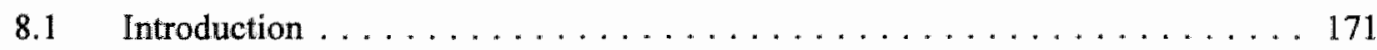

8.2 The use of taxes and charges for ecological purposes in OECD countries . . . . . . . . . . . . . . . . . . . . . . 171

8.3 Trends and main features of ecological taxation in the Netherlands $\ldots \ldots \ldots \ldots \ldots \ldots \ldots \ldots \ldots \ldots . \ldots \ldots$

8.4 Ecological taxation in the Netherlands: stages of development . . . . . . . . . . . . . . . . . . . . . 191

9 Development of ecological taxation: vertical dimension $\ldots \ldots \ldots \ldots \ldots$

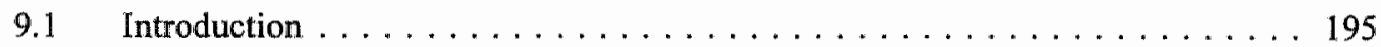

9.2 Sub national governments and the development of ecological taxation via the incorporation of environmentally relevant elements into existing taxes . . . . . . . . . . 195

9.2 .1 Analytical framework . . . . . . . . . . . . . . . . . 195

9.2.2 The use of existing taxes for ecological purposes: sub national governments . . . . . . . . . . . . . . . . 196

9.2.2.1 Relating environmental elements to the existing tax code . . . . . . 198

9.2.2.2 Expected effects, restrictions and required changes in law ...... 211

9.3 The national government and the development of ecological taxation via the incorporation of environmentally relevant elements into existing taxes $\ldots \ldots \ldots \ldots \ldots 220$

9.4 Ecological tax reform and the roles that can be played by different levels of government $\ldots \ldots \ldots \ldots \ldots \ldots \ldots \ldots$ 
10 Development of ecological taxation: horizontal dimension,

feasibility and policy implications . . . . . . . . . . . . . . . . 239

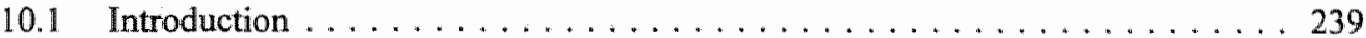

10.2 Horizontal dimension of ecological taxation:

further development stages? . . . . . . . . . . . . . . . . . . . 240

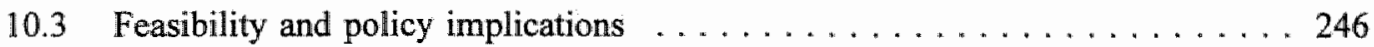

11 Summary, conclusions and directions for further research . . . . . . . 255

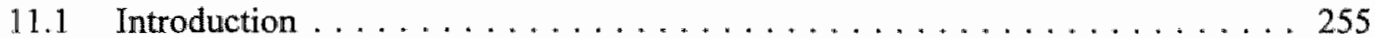

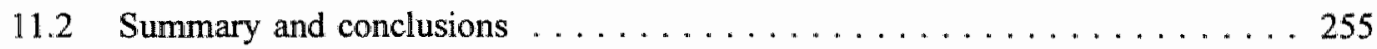

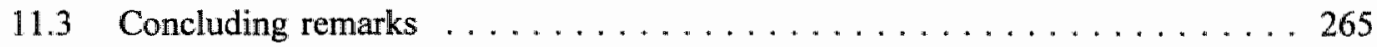

$\begin{array}{lr}\text { References } & 269-283\end{array}$

$\begin{array}{lr}\text { Author index } & 285-286\end{array}$

$\begin{array}{lr}\text { Subject index } & 287-290\end{array}$

$\begin{array}{lr}\text { Samenvatting } & 291-302\end{array}$

$\begin{array}{ll}\text { Curriculum Vitae } & 303\end{array}$ 


\section{List of Figures}

Figure 2.1

Coase Theorem

Figure 2.2

The internalization of externalities

through Pigouvian taxes

Figure 2.3

Enforcement and compliance costs

\section{List of Tables and Schemes}

Table 3.1

Different purposes of taxes

Table 3.2

Ecological taxes as defined in this study

Table 3.3

Ecological tax reform

Table 3.4

Ecological tax reform:

arguments and counterarguments

Table 5.1

The development of ecological taxation

Table 6.1

Budget funds

Table 6.2

Municipal and provincial revenues

Table 6.3

Tax revenues different government bodies

in the Netherlands

Table 6.4

The proposals of the De Kam Commission

Table 6.5

Municipal taxes and charges

Table 6.6

Environmental policy in the Netherlands:

targets and (expected) results

Table 7.1

Authorities permitted to introduce, change or abolish particular enviromental levies

Table 7.2

The new general fuel charge in the Netherlands

Table 7.3

Environmental levies: revenues 1975-1988

Table 7.4

Ecological taxes in the Netherlands: 1991-1993 
Table 7.5

Table 8.1

Table 8.2

Table 8.3

Table 8.4

Table 8.5

Table 8.6

Table 8.7

Table 8.8

Table 8.9

Table 9.1

Table 9.2

Table 9.3

Table 9.4

Table 9.5

Table 9.6

Table 9.7

The Netherlands: performances of taxes designed for environmental purposes $\ldots \ldots \ldots \ldots \ldots \ldots \ldots . \ldots 168$

Environmental charges in OECD countries (until 1987) . . . . . . . . . . . . . . . 173

Charges on emissions in OECD countries (1992) . . . . . 174

Charges on products/tax differentiation in OECD countries $(1992) \ldots \ldots \ldots \ldots \ldots \ldots \ldots$

Taxes and charges on emissions:

fiscal and steering effects . . . . . . . . . . . . 177

Product charges: fiscal and steering effects $\ldots \ldots \ldots \ldots \ldots 178$

Incentive effects of emission charges and product charges . . . 179

Main features of ecological taxation in the Netherlands $\ldots \ldots 181$

Possibilities to (further) use fiscal instruments for environmental policy in the Netherlands.

Development stages environmental levies in the Netherlands . . 193

Sub national governments in the Netherlands:

main environmental tasks . . . . . . . . . . . . . . . . 197

Sub national governments in the Netherlands:

the use of environmental taxes and levies . . . . . . . . . 198

Taxes and levies which can be imposed by sub

national governments in the Netherlands

Options for the incorporation of environmental aspects in taxes and related levies of sub national government bodies in the Netherlands

Tax differentiation with regard to household waste: the Netherlands . . . . . . . . . . . . . . 216

Tax differentiation systems for household waste:

expected and actual effects . . . . . . . . . . . . 217

Charges with regard to waste: environmental

effectiveness, feasibility and acceptability 
Table 9.8

Table 9.9

Table 9.10

Table 9.11

Table 9.12

Table 9.13

Table 9.14
Ecologically relevant elements of direct national taxes in the Netherlands . . . . . . . . . . . . . 221

Ecologically relevant elements of indirect national taxes in the Netherlands . . . . . . . . . . . . . 222

Environmentally relevant taxes and tax provisions in the Netherlands . . . . . . . . . . . . . . . . . . 224

Ecological tax reform: a first step . . . . . . . . . . . 227

The destination of possible revenues $\ldots \ldots \ldots \ldots \ldots \ldots 228$

Suggested further uses of financial instruments in the Netherlands

Sub national governments: options for the introduction of additional environmental taxes and levies. 237 


\section{List of Translated Terms'}

\section{English/Dutch}

Accelerated depreciation Acidification

Act on Chemical Wastes

Act on Chemical Waste Substances

Act on Environmentally

Hazardous Substances

Versnelde afschrijwing Verzuring

Wet chemisch afval

Wet chemische afvalstoffen

Act on Financial Relationships 1984

Act on Fuel User Taxes with

an Environmental Tax Base

Wet milieugevaarlijke stoffen

Financiële verhoudingenwet 1984

Wet verbruiksbelastingen van brandstof, geheven naar een milieugrondslag

Act on Joint Arrangements

Wet gemeenschappelijke regelingen

Act on Noise Nuisance

Wet geluidhinder

Act on Nuclear Energy

Kernenergiewet:

Act on Waste Substances

Afvalstoffenwet

Administrative charges

Leges

Administrative/intergovernmental relationships

Bestuurlijke verhoudingen

Advertising tax

Air Pollution Act

Air Traffic Act

Belasting op openbare aankondigingen

Wet inzake de luchtverontreiniging

Luchtvaartwet

'Benefit' tax

Baatbelasting

Block grants

Algemene uitkeringen

Building site tax

By law

(Gemeente- of provinciefonds)

Bouwgrondbelasting

Belastingverordening

(lagere overheden)

Charge for soil protection

Heffing bodembescherming Charge on surplus manure Mestoverschotheffing

Co-government

Medlebewind

1 In chapters 6-10 of this study, ecological taxation is discussed and analyzed within the institutional, fiscal and environmental policy framework of the Netherlands. In order to discuss and analyze ecological taxation within this particular framework, different fiscal, legal and administrative terms that are commonly used in the Netherlands and in the Dutch language had to be translated into English. This list provides an overview of the translations of several of these terms. Where possible, translations have been based on prior publications on the subject of (ecological) taxation in the Netherlands. They include different OECD studies (e.g. OECD, 1993a,b; Opschoor \& Vos, 1989; Oosterhuis \& De Savornin Lohman, 1994), publications by Dutch researchers in english language journals (e.g van der Hoek, 1991) and the English translation of the Netherlands National Environmental Policy Plan (Second Chamber of the States General, 1988/1989). 
Commuter tax

Control region/Water board district

Council for Municipal Finance

Decentralized unitary state

Decree

Dehydration

Disposal charges

Dog tax

Earmarked taxes

'Entertainment' charges

Environmental charge on fuels

Environmental Hygiene Law

Environmental Protection Act

Environmental protection regions

Environmental Protection Law

Environmental user taxes

Equalization grant

Eutrophication

Fertilizers Act

Financial relationships

Framework Act for

Changing Administrative Relationships

Fuel charge

General Decrees

General tax service

Ground Water Act

Ground water charge

Ground water protection region

Installations.

Intermunicipal co-operation arrangement

Legal charges

Levies

Licence

Livestock fodder charge

Local Council

Lubricating oil

Manure Agency

Manure Board

Market charges
Woonforensenbelasting

Beheersgebied waterschap

Raad voor Gemeentefinanciën

Gedecentraliseerde eenheidsstaat

Belastingverordening

(lagere overheden)

Verdroging

Verwijderingsbijdragen

Hondenbelasting

Bestemmingsheffingen Vermakelijkheidsretributies

Brandstoffenheffing

Milieuhygiënerecht

Wet milieubeheer

Milieubeschermingsgebieden

Millieubeschermingsrecht

Belastingen op milieugrondslag

Verevenüngsuitkering

Vermesting

Meststoffenwet

Financiële verhoudingen

Kaderwet voor veranderende bestuurlijke verhoudingen

Brandstoffenheffing

A.gemene maatregelen van bestuur

Rijksbelastingsdjenst

Grondwaterwet

Grondwaterheffing

Grondwaterbeschermingsgebied

Inrichtingen

Intergemeentelijk

samenwerkingsverband

Heffing op veevoer

Heffingen

Vergunning

Gemeenteraad

Smeerolie

Mestbank

Mestschap

Marktgelden 
Mining Act 1903

Ministry of Public Housing, Physical

Planning and Eavironment

Municipality

Municipality Act

Municipality Fund

National Environmental Policy Plan

National Institute of Public. Health

and Environmental Protection

Nature Protection Act

Netherlands Scientific Council

for Government Policy

Noise charge (on civil aviation)

Order(s) in Council

Parking tax

Physical Planning and Constructions Act

Memorandum

'Precario' dues

Principal amount of the tax

Province

Province Act

Provincial Executive

Province fund

Public Industrial Organization

Quid pro quo reductions

Quid pro quo relationship

Real estate taxes

Refuse collection charges/rates

Region oriented environmental policy

Regulation (local governments)

Service or user charges

Sewerage charges

Sewage treatment plant

Silence region

Socio-Economic Council

Soil Protection Act

Soil protection region

Special Acts

Specific grants

State Council

Sufferance dues
Mijnwet 1903

VROM

Gemeente

Gemeentewet

Gemeentefonds

Nationaal milieubeleidsplan

RIVM

Natuurbescherningswet

WRR

Heffing op grond van de Luchtwaartwet

Algemene Maatregelen van Bestuur

Parkeerbelasting

Wet Ruimtelijke Ordening

Beleidsnota

Precariorechten

Hoofdsom

Provincie

Provinciewet

Gedeputeerde Staten

Provinciefonds

Publiekrechtelijke bedrijfsorganisatie

Profijtkortingen

Tegenprestatie

Onroerende zaakbelastingen

Reinigingsrechten

Gebiedsgericht milieubeleid

Verordening

Genotsretributies

Rioolrechten

RWZI"s

Stiltegebied

SER

Wet Bodembescherming

Bodembeschermingsgebied

Bijzondere wetten

Specifieke uitkeringen

(Gemeente- of provinciefonds)

Raad van State

Precariorechten 


\section{Taxies}

Tax allowance schemes

for enwironmentall investments

Tourist taxes

Transfer taxes

User charges

WABM Act

Waterboard

Water Board Act

Water pollution charge

Water quantity assessments

Waste (disposal) tax

Water purification plant
Belastingen

Verwroegde afschrijvingen milieu-investeringen (VAMIL)

Toeristenbelastingen Overdrachtsbelastingen

Gebruiksretributies

Wet Algemene Bepalingen Milieuhygiëne (WABM) Waterschap Waterschapswet Verontreinigingsheffing oppervlaktewateren Waterschapsomslagen Afvalstoffenbelasting RWZI's 


\section{Dutch/English}

Afvalstoffenbelasting

Afvalstoffenwet

Algemene Maatregelen van Bestuur

Algemene uitkeringen (gemeente- of provinciefonds)

Belastingen

Baatbelasting

Beheersgebied waterschap

Belastingen op millieugrondslag

Belasting op openbare aankondigingen/reclamebelasting.

Belastingverordening (lagere overheden)

Beleidsnota

Bestemmingsheffingen

Bestuurlijke verhoudingen

Bijzondere wetten

Bodembeschermingsgebied

Brandstoffenheffing

Bouwgrondbelasting

Financiële verhoudingen

Financiële verhoudingenwet 1984

Gebiedsgericht millieubeleid

Gebruiksretributies.

Gedecentraliseerde eenheidsstaat

Gedeputeerde Staten

Gemeente

Gemeentefonds

Gemeenteraad

Gemeentewet

Genotsretributies

Grondwaterbeschermingsgebied

Grondwaterheffing

Grondwaterwet

Heffing bodembescherming

Heffing op veevoer

Heffingen

Heffingen op grond van de Luchtvaartwet

Hondenbelasting

Hoofdsom

Inrichtingen

Intergemeentelijk samenwerkingsverband

Kaderwet voor veranderende

bestuurlijke verhoudingen
Waste (disposal) tax

Act on Waste Substances

Order(s) in Council/Generall Decrees

Block grants

Taxes

"Benefit" tax

Control region/Water board district

Environmental user taxes

Advertising tax

By law/Decree/Regulation

(Policy) Memorandum

Earmarked taxes

Administrative/intergovernmental relationships

Special Acts

Soil protection region

Fuel charge/environmental charge on fuels

Building site tax

Financial relationships

Act on financial relationships 1984

Region oriented environmental policy

User charges

Decentralized unitary state

Provincial Executive

Municipality

Municipality Fund

Local Council

Municipality Act/Local government act

Service or user charges

Ground water protection region

Ground water charge

Ground Water Act

Charge for soil protection

Livestock fodder charge

Levies/charges

Noise charges (on civil aviation)

Dog tax

Principal amount of the tax

Installations

Intermunicipal co-operation arrangement

Framework Act for

Changing Administrative Relationships 
Leges

Luchtvaartwet

Marktgelden

Mediebewind

Mestbank

Mestoverschotheffing

Mestschap

Meststoffenwet

Mijnwet 1903

Milieubeschermingsgebieden

Milieubeschermingsrecht

Milieuhygiënerecht

Nationaal milieubeleidsplan

Natuurbeschermingswet

Onroerende zaakbelastingen

Opcenten

Overdrachtsbelastingen

Parkeerbelasting

Precariorechten

Profijtkortingen

Provincie

Provinciefonds

Provinciewet

Publiekrechtelijke bedrijfsorganisatie

Raad van State

Raad voor Gemeentefinanciën

Reinigingsrechten

Rijksbelastingsdienst

Rioolrechten

RIVM

RWZI's

SER

Smeerolie

Specifieke uitkeringen (gemeente- of provinciefonds)

Stiltegebied

Tegenprestatie

Toeristenbelastingen
Legal charges/administrative charg: Air Traffic A

Market charg

Co-governme

Manure Ageni

Charge on surplus manu

Manure Boa

Fertilizers A

Mining Act 191

Environmental protection regio

Environmental Protection La

Environmental Hygiene La

National environmental policy $\mathrm{pl}$

Nature Protection A

Real estate tax

Surcharg

Transfer tax

Parking $t$

Sufferance or 'precario' du

Quid pro quo reductio

Provin

Province fu

Province $A$

Public Industrial Organizati

State Coun

Council for Municipal Finar

Refuse collection charges/ra

General tax serv

Sewerage charg

National Institute of Public Hea

and Environmental Protecti

Water purification pla

Sewage treatment pli

Socio-Economic Cour

Lubricating

Specific gra

Silence reg

Quid pro quo relations

Tourist ta: 
Verdroging

Vereveningsuitkering

Vergunning

Vermakelijkheidsretributies

Vermesting

Verontreinigingsheffing oppervlaktewateren

Verordening

Versnelde afschrijving

Vervroegde afschrijwingen

milieu-investeringen (VAMIL)

Verwijderingsbijdragen

Verzuring

VROM

Waterschap

Waterschapsomslagen

Waterschapswet

Wet Algemene Bepalingen Milieuhygiëne (WABM)

Wet Bodembescherming

Wet chemisch afval

Wet chemische afvalstoffen

Wet gemeenschappelijke regelingen

Wet millieubeheer

Wet millieugevarlijke stoffen

Wet geluidhinder

Wet inzake de luchtverontreiniging

Wet Ruimtelijke Ordening

Wet verbruiksbelastingen van

brandstof, geheven naar

een milieugrondslag

Wet Verontreiniging Oppervlaktewateren

Woonforensenbelasting

WRR
Dehydration

Equalization grant

Licence

'Entertainment' charges

Eutrophication

Water pollution charge

Regulation/Ordinance/

By law (local governments)

Accelerated depreciation

Tax allowance schemes

for Environmental Investments

Disposal charges

Acidification

Ministry of Public Housing, Physical

Planning and Environment

Waterboard

Water quantity assessments

Water Board Act

WABM Act

Soil Protection Act

Act on Chemical Wastes

Act on Chemical Waste Substances

Act on Joint Arrangements

Environmental Protection Act

Act on Environmentally

Hazardous Substances

Act on Noise Nuisance

Air Pollution Act

Physical Planning and Constructions Act

Act on Fuel User Taxes with an Environmental Tax Base Surface Waters Pollution Act

Commuter tax

Netherlands Scientific Council]

for Government Policy 



\section{Introduction, Background and Scope}

\subsection{Introduction}

The main purpose of this study is to analyze the feasibility of ecological taxation and, on the basis of this feasibility analysis, to derive relevant policy options and implications for the use of taxes for ecological purposes. In order to conduct such an analysis and derive these policy options and implications, ecological taxation is first placed within a broader theoretical framework. Several elements of this framework, including different theories on market and government failures, are delineated in section 1.2. The central research questions, analytical framework and the aim of the research, which can be embedded into this theoretical framework, are further considered in section 1.3. In this section, also the relevance of the study in the light of previous national and international research on the subject of ecological taxation is discussed. In section 1.4, the research approach is further described. This section also exhibits the main assumptions and provides an outline of the study.

\subsection{From market to government failures}

For those who move beyond the idea of a minimal state, i.e. a state in which markets are the rule and governments are necessary for (only) the protection of property rights and/or the transfer of initial endowments, governments are considered necessary because of market failures. Following Inman (1987), it can be stated that markets fail in those cases in which they cannot prevent individuals from cheating against a mutually co-operative outcome. This generally occurs in case of public goods, externalities, increasing returns to scale and in case of incomplete information. According to Inman (1987), such cases present a potential role for an extra market institution such as a government, which can enforce a certain co-operative outcome and thus collective action. In that sense, governments perform the role of economic institutions. Generally, this role has to be compared to the role of markets in order to determine under what circumstances governments or markets are the preferred institution for the allocation of resources.

Throughout the history of economic thought, different contributions have been made to this mutual comparison of the role of markets and governments for the allocation of resources. Following Musgrave (1985), the ideas on the role of markets and governments as they arise within and from the earlier British fiscal theory and the so-called Continental Approach can serve as a starting point. In the former approach, building on the ideas of Locke, markets are considered the rule and governments the exception. In the latter approach, building on the ideas of the Cameralists, a public sector is considered equal in birthright to a private sector. 
Supplementing the Continental Approach, several Austrian and Italian w1 including Sax, Panteleoni, Mazzola and de Viti de Marco laid the foundation c economic theory of public goods. Central to this theory is the idea that the der and evaluation of consumers and the equation of marginal utilities with pric decisive for the maximization of welfare. This holds for private as well as $p$ goods. Musgrave $(1985$, p. 9) argues that, although accepting part of the new th of public goods, Wicksell had reservations i.a. with respect to the analogy that drawn between the private and the public sector. In what has become to be knov the voluntary exchange theory, Wicksell (1896) views collective action in tern voluntary exchange. Wicksell suggests an ideal competitive political process in v consumers or tax payers would be asked to vote on different packages of govern expenditures and tax shares. In an ideal situation, the provision of a particular pac would be directly connected to the unanimous support by consumers or tax pay Musgrave (1985) describes that "[t]he Austrian and Italian model of: analysis and its Wicksellian interpretation in voting behaviour did not enter the view of English language authors for over half a century"....."...[i]t was not Pigou's (1920) Economics of Welfare that a new perspective was introduced. perspective emerged from the concept of externalities, central to the Pigouviar. tinction between social and private net products...." (p. 11).

\subsubsection{The internalization of suggestions of Pigou into environmental economic: public finance}

When referring to the divergences between private and social net product, ${ }^{1}$ I (1920) stated: "The source of the general divergences between the values of mar social and marginal private net product that occur under simple competition is th that, in some occupations, a part of the product of a unit of resources consis something, which instead of coming in the first instance to the person who inves unit, comes instead, in the first instance (....), as a positive or negative item, to people" (p. 174). ${ }^{2}$ To overcome the divergences between private and social net duct, Pigou tells us that: "It is, however, possible for the State, if it so choosi remove the divergence in any field by "extraordinary encouragements" or "extra nary restraints" upon investments in that field. The most obvious forms which encouragements and restraints may assume are, of course, those of bounties and 1 Broad illustrations of the policy of intervention in both its negative and po aspects are easily provided" (p. 192).

In a more modern terminology, divergences between private and socic product can be referred to as external effects or externalities. Encouragement:

1 Divergences between private and social net product were first presented by Marshal termed these divergences external economies. See Marshall (1969, 8th edition).

2 Pigou (1946, 4th edition. First edition: 1920). 
restraints can be referred to as subsidies and taxes, respectively. Following Baumol and Oates (1988), external effects can be defined as being present "whenever some individual's (say A"s) utility or production relationships include real (that is nonmonetary) variables, whose values are chosen by others (persons, corporations, governments) without particular attention to the effects on $A^{\prime}$ 's welfare" (p. 17). To qualify as an externality, those who affect others" utility level by particular activities should also not receive (pay) compensation equal in value to the external benefits (or costs) imposed on others. ${ }^{3}$

Within environmental economics, the concept of externalities is central to the explanation of environmental problems. Environmental problems, e.g. pollution, can be explained to arise if economic agents impose negative external environmental effects upon society. Using the terminology of Pigou, negative items (in this case negative environmental effects in the form of pollution) accrue to others than the polluter, resulting in a divergence between private and social net product. The divergence is equal to the environmental burden which arises due to the polluter's activities. This burden is taken into account in the social net product but not in the private net product. To reduce the divergence between the private and social net product in the example above and following the suggestions of Pigou, by imposing a tax, polluters could be confronted with the total costs of the environmental burden which arises due to the polluters" activities. In the ideal case, the imposition of the tax accomplishes a complete internalization of external effects. The imposition of a tax in the sense of Pigou is described in more detail in chapters 2 and 3 of this study.

The focus on externalities in the explanation for environmental problems within environmental economics ${ }^{4}$ together with the suggestions of Pigou $(1912 ; 1920)$ and Baumol and Oates (1971), and further elaborations and improvements of these suggestions, are central to the idea of using taxes for environmental policy purposes. The idea of using taxes for these purposes has become increasingly popular in recent years. This popularity can be attributed to increasing environmental problems and the perception that command and control instruments seem ineffective. ${ }^{5}$ The usefulness of command and control instruments (e.g. direct regulation, legislative requirements) ${ }^{6}$

See e.g. Baumol \& Oates, chapter 3 (1988, 2nd. Edition). They also add to this definition the condition that the relationship holds in the absence of regulatory pressures for the control of the activity (pp. 17-18).

4 Environmental externalities can arise when property rights for the ownership and use of particular resources are not exclusive in the sense that all benefits and costs accrue to the owner, and only the owner (see Tietenberg, 1992, pp. 45-54).

5 See Benkert et al. (1990), Nutzinger and Zahmt (1989) and Wilhelm (1990).

6 In the literature on the theory of environmental policy (e.g. Tietenberg, 1992), different options are indicated for the internalization of environmental externalities. The options range from private negotiation (see e.g. Coase, 1960) and judicial determination of private property rights to 
is especially questioned when polluting activities can be decreased only gradually and incrementally. For such cases, taxes are considered an alternative means of pursuing environmental goals.

If taxes are used as suggested by Pigou, their main objective is to influence and steer behaviour in a direction considered desirable from an environmental point of view. Being aimed at accomplishing tax avoiding changes in behaviour, the taxes are therefore intended to be used only for allocational and not for fiscal ends. This is in conflict with the point of view embedded in the classical theory of taxation. From this point of view, the only purpose of taxes, i.e. compulsory contributions that are levied according to general rules and for which there is no quid pro quo relationship ('tegenprestatie') between the taxes paid and the services and goods provided by the government, is seen in fiscal ends: in providing a stream of tax revenues to the state. From this point of view, lump sum taxes present the ideal image of taxes. Since lump sum taxes are related to unalterable characteristics as age and gender, liable individuals can do nothing to avoid their tax liability. In this form, these taxes therefore lead to the maximum amount of tax revenues for the state. ${ }^{8}$ From this point of view, taxes should not induce tax avoiding changes in behaviour such as those intended and induced by Pigouvian taxes.

Although there are conflicting views on the main purposes of taxes, it is recognized in modern public finance that tax systems in practice do influence the economic behaviour of individuals and therefore, unintendedly, lead to undesired distortions in the allocation of resources. ${ }^{9}$ Within modern public finance, the main purpose is no longer neutral taxation but "taxation of the things we don't want (for instance, environmental damages)". ${ }^{10}$ With this insight and within the context of an increasing deterioration of the environment, both public finance theory and environmental economics, have, in recent years, been increasingly concerned with the question whether taxes can be used for environmental (policy) purposes, and if so: how taxes can be used for these kind of purposes. ${ }^{11}$

regulation by the legislative and executive branches of government. The latter option includes the use of different environmental policy instruments such as command and control instruments, social regulation instruments and financial or economic regulation instruments.

7 See Teufel (1989).

\&ee e.g. Musgrave \& Musgrave (1984, pp. 284-312).

${ }^{9}$ See Netherlands Scientific Council for Government Policy (1992, pp. 75-76). In this and the following chapters of this study, the council is referred to as the WRR.

${ }^{10}$ According to WRR (1992, p. 76).

${ }^{11}$ See e.g. Cansier (1988). 
From the point of view of public finance, this question is interesting for several reasons. First, Pigouvian taxes, in the ideal case, raise (almost) no additional revenues for the state. This is in conflict with the opinions of those who regard revenue raising as the only purpose of taxes. Second, in non-ideal cases, when external effects are not completely internalized, Pigouvian taxes also have fiscal effects in the sense that they raise additional tax revenues. In practice, there are several reasons to expect an above zero tax revenue from Pigouvian taxes, considering the fact that: ${ }^{12}$

- For most environmental problems it seems undesirable, from an ecological and economic point of view, to reduce the emission of polluting substances by $100 \%$. From an ecological point of view this seems undesirable because the environment has a certain capacity to absorb polluting substances. This allows a certain amount of emissions. From an economic point of view this seems undesirable because a non optimal protection of the environment raises opportunity costs in the sense that particular resources might have been put to other welfare increasing uses. In case of Pigouvian taxes, if the emission of polluting substances is not reduced by $100 \%$, the remaining emission is taxed, implying an above zero tax revenue.

Since of economic growth, agglomeration and other tendencies, in sum, the elements which need to be handled by environmental policy can be expected to increase in future. If taxes constitute a large part of (future) environmental policy instruments in this case, increasing (future) tax revenues can be expected accordingly.

For some areas, products or activities, there are limited opportunities, in a technical sense, for environmentally friendly alternatives. When Pigouvian taxes are used in this particular situation, they will not erode the entire tax base, implying additional fiscal revenues. In chapters 2 and 3 of this study, it is, however, argued that the use of Pigouvian taxes in this case, does not make sense.

Even if Pigouvian taxes are introduced within a context in which the three aspects mentioned above do not hold, an above zero tax revenue can be expected from these taxes. This is due to the fact that it takes time for those confronted with the taxes, and who do not expet a net benefit from paying these taxes, to make tax avoiding changes in behaviour. So, although this might only be for a brief period of time in which those confronted with the tax adapt to a new situation, the introduction of Pigouvian taxes can be associated with fiscal effects.

${ }^{12}$ Hansjürgens (1992, p. 18). 
Both revenue raising and Pigouvian taxes not only are an important subjec analysis from the point of view of public finance but also from the point of viev environmental economics. First and obviously, taxes in the sense of Pigou can be $u$ to confront polluters with the environmental costs imposed on others, which is, doubtedly, an important aspect from the point of view of environmental econon and environmental policy. Second, revenue raising taxes in particular and tax syst in general may contain elements or structures which are (un)desirable from an el ronmental point of view (see section 3.2 .3 of this study). If revenue raising taxes, instance, are structured in such a way that relatively high (low) marginal tax rates imposed on environmentally (un)friendly products or activities, then elements of th taxes themselves may contribute to environmental problems. The opposite also h in the sense that revenue raising taxes may contain elements (e.g. rates, deducti credits) which could discourage the use of environmentally undesirable product: activities. In both cases, revenue raising taxes may unintendedly influence partic aspects and elements which are important from an environmental (economics) poir view. Third, revenue raising taxes are of interest from an environmental policy $p$ of view merely because they raise revenues which can serve as funding sources particular environmental policies. The possibility to use tax revenues for these poses is important for those who emphasize the use of earmarked environmental $t$ (see section 3.4 of this study).

\subsubsection{Political economy}

Although Pigou presented a new perspective, emerging from the concept of exte lities, within the purview of English language authors, the previously mentic continental discussion of the 1880's and 1890's, however, did not enter the En reading part of the profession before the late 1930's (Musgrave, 1985). A final br through was created by Samuelson in his formulation of the essential conditions an efficient solution to the public goods problem. Samuelson showed that tc efficient, the sum of the differing marginal rates of substitution in the consumptio the public good in question should equal the marginal rate of transformation in production of this good.

The advances of the Pigou and Samuelson cases for government intervent and the possible risk of public sector growth, at the same time created room $f$ theory of government failure. Within this theory, it was questioned among ot whether a government could obtain all the information necessary to achieve the of efficiency suggested by Samuelson and at the same time be non-dictatorial. I wise it was questioned, whether policy makers, who may frequently pursue their self interest, would actually implement the desired allocations (see Oakland, 198 522). The use of Pigouvian taxes for the internalization of external effects prese clear example of the difficulties involved. On the one hand, to be able to set $\mathrm{Pi}$ vian taxes that are economically efficient requires knowledge, among others relevant marginal external costs and benefits. The task of obtaining this kin 
information is formidable and in most cases even impossible. At the same time, tax avoiding changes in behaviour are only known to those who actually plan to make these changes. ${ }^{13}$ Again, this raises difficulties for the taxing authority in securing all of the information necessary to set the proper tax rates and thus in designing feasible types of ecological taxes. On the other hand, since Pigouvian taxes, at least in the short run, raise revenues, policy makers can be induced to maintain this source of income. In this particular case, this source is the existing set of externalities. Maintaining this source of income may then even contradict the outcome pursued with the tax, i.e. the internalization of external effects. ${ }^{14}$ It follows that, next to the design of ecological taxation, administrative ("bestuurlijke") ${ }^{15}$ and (dis)incentive structures by which those who impose and decide on ecological taxation are confronted, are also relevant for achieving the ultimate (environmental) goal pursued with the tax in question. In this sense, political actors and government structures themselves can no longer be considered exogenous to economic processes.

The view that (political) actors can be seen as endogenous to economic processes, e.g. in the sense that they are actors who, within constraints, pursue their own self interest in order to maximize certain proceeds (e.g. votes) or minimize certain processes (e.g. conflicts), is central to the branch of economics known as political economy or public choice. Mueller $(1989$, p. 1$)$ defines public choice as the economic study of nonmarket decision making or simply the application of economics to political science. As one of the forerunners of modern public choice theory, the contribution of Knut Wicksell springs to mind. In 1896, in his essay "A New Principle of Just Taxation", Wicksell argued that, under the requirement of unanimity and voluntary consent among all parties, particular expenditure and tax packages should be submitted to consumers or tax payers for vote (see page 2 above). In his analysis of the political process involved, Wicksell laid the foundation of what has become to be known as constitutional political economy.

Building on the suggestions of Wicksell, Buchanan and Tullock (1962) developed a contractarian approach to public choice, presented in a model in which the institutions of collective decision and choice making are variables themselves, to be determined by actors who are ignorant about their future position. When collective decision and choice making institutions are variables themselves, the question is how government structures and the related performances of the government can be

${ }^{13}$ See also Pigou (1947, pp. 42 44), who himself emphasizes and discusses the difficulties involved in using taxes and subsidies for the internalization of external effects.

${ }^{14}$ See also Lee (1985) and Brooks and Heijdra (1987) for further comments on rentseeking and pollution taxation.

${ }^{15}$ In the list of translated terms (p. xi ff. of this study), an overview is provided of the English translation of several Dutch fiscal, legal and administrative terms. 
changed. ${ }^{16}$ This is the central theme of constitutional political economy. Within this type of political economy, the central question is how a particular problem can be dealt with by the appropriate choice of a structure. The latter then determines the constraints under which decisions can be taken. Constitutional political economy is especially relevant with regard to ecological problems that occur within specific ecological systems or ecological units (e.g. a watershed, a mountain range, a river basin etc.). Generally, the boundaries of ecological units do not co-incide with the boundaries of existing political units. The latter tend to be decision making units which do most of the times not fit the description of being closely related to relevant ecological circumstances. Within an environmental context, a central element of this approach is that; depending on the ecological circumstances in question, decision making structures themselves can be a subject of investigation. The latter calls for an analysis of environmental problems and environmental policy including ecological taxation in terms of constitutional environmental economics. As is argued in the following section, the main body of literature on ecological taxation has generally neglected such an analysis of ecological taxation.

\subsection{Background and scope: analytical framework and research questions}

In practice, ecological taxes constitute only a small part of the environmental policy instruments that are used by policy makers. Nevertheless, within the international and national literature, the use of taxes for environmental purposes in combination with other purposes has been extensively discussed. Especially in recent years and mainly after the publication of the report 'Our Common Future' by the World Commission on Environment and Development (WCED, 1987), in which economic instruments (including environmental levies) are indicated as a major element in the strive for sustainable development, an unaccountable amount of studies has emerged on the subject. International contributions that can be noted and that mainly arise from the German and English language countries and from Scandinavian countries, include studies by von Weizsåcker $(1988 ; 1989)$, Nutzinger \& Zahrnt $(1989 ; 1990)$, Benkert, Bunde and Hansjürgens (1990), Pearce (1991), Poterba (1991; 1993), Hansjürgens (1992), Hoel (1992), Mauch et al. (1992), Andersen (1993) and Hagem (1994). The role of energy taxes within the context of the problems that are related to the emissions of carbon dioxide, constitutes an important element of these contributions. In the Netherlands, important contributions include i.a. those of Bressers (1983) and Schuurman (1988) on the use of ecological taxes with regard to water pollution and those of Wasch (1983), Wiersma (1989), Simons (1990), Schuurman (1990), Vollebergh (1992a, 1992b), de Savornin Lohman (1994), van Ierland (1993) and Boele (ed., 1994) on the use of ecological taxes in general and with regard to energy and international environmental problems in particular. Case studies in which the effects and

${ }^{16}$ See also Brennan and Buchanan $(1980,1985)$ in this respect. 
the experiences with the actual use of ecological taxes by different countries are shown, entail particular OECD studies $(1992,1993 \mathrm{a}, \mathrm{b})$ and the studies conducted by Opschoor and Vos (1989) and Oosterhuis and De Savornin Lohman (1994).

Although there is a wide variety of studies on the subject of ecological taxation, several general elements and shortcomings in the greater part of this body of literature can be noted. First, there is a general neglect of the institutional framework for ecological taxation. This neglect arises mainly from the fact that most studies proceed on the basis of a sketch of an ideal theoretical type of ecological taxation, followed by an empirical study of the associated economic and income redistribution effects if the tax would actually be implemented in practice (e.g. in a particular country). This general approach, however, does not take into consideration that there is no ideal type of ecological tax, which is applicable to all countries and jurisdictions. Each decision making unit, however, is embedded into an institutional framework, which expresses among others the existing fiscal, political and administrative structures and ruling opinions on ecological taxation. Since the latter differ per country and jurisdiction, the viability of ecological taxes also differs for each decision making unit. Second, the greater part of the literature on ecological taxation is concerned with an analysis of either the part of ecological taxation that is interesting from an environmental point of view or with the part that is interesting from a public finance point of view. Analyses of the public finance part of ecological taxation, in that respect, constitute a clear minority. Analyses of ecological taxes, in which both views are taken into consideration, are scarce. Exceptions include, among others, Benkert, Bunde and Hansjürgens (1990), and Hansjürgens (1992). A third general element of most studies is the solely implicit attention that is paid to the role of sub national government bodies in the process of creating or introducing viable ecological taxes. Although this implicit attention is usually justified in terms of the level at which most environmental problems occur, this neglects the possible pioneering and experimenting function that can be played by these governments as regards the introduction and use of ecological taxes that are imposed on a surveyable level.

In relation to and besides the afore mentioned shortcomings of the greater body of literature on ecological taxation, there is also a general neglect of the implications for the feasibility of ecological taxation that result from the mismatch between the boundaries of decision making structures and those of relevant ecological circumstances. Likewise, although there is a wide variety of studies on the subject of ecological taxation and a growing interest by policy makers, the attention to use revenue raising taxes for ecological purposes and the possible fiscal effects that are associated with Pigouvian taxes, has shifted the attention of both theorists and actual policy makers away from taxes that are solely based on ecological concerns.

In this respect, in both theory and practice, ecological taxes have generally been presented under the heading of what can be designated as a "double dividend" (DD) approach of ecological taxation. A general feature of this approach is the "various purposes' attribute which is commonly ascribed to ecological taxes. Taxes are not only aimed at achieving particular ecological purposes, but, at the same time, also 
at raising tax revenues and at accomplishing other purposes, e.g. with regard to employment or the redistribution of income. To achieve a revenue neutral introduction of ecological taxation, the adjustment or imposition of (additional) revenue raising ecologically relevant taxes can be accompanied by corresponding shifts in appropriate other taxes or grants. The latter implies that in the design of these taxes, also other than environmental concerns are taken into consideration. Consequently, the ecological effectiveness and acceptability and the associated feasibility of these taxes can differ from those that are established on the basis of only ecological circumstances or for only ecological reasons. When these purposes are mutually competitive, the ecological effectiveness of taxes that are set under a double dividend approach can be expected to be lower, in comparison to approaches in which only ecollogical concerns are taken into consideration. For the same reason, the acceptability of such taxes can generally be expected to be higher. The effects on the ecological effectiveness and acceptability of ecological taxation, which can be expected to differ under both approaches, also affect the feasibility of this type of taxation. In this respect, and within the context of the theories on market and government failures described above, the central aim of this study can now be described as the analysis of the feasibility of ecological taxation, under both approaches, and the derivation of relevant policy implications for the general and specific use of ecological taxation.

Generally, feasibility is described as a concept which expresses whether something is possible and practical (i.e. viable, workable, achievable and/or attainable). Within this context, feasible ecological taxes represent taxes that are realistic and thus imaginable policy options. Given this general description, in this study a feasibility analysis is conceived as an analysis of the possibilities and problems of ecological taxation in order to identify those aspects that make them realistic policy options. Given the afore mentioned aim, the central research questions of this study are the following. Within the context of both approaches:

What are the possibilities and complexities of ecological taxation and which aspects determine the feasibility of ecological taxation?

What are the associated policy implications for a general and specific use of ecological taxation?

Given the general lack of attention to an approach of ecological taxation in which purely ecological concerns or relevant ecological systems are utilized as the starting point for the introduction of ecological taxes, in relation to the two research questions, such an 'ecological concerns' (EC) approach is further examined, detailec and compared to the 'double dividend' approach. Following the research approacl suggested by Buchanan (1959), the ecological concerns approach is presented as : policy alternative for the double dividend approach of ecological taxation. Accordin to Buchanan, the main role for a "positivistic" political economist is that of becoming an inventor of testable hypotheses. In that sense, a political economist does not re commend a particular policy over another policy. Instead, the political economis 
analyzes particular social situations and shows, by way of presenting testable hypotheses, a set of possible policy changes. "The hypothesis is that policy A will, in fact prove to be Pareto-optimal. The conceptual test is consensus among the members of the choosing group, not objective improvement in some measurable aggregate" (p. 127). The element of consensus suggested by Buchanan is based on several of Wicksell's ideas on fiscal theory (see page 2 above). According to Buchanan (p. 137),

"... the political economist is concerned with discovering "what people want". The content of his efforts may be reduced to very simple terms. This may be summed up in the familiar statement: There exist mutual gains from trade. His task is that of locating possible flaws in the existing social structure and in presenting possible "improvements". His specific hypothesis is that mutual gains do, in fact, exist as a result of possible changes (trades). This hypothesis is tested by the behaviour of private people in response to the suggested alternatives. Since "social" values do not exist apart from individual values in a free society, consensus or unanimity (mutuality of gain) is the only test which can insure that a change is beneficial".

In the style of Buchanan's approach, in this study, the gains from using different approaches of ecological taxation will be compared to one another.

\subsection{Research approach and outline of the study}

To be able to assess the feasibility, problems and possibilities of using taxes for ecological and/or other purposes, in this study the concept of taxes is broadly perceived as including not only ordinary revenue raising taxes but allso earmarked taxes and Pigouvian or regulatory taxes. ${ }^{17}$ For reasons of simplicity and because defining ecological taxes is a separate aim of the study itself, it is, at the moment, assumed that ecological taxes can be perceived as types of levies that are linked to elements and factors that can be considered important from an ecological point of view. A more detailed description and definition of ecological taxes is provided in chapter 3 of this study. For the assessment of the feasibility of ecological taxes, the greater part of the analysis in this study is carried out on the basis of the a priori assumption that relevant decision making authorities have already decided to use taxes, directly or indirectly, for environmental policy purposes. In this sense, it is thus initially assumed that the feasibility of ecological taxes need not be determined on the basis of a comparative analysis in which the comparative (dis)advantages of ecological taxes have to be weighed against those of other environmental policy instruments (see also section 11.3 of this study). Feasibility is thus initially perceived as being solely determined by

${ }^{17}$ When applied to the Dutch context, this study conceives taxes as including not only revenue raising taxes (i.e. "belastingen") but also other types of taxes (i.e. "heffingen"). 
several characteristics which are directly related to the use and imposition of the instrument of taxes itself. Under these assumptions, the feasibility analysis conducted in this study proceeds on the basis of the following steps:

1) A determination of the origins of the idea of using taxes for ecological purposes.

2) A description of the concept of ecological taxes.

3) A determination of the most important problems and possibilities of ecological taxation.

4) A derivation of a checklist in which the viability of ecological taxes in terms of the elements relevant for the design of feasible ecological taxes is indicated.

5) A determination and a derivation of a checklist in which the (dis)incentive and administrative structures that allow the imposition of taxes that are ecologically: effective and acceptable, is indicated.

6) An illustration of the main elements of the feasibility of ecological taxation within the context of particular ecological circumstances.

7) A description of the main elements of ecological taxation in the Netherlands.

8) A description of the (dis)incentive structures into which ecological taxation in the Netherlands is embedded.

9) A confrontation of the theoretical results with the actual practice of ecological taxation in the Netherlands.

10) A derivation of policy implications for ecological taxation in the Netherlands.

11) A determination of the feasibility of ecological taxation in general and with regard to the Netherlands in specific.

For each of these steps, the relevant implications for ecological taxation as they arise from the ecological concerns approach and the double dividend approach are identified and compared. The two central research questions of this study are also analyzed within the context of a particular case, i.e. the development and use of ecological taxes in the Netherlands. The case is not only used to confront the theoretical results with the actual use and development of ecological taxes in practice, but also as a means to respond to the general shortcomings that are present in the greater part of the body of literature on ecological taxation. In this respect, the analysis of the feasibility of ecological taxation in the Netherlands, especially focuses on the institutional and other relevant frameworks for ecological taxation in this country and on the role that can be played by sub national governments in the development of this type of taxation.

In carrying out a feasibility analysis of the type described above, it is assumed that, in order to be feasible, ecological taxes not only have to be properly designed but also have to be embedded into particular administrative and (dis)incentive structures. The latter structures (e.g. certain constitutional, institutional and fiscal structures) are relevant, because a well designed tax will not automatically bring about the desired effects. The degree to which these effects can be attained depends, among 
others, on the behavioural reactions of those who are confronted with these taxes. On the one hand, those who are liable for the taxes have to be confronted with a fiscal (dis)incentive structure that makes the tax acceptable. On the other hand, those who design and impose the tax (e.g. policy makers and/or taxing authorities) have to be confronted with proper incentives in order to include all necessary ingredients. Since these structures are relevant, the feasibility analysis in this study also incorporates an analysis of elements and structures that likely increase the acceptability and ecological effectiveness of ecological taxes. In this sense, the analysis of the feasibility of ecological taxation in this study is also carried out on the basis of constitutional public finance and constitutional environmental economics.

To conduct the analysis described above within the context of the stated research topics, this study is divided into 11 chapters. In chapters 2 and 3 , the main sources of origin, concepts, theories and the design of taxes that are intended to be used directly or indirectly for environmental policy purposes are indicated. In this chapter, also the theoretical context for the use of taxes for these purposes is provided. Within the literature on the subject of ecological taxation, there is a wide variety of terms and characteristics which are used to define or describe ecological taxes. A separate aim of this study is to present several basic concepts of ecological taxation which can be used to clarify discussions on this subject. The basic concepts of ecological taxation are presented in chapter 3 . This chapter also describes the main elements of the double dividend approach and provides a general overview of the most important possibilities and problems of using different types of taxes and tax reform for ecological purposes in combination with other purposes. Within the same chapter, this general overview is used to derive several elements that are relevant for the design of feasible ecological taxes and tax reforms. The overview is also used to emphasize the accommodating framework for different types of ecological taxes. The framework can be used to induce or prevent particular tax avoiding changes in the behaviour of those who are confronted with these taxes.

In chapter 4 , the imposition of ecological taxes is further analyzed. In this chapter, a constitutional political economic approach is used to embed ecological taxation into a broader institutional and constitutional framework. Based on, among others, the theories of fiscal federalism, clubs, constitutional public finance, constitutional environmental economics and the principle of subsidiarity, chapter 4 presents a theoretical framework which incorporates the main elements of the ecological concerns approach of ecological taxation. Based on the results and conclusions of the previous chapters, the first purpose of chapter 5 is to discuss and present a brief overview of the elements that, according to the DD and EC approaches, are significant for the feasibility of ecological taxation. The second purpose of this chapter is to formulate an analytical framework that can be used for an analysis of the feasibility of this type of taxation in the Netherlands.

In chapters 6 and 7, the institutional, fiscal and environmental policy context for ecological taxation in the Netherlands is described. This part of the study presents the situation until the end of 1994 . Where possible, relevant developments with regard 
to ecological taxation that (can be expected to) occur(ed) at the beginning of 1995 also taken into consideration. Following the theoretical considerations of the previi chapters, relevant features of the actual use of ecological taxation in this country derived and further explained. In chapter 6, the institutional, fiscal and environmer policy framework for ecological taxation by different levels of government in Netherlands is further discussed. These frameworks are then used to discuss analyze the recent and actual use of ecological taxes. An overview of the main 1 tures of ecological taxation in this country is provided in chapter 7 .

Building on the results of the previous chapters, in chapters 8-11, the possit ties, problems and the roles that can be played by different levels of government: the process of further developing ecological taxation in the Netherlands are furt analyzed. In chapter 8 , the main trends and features of ecological taxation are furt outlined in order to derive the most important stages in the development process ecological taxation in this country so far. Several possibilities for different levels government to further develop this type of taxation and to move to subsequent sta in the development process of ecological taxation in this country are describec chapter 9. Within the context of the two approaches of ecological taxation and $b$ ding on the results of previous chapters, the most important policy implications ecological taxation in general and for the use of this type of taxation in the $\mathrm{N}_{1}$ erlands in specific are described in chapters 10 and 11. In chapter 11, the main search results and conclusions of this study are also summarized.

In conclusion, it can be stated that this study is a feasibility study in which general theoretical and practical possibilities, problems and feasibility of ecolog taxation are further analyzed within the context of two different approaches. explicitly including into the analysis, ecological concerns approaches of ecolog taxation, public finance elements, the role of different levels of government and institutional framework for ecological taxation, the significance of this study is only its practical relevance but also its elaboration of some important aspects wh until now have only scarcely been treated in the theoretical national and internatic body of literature on ecological taxation. By taking these specific elements into count, this study aims at identifying elements relevant for the actual viability feasibility of ecological taxes but that so far have not received explicit attention. 


\section{Ecological Taxation: Origin and Theoretical Context}

\subsection{Introduction}

According to Oates (1992, p. xiii), over the last two decades, a more constructive role for the economic analysis of environmental problems in relation to environmental policy can be noted. This has manifested itself in actual environmental policy making in the sense that systems of tradeable permits have been introduced in the United States, while mainly in European countries several ecological taxes have been introduced. In following up this role, in chapter 2 , the main sources of origin of the idea of using taxes and tax reform for ecological purposes are described within the context of the economic approach to environmental problems and the (neo-classical) theory of environmental policy. The chapter starts with a brief description of the relationships between economic and ecological systems. The environmental problems which can be derived from these relationships can, from an environmental economics point of view, be explained by collective goods and externalities theories. Both theories and the economic approach to environmental problems are further described in section 2.2 . In the same section, different options with which it is, at least in theory, possible to internalize environmental externalities are also further described. These options range from private negotiation and the judicial determination of private property rights to regulation by the legislative and executive branches of government. The latter option includes the use of financial incentive instruments such as, for instance, subsidies, tradeable permits and taxes. Taxes are further analyzed in the remaining sections of this chapter. Presenting different views on the possibilities to use taxes for ecological purposes, two main sources of origin of the idea of using taxes, primarily or nonprimarily, for these purposes are derived and described in section 2.3. After further elaborations of both sources of origin, the chapter ends with several conclusions and remarks (section 2.4 ).

\subsection{The economic approach to environmental problems and the theory of envi- ronmental policy}

\subsubsection{Relationships between ecological and economic systems}

In standard textbooks on the subject of environmental and natural resource economics, ${ }^{\prime}$ delineations of the economic approach to environmental problems usually depart from a sketch of the relationships between ecological and economic systems.

1 For instance Common (1988) and Tietenberg (1992). 
Most generally, ecological systems can be described as systems supporting life on earth and functioning through biochemical cycles and energy flows. These cycles and flows circulate the essential chemicals of life between the environment to living organisms and back to the environment. ${ }^{2}$ The simple textbook case of economic systems involves the allocation of scarce resources through markets under conditions of perfect competition. The latter conditions include the presence of many participating actors on both the demand and supply side, homogeneous products, no entry barriers, market perfection and unrestricted formation of prices. Under these conditions, the working of the economic system is assumed to be such that an efficient allocation of resources arises, i.e. a situation arises in which no possibilities of exchange, which are beneficial to participating actors, have been left unnoticed. Given the brief descriptions of ecological and economic systems, two important relationships between these systems can be detected. On the one hand, there is an extraction flow of natural resources from ecological to economic systems. This flow of raw materials, energy, amenity etc. indicates the need of (natural) resources by the economic system, necessary, for instance, for economic activities such as production and consumption. On the other hand, there is a flow of waste products from economic systems to ecological systems. This flow indicates the return of natural resources to the ecological system after the resources have been used (and have not been completely recycled) in and for economic processes and activities. It can be concluded that to the economic system, the ecological system serves as an asset which provides three different services. The system serves as a provider of natural resources, as a waste-basket, and as a consumption good. Serving as an asset for the economic system, ecological or environmental problems will arise in case extraction leads to a net decumulation of natural resources and/or if the flow of residuals leads to a net accumulation of waste in the ecological system. ${ }^{3}$

Net decumulation of natural resources can be described as the decumulation which results after taking into consideration the fact that some natural resources are renewable and/or recyclable. Net decumulation of natural resources than involves only depletable resources. ${ }^{4}$ Net accumulation of residuals or waste can be described as the accumulation which results after taking into consideration the fact that ecological systems have a certain capacity to absorb residuals, waste or in general pollutants. Net

2 See Mercuro (1992, p. 21).

3. Environmental problems also appear when the use of non-renewable resources exceeds the pace with which new renewable resources can be developed. In this sense, environmental problems indicate situations when allocations of resources are inefficient or leave future generations worse off than present generations.

4 For a more detailed description of depletable, renewable and recyclable resources, see, i.a. Tietenberg (1992, chapter 6). In comparison to environmental economics, the subject of natural resource economics is only marginally discussed in the remaining part of the study. 
accumulation of pollutants then occurs if the load of residuals exceeds this capacity to absorb. The economics analyzing all facets of the accumulation of pollution in the ecological system is known as environmental economics.

\subsubsection{Environmental economics and the theory of environmental policy}

Within environmental economics, it is assumed that environmental problems can arise because of a misallocation of environmental resources. Given the fact that, under certain conditions, an efficient allocation of resources can be achieved through the working of markets, the question is why markets misallocate environmental resources or, in other words, allow environmental problems to occur and to persist. ${ }^{5}$ Generally, the existence of these problems is ascribed to market failures, or in other words, the inability of markets to lead the economic process towards a social optimum. Following the OECD (1993b), it can be stated that market failures arise in case of market absence (i.e. failures of markets to emerge) or in case of performance failure (i.e. failure of existing markets). The latter includes internal and external performance failures. Internal performance failures are related to the nature of the good involved (collective goods, club goods etc.), to market power (e.g. a competitive or monopolistic market), to dynamic performance (e.g. instability of solutions) and to lack of information or knowledge. External performance failures are mainly related to different types of externalities. ${ }^{6}$

Within this context and in order to explain environmental problems, environmental economics relies on two closely related theories: the theory of collective goods/bads and the theory of externalities. ${ }^{7}$ In the theory of collective goods/bads, a collective good/bad is described as a good which is characterized by non rivalry and non excludability. Non rivalry refers to the fact that an increase in the consumption of the good by one individual does not reduce the availability of the good to others. Non excludability refers to the fact that it is impossible to exclude potential consumers of the good. Since an additional user of a collective good/bad inflicts no additional marginal costs, since the same benefits are available to all, efficient resource use requires that prices be zero. Only in that case, prices equal marginal costs. ${ }^{8}$ Although the marginal costs of an additional use of a collective good/bad are zero, the cost of providing the good is not. This implies that the social marginal costs of the collective good/bad differ from the private marginal costs. Since only private marginal costs are

\footnotetext{
See Kemper (1989), Hansjürgens (1992) and Paulus (1993b).

${ }^{6}$ See OECD (1993b, draft).

${ }^{7}$ Kemper (1989).

${ }^{8}$ Musgrave \& Musgrave (1984, p. 83).
} 
reflected in market prices, misallocations of the good in question arise. ${ }^{9}$ Since many ecological circumstances or environmental problems contemplate the characteristics of the good described above (e.g. climate issues), the theory of collective goods/bads can be used to explain why in these cases market prices may not correctly reflect all costs of the good and why, consequently, the good is misallocated.

Misallocations also can result in the case of externalities (see chapter 1). Following Baumol and Oates (1988), different types of externalities can be distinguished. The most familiar types include public, private, technological and pecuniary externalities. In reference to Bator (1958), Baumol and Oates explain the differences between the two former externalities in terms of the nature of the externality, which can partake the form of a public or a private good. The differences between the two latter externalities are explained in terms of the effect of the externality on resource allocation under conditions of pure competition. While technological or true externalities produce shifts in the functions relating independent (resources) and dependent (utility of consumers) variables, pecuniary or pseudo-externalities only affect the financial circumstances of others and thus need not produce a misallocation of resources.

External effects were first presented by Marshall who termed these effects external economies. ${ }^{10}$ In the previous chapter it was already indicated that Pigou analyzed these effects with his treatment of the divergences between the values of marginal private and marginal social net products. ${ }^{11}$ Pigou described these products as follows:

"The marginal private net product is that part of the total net product of physical things or objective services due to the marginal increment of resources in any given use or place which accrues in the first instance -i.e. prior to sale- to the person responsible for investing there. In some conditions this is equal to, in some it is greater than, in others it is less than the marginal social net product" (p. 134/135).

"The marginal social net product is the total net product of physical things or objective services due to the marginal increment of resources in any given use or place, no matter to whom any part of this product may accrue" (p. 134).

As argued in the previous chapter, divergences can result in case parts of the product of a unit of resources accrue to others in the form of a positive or negative item. In this sense both positive and negative externalities can be distinguished. Pollution is a famous example of a negative externality. Both negative and positive exter-

\footnotetext{
9 See Kemper (1989) and Musgrave and Musgrave (1984).

${ }^{10}$ Marshall (1969, 8th Edition, p. 221).

"Iigou (1946, 4th Edition).
} 
nalities lead to inefficiencies resulting from the fact that what is optimal for a private decision maker may be non optimal from a societal point of view. To reduce the inefficiencies associated with positive or negative externalities, or, in other words to partly or totally internalize these externalities, there are different remedial options, institutions and instruments. The main issue is an inducement of a socially optimal behaviour of both polluters and pollutees through a set of proper incentives. Theoretically, different options can be used to induce a socially optimal behaviour. The options range from private negotiation and judicial determination of private property rights to regulation by the legislative and executive branches of government. ${ }^{12}$

Assuming zero transaction costs and the absence of strategic bargaining behaviour on the part of polluters and pollutees, Coase (1960) argues that an internalization of external effects can be achieved through private negotiations between affected parties. ${ }^{13}$ Figure 2.1 clarifies this argument.

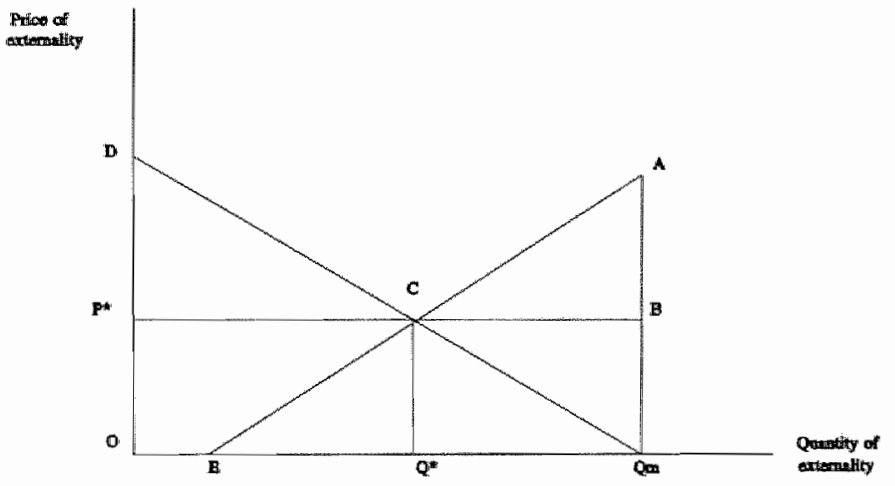

Figure 2.1 The Coase Theorem. Source: Based on Tietenberg (1992, p. 65 ).

The situation is one in which an individual polluter $(\mathrm{P})$ imposes external costs upon another individual (S). Line D-Qm represents the demand for the externality by polluter $P$. Line E-A represents the marginal costs of this externality for $S$. When $P$ does not take into consideration the costs imposed on $\mathrm{S}$, he will choose quantity $\mathrm{Qm}$ of the external effect with a price equal to zero. However, $Q^{*}$ and not $Q m$ is the efficient quantity level because at $\mathrm{Q}^{*}$ net benefits are maximized. There is, in other words, room for individual negotiation. Individual $\mathrm{S}$, for instance, could offer to pay

\footnotetext{
${ }^{12}$ See Tietenberg (1992, pp. 64-68).

${ }^{13}$ Coase (1960, pp. 1-44).
} 
the polluter $\mathrm{P}^{*}$ for each unit of externality reduced. The polluter will accept this offer because he gains a benefit equal to $\mathrm{CBQm}$. Individual $\mathrm{S}$ will accept the offer because he gains a benefit equal to $\mathrm{ABC}$. At $\mathrm{C}$, external effects are internalized and an efficient outcome results. The same outcome results if, instead of $P$, individual $S$ owns the (property) right to non pollution. In this case, $\mathrm{P}$ could offer $\mathrm{S}$ to pay $\mathrm{P} *$ for each unit of externality allowed. This offer will also be accepted by the two individuals because both will benefit from this offer. Due to private negotiation or bargaining a situation arises in which external effects are completely internalized, irrespective of who owns the property right. ${ }^{14}$ The logic behind this outcome is more familiarly known as the Coase Theorem. In reference to his article "The Problem of Social Cost" (1960), Coase (1992) indicates that "What I showed in that article, as I thought, was that a regime of zero transaction costs, an assumption of standard economic theory, negotiations between the parties would lead to those arrangements being made which would maximize wealth and this irrespective of the initial assignment of rights. This is the infamous Coase theorem, named and formulated by G. Stigler, although it is based on work of mine. Stigler argues that the Coase theorem follows from the standard assumptions of economic theory. Its logic cannot be questioned, only its domain" (p. 717).

Since the domain to which the negotiation solution to the externality problem as proposed by Coase is rather limited, ${ }^{15}$ due to the assumption of zero transaction costs and the absence of strategic behaviour, many practical and theoretical points of criticism have been raised against this approach. The first point of criticism is the limited use that can be made of the Coasian approach for recent environmental problems. Several environmental problems (e.g. mobile source air pollution) involve many pollutees and/or many polluters. A large number of affected parties hampers bargaining, negotiating and eventually achieving a bargaining solution and entails the risk of increasing transaction costs and the possibilities for freeriding behaviour. A second point of criticism of the Coasian approach is the limited attention to situations

${ }^{14}$ If a particular allocation of private property rights is considered pre-eminent, court systems can impose property rules and decide which right (that of the polluter or the one who suffers from pollution) is pre-eminent. Mishan (1968), for instance, argues that individuals have a right to a clean environment. This 'amenity right' could be judicially determined and be laid down in laws. On the basis of these laws, individuals than have a legal right to a clean environment. These rights may also provide incentives to private firms to operate in conformity with the interests of society. "What is being proposed...may be regarded as an alternation of the legal framework within which private firms operate in order to direct their enterprise towards ends that accord more closely with the interests of society. More specifically, it would provide industry with the incentive necessary to undertake prolonged research into methods of removing the potential amenity-destroying features of so many today's existing products and services" (p. 73).

is See e.g. Burrows (1979), Common (1988), Cropper and Oates (1992), Socio-Economic Council (SER, 1991) and Tietenberg (1992). In this and the remaining chapters of this study, the Socio-Economic Council is referred to as the SER. 
in which time is an important element. There is no guarantee that the bargaining solution will not leave future generations worse off. More theoretical points of criticism of the Coasian approach concern the assumption of zero wealth effects with the conferment of property rights and the assumption that there are no obstacles to bargaining such as threatmaking, bribery and intricate bargaining issues. ${ }^{16}$

In reaction to some of these points of criticism, Coase (1992) himself argues: "....I tend to regard the Coase theorem as a stepping stone on the way to an analysis of an economy with positive transaction costs...it does not imply, when transaction costs are positive, that government actions (such as government operation, regulation, or taxation, including subsidies) could not produce a better result than relying on negotiations between individuals in the market. Whether this would be so could be discovered not by studying imaginary governments but what real governments actually do. My conclusion: let us study the world of positive transaction costs" ( $p, 717$ ).

The government actions to which Coase (1992) refers, represent different options for the legislative and executive branches of government to internalize external effects. ${ }^{17}$ Departing from the notion that environmental problems are the result of particular behaviour of individuals and institutions, the Netherlands Scientific Council for Government Policy indicates several options for governments to influence such behaviour. ${ }^{18}$ The goal of environmental policy, from this point of view, can be considered in terms of influencing choice behaviour of (economic) actors. This behaviour can be described in terms of preferences, conditions and choice parameters. These factors can be influenced, by government intervention, through: ${ }^{19}$

1. The introduction of an immovable parameter of direct order, for instance, in the form of a prohibition.

2. Persuasion and consultation which influence preferences.

3. Transactional conditions, i.e. manipulation of choice influencing factors.

\footnotetext{
${ }^{16}$ See e.g. Tietenberg (1992, pp. 66-67).
}

${ }^{17}$ Burrows $(1979$, p. 80$)$ argues that: "In the last twenty years economists have made a substantial, and arguably excessive, effort to identify the characteristics of theoretical market solutions to pollution problems. The main result of this effort has been a lengthy list of likely obstacles to the achievement of socially efficient outcomes without government intervention". This however, does not imply that government intervention will be successful in achieving allocative efficiency, nor that allocative efficiency is a sufficient condition for government intervention.

${ }^{18}$ WRR (1992).

19 See WRR report (1992). Again it is stressed that government intervention does not automatically mean that an allocative efficiency is achieved or that market failures are a sufficient condition for government intervention. 
On the basis of the choice influencing parameters mentioned above, the following environmental policy instruments can be distinguished. ${ }^{20}$

1. Direct regulation instruments: these instruments refer to measures which are used to directly influence the behaviour of individuals with regard to the environment Examples include, for instance, legal limits on the amount of pollutants emitted and legal requirements with regard to the use of specific technologies, products etc. The most important characteristic of these instruments is that they directly order or force individuals to conduct a particular behaviour with regard to the environment. In the literature on the subject of environmental policy instruments, direct regulation instruments are mainly referred to as command and control instruments.

2. Social regulation instruments: these instruments refer to measures which are used to motivate individuals to voluntarily change their behaviour with regard to the environment. Examples include information and education like, for instance, teaching individuals that some activities have greater detrimental effects on the environment than others. The most important characteristic of these instruments is that they do not force individuals to change their behaviour with regard to the environment. Social regulation instruments are sometimes referred to as persuasive instruments.

3. Financial regulation instruments: these instruments refer to measures which are used to influence behaviour of individuals with regard to the environment by connecting this behaviour to financial incentives. Examples include taxes, tradeable permits, ${ }^{21}$ subsidies and deposits (refunds). ${ }^{22}$ The most important characteristic of these instruments is that they influence behaviour by changing transactional conditions in terms of costs and benefits of behavioural alternatives. Financial regulation instruments are sometimes referred to as financial incentive instruments, market conform instruments or economic instruments.

${ }^{20}$ In the WRR report (1992) it is indicated that a classification of different instruments is useful for descriptive purposes. Judgement of different instruments, however, is not a matter of classification but of the analytical aspects of the different forms and types of instruments. In Huppes et al. (1988) and in SER (1991), direct (or physical) regulation, financial (or economic or market-conform) regulation, and social (or persuasive) regulation are also distinguished. SER (1991) also indicates a classification of instruments on the basis of the system to which enwironmental policy is directly related, i.e. the economic or the ecological system.

${ }^{21}$ Part of this type of instrument could also be categorized as a direct regulation instrument (see WRR, 1992, p. 48).

22 Sometimes liability rules and fines are also considered examples of financial regulation instruments. 
Both the intensity of the input of these different environmental policy instruments and the choice of a single instrument or a mix of instruments are part of the factors contributing to the realization of environmental policy goals. To select a particular environmental policy instrument, all the various details of design for each alternative and their implications have to be analyzed (Downing, 1984). In the 1992 report of the Netherlands Scientific Council for Government Policy it is indicated that the choice of a particular environmental policy instrument depends on the characteristics of the environmental problems involved, on the way in which the instruments are able to meet some general criteria and on the characteristics of the different instruments (e.g. their main choice influencing parameter). ${ }^{23}$ The WRR (1992) refers to this approach as the 'situation characteristics approach'.

While specific characteristics of particular environmental problems are further discussed in several other chapters of this study, general characteristics of these problems are usually considered to be related i.a. to the ease by which polluting emissions and effects can be recognized, the number of polluting sources, the structure of the groups for which the tax is intended, the opposition to the tax and the costs for those who are confronted with the tax (see WRR, 1992, p. 11).

Within the specific context of a particular environmental problem, ecological tax instruments not only have to be designed in such a way that the relevant features of this problem are taken into account but also in such a way that several general criteria can be met. The relative weight of these criteria differs from case to case and from country to country (see SERV, 1992, p. 41). Generally these criteria include the economic efficiency, effectiveness and practicability of the different instruments and the concordance with existing institutional frameworks. ${ }^{24}$ Economic efficiency refers to the realization of environmental policy goals against minimum costs. Within the framework of the theory of environmental policy, a static efficient allocation refers to an allocation in which the marginal damages caused by a unit of pollution and the marginal costs of avoiding that unit of pollution are equal. Within the same framework, dynamic efficiency refers to a situation in which environmental policy instruments induce environmentally friendly technologies, innovation and production processes. Within the context of environmental policy, the effectiveness and practicability of environmental policy instruments delineate the way in which a specific environmental policy target can be realized given implementation and enforcement constraints. The latter include the amount of information required to design and use

${ }^{23}$ WRR $(1992$, p. $10 \mathrm{ff})$.

${ }^{24}$ See Dewees (1983), SERV (1992, pp. 40-41), Opschoor \& Vos (1989, pp. 18-20), Kriuppel (1989), Bovenberg et al. (1991, pp. 9 ff.), Nentjes \& de Wries (Ed., 1990), Europees Parlement (1990) and SERV (1992) for a further elaboration of these choice criteria and the comparison of different environmental policy instruments. 
the instruments, the level of administrative costs and the likelihood of opposition: The concordance of environmental policy instruments with institutional framework refers to the practical feasibility of these instruments, given institutional, fiscal, politi cal and environmental policy frameworks. When compared to other environmenta policy instruments, economic regulation instruments such as ecological taxes ar generally presented ${ }^{26}$ as options which, from a theoretical point of view, seem espe cially appropriate in the preventive phase of environmental policy. Moreover, they ar usually presented as being efficient in a dynamic and static sense. ${ }^{27}$

In a comparison of direct and financial regulation instruments, the $\mathrm{OECC}$ (1993a, p. 21) states that "[b]oth require enforcement, which in turn requires effective monitoring activity and clear criteria for identifying violations. Also, where infringe. ments are noted, both require a framework of administrative and legal processes to take appropriate action to ensure compliance. There tend however to be differences between tax authorities and environmental regulators in practices regarding enforcement and compliance. In any practical application these differences may be important factors influencing the likely relative effectiveness of policies based on regulation or market mechanisms; they also provide important material for a comparative assessment of enforcement practices and effectiveness".

Although the comparative advantages of economic regulation instruments make these instruments extremely attractive for environmental policy making, the actual benefits that can be gained by using these instruments depend strongly on whether or not there are government failures. Following the OECD (1993b), these failures can be described to occur when the end result of political and administrative processes is such that prices are leading away from the social optimum, for reasons entrenched in the institutional system. Government failures arise in case of lack of intervention or in case of intervention failure. The latter include policy and administrative failures such as the distortion of the private costs of environmental resource use resulting from particular governmental policies. They also consist of organizational problems such as the existence of particular administrative rigidities. Administrative and other failures of instruments likely differ per type of instrument. It can therefore be concluded that, since all environmental policy instruments are accompanied by their own set of characteristics, the choice of a particular instrument requires a case by case approach

${ }^{25}$ Opschoor and Vos $(1989$, p. 19).

${ }^{26}$ See i.a. Opschoor \& Vos (1989, p. 9)

${ }^{27}$ Since taxes are the main subject of analysis, analyses in this study are less directed at comparing the comparative (dis)advantages of different environmental regulation instruments. For further analyses of this kind see, among others, Baumol and Oates (1988), Tietenberg (1992) and WRR (1992). Direct and social regulation instruments and non tax economic regulation instruments are only considered in so far as this is necessary for an evaluation of particular characteristics of the instrument of taxes. 
(see also SERV, 1992, p. 88 and Hahn, 1989). In this respect, in this and the following chapter, several problems and attractive features of the instrument of ecological taxes are considered and presented.

\subsection{The idea of using taxes for ecological purposes: main sources of origin}

Given the theoretical context into which the economic approach to environmental problems and the use of specific environmental policy instruments can generally be embedded, in the following the main sources of origin of the idea of using taxes directly or indirectly for ecological and environmental policy purposes are further discussed.

\subsubsection{Pigouvian taxes}

In this and the previous chapter, several references have been made to Pigou's treatment of the divergences between private and social net product and his suggestions to use taxes and subsidies for the internalization of negative and positive externalities, respectively. ${ }^{28}$ According to Pigou, profit maximizing entrepreneurs are interested in only the marginal private net product. The value of marginal private net product, however, can diverge from the value of marginal social net product because of (positive or negative) external effects. ${ }^{29}$ From section 2.2 it can be concluded that within environmental economics, the concept of externalities is central to the explanation of environmental problems. ${ }^{30}$

Externalities lead to inefficiencies resulting from the fact that what is optimal for a private decision maker's point of view may be non optimal from a societal point of view. Figure 2.2 sketches this situation for a producer in a competitive market who causes (negative) external effects in the form of pollution but who does not take these effects into account when making particular decisions. The situation is as follows. With a fixed technology and supposing that more output means more pollution, the producer chooses Qv as his level of production. This level of production is optimal for the producer because his marginal private costs equal his marginal private revenues. This level of production, however, is not optimal for society. Since there are externalities in the form of pollution, society faces higher marginal costs (SMK).

${ }^{28}$ See Pigou (1946, 4th Edition). The most important aspects with regard to the divergences between marginal private and marginal social net product were already described in Pigou"s Wealth and Welfore (1912).

29 See Jaeger $(1993,28 \mathrm{ff})$.

30. For a further elaboration of the transformation of the theory of external effects to environmental problems, see Jaeger $(1993,37 \mathrm{ff})$ and the references cited there. 


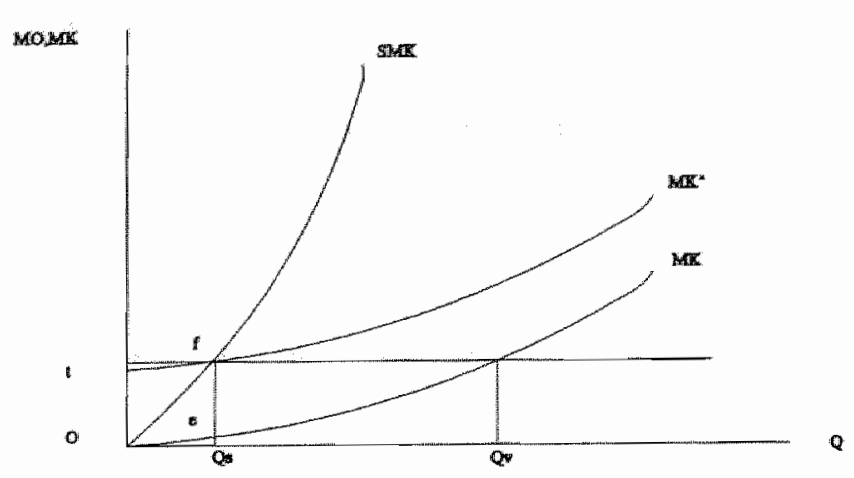

Figure 2.2 The internalization of externalities through Pigowvian taxes.

From the point of view of society, the optimal level of production is Qs becau se at that level marginal social costs equal marginal revenues. The presence of externalities in this case leads to a higher quantity of production and related to this more pollution and a lower price than is efficient. The level of output and prices, in other words, is not the one required for an efficient allocation. Since market prices do not correctly reflect the existing scarcity of environmental resources, resources will be over used. ${ }^{31}$ It can be concluded that environmental problems, from an economic point of view, can be considered as allocational problems.

To reduce the divergences between private and social net product, Pigou tells. us that governments can introduce "extraordinary restraints" in the form of taxes. Following the suggestions of Pigou, the polluter in the example mentioned above could be confronted with a tax equal to Ot (see figure 2.2). As a result of the tax, the private marginal cost curve will shift from $\mathrm{MK}$ to $\mathrm{MK}^{\wedge}$. The tax reduces the profit per unit of output and induces the polluter to reduce production to Qs, the level of production where all external effects are completely internalized. In theory, a tax per unit of emissions set equal to the marginal social damage caused by the emissions is usually referred to as a Pigowvian tax (See Baumol and Oates, 1988, p. 58). In theory, the Pigouvian tax solution is stated to be allocatively efficient, i.e. able to lead to a Pareto optimal level of emissions reduction. Confronted with the tax, individual polluters will weigh the costs of paying the tax at the existing amount of emissions with the benefits of avoiding (parts of) the tax by reducing the amount of emissions. Emissions will be reduced if the marginal costs of emissions control for the first unit of reduction are smaller than the tax rate. Emissions will continue to be reduced until

\footnotetext{
${ }^{31}$ See SER (1991, p. 36-37).
} 
the marginal costs of emissions control are equal to the tax rate. In this case, an efficient level of emissions reduction will result. ${ }^{32}$ Assuming that all polluters behave rationally, the total costs of emissions control will be minimized. This characteristic of Pigouvian taxes is also known as the least cost characteristic. ${ }^{3.3}$

Within a static context, unless all emissions are reduced, the remaining emissions are taxed. ${ }^{34}$ The fact that the remaining emissions are taxed, however, provides incentives for those confronted with the tax to seek for options with which it is possible to further reduce the amount of taxes to be paid (in the future). Within the latter dynamic context, higher emissions reductions can, for instance, be achieved through technological developments and innovations. Compared to a static situation and assuming unchanged tax rates, these developments and innovations then result in lower amounts of (future) taxes to be paid. In the sense that Pigouvian taxes provide incentives to seek for options to further reduce emissions they are usually described as also being dynamically efficient. Both the static and the dynamic efficiency of Pigouvian taxes are considered main advantages of these instruments when compared to ordinary command and control instruments. ${ }^{35}$ An optimall level of emissions reduction can, in theory, be achieved through the imposition of a Pigouvian tax set equal to the marginal costs and benefits of the emissions reduction at the optimal level. This however implicitly assumes that the authority which imposes the tax has complete knowledge on all relevant costs and benefits. To be able to set a tax with which it is possible to completely internalize all external effects, in other words, requires the presence of a system which not only provides accurate if not perfect information on the externalities and the activities by which they are caused but also on associated utilities, damages and marginal costs. ${ }^{36}$ Since the actual occurrence of such a system can be questioned for many externalities and environmental problems, the imposition of a Pigouvian tax set equal to the marginal costs and benefits of the emissions reduction at the optimal level is not only on intricate but more often an impossible

${ }^{32} \operatorname{SERV}(1992$, p. 45).

${ }^{33}$ For a more detailed description of the least cost characteristic of different (environmental policy) instruments, see, i.a. WRR (1992) and Baumol and Oates (1988).

${ }^{34}$ The imposition of Pigouvian taxes does not necessarily lead to a situation in which all emissions are reduced. Emissions are reduced for so far as this is optimal from the point of view of the marginal costs and benefits of emissions reduction. A. less than $100 \%$ reduction in emissions implies that the tax base is not completely eroded. Tax revenues can therefore also result from the imposition of Pigouvian taxes.

${ }^{35}$ See SERV (1992, p. $42 \mathrm{ff}$ ). For a thorough sketch of the main theoretical assumptions and the first and second order conditions underlying the imposition of efficient Pigouvian taxes, see i.a. Baumol and Oates (1988).

${ }^{36}$ Jaeger (1993, p. 34). 
matter in practice. Pigou (1947) himself, referring to the divergencies between social and private costs, emphasizes the difficulties of what he calls bounties and duties: "How are we to make the corresponding calculation for a factory industry the smoke of which increases the expenses of the public in washing and cleaning?......Plainly the difficulties are formidable..... The relevant knowledge is of a sort that we do not af present possess" (pp. 42-44).

\subsubsection{Possibilities to incorporate the idea of Pigouvian taxes into actual environ- mental policy making}

Besides the lack of a proper system of information, setting the proper level of a Pigouvian tax is further complicated by the fact that it may be difficult to identify those who caused the external effects. ${ }^{37}$ Besides this, it is often difficult to determine exactly (both in terms of quality and quantity) which part of the total externalities has been caused by a particular externality generating source. Further complications arise with the evaluation of external effects in monetary terms and with the possibility that negative externalities and marginal costs may change non proportionally with an increase in the activities by which they are caused. In the latter case, it is necessary that Pigouvian taxes can flexibly be adapted to changed situations. Flexible taxes and tax systems, however, may increase the transaction and administration costs associated with the levying of Pigouvian taxes. If these costs outweigh the benefits of a flexible Pigouvian tax, the tax is not efficient. Non efficiencies, however, also occur if the Pigouvian tax is too rigid which may result in tax rates which are set at too high or too low a level to be efficient. ${ }^{38}$

It can be concluded that the Pigouvian tax, in theory, is assumed to be able to meet a whole set of requirements. These requirements are necessary to achieve a complete internalization of external effects. To meet these requirements in practice however is very complicated and is sometimes even considered impossible. ${ }^{39}$ The Pigouvian tax is therefore often considered an ideal image which cannot, however, serve as a policy device for practice itself. Burrows (1979) indicates that in situations with imperfect or poor information on policy instruments, governments have two policy options. First, pursuing the quest for socially efficient solutions through iterative control (improvement little by little). In this sense, Pigouvian taxes that are set at too high or too low a level can be re-adjusted until an optimal tax rate is found. Important disadvantages of this procedure, however, are the uncertainty and the costs that are associated with trial and error re-adjustments. Instead of using such a trial and ${ }^{37}$ See Jaeger (1993, pp 34-36) for this and the following complications of Pigouvian taxes.
${ }^{38}$ For more detailed description of these and further complications of Pigouvian taxes, see e.g.
Hansjürgens (1992) and Baumol and Oates (1988).

${ }^{39}$ See i.a. Jaeger (1993), Hansjürgens (1992). 
error procedure, governments can also opt for the use of particular control policies to move the system towards pollution limits that do not claim to be socially efficient. These limits or standards can, for instance, be set by politicians. In this respect, given the fact that the Pigouvian tax cannot serve as a practical policy device itself, second best approximates have been suggested of which the most familiar include the regulatory charge and the standard and charges approach.

In practice, the regulatory charge is used to make polluting activities more expensive. The basic idea is that this induces polluters to make tax avoiding changes in behaviour: to avoid (part of) the regulatory charge, polluters have to produce less pollution. Unlike Pigouvian taxes, which are set equal to marginal social damages, regulatory charges are set by a trial and error process in such a way that a particular standard of environmental quality can be achieved. The standard of environmental quality is arbitrarily set by politicians. The basic elements of this approach, which is also known as the standard and charges approach, were first presented by Baumol and Oates (1971). In reaction to proposals in the Pigouvian tradition to adopt a system of unit taxes set equal to marginal social damages, Baumol and Oates describe the difficulties of designing and calculating such taxes in practice and propose a substitute approach to the problem of externalities. ${ }^{40}$ The proposed substitute approach is called the environmental pricing and standards procedure, which "represents what we consider to be as close an approximation as one can generally achieve in practice to the spirit of the Pigouvian tradition". 41 The procedure involves the selection of an arbitrary standard for an acceptable environment, e.g. that the sulfur-dioxide content of the atmosphere in a city should not exceed $x$ percent. The standard can be based on evidence concerning the effects of unclear air on health. The standard puts a constraint on particular activities representing "the decision-makers subjective evaluation of the minimum standards that must be met in order to achieve what may be described in persuasive terms as "a reasonably quality of life"." 42 The taxing authority can set and reset tax rates until the standard is achieved. The main advantage of this pricing and standard procedure is the fact that no longer information is required on the optimal marginal social damage. A further advantage of this procedure is the least cost characteristic of charges: confronted with the charge each externality generator will reduce emissions until the marginal costs of emissions reduction equal the tax, resulting in a minimization of the total costs of emissions control. Acceptability standards are considered to be appropriate by the two authors in those cases only "where there is clear reason to believe that the existing situation imposes a high level

${ }^{40}$ Baumol and Oates (1971, p. 42).

41 Ibid.

${ }^{42}$ Ibid. (pp. 44-45) 
of social costs and that these costs can be significantly reduced by feasible decreases in the levels of particular activities" (p. 48). ${ }^{43}$

In order to avoid the problems that are related to the internalization of externalities by way of a tax set equal to the marginal costs and benefits of emissions reduction at the optimall level, policy makers might opt for the introduction of Pigouvian types of charges via the adoption of a standards and charges approach. On the other hand, policy makers might opt for an introduction of charges or credits which represent the central elements of Pigouvian taxes but which, instead of being imposed on emissions as suggested by Pigou, are related to inputs, throughputs and/or outputs. This option might especially be relevant in those cases in which emissions can only be measured with great difficulties, in which there is a clear relationship between that which is taxed and that which is emitted and in which the environmental context requires structural behavioural changes from relevant actors. Examples include the imposition of Pigouvian charges on the ability to produce externalities and the use of tax credits to stimulate environmentally friendly technologies. In the first case, instead of a Pigouvian tax per unit of emissions or externalities, a Pigouvian charge can be imposed on the ability to produce externalities. In this sense, different technologies can be taxed differentlly to the degree in which they create externalities. To induce such structural behavioural changes and thus be a viable environmental policy option, Pigouvian charges have to be directly connected to a point of choice. If these charges, for instance, are used with the aim of inducing economic actors to employ environmentally friendly production processes, Pigouvian charges have to kick in precisely at the point at which these actors choose between using either the production process which is undesirable from an environmental point of view or the environmentally friendly alternative. It can be concluded that Pigouvian taxes can only induce structural behavioural changes in those cases in which those who are confronted with these taxes also actually have options or possible alternative ways of behaviour and thus if it can reasonably be assumed that that which is taxed is not completely inelastic. When imposed such that they kick in at the point of choice, Pigouvian taxes will make the environmentally unfriendly alternative more expensive and thus ceteris paribus less attractive. This induces economic actors to use environmentally friendly alternatives. In the longer run, when the environmentally unfriendly production process starts to depreciate over time (the precise moment in time can of course differ between economic actors), environmentally friendly alternatives will become more

${ }^{43}$ An interesting feature of the prices and charges procedure is its focus on the combination of a) the setting of a particular standard and b) the use of the least cost characteristic of the instrument of charges. In recent years, much attention has been paid to the combination of different instruments of environmental policy. Gawel (1991), for instance, analyzes how particular attractive features of different environmental pollicy instruments can be combined. Gawel's analysis shows that suitable combinations of instruments involve a combination of direct regulation, subsidies and charges and a combination of direct regulation and tradeable permits (See chapter 5 of Gawel, for a concrete analysis of these different combinations of instruments). 
and more attractive. In this sense, at least in the long run, only minor tax revenues can be expected from the imposition of Pigouvian types of taxes. To be able to make such structural changes, it is important that Pigouvian charges are accompanied by a framework which provides information on possible alternative ways of behaviour for those confronted with the taxes. ${ }^{44}$ The latter is extremely important for the feasibility of these taxes in practice.

Instead of using quasi Pigouvian charges to induce the use of environmentally friendly production processes, also particular credits can be used. In this sense, it is for instance possible that a tax credit is provided by the government in case a clean technology is introduced by a particular company. This credit, which can be built into the taxes that are already paid by the company in question (e.g. the corporate income tax), can represent an amount which partially or totally covers the costs of the necessary investments. The option of tax credits seems especially relevant in those cases in which the use of Pigouvian taxes would induce policy makers to maintain their source of revenues, in this case the activities leading to the externalities in question. Credits introduce the opposite incentive. An additional advantage of tax credits is related to the fact that they induce polluting actors to reveal (part of) their polluting activities. By revealing these activities, these actors will be rewarded with a tax credit. With a tax or charge, on the other hand, there is an incentive not to reveal these activities, since this can raise the tax bill for the actors involved.

Where the difficulties of using Pigouvian taxes or their approximates for environmental purposes are formidable, the theory of environmental policy suggests the use of those instruments that can achieve the same purpose with the same but preferably lesser costs and difficulties. Within the theory of environmental policy, tradeable permits are often considered as a possible benchmark in this respect. Under a system of tradeable permits, the government specifies an admissible amount of emissions, which can then be traded among emitters by way of permits. The permits indicate the right to emit a certain amount of pollutant substances. In theory, in a competitive market setting with complete certainty, a once and for all choice between the instrument of taxes or tradeable permits makes no difference. The decision merely boils down to choosing an equilibrium price (with taxes) or quantity (with permits). In a setting of uncertainty, however, the expected value of social welfare may differ significantly in a regime with either one of these instruments. In such a setting, the effects on social welfare of the two instruments strongly depends on the position and steepness of the marginal cost curve. This curve represents the marginal control costs of emission reduction. If the position of this curve is lower than expected, the reduction of emissions will not be sufficient under a system of permits and will be exces-

${ }^{44}$ See Hayek (1945) on the rolle of governments in case knowledge and information is dispersed throughout society. 
sive under a system of taxes if both are set at their ex ante optimal level. ${ }^{45}$ Even from this brief description it can be concluded that, as in the case of taxes, uncertainty also creates difficulties in designing and introducing a feasible system of tradeable permits. The decision to use either one of these policy instruments therefore has to be taken on a case by case basis. ${ }^{46}$ In his analysis of marketable permits and charges, Hahn (1989) for instance shows that the capacity to monitor and enforce can dramatically affect the choice of instruments. In this sense, Hahn argues to also take into account particular institutional constraints under which policy instruments are introduced. Downing and Watson $(1974$, p. $219 \mathrm{ff})$ in this respect argue, that the costs of pollution control to firms incur differential expenses in addition to (or instead of) the actual installation and operation costs of control devices or process changes themselves. Commonly, the costs of pollution control involve:

1. The costs of control devices or process changes, i.e. the actual costs of installation and operation. These costs are generally expressed in the usual marginal cost (MC) curve which, together with a marginal benefit (MB) curve, is used to determine the optimal level of pollution.

2. Enforcement costs, i.e. expenses for compliance testing, for certification, legal expenses, fines and other enforcement costs.

3. Costs to the control agency of insuring that the firm complies with control requirements.

The enforcement costs in fact represent the institutional constraints placed on the firm by the control agency and the legislature. These costs depend on the implementation and enforcement policies available to the control agency and affect, among others, the firm's control action of environmental pollution. The control agency has several tools at its disposal to control these efforts by firms. Downing and Watson (p. 510 in Oates (1992) and 222 in the original) mention the setting of higher or lower emission standards; the change of penalties for non compliance; the possibility to make court actions more prompt and the possibility to impose external pressures on the firm through public statements. In the following figure, which is based on Downing and Watson (p. 508 in Oates, 1992 and p. 220 in the original), curve MC represents the standard marginal cost curve of pollution control, enforcement costs excluded. Curve MCei represent these costs when enforcement costs are included. Area 1 indicates the enforcement costs incurred upon the firm. At the same time, area 2 represents the enforcement costs for the control agency. With all the costs of enforce-

${ }^{45}$ For a more formal analysis, see Baumol and Oates (1988, chapter 5).
${ }^{46}$ For such comparisons see i.a. Adar \& J.M. Griffin (1976) and Hahn (1989). 
ment for the firm and control agency in question included, MSC represents the total costs of controlling the removal of pollution. As can be noticed from this figure, the optimal rate of removal, once enforcement costs are included, is considerably lower than the optimal rate of removal when only the costs of the control of devices or process changes are included. Since the costs of pollution control, including enforcement and compliance costs, are likely to vary with policy instruments, already these costs, as Hahn indicates, can dramatically affect the choice of instruments. ${ }^{47}$

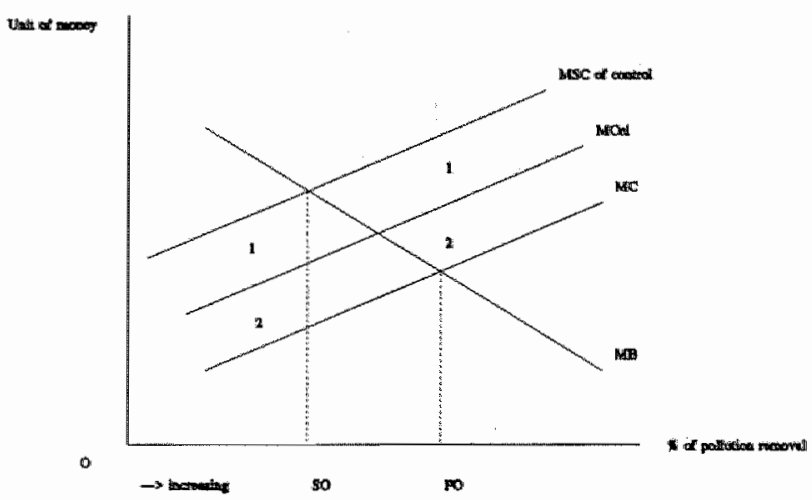

Figure 2.3 Enforcement and compliance costs. Source: Based on Downing and Watson (1974, p. 220).

An examination of several charges and marketable permits by Hahn reveals that, in practice, these instruments are rarely introduced in their textbook form. Virtually all environmental regulatory systems using charges and marketable permits rely on the existing command and control permitting system. Hahn therefore suggests that the fundamental problem is to determine the most appropriate mix of environmental policy instruments, with an eye to both economic and political realities. In addition, Hahn states that "existing theories on environmental policy instruments could benefit from more careful analysis of the regulatory status quo, underlying beliefs about property rights, and how political choices are actually made in different countries" (p. $295)$. In this sense, not unlike Coase (1992, see above), Hahn argues for a more careful analysis of environmental policy instruments within the world of positive transactions costs.

${ }^{47}$ See also Downing \& Watson (1974), Harford (1978) and Harrington (1988). 


\subsubsection{The use of revenue raising taxes for ecological purposes}

The previous considerations indicate that the focus on externalities in the explanation for environmental problems within environmental economics together with the suggestions of Pigou $(1912 ; 1920)$ and Baumol and Oates (1971) and further treatments, adaptions and improvements of these suggestions are central to the idea of using taxes for ecological and/or environmental (policy) purposes. If taxes are used in the sense of Pigou, their main objective is to confront those who harm the environment with the environmental costs they impose on others. Such Pigouvian types of taxes, in other words, are a means to influence and direct particular behaviour in a direction considered desirable from an environmental point of view. Pigouvian types of taxes (e.g. regulatory charges), therefore, are intended to be used only for allocational ends and are not intended to raise additional revenues for the state.

From the point of view embedded in the classical theory of taxation, the only purpose of taxes is seen in fiscal ends: in providing a stream of tax revenues to the state. In the ordinary sense, revenue raising taxes can generally be described as compulsory contributions that are levied according to general rules and for which there is no quid pro quo relationship between the taxes paid and the services and goods provided by the government. Wicksell, ${ }^{48}$ emphasizing the principle of voluntary consent, ${ }^{49}$ arrives at another description and argues:

"There can be no doubt that, from the point of view of general solidarity or charity, parties and social classes should on occasion share an expense from which they expect no great or direct benefit, or should contribute beyond the measure of their own advantage....Coercion is always an evil in itself and its exercise, in my opinion can be justified only in cases of clear necessity...If the distribution of taxes always rested on the principle of voluntary consent, it seems to me that many such activities which today can be undertaken only by private groups, would come to be incorporated by the state" ${ }^{110}$

In the classical theory of taxation, however, taxes and tax financed expenditures are dissociated. The main principles and ideals of these "ordinary" taxes can be traced back to Adam Smith. In the second part of the fifth book of the "Wealth of Nations", he argues with regard to taxes in general:

"The subjects of every state ought to contribute towards the support of the government, as nearly as possible, in proportion to their respective abilities;

Wicksell (1896) and Musgrave \& Peacock (eds.) (1958 pp. 72-118).

${ }^{49}$ See Musgrave (1985, p. 79).

90. Wicksell (1958, pp. 90-91) in Buchanan's translation of Wicksell (1896). 
that is, in proportion to the revenue which they respectively enjoy under the protection of the state. The expense of government to the individuals of a great nation, is like the expense of management to the joint tenants of a great estate, who are all obliged to contribute in proportion to their respective interests in the estate. In this observation or neglect of this maxim consists, what is called the equality or inequality of taxation.... The tax which each individual is bound to pay ought to be certain, and not arbitrary....Every tax ought to be levied at the time, or in the manner, in which it is likely to be convenient for the contributor to pay it.....Every tax ought to be so contrived as both to take out and to keep out of the pockets of the people as little as possible over and above what it brings into the public treasury of the state". ${ }^{51}$

Building on the principles put forward by Adam Smith, Stiglitz (1986, p. 328) describes the ideal tax system as the system that is marked by:

Economic efficiency: the system does not stand in the way of an efficient allocation of resources.

Administrative simplicity: the system is simple and relatively cheap to administer.

Flexibility: the system is adaptable to economic and technological changes.

Political responsiveness: the system is responsive to political convictions and views prevailing in a particular society. These differ from society to society.

Fairness: the system is fair in its relative treatment of different individuals. Opinions as to what a fair treatment is may differ per individual and per society. The Dutch society e.g. can generally be referred to as a society in which consultation and equality is emphasized.

With regard to taxes, the "ideal image" of the so-called lump sum tax is important. A lump sum tax is a tax that is not related to economic activities but to unalterable characteristics as age and gender. Only in this form the tax leads to the maximum amount of revenues for the state. ${ }^{52}$ The most important characteristic of lump sum taxes is the fact that liable individuals can do nothing to avoid the tax liability. Lump sum taxes, in that case, do not lead to behavioural changes that are aimed at avoiding the tax burden. Lump sum taxes, in other words, lead to income effects only and cause no substitution effects. Traditional fiscal theory emphasizes this concept of

\footnotetext{
${ }^{51}$ Smith, Adam (1971 edition), Volume Two, p. $307 \mathrm{ff}$ (original ed. 1776).

${ }^{52}$ See e.g. Musgrave and Musgrave (1984, pp. 284-312).
} 
neutrality: the influence of fiscal systems on choice parameters in the economy should be minimized. ${ }^{53}$

In practice, (non lump sum) fiscal systems do influence the economic behavir our of individuals in the sense that these individuals try to avoid their tax liability: Although these taxes are not meant to work in this way, they lead to substitution effects and therefore, unintendedly, lead to undesired distortions in the allocation of resources. The revenues raised from these taxes will ceteris paribus be lower than the revenues raised from lump sum taxes. The difference in revenues raised is the excess burden. The lump sum tax can be used as an analytical instrument to indicate the extent of the excess burden of a particular tax analyzed that way. The lump sum tax itself, however, is not a policy alternative. It is a device used to indicate the relative inefficiency of a tax system. ${ }^{54}$

Based on the general sketch of some important principles and ideals of taxes in this section so far, it can be concluded that from the point of view embedded in the classical theory of taxation, taxes are only used for fiscal ends. Taxes, however, may lead to changes in behaviour motivated by a desire to avoid the tax which may conflict with the goal of efficient resource allocation. The extent of the inefficiency can be shown by taking the lump sum tax as a benchmark.

The fact that fiscal systems in practice do influence the economic behaviour of individuals is also recognized by traditional fiscal theory. Based on this recognition, traditional fiscal theory has adjusted the neutrality concept to a concept of equalization of behavioural reactions in a system of optimal taxation. ${ }^{55}$ This adjusted concept, however, does not reckon with the possibility that a change of allocation can be the main purpose of intervention as is the case, for instance, in the presence of externalities. To the extent that environmental effects appear in the form of spillovers and collective goods or bads, the efficient allocation of resources may require intervention into the market process by means of taxation. One can, therefore, conclude that a strict use of the neutrality concept ${ }^{56}$ as a principle of taxation is not always in agree-

53 See WRR (1992).

\$4 Stiglitz (1986, p. 375).

${ }^{45}$ The arguments given in this part of the section are based on WRR (1992).

56 Although the neutrality concept lends itself for different interpretations, the concepts used in this study refer to neutral taxation, revenue or fiscal neutrality and budgetary neutrality. The concept of neutral taxation is used in reference to a situation in which the allocation of resources is the same before and after tax measures. Revenue or fiscal neutrality refers to a situation in which the total tax revenues are the same before and after tax measures. Budgetary neutrality refers to a situation in which tax measures have no budgetary consequences for the government. For a more explicit and alternative description of the concept of newtral taxation, see Benham (1934). According to Benham, a "neutral system of taxation and public expenditures is one which translates into effect the voluntary judgements and preferences of the citizens, whatever they may bet" (p. 450). 
ment with an optimal allocation of resources. A less strict principle of taxation (which is more in agreement with practice) is the principle that the efficient allocation of resources is not to be hindered, perhaps even to be stimulated by the system of taxation. According to the WRR (1992, p. 76), in modern public finance the main purpose is no longer neutral taxation but "taxation of the things we don't want (for instance, environmental damages)". With this insight and within the context of an increasing deterioration of the environment, also public finance theory has served as a source of origin of the idea of using taxes (in this case ordinary revenue raising taxes) for ecological or environmental (policy) purposes.

The main difference between the latter source of origin and the one that stems from the Pigouvian tax tradition, however, is that by using ordinary revenue raising taxes for environmental policy goals, both fiscal and ecological purposes are assigned to these taxes. As previously argued in chapter 1 of this study, the assignment of more than one purpose to ecological taxes is a characteristic feature of the double dividend approach of ecological taxation. In chapters 1 and 3 of this study, it is indicated that the latter approach has gained more popularity in recent years. This popularity is among others related to the fiscal implications in terms of tax revenues that are expected to be associated with the approximates that have been formulated for Pigouvian taxes. Besides this, the increased popularity is related to the fact that possible double dividend features of taxes present a relatively attractive policy option for policy makers (see Goulder, 1994). The attractiveness of taxes that are used for fiscal and ecological purposes is illustrated below by way of an example.

A famous example of the use of ordinary revenue raising taxes for environmental purposes is one that arises from the theory of Henry George (1839-1897). ${ }^{57}$ As one of the first, this American economist and journalist treated the systematical relationship between the tax system and the preservation of nature. The foundation of his analysis is laid in his Progress and Poverty (1879) in which he proposes a tax reform in which there is just one tax, i.e. a single tax on land. Following Backhaus (1991a and 1993), land can be considered to represent the endowment of natural resources. The underlying principle of the tax reform is seen in the fact that "it is not necessary to confiscate land, it is only necessary to confiscate rent" (George, 1979, p. 405). The rent on land can be described as "being determined by the excess of its produce over that which the same application can secure from the least productive land in use" (1979, p. 168). For confiscating the land "What is necessary for the use of land is not its private ownership, but the security of improvements" (George, 1979, p. 398).

According to Backhaus (1991a), the twin objective of the proposed tax reform is seen in an optimal use of all opportunities provided by the natural environment and

${ }^{57}$ See Backhaus (1991a) and Backhaus and Krabbe (1988). For a description of George's place within the history of economic analysis and for a critical assessment of George's proposal for a single tax on land, see Schumpeter (1954, p. 865). 
the full security of all improvements made upon natural resources. To achieve this twin objective, property rights have to be partitioned along this distinction. This can be effected through the instruments provided by the modern tax state. "Owners retain their property titles but these titles are re-interpreted as designating the accumulated improvements, while the entire land rent remains in common property of the state: In an ideal Georgian world the land rent will be claimed by the government and will be its main source of income ${ }^{11} .{ }^{58}$ The suggested tax constitution shows a broad tax base (natural resources) with one tax (a single tax on natural resources).

According to Backhaus (1994), Henry George's single tax constitution is a self: enforcing one. Since there is only a single tax, i.e. the rental value of natural resources, the government can raise more revenues by stimulating economic development. In this sense, public sector growth is closely related to economic growth, and George actually proposes a growth oriented self-enforcing environmental tax constitur tion. The structure of the Georgian tax system can be labelled as an "ecological" tax system because it is aimed at stimulating an optimal use of natural resources. The latter is achieved via a partitioning of property rights into improvements (private ownership) and the rent of resources as such (public ownership). ${ }^{59}$

\subsection{Conclusions and remarks}

Within the context of the theory of environmental policy, environmental economics, modern public finance and the point of view embedded in the classical theory of taxation, two main sources of origin of the idea of using taxes for ecological purposes have been derived. Following Pigou and the Pigouvian tax tradition, taxes and regulatory charges can be used to confront polluters with the external environmental effects imposed upon society. Following certain views within modern public finance, in which it is taken into consideration that taxes in practice can also induce tax avoiding changes in behaviour, ordinary revenue raising taxes can also be used to tax "the things we don't want", as in the case of environmental externalities. Unlike Pigouvian taxes, the main purpose of ordinary revenue raising taxes, however, is still a fiscal one. For both Pigouvian and revenue raising environmental taxes, the institutional framework in which they are embedded is also decisive for their policy choice. Pigouvian taxes and their approximates are usually in need of being enforced. The tax constitution of the type suggested by Henry George, on the other hand, can be selfenforcing, if the amount of tax revenues raised depends on the economic development.

Within the context of the environmental concern and double dividend approaches (see chapter 1 of this study), the analysis in this chapter shows that, in the original formulation, the Pigouvian tax approach constitutes a clear example of

\footnotetext{
${ }^{58}$ Backhaus (1991a). See also Backhaus (1991b).

59. See Backhaus (1991a) and (1994).
} 
approaches in which taxes are set on the basis of ecological concerns. Under a Pigouvian tax approach, the singular purpose assigned to ecological taxes is the taxation of those types of behaviour which, from an ecological point of view, can be considered inappropriate. In an ideal case, the tax accomplishes this purpose, internalizes external environmental effects and raises no additional tax revenues. In this sense, the only concern is the accomplishment of a particular ecological purpose. The analysis in this chapter however also indicates that Pigouvian taxes, in their original formulation, only present a theoretical ideal image, which can not be used as a policy device in actual policy making. Consequently, the attention to use revenue raising taxes for ecological purposes has steadily increased, also due to the fiscal effects that can be expected to arise from the introduction of regulatory charges. In this respect, the attention to use taxes for ecological purposes has gradually shifted towards an approach in which these taxes are aimed at accomplishing both ecological and revenue raising purposes. The proposals formulated by Henry George portray an early representative of this approach. 


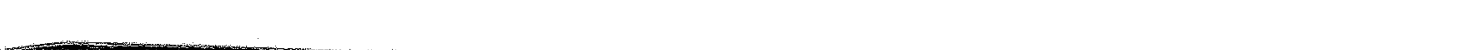


Purposes

\subsection{Introduction}

The idea of using economic incentive instruments, such as taxes, for environmental and other purposes began to catch on in the field of environmental policy not before the 1980 's. Following the report on sustainable development presented by the WCED in 1987, the use of economic instruments has since then been advocated, inter alia, by the UNCED (Declaration of Rio, Agenda 21) and the European Union (5th Environmental Action Plan).' In practice, ecologically relevant taxes are used in different policy fields including air pollution, waste management, water use, agriculture, fuels and other energy sources and transportation. The central theme of chapter 3 is related to the general possibilities and problems of ecological taxation. The aim of this chapter is twofold. On the one hand, the purpose is to define ecological taxes, ecological taxation and ecological tax reform. On the other hand, the purpose is to indicate when ecological taxes can be labelled as feasible policy options. In the previous chapter it was argued, that, among others, because of the difficulties involved in introducing taxes that are strictly intended for ecological purposes, the attention to use revenue raising taxes for ecological purposes has steadily increased. The latter taxes are aimed at accomplishing both ecological and revenue raising purposes. In chapter 3 , it is argued that this shift of attention has provided a basis for the double dividend approach of ecological taxation, as expressed in for instance the concept of ecological tax reform. After this introductory section (3.1), ecological taxes are further defined in section 3.2 within the context of the theoretical framework provided in the previous chapter. In section 3.3, several general possibilities of using taxes and tax reforms for ecological and other purposes are discussed. Several general problems of using taxes and tax reforms for these purposes are further analyzed and discussed in section 3.4. Building on the results of previous sections, a checklist is derived in section 3.5 in which the preconditions for feasible types of ecologically relevant taxes are indicated. The chapter ends with several concluding remarks.

\subsection{Defining taxes that are relevant from an ecological point of view}

\subsubsection{Introduction}

In the last section of the previous chapter, the suggestion of Pigou, that taxes can be used to internalize externalities and the recognition by modern public finance that

See OECD (1993b, draft). 
taxes can also serve other than fiscal ends, were indicated as the main sources of origin of the idea of linking taxes to and using taxes for specific ecological purposes Taxes, presented in the previous chapter as one of the policy instruments for policy with regard to environmental problems, can be used to tax and confront polluters witt (part) of the environmental burden imposed on others. In the discussion so far, how ever, taxes linked to or used for ecological or environmental purposes have not yet been explicitly defined. Implicitly, it is possible to assume that taxes used within the context of specific ecological problems and/or for ecological or environmental purpo. ses can be termed "ecological" or "environmental" taxes. This, however, presupposes that there is a generally accepted notion of the term "tax" and that there is a general agreement on the inclusion of different types of taxes and tax measures into the definition of ecological taxes. This, however, is not the case. On the one hand, the term "tax" means different things (with)in different languages and countries, resulting in a usage of different terms (including "environmental levies", "charges", "pollution taxes" or "fees" and "environmental taxes") in descriptions and definitions of taxes linked to or used for ecological purfoses. ${ }^{2}$ On the other hand, there is disagreement on whether or not to include particular types of taxes and tax measures into the definition of ecological taxes. Consequently, in some studies ecological taxes are synonymous to regulatory pollution taxes while in others they are synonymous to specific revenue raising taxes. ${ }^{3}$ The use of different terminologies and disagreement on whether or not to include particular taxes and tax measures into the definition of ecological taxes are further illustrated below by means of several quotes as they are given in studies on the subject of ecological taxation in different countries.

"Environmental levies are all levies which are imposed within the framework of anti-pollution policy. It boils down to polluters paying a price in relation to the magnitude of their polluting behaviour" (SERV, 1992, p. 25). ${ }^{4}$

"Charges constitute, to some extent, a "price" to be paid for pollution; as a result, the social costs of the demands which polluters make on environmental

See The Greens in the European Parliament (Europees Parlement, 1990, pp. $23 \mathrm{ff}$ ) and Gaine and Westin (1991). In the latter book it is stated that there is no standardized terminology on different types of environmental fiscal measures. "Most legal systems employ a variety of common terms, such as a tax, fee, or charge, but these terms have precise legal meanings within each legal system and thus differ from one country to the next" (p. 8).

3 For further discussions of this point, see, i.a. WRR (1992, p. 17, footnote 48); Taselaar, Wit, van Driel (red.) (1993, p. 116); Europees Parlement (1990, p. 23-24); Wasch (1990, chapter 1);
OECD (1993a, p. 27 ff). The original text of this quotation is in Dutch. The term "environmental levies" refers to the
Dutch term "milieuheffingen". 
"services" are internalized in private calculations of costs and benefits" (OECD, $1993 \mathrm{a}$, p. 22 , in reference to the study by Opschoor and Vos, 1989).

"Fiscal analysis in the OECD draws a distinction between charges, which are payments for which the payer receives a benefit in return, in direct proportion to the amount paid, and taxes, which are unrequited payments - i.e. no direct exactly equivalent benefit is received in return. In the case of a pollution tax, this distinction may lead to rather more ambiguity in usage than in the case of other taxes" (OECD, 1993a, p. 27). ${ }^{5}$

Pollution taxes or fees are "fiscal measures which require payment for the release of pollutants into the environment, usually based on the type of substance and the quantity released" (Gaines and Westin, 1991, p. 9). ${ }^{6}$

"Environmental taxes may take a number of forms allowing a distinction to be made on the basis of the purpose or particular objective of the levy: influencing behaviour (regulatory) or generating funds (i.e. revenue raising)" (Schuurman, 1992, p. 9).

"Ecologizing the tax system can be described as integrating an environmental component into traditional taxes, as well as shifting the levying of taxes and the burden of taxation on labour and profit to environmentally polluting activities and products. A generally accepted starting point of such an interference in the tax system is that the overall collective fiscal burden remains unchanged". (De Wit, 1993, p. 49). ${ }^{\text {? }}$

5 The footnote is left out of the quotation.

6 Taxes are referred to by Gaines and Westin as the most common fiscal measures. These measures are defined as "almost every method by which the government - be it local, regional, or national - establishes the legal requirement of individuals or enterprises to pay a sum of money that ultimately goes to the government or to some public or quasi-public entity. We also mean to include those elements of any fiscal measure, such as credits or subsidies, that reduce or rebate the amount of money owed if the paying party takes certain actions" (p. 7).

7 The original text of this quotation is in Dutch. The term "overall collective fiscal burden" refers to the Dutch term "collectieve lastendruk". The footnote is left out of the quotation. 
Following the public finance notion of taxes and levies, environmental levies can be defined as "sovereign revenues of the state, which are connected to environmentally relevant facts". (Hansjürgens, 1992, p. 19). ${ }^{8}$

The different quotes show that there is neither a generally accepted terminology nor a generally accepted definition of taxes linked to and/or used for ecological or enwironmental purposes. ${ }^{9}$ In the absence of such a generally accepted definition, this study provides a definition of such taxes on the basis of the theoretical considerations of chapter 2 .

\section{2 .2 Ecological taxes}

In chapter 2, taxes were described on the basis of their main characteristics and purposes (see Table 3.1).

\begin{tabular}{|c|c|c|}
\hline Main purpose of taxes & Theoretical background & $\begin{array}{l}\text { Commion term in recent studies } \\
\text { and practical use }\end{array}$ \\
\hline $\begin{array}{l}\text { Confromi polluters with the nega } \\
\text { tive (erivironmental) externalities } \\
\text { imposed on others }\end{array}$ & $\begin{array}{l}\text { Pigou and Pigouvian Tax Tradition (within } \\
\text { environmental economics) }\end{array}$ & $\begin{array}{l}\text { Regulatory tax or regulatory char- } \\
\text { ge }\end{array}$ \\
\hline Raising revenues & $\begin{array}{l}\text { Classical theory of taxation (A. Smith and } \\
\text { others) }\end{array}$ & Tax or revente raising tax \\
\hline $\begin{array}{l}\text { Raising revenues to fund specific } \\
\text { services or goods provided by the } \\
\text { government }\end{array}$ & $\begin{array}{l}\text { Among others, Wicksell has emphasized } \\
\text { the importance of a guid pro guo relation- } \\
\text { ship between taxes and governmental ser- } \\
\text { vices. }\end{array}$ & Earmarked tax \\
\hline $\begin{array}{l}\text { Raising revenues via new types of } \\
\text { taxes which serwe as substitutes } \\
\text { for existhing revenue raising taxes } \\
\text { with the sidle whect of stimulating } \\
\text { opthmal use of natural resources }\end{array}$ & $\begin{array}{l}\text { (Among others) } \\
\text { Henry Gieorge }\end{array}$ & (Ecological) tha reform \\
\hline
\end{tabular}

Table 3.1 Different purposes of taxes

* The quotation is a translation of a text which originally was in German. The term "environmental levies" is a translation of "Umweltabgaben", with the latter described as "hoheitliche Einnahmen der öffentlichen Hand, die an umweltrelevanten Tatbeständen anknüpfen". (Hansjürgens, 1992 , p. 19). For a more detalled description of ecological taxes from a public finance point of view, see Benkert et al. (1990, pp. 69-79).

9 See also Taselaar et al. (1993, pp. 114-119) for possible definitions and classifications of taxes that are intended to be used for ecological purposes. 
These characteristics and purposes range from using taxes for the internalization of external effects to using taxes for general or specific revenue raising purposes, with the either intended or unintended side effect of stimulating an optimal use of natural resources. On the basis of these characteristics and purposes, several types of taxes, each related to its specific theoretical background, can be distinguished (see Table 3.1). Each type of tax can also directly or indirectly be linked to or used for ecological purposes.

The first type of taxes mentioned in Table 3.1 is the Pigouvian or regulatory tax. As previously shown, this tax finds its theoretical roots in the suggestions of Pigou $(1912 ; 1920)$ and in the Pigouvian tax tradition. In order to arive at an internalization of external effects, Pigouvian taxes are aimed at accomplishing tax avoiding changes in behaviour of those confronted with the tax (e.g. polluters). These taxes, in other words, are aimed at incorporating relevant external effects into the decision calculus of the externality generator(s). Pigouvian taxes can be linked to or used for ecological purposes through an enhancement and further development of the effectiveness and the ability of the system of taxes and related types of levies to direct behaviour in a direction considered desirable from an ecological point of view. This can be achieved by setting and designing taxes in such a way that an environmental goal can be achieved. The ideal Pigouvian tax gives an optimal incentive to internalize external effects, provides no additional revenues to the state and indicates alternative ways of behaviour for those confronted with the tax. In this sense, the main function of Pigouvian taxes is an allocational one. Pigouvian taxes and their related proxies (e.g. regulatory charges) are therefore not intended to serve a fiscal function.

The second type of taxes mentioned in Table 3.1, i.e. the revenue raising taxes, are intented to serve a fiscal function. These types of taxes find their roots in specific points of view embedded in the classical theory of taxation. The main principles and ideals of these kind of taxes can be traced back to Adam Smith. Being compulsory contributions which are levied according to general rules and for which there is no quid pro quo relationship between the taxes paid and the services or goods provided by the government, these types of taxes are aimed at accomplishing a stream of revenues to the state. The ideal revenue raising tax, in theory, is a lump sum tax, i.e. a tax which does not lead to tax avoiding changes in behaviour for those confronted with the tax. It was previously indicated that the lump sum tax, however, is not a practical policy device itself. Revenue raising taxes, therefore, unintendedly lead to tax avoiding changes in behaviour, resulting in lower tax revenues than theoretically possible. From an ecological point of view, these unintended side effects of ordinary revenue raising taxes can be used to link these taxes to ecological purposes. This can be accomplished through an incorporation of environmental policies into the tax code. This means a change in the normal structure of tax raising via the introduction of new tax bases, tax deductions and other tax elements that are based on particular environmental considerations. The primary goal of revenue raising taxes, i.e. the raising of revenues, however, remains the same. This means that tax elements are not primarily set to achieve an environmental goal but are set in such a way that a desired amount 
of tax revenues can be raised. Ordinary revenue raising taxes are also characterized by the fact that there is no relationship between the taxes and the services and the goods provided by the government.

The existence of the latter relationship is one of the main characteristics of the third type of taxes mentioned in Table 3.1, ie. the earmarked taxes. Earmarked taxes can either be specific or general. A specific earmarked tax is a tax of which the revenues raised, by taxing the individuals of an identifiable group, are used for the funding of specific provisions needed by the group. A general earmarked tax is a tax imposed on certain products or activities, but for which the revenues are earmarked to be used for specific policy purposes..$^{10}$ Although the primary purpose of earmarked taxes is to raise revenues, they differ from ordinary revenue raising taxes in the sense that their revenues are "earmarked" or restricted to be used for the funding of only particular government expenditures. Earmarked taxes can be linked to or used for ecological purposes ${ }^{11}$ mainly by using tax revenues for the funding of certain environmental policy measures or provisions. These taxes can be levied in the form of earmarked and not in the form of ordinary revenue raising taxes for reasons of conformity of the former with the so-called "the polluter pays" principle (PPP). According to this principle the costs for cleaning or preventing pollution should be paid by the person(s) responsible for the pollution. Tax elements and taxes can be set in such a way that a desired amount of tax revenues, necessary for particular environmental policy measures, can be raised. ${ }^{12}$ Following Wicksell who insists, as a matter of principle, on a quid pro quo relationship between taxation and the services provided by the government, a clear connection would have to be shown between the taxes and the provision of an ecologically relevant service.

The main purpose of the fourth type of taxes mentioned in Table 3.1, the "Georgian tax on land", is also primarily a fiscal one. The central aim of the associated tax constitution is to stimulate a sustainable long term economic development. By taxing the rent of natural resources, the stimulation of an optimal use of these resources arises as a desirable by-product of this development process.

It follows that two main categories of taxes can directly or indirectly be used for or connected to ecological or environmental purposes, i.e. taxes for which the main purpose is to accomplish tax avoiding changes in behaviour (type 1) and taxes

${ }^{10}$ See SER (1991).

${ }^{11}$ In the literature, earmarked taxes are often referred to as user charges (for example if they include payments for public services) or effluent charges (for example if they along with their financing functions, allso serve to influence behaviour). See von Weiszäcker \& Jesinghaus (1992).

${ }^{12}$ See SER (1991). 
for which the main purpose is to raise revenues (types 2,3 and 4). ${ }^{13}$ Based on the previous considerations, ecological or envirommental taxes in this study can now be defined as types of levies (i.e. compulsory contributions or forms of payments) which conform with one or more of the following characteristics:

Taxes are aimed at accomplishing tax avoiding changes in behaviour of those confronted with the tax in order to incorporate (part of the) negative external environmental effects into the decision calculus of the externality generator.

Taxes are aimed at raising revenues which can be used for an environmental sector involved in so far as this is necessary to achieve a particular environmental or ecological goal.

There is a relationship between the tax base and the nature and size of environmentally (un)desired aspects, factors and/or activities.

Given this description and depending on their main purposes, characteristics or object in view, this study distinguishes between different types of ecological taxes. The main differences between these types of ecological taxes are summarized in Table $3.2 .^{14}$

\begin{tabular}{|c|c|c|c|}
\hline Type of tax & Object in View & $\begin{array}{l}\text { Destination of possible } \\
\text { revenues }\end{array}$ & $\begin{array}{l}\text { Term to be used in this } \\
\text { study }\end{array}$ \\
\hline Revenue raising & $\begin{array}{l}\text { Changing the structure of } \\
\text { tax raising }\end{array}$ & Substitution of other taxes & $\begin{array}{l}\text { Ecological revenue raising } \\
\text { tax or if the substitution } \\
\text { of taxes is carried to an } \\
\text { extreme. ecological tax } \\
\text { reform }\end{array}$ \\
\hline Pigouvian or regulatory & Influencing behaviour & $\begin{array}{l}\text { In the ideal case there are } \\
\text { no revenues, In case there } \\
\text { are revenues, possible } \\
\text { revenues can be shifted } \\
\text { back to companies and } \\
\text { households }\end{array}$ & $\begin{array}{l}\text { Pigonviary tax or } \\
\text { reguldatory tax }\end{array}$ \\
\hline Earmarked & Railsing revenures & $\begin{array}{l}\text { Eavironmental policy } \\
\text { metasures }\end{array}$ & Ecological earmarked tax \\
\hline
\end{tabular}

Table 3.2 Ecological taxes as defined in this study

13. A strict separation of these two categories of taxes, however, is not always possible if, although not intended, taxes of the first category, for instance, raise some additional revenues for the state and taxes of the second category lead to tax avoiding changes in behaviour.

${ }^{14}$ Compare to, for instance, WRR (1992) and see Paulus (1993c). 
Table 3.2 shows that, in this study, ecological taxes are defined on the basis of their main characteristics and purposes in view. In this sense, different types of levies are included into the definition of ecological taxes, encompassing the different defini. tions of ecological taxes, as expressed in the quotes above. Moreover, this definition of ecological taxes on the basis of their primary purposes corresponds with the description of environmental levies in Dutch fiscal law. ${ }^{15}$

\subsubsection{Ecologically relevant taxes}

Generally, the main elements of each tax can be expressed in terms of its tax base, it tax rate(s) and relevant tax exemptions and tax provisions. In this sense, each tax can generally be expressed in terms of what is taxed and according to which rates. In principle, each taxing authority can decide to impose a tax on the basis of a preset goal, for instance in order to raise a particular amount of tax revenues. Assuming that the costs associated with the administration and compliance of the tax are already taken into account by the taxing authority before setting the tax, actual tax revenues will coincide with intended tax revenues in only two cases. First in case of lump sum taxes when liable economic actors have no possibilities to avoid paying (part of) the tax. Second, in case the imposition of these taxes has been fully agreed to by liable actors. In all other cases, actual tax revenues will diverge from intended tax revenues mainly because of tax avoiding changes in behaviour. ${ }^{16}$ These changes can result in tax revenues which are below or above those intended. As argued in this and the previous chapter, tax avoiding changes in behaviour constitute a significant component of taxes that are intended to be used for ecological purposes such as Pigouvian taxes or regulatory charges. A characteristic feature of these charges is that, via their tax base, they are related to the nature and size of environmentally (un)desirable activities, products etc. These taxes can or can not be combined with relevant ecological tax rates or tax exemptions and provisions. Taxes imposed on the emission of carbon dioxide or fossil fuels constitute pertinent examples.

Although it is generally accepted to indicate taxes that have an environmental tax base as environmental taxes (such as the environmental taxes defined in section 3.2 .2 ), questions are commonly raised as regards those taxes that have no environmental tax base but that, for instance, are marked by one or more of the following
characteristics.

${ }^{15}$ See Boele er al. (ed.), (1992).

16 Actual tax revenues will also differ from intended tax revenues because actors will (illegally) try to evade the taxes imposed. Tax evasion lies outside the scope of this study. 
* Taxes with ecologically differentiated tax rates, expressed in terms of lower (higher) tax rates for those products, activities and/or other elements that are more (less) desirable from an environmental point of view. Ecologically differentiated value added tax systems constitute an example of this group of taxes.

* Taxes that allow or include particular exemptions or provisions that are relevant from an ecological point of view. Examples include accelerated depreciations for environmental investments in income taxes or provisions for environmentally friendly cars in road taxes.

Taxes that have been introduced for other than environmental purposes but which unintendedly affect the state of the environment. Examples include deductions for travelling expenses in the income tax or excise taxes on fuel. The latter (former) may be (un)desirable from an environmental point of view.

Although the taxes that are marked by one or more of these characteristics are relevant from an ecological point of view, they can not be indicated as strict environmental taxes. Income taxes which contain standardized deductions for travelling expenses e.g. can not be considered environmental taxes, although they might have a direct or indirect (un)desirable impact on the environment. In this study, the latter taxes are therefore considered as ecologically relevant taxes. This implies that in this study, environmental taxes are distinguished from ecologically relevant taxes. Although both categories of taxes are relevant from an environmental point of view, the taxes of the latter category are introduced for non-environmental reasons, while the taxes of the former category have a clear environmental tax base. ${ }^{17}$

\subsection{General possibilities of using taxes for ecological purposes}

To introduce ecological taxes within a particular country, governments have several options. In general, governments have the option to introduce ecological taxation within the existing tax system or the option to introduce this kind of taxation by leaving the existing system of taxes and related levies unchanged. More specifically, the options to introduce ecological taxation in and outside the existing tax system include: ${ }^{18}$

${ }^{17}$ See OECD (1993a, p. 28) in which taxes of the former kind are identified as (direct) "environmental taxes" and taxes of the latter kind as "indirect" environmental taxes. It is stated that in practice, the principal attention of policy makers in the OECD appears to be focused on the latter kind of taxes and that "[M]any options exist to design an "indlirect" environmental tax to work in a very similar way to a direct emissions tax" (p. 28).

18 Also see Ewringmann (1990). 
- Implementing new taxes aimed primarily at raising revenues for the funding of environmental expenditures (i.e. introducing new ecological earmarked taxes).

Supplementing the existing system of taxes and related types of levies with additional types of levies based on the suggestions of Pigon (i.e. supplementing existing taxes with Pigouvian taxes or regulatory charges).

- Re-orienting existing taxes and types of levies by incorporating principles of environmental policies into the tax code by, for instance, differentiating or changing existing marginal tax rates, tax credits and tax deductions (i.e. reorienting existing revenue raising taxes in the direction of ecological revenue raising taxes).

- Replacing existing taxes and types of levies by ecological revenue raising taxes (i.e. introducing ecological tax reform).

While the first two options leave the existing tax system unchanged in the sense that existing taxes remain unchanged, the third option modifies existing taxes by incorporating environmental policies into the tax code. The latter includes the use of the direct tax system for ecological purposes, for example the use of tax allowances in the form of accelerated depreciation provisions for the installation of certain types of pollution control equipment. ${ }^{19}$ Wasch (1990) considers the modification of existing taxes for environmental reasons one of the elements of the option of ecological tax reform. In reference to E.U. von Weizsäcker (1988), Wasch more specifically considers ecological tax reform to consist of the following elements: ${ }^{20}$

- Removing ecologically undesirable tax elements from existing taxes.

- Differentiating marginal tax rates in favour of activities considered desirable from an ecological point of view.

Replacing existing taxes or tax elements by ecologically favourable taxes and tax-elements.

Since ecological tax reform incorporates several elements of the other three options for introducing ecological taxation and because this type of tax reform has only been treated in this study in reference to Henry George's proposal to replace the existing tax system with a single tax on the rent of land (i.e. natural resources), this option is further described below. Evolving especially from increasing discussions on

${ }^{19}$ See OECD (1993a, p. 29).

${ }^{20}$ See Wasch (1990) and Paulus (1993a). 
ecological taxation in Germany at the beginning of the 1980 's, ${ }^{21}$ the concept of ecological tax reform has in recent times been usually discussed against the background of a specific reasoning. This reasoning generally starts from the idea that the input of existing environmental policy instruments (for the greater part based on the transaction mechanism of direct order) alone is not enough to handle environmental crises. Since revenue raising taxes and tax systems have side effects which influence the behaviour of economic actors, some of these side effects (the steering effects) of taxation can also be used to induce a particular environmental behaviour of economic actors. With the assumption that taxation of scarce natural resources and pollution is relatively low in comparison to taxation of labour, shifting taxation from labour to pollution and the use of natural resources, presents an option with which it is, in principle, possible to encourage behaviour that is considered desirable from an environmental point of view. Ecological tax reform, in other words, presents an option to use taxes and tax systems for attaining a "sustainable development". ${ }^{22}$ Against the background of this basic reasoning, the most general descriptions of ecological tax reform are represented in the following quotes:

"The basic idea is to eventually shift the bulk of the tax burden, representing some thirty to fifty percent of the GNP, from labour and capital to resources and pollution. Such high taxes on energy, other resource consumption (e.g. land) and pollution would lead to an absolute economic necessity for industry, trade, and consumers to minimise these factors. Conversely, an equivalent burden of taxes, social security costs, etc. is taken away from labour and capital, with a view to spur entrepreneurship and to dramatically reduce the economic pressure towards labour rationalisation". ${ }^{23}$

"The idea is to put taxes on fossil fuels and nuclear energy, on water consumption, on raw materials (especially on those which are likely to end up as toxic pollutants or hazardous waste), and also possibly on emissions and waste, and to reduce other taxes instead. A revenue neutral tax reform would observe the stipulation that the overall fiscal burden on business must not increase" ${ }^{m}{ }^{24}$

${ }^{21}$ For a more detailed description and overview of ecological tax reform discussions in Germany, see Luhmann (1994).

${ }^{22}$ See WCED (1987). Within this report of the World Commission on Environment and Development it is explicitly stated that environmental policy goals should be incorporated into the levying of taxes. See also Sociaal-Economische Raad (1989a) on this specific issue.

${ }^{23}$ See von Weizsäcker $(1988$, p. 7$)$.

24 von Weizsäcker \& Jesinghaus (1992, p. 18). 
Table 3.3 indicates the basic idea of an ecological tax reform. Schuurman (1990) describes the basic thoughts of ecological tax reform in terms of the levying of ecological taxes. The levying of ecological taxes, on the basis of this idea, is the levying of taxes which incites people to ecological thinking and acting which, eventually, will result in a responsible way of dealing with the natural environment. The main purpose of ecological taxation is the creation of a society concerned with resour: ce management. This purpose can be achieved by a structural taxation on the basis of the use of the factor environment, which in its turn can be accomplished by changing tax bases, tax rates, marginal tax rate structures, tax objects, tax subjects, the taxation of phases in the production process and by changing the ratios between direct and indirect taxes and between different burdens of taxation. ${ }^{25}$

\begin{tabular}{|c|c|c|c|}
\hline Tax/Tax system & Existing Tax System & Ecologized Tax System & Ecologized Tax System \\
\hline & & (revenue raising taxes) & (Pigouvian types of taxes) \\
\hline Taxution of Labour & a & $c(c<a)$ & a \\
\hline $\begin{array}{l}\text { Taxation of Natural } \\
\text { Resources and Pol- } \\
\text { lution }\end{array}$ & $b$ & $d(d>b)$ & $b+e^{*}$ \\
\hline Other Taxes & 2 & $z$ & $\mathrm{z}$ \\
\hline Total Tax Revenues & $x(=a+b+z)$ & $X(=c+d+z)$ & $x\left(=a+b+e^{*}+z\right)$ \\
\hline
\end{tabular}

Table 3.3 Ecological Tax Reform

In the most simplest case, when taxes are fixed, the amount of ecological taxes to be paid is usually determined by multiplying the tax base with the tax rate. ${ }^{26}$ The main tax base is either: 27

An input into some economic process, e.g. taxes on natural resources ${ }^{28}$ or taxes on products containing scarce resources. Or:

${ }^{25}$ See Schuurman (1990, pp. 603-619).

${ }^{26}$ See SERV (1992).

${ }^{27}$ See i.a. WRR (1992), Huppes et al. (1992), SERV (1992).

${ }^{28}$ For further theoretical considerations on the taxation of natural resources, see Heaps \& Hel. liwel (1985). 
- A throughput or a production process (e.g. process taxes).

- An output, e.g. product taxes on commercial outputs.

- Emissions, e.g. effluent taxes on environmental outputs.

Depending on the tax base, ecologicall taxes are than referred to as input, process or installation, product or emissions taxes, respectively. Since these taxes also usually have to be enforced and monitored, there are also administrative charges. These charges contain, among others, control and authorization fees and payments for administrative services. Emission or effluent taxes, for which the tax payment per unit of measured pollution output is directly related to the measured quantities of the polluting effluent are the types of taxes which historically can be traced back to A.C. Pigou. ${ }^{29}$ Generally, emission or effluent taxes are presented as charges that are imposed on discharges into the environment. In principle, ${ }^{30}$ they are based on the quantity and/or quality of discharged pollutants. Emission charges may also take the form of user charges. User charges are payments for the costs of the collective or public treatment of effluents. Particular input and output taxes can be presented as product charges or taxes. These are charges or taxes that are imposed on products that are polluting in a particular manufacturing or consumption phase or for which a disposal system has been organized. Product charges can be based on some product characteristic (e.g. sulphur content) or on the product itself (e.g. mineral oil). One form which product charges may take in economic practice is that of tax differentiation by which more (less) favourable prices can be set for environmentally (un)friendly products. ${ }^{31}$ For all different types of the taxes and charges, the associated tax or charge rate can either be fixed or variable in the sense of time, place etc.

Against the background idea that ecological taxes can be used to shift the burden of taxation from labour (and capital) to natural resources, energy and pollution, the main purposes of ecological taxation and ecological tax reform include the following: ${ }^{32}$

- A reduction of the pollution of the environment.

- A reduction of the use of energy.

- A reduction of the use of natural resources.

- A stimulation of activities aimed at re-use and repair.

A switch to differentiated and less large-scale activities.

A switch to more labour-intensive means of production.

${ }^{29}$ See OECD (1993a, p. 27 ff).

${ }^{30}$ See OECD (1993b).

31 Ibid.

32 See Schuurman (1990). 
According to von Weizsãcker \& Jesinghaus (1992), these purposes can be achieved if ecological taxes are introduced gradually, and in ways that are revenue neutral and easy to administer. Besides this, these purposes can be achieved if eco. logical taxes can be internationally harmonized and be combined with measures to compensate for any negative social distribution effects. Subsidies on energy and other natural resources involved should also be removed before ecological taxes are placed on them.

A gradual and predictable introduction of ecological tax reform is important for the stimulation of technological change in a direction considered desirable from an environmental point of view. Whether it is possible for ecological taxes to direct technologicall change in a desirable direction depends (among other things) on the steering effectiveness of these taxes. This effectiveness again depends on price elasticities, i.e. on how behaviour will be changed in reaction to the price increases that result (for particular economic actors) because of the imposition of ecological taxes. By considering both short term and long term price elasticities, von Weizsäcker and Jesinghaus (1992) distinguish between five phases of adjustment to higher prices. Applied to energy price movements in the seventies, they sketch the following stages of behavioural adjustment:

1) The consumer tries to get by with less energy.

2) Energy efficiency becomes more important when purchasing energy-dependent goods and systems.

3) Suppliers of energy consuming goods respond to the change in demand structure by developing more efficient types.

4) The state and producers of energy consuming goods invest in the research and development of energy efficient systems and in technologies which are able to do without fossil energy.

5) The demand for energy decreases due to changes in the housing structure, the infrastructure and changes in life style.

From their analysis of these five stages of adjustment, the two authors conclude that: "The important point to note is that....there can be a very high price elasticity for a raw material ....if prices rise steadily and significantly over a period of many years. This is where an ecological tax reform - in this case, sustained energy price rises as a result of rising taxes - can intervene in the market place with the reliable expectation that it will have a major impact on economic behaviour, steering it into more benign resource and environment-friendly patterns" (p. 30).

The incentive to steer technology in an environmentally friendly direction is one of the most attractive properties of ecological tax reform. Generally, the attractive properties of ecological tax reform include the following. ${ }^{33}$

${ }^{33}$ See Selhuurman (1990). 
- By taxing natural resources (e.g. energy and water), investments in saving-technologies are stimulated.

By taxing environmental unfriendly products, technological innovation will take place and markets for alternative cleaner products will arise.

By lowering the taxes on labour, labour gets cheaper. This will induce companies to attract new workers. This has positive effects on unemployment rates. Present investments of companies aimed at reducing labour costs will be replaced by investments for new technologies aimed at resource rationalization. Some rules with regard to environmental regulation could be abolished.

Since ecological taxes provide incentives to reduce emissions and steer technology in an environmentally friendly direction, these instruments, when compared to command and control regulation instruments, are often stated to be dynamically efficient. The latter instruments usually require emissions to be reduced to a specific target level, without inducing those confronted with the regulation to reduce emissions below the target level. Depending on the type of tax, another attractive feature of ecological taxation, in comparison to command and control regulations, is related to specific lower informational needs, necessary to attain a particular policy outcome. ${ }^{34}$ Lower informational needs for the government are especially related to the allocation of the abatement of pollution across individual polluters. To achieve an efficient allocation, a government which uses direct regulation as the instrument for its policies, needs information on the costs and circumstances of individual polluters. This kind of information, however, is not required for a government which uses the instrument of (ecological) taxes for its policy. Confronted with the taxes, "...polluters with the lowest cost in effect "select themselves" in response to the signal provided by a pollution charge or tax". ${ }^{35}$ As previously argued with regard to Pigouvian taxes, to be able to set the proper tax rates, however, also requires pieces of information which may be difficult to gather by governments which use ecological taxes as policy instruments. The associated difficulties and other problems of ecological taxation are further discussed in section 3.4.

\subsection{General problems of using taxes for ecological purposes}

In the previous section several options, possibilities and attractive features of ecological taxes have been described. The options that aim at introducing the concept of

34 Another attractive feature of (ecological) taxes, in comparison to command and control regulations, is related to the possibilities to use tax revenues for the compensation of negative side effects of ecological taxes (See OECD, 1993a, p. 19ff.).

35 Ibid. 
ecological tax reform constitute a clear example of the double dividend approach o ecological taxation. In this section, several problems of ecological taxes in general an of those that are used within the context of the double dividend approach are furthe described. In general, the most important problems of using (revenue raising) taxe and tax reform for ecological purposes are related to the ecological effectiveness o these taxes, the linkage between the tax point and the point of pollution and related administrative costs. Further problems are related to specific informational need required to set the proper ecological tax rates, the fiscal and steering effects of ecolo. gical taxes and to the (earmarking of) ecological tax revenues. Problems are also related to the concordance of ecological taxes and tax reform with existing national and international tax and legal systems. Other problems of ecological taxes and tax reform are related to the distributional incidence of ecological taxes and the national and international economic effects of these taxes. The most important elements of these problems are further described below.

\section{Ecological effectiveness and the linkage between the tax point and the point of pollution $^{36}$}

In the previous section it was shown that the main tax bases for ecological taxes are the input into some economic process, a throughput (or production process), an output (or product) or emissions of polluting substances. In general, emissions taxes are directly related to the environmental problem (the amount of pollution caused) which the taxes seek to influence. Taxes on input, throughput and output, on the other hand, are not levied directly on the quantity of emissions, but on a base "which is assumed to be linked in some dependable relationship to the amount of pollution caused". ${ }^{37}$ These latter kinds of taxes, therefore, only show an indirect relationship between the amounts paid in taxes and the environmental problems which the taxes seek to influence.

Following the OECD (1993a), two important factors which determine the choice between emission taxes on the one hand and input, throughput and output taxes on the other can be distinguished. These factors, related to the administrative costs and the linkage between the tax point and the point of pollution, indicate the advantages and disadvantages of both types of taxes in different situations. The first factor, the administrative costs, refers to the costs of assessment, collection or enforcement of taxes. These costs will normally be lower for new ecological taxes, the greater the scope for incorporating these taxes into existing tax administration and controlling systems. Differentiating existing tax rates by incorporating environmental policies into the tax code, for instance, may result in considerable gains in terms of lower admini-

\footnotetext{
36 This section is mainly based on OECD (1993a, chapter 4).

${ }^{37}$ OECD $(1993$ a, p. 49).
} 
strative costs in comparison to emissions taxes, which lack a close compatibility with existing tax administration systems. The latter is due to the fact that they are mainly based on measured emissions and not on transaction value, which is the basis for the majority of existing taxes. ${ }^{38}$ The additional administrative costs for emissions taxes are related to the measurement and assessment of emission quantities which depend on the measurement costs per source, the number of emissions sources and the scope for integration with normal commercial activities. ${ }^{39}$ Measurement costs per source depend, among others, on the range of technologies available for monitoring concentrations and flows of emissions and on the substances involved. The higher the number of separate emission sources which have to be measured, the more imprecise or costly direct measurement is likely to be. If measurement of emissions, however, can be integrated with normal commercial activities, the costs of measuring emissions can generally be reduced.

Depending on the aspects mentioned above, the possible additional (administrative) costs of emissions taxes have to be weighed against the possible additional benefits of the more direct linkage of emissions taxes to the amount of pollution caused. This is the second determining factor mentioned above. Linkage of ecological taxes to the amount of pollution caused, refers to the linkage between the tax point and the point of pollution. This linkage is important for the environmental effectiveness of ecological taxes. If the linkage is very weak, ecological taxes may not have the desired ecological effect or impact and may in addition lead to economic distortions. A central aspect of an effective ecological tax policy, therefore, is the choice of a particular tax base and the associated type of tax. This choice involves different considerations which are related, among others, to the intricacies of the pollution problem(s) in question, the possibility to relate taxes to quantities (e.g. to the amount of commodities used), the manner in which the relationship between the tax base and the pollution is affected by production technology, the possibility to discourage pollution emissions from production processes through the use of input taxes and to the manner in which the costs of emissions are affected by their location, concentration and their aggregate level. ${ }^{40}$

Depending on the importance of each of these considerations, it can next be decided which is the cost effective alternative: emissions taxes or taxes on inputs or other tax bases. Emissions taxes will be the likely alternative if the costs of measuring emissions are low and if there are no clear linkages between tax bases and environmental problems other than on the basis of emissions. Input or other taxes will be the likely alternative if, among others, the costs of emissions are strongly affected by the

\footnotetext{
38 Ibid., pp. 50-51.

${ }^{39}$ Ibid., p. 5 Iff (also for a further elaboration of these cost aspects).

40 lbid., pp. 53-57.
} 
location and concentration of emissions. For each individual case, the costs and benefits of alternatives and the previous considerations have to be taken into account

\section{Fiscal and steering effects}

In the previous sections, both Pigouvian and revenue raising types of taxes have been identified as types of taxes which can be used for ecological or environmental policy purposes. From a fiscal and ecological point of view, both types of taxes present an interesting case in the sense that the taxes might have conflicting fiscal and steering effects. While fiscal effects refer to possible tax revenues resulting from the imposition of a tax, steering effects refer to possible tax avoiding changes in behaviour of those confronted with a tax. If steering effects are substantial, tax bases might even be largely or completely eroded. Although, the latter is the main purpose of Pigouvian taxes, substantial steering effects seem undesirable for revenue raising taxes. The main purpose of the latter taxes is to provide a stream of tax revenues to the state. From an ecological point of view, non substantial steering effects are considered desirable (although secondary) side effects of revenue raising taxes. For Pigouvian taxes, on the other hand, non substantial steering effects do not only present a situation in which a preset environmental goal cannot be fully met, but also one that has fiscal implications in terms of tax revenues. It is these conflicting fiscal and steering effects of taxes which present one of the most important problems of ecological taxes. ${ }^{41}$ The main aspects of these problems and the implications for the design of ecological taxes are, therefore, further described below.

If Pigouvian taxes are used to affect a particular level of pollution, the taxes should induce polluters to tax avoiding changes in behaviour. Whether or not such changes can be made, depends i.a. on the structures in to which decision making and incentives are embedded. The internal structure of a particular company, for instance, may be such that there is only a weak relationship between technology decisions and financial incentives. To induce and direct technology in a particular environmentally friendly direction, Pigouvian taxes, in this particular case, may then even be inappropriate. $^{42}$

To analyze whether ecological taxes can create substantial or non-substantial steering effects, the separate stages of behavioural adjustment in response to the tax have to be taken into consideration. Taking the example of an ecological tax of the Pigouvian type, three separate stages can be distinghuished. ${ }^{43}$ In the first phase, the perception phase, those confronted with the tax try to avoid the tax by fully or partly reducing that which is taxed through adjustments in terms of time (by temporarily

\footnotetext{
${ }^{41}$ See also Bergmann and Ewringmann (1989, pp. 43-71).

${ }^{42}$ See OECD (1993a, pp. $\left.20 \mathrm{ff}\right)$.

${ }^{43}$ Based on Hansjitgens (1992, p. 57ff).
} 
avoiding or reducing that which is taxed), place (by moving to another place) or activities (e.g. by introducing new production technologies). These tax avoiding or reducing changes in behaviour will only take place if the burden of the tax payment is directly experienced or felt by those who are confronted with the tax and if there are possible alternative ways of behaviour. In the second phase, the payment phase, those not succeeding in fully reducing or avoiding the tax, have to pay the tax according to the remaining part of that which is taxed. Those confronted with the tax payment will try to shift the burden of this payment to others. Whether this is possible depends on price and market reactions, which in turn depend on factors such as e.g. price elasticities. When all possibilities to shift the burden of the tax payment to others are exhausted, those confronted with the tax will, in the longer run, be induced to search for further alternatives, i.e. environmentally friendly ways of behaviour.

In the third phase, the incidence phase, when there are neither possibilities to avoid or reduce that which is taxed nor possibilities to shift the payment of the tax to others, those confronted with the tax will, ceteris paribus, adjust their behaviour in reaction to the lower income resulting from paying the remaining part of that which is taxed and which could not be avoided through tax avoiding or reducing changes in behaviour. It follows that taxes which are aimed at accomplishing substantial steering effects should be designed in such a way that those confronted with the tax have the option to choose freely between paying the tax and avoiding to pay (part of) the tax through tax avoiding or reducing changes in behaviour. ${ }^{44}$ The latter can only be achieved if there exist environmentally friendly alternative ways of behaviour for those confronted with the tax. This implies that all environmentally unfriendly altematives, in fact, should also be taxed in order to achieve a particular environmental policy goal. ${ }^{45}$ To achieve this goal also requires the right choice of the tax point in relation to the point of pollution. This means that the tax base has to be chosen in close connection with the desired behavioural changes. Besides this, to achieve the particular goal of inducing substantial steering effects, the design of the tax should preferably be such that relatively elastic tax bases or tax objects are taxed. If the main purpose of the ecological tax, on the other hand, is to raise revenues, the design of the tax should preferably be such that rather inelastic tax bases or objects are taxed. ${ }^{46}$

It can be concluded that to be able to set and/or design ecological taxes, taxing authorities need different pieces of information. With regard to Pigouvian taxes on polluting emissions, it has already been indicated in the previous chapter that to set a tax equal to the marginal costs and benefits of emissions reduction at the optimal

44 As argued in previous chapters, Wicksell (1896), by emphasizing the principle of consensus, also stresses the importance of the option to choose freely between paying and not paying a particular $\operatorname{tax}$.

${ }^{45}$ Based on Hansjürgens (1992, p. 59).

${ }^{46}$ It can be expected that long run ellasticities are higher than short run elasticities. 
level, requires the presence of an information system. This system should not only provide accurate if not perfect information on the environmental externalities caused by the emissions but also on the activities which cause the externalities and the utilities, damages and marginal costs associated with these externalities. ${ }^{47}$ Since such an information system is generally absent in practice, setting environmental tax rates requires an iterative trial and error process in which taxes have to be designed and redesigned time and again. This of course raises its own set of problems, including the uncertainties that arise for those who want to make decisions on the basis of the tax (e.g. polluters who want to invest in environmentally friendly equipment). The analysis of the problems of ecological taxes in this chapter, so far, has demonstrated that depending on the main purpose of the ecological tax in question and to be able to find the proper tax rate and tax base, also requires additional information on the expected fiscal and steering effects (and thus the related ecological effectiveness) of the tax. The latter, in other words, means that information is required on the tax avoiding and reducing changes in behaviour for those confronted with the tax ${ }^{48}$ Behavioural changes in reaction to ecological taxes, however, are not (always) predictable because these changes, in fact, are only known to the individual who actually makes these changes once confronted with the tax. The fact that the taxing authority does not have (complete) knowledge on the changes in behaviour that will actually take place and so does, in fact, not have the entire desired information, may result in ecological taxes set at too high or too low a levell. In comparison to revenue raising taxes, requirements for ecological taxes in the sense of Pigou are even stronger if it is recognized that, besides the fact that these taxes are aimed at accomplishing tax avoiding changes in behaviour, these taxes are also unfamiliar to existing traditional taxing authorities. With the aim of accomplishing tax avoiding changes in behaviour; taxing

${ }^{47}$ See Backhaus, J.G. (1991b, pp. 195-203) and Pigou (1947).

48 Besides this it is also important to assess the ecological effects of the alternative use of that which is taxed. What e.g., are the ecological effects of natural gas when ecological taxes lead to an incentive to no longer rely on the use of energy based on natural gas? As the gas keeps flowing the alternative use of natural gas could also thave ecological effects. The costs of the use and the alternative use of that which is taxed should then be weighed against each other. Estimating the precise costs and benefits of these effects of ecological taxes, however, may again require specific information, knowledge and technique and thus may require the input of environmental experts.

${ }^{49}$ Further problems of Pigouvian types of taxes are discussed, among others, by Dragun (1985) who argues that institutional obstacles exist in remedial taxes that inhibit their widespread implementation ( $\mathrm{p}$. 115). Considering environmental taxes from a public choice perspective, Yandle (1989, $\mathrm{pp}$. $751-52$ ) states that recommendations for the design of economic incentives for the purpose of internalizing external effects exhibit analytical failures. These include the general neglect for adjustments made by those who will pay the charges and the minor attention to the public choice dimensions of regulatory institutions. The problems of Pigouvian taxes in relation to the Coase Theorem are described in Hamilton, Sheshinski and Slutsky (1989). 
authorities, preferably, should indicate alternative ways of behaviour in order to facilitate behavioural changes in a desired direction. Traditional taxing administrations, however, are unfamiliar with taxes which are considered ideal if they provide no additional tax revenues to the state. ${ }^{50}$ The fact that existing tax authorities may be more competent in handling ordinary revenue raising taxes, may result in considerable administrative problems and costs if these authorities are also used for handling Pigouvian types of taxes. For each ecological tax in the sense of Pigou; one then has to decide which authority can best achieve the goals pursued by this type of tax.

It can be concluded that the benefits and costs of using ecological taxes in the sense of Pigou should then be weighed against the benefits and costs of using revenue raising taxes for ecological purposes. If taxing authorities are unable to supply information which facilitates tax avoiding changes in behaviour in case of Pigouvian taxes, an agency has to be indicated which can monitor and bring about the desired behavioural or attitude changes and a framework for policy has to be formulated in which possible alternative courses of behaviour are indicated. ${ }^{51}$ Depending mainly on how those who are liable for the levy in question will respond by means of behavioural changes, the actual impact of ecological levies can differ from their intended impact. In this sense it is possible that Pigouvian taxes that are intended to induce tax avoiding changes in behaviour can operate mainly as revenue raising instruments while levies intended to raise tax revenues can create substantial steering effects. From this it follows, that in order to be consistent with their intended impact, ecologically relevant taxes not only have to be properly designed but also have to be embedded into an accommodating framework so that behavioural reactions can be reasonably anticipated.

\section{Earmarking and the use of possible revenues to compensate those who suffer from undesirable side effects of ecological taxation}

Within the literature on the subject of ecological taxation, possible conflicting fiscal and steering effects of ecological taxes have also been treated in relation to two related subjects, i.e. the earmarking of possible ecological tax revenues for the funding of specific environmental policy measures and the use of such revenues to compensate for possible undesirable (distributional or economic) side effects. Following Buchanan (1963, pp. 457-458), earmarking can be defined as the practice of designating or dedicating specific revenues to the financing of specific public services. Earmarking is principally a question of constitutional public finance, i.e. the branch of economics in which the central theme is the appropriate choice of decision making structures and the constraints under which decisions can be taken (see also section

\footnotetext{
${ }^{50}$ See e.g. Backhaus \& Paulus (1991).

${ }^{51}$ See Morgenstern (1991, p. 144).
} 
4.3.3 of this study for a further elaboration of the essence of earmarking within the context of constitutional public finance).

Within the literature on the subject, different arguments have been put forward in favour or against the earmarking of possible ecological tax revenues. One of the main arguments in favour of earmarking, in comparison to a situation in which ecological tax revenues are used for general (including other than environmental) policy measures and provisions, is an expected increase in the public support for and acceptability of these kind of taxes. An increase in public support and acceptability is expected because of the more direct relationship between the tax payment and the benefits from the provisions that are funded from these payments. Those in favour of earmarking also put forward that "...most of the initiatives to introduce environmental taxes have arisen because of the need to find revenue sources which can be assigned to finance environmental expenditures, rather than for their incentive value." ${ }^{22}$ Those against the earmarking of ecological tax revenues, however, put forward that earmarking can result in inefficiencies. Inefficiencies can arise either because tax rates are determined on the basis of the revenues required and not on the basis of the costs and benefits of the particular tax in question or because revenues and expenditure requirements can move out of line in the longer run. ${ }^{53}$ Other shortcomings of earmarking are related to the potential danger that appropriate revenue sources for particular expenditures can only be determined and identified with great difficulties, while the "tagging" of tax revenues is only viable for specific areas, likely those which do not require public involvement and common finance.

It follows that the earmarking of possible (ecological) tax revenues is a question of weighing the costs in terms of possible inefficiencies with the benefits in terms of a possible higher support for these types of taxes when their revenues are restricted to be used for only the funding of specific provisions and/or for specific groups of persons. In those cases in which the earmarking of possible ecological tax revenues is considered undesirable or non feasible, these revenues can be used for general policy purposes. The latter may include using these revenues as substitutes for existing tax revenues or to compensate those who suffer from possible undesirable side effects of ecological taxes. Again the question is one of efficiency and public support. On the one hand, following the basic idea of ecological tax reform, possible ecological tax revenues can be used to substitute the revenues that result from existing distortionary taxes. In an ideal case, these ecological tax measures can be used to decrease the inefficiencies that are associated with distortionary taxes. On the other hand, ecological tax revenues can be used to offer compensation to those who suffer from possible undesirable side effects of the taxes (e.g. possible undesirable income distribution or economic effects). In comparison to a situation in which no such

\footnotetext{
$\$ 2$ OECD (1993a, p. 68) in reference to Opschoor and Vos (1989).

53 See OECD (1993a).
} 
compensation schemes are offered, the use of tax revenues for compensation can play an important role in the eventual support for and acceptability of ecological taxes.

Although compensation for undesirable side effects can play an important role in the eventual support for and acceptability of ecological taxes, finding the proper compensation schemes is difficult. Such schemes do not only have to properly and fairly compensate those who suffer from ecological taxation but also not create further distortions and obstacles which disturb achieving the final goal pursued. Difficulties are also associated with the assessments of the direct and indirect effects of ecological taxes. ${ }^{54}$ To be able to assess the distributional effects of ecological taxation, for instance, requires, among others, that the distribution of the tax burdens within and between different groups of economic actors (e.g. households, producers, industries, sectors etc.) can be determined. Compensation schemes can be considered in those cases in which particular groups or regions face relatively high tax burdens in comparison to other relevant groups and regions. For each case it has to be determined however, what can be considered a "fair" or "proper" situation for compensation. Assessing the direct and indirect effects of ecological taxes on the economy and offering relevant compensation schemes present corresponding problems. Not unlike other taxes, ecological taxes can be accompanied by side effects that can make them more or less acceptable for policy makers and tax payers. In case of undesirable side effects, acceptability demands these taxes to be embedded into a broad policy package in which specific compensation schemes are also included.

\section{Concordance with existing systems, frameworks and starting points}

In the previous section (3.3) it was argued that governments can choose from different options when considering the introduction of ecological taxation in their countries. The actual introduction of one or more of these options, however, may be intricate if the options are not or just partly in agreement with particular existing systems, frameworks and starting points. More specifically, important problems may arise if (specific aspects of) ecological taxes or tax reforms are in conflict with national and supra national tax and legal systems and with environmental policy guidelines and their respective starting points. Possible conflicts with current national and supra national tax or legal systems can arise when ecological taxes and tax reforms can not be embedded into the existing system of taxes and related forms of levy and when they are inconsistent with the restrictions provided by these systems. Mostly, these

54 If financing the compensation scheme, however, also has undesirable side effects, further problems arise. In case of ecological taxes which are aimed at accomplishing tax avoiding changes in behaviour, compensation schemes should be designed in such a way that the schemes do not lead to a substantial reduction in the steering effects of these taxes. 
systems have evolved over a long period of time ${ }^{55}$ For ecological taxes of the re venue raising type, important conflicts may arise if the taxes also have considerable steering effects and bear the danger of becoming what is also known as an "Erdrosselungssteuer". ${ }^{56}$ The latter refers to revenue raising taxes which are marked by steering effects that are so substantial that tax bases can be completely eroded. This may not only have fiscal implications in the sense that there are decreasing tax revenues, but also in the sense that from a fiscal law point of view, these types of levies may no longer be considered 'taxes'. ${ }^{57}$ The latter, of course, may have severe legal implications. ${ }^{58}$ Since in most countries, there are strict conditions and restrictions for the imposition of different types of taxes, the 'legal nature' of Pigouvian and earmarked taxes present corresponding complications. For ecological taxation this implies that right from the start, the exact nature and character of the ecological tax in question has to be clarified. For all types of taxes, further complications may arise if the taxes, when integrated into the existing system of related taxes and levies, can not or just partly coincide with the rules and conditions provided by the system.

Ecological taxes and tax reforms may give rise to (further) complications, once they have to be embedded into particular supra national systems and frameworks. For the introduction of ecological taxation by Member countries of the European Union (EU), for instance, the existing EU legislation and/or guidelines do not allow individual Member countries complete freedom in the levying of particular types of taxes. Taxes which are discriminatory between Member countries and which could stand in the way of achieving an internal market with a free flow of capital, goods and services, for instance, are not allowed to be introduced. ${ }^{59}$ Particular restrictions for ecological taxation by EU Member countries are more specifically related to Art. 95-99 of the Treaty of Establishment of the European Economic Community (TE-EEC), in which several directives for taxation are laid down. ${ }^{60}$ Art. 95 TE-EEC prohibits

${ }^{55}$ Also see Benkert ef al. (1990).

56 See, e.g. Wasch (1990).

57 Another intricacy of taxes and other policy options is related to the legal issue of whether these options can also in fact be used as policy instruments. This intricacy is related to such questions as to whether or not taxes can be considered as takings ('onteigeningen') and to whether or not taxation is in agreement with due process ('behoorlijke rechtsbedeling").

\$8. For levies to be considered a particular type of levy (e.g. an ordinary revenue raising tax), several restrictions are provided by the fiscal laws in different countries. For the specific case of the Netherlands, several of these restrictions are further described in chapter 6 of this study.

${ }^{59}$ See e.g. von Weizsalcker (1989) and Delbeke (1993) for further elaborations of the possibilities and problems for EU Member countries to introduce particular types of ecological taxes.

${ }^{60}$ See, ia. Becker (1991) and Hansjürgens (1992). 
transboundary discriminations. With regard to (ecological) taxation, this means that an EU Member country is not allowed to impose particular levies on products of other Member countries if national products are not also confronted with these levies. They are also not allowed to use levies for the protection of national products. ${ }^{61}$ Ecological taxes, however, are not prohibited in case only national products are taxed or in case products of a single Member state and other Member countries are equally taxed. ${ }^{62}$ Further restrictions for ecological taxation, resulting from EU legislation, are related to specific (European) tax harmonization processes (art. 99 TE-EEC). In order to avoid specific trade barriers, the latter processes are mainly related to the harmonization of indirect taxes, especially user taxes. The latter implies that problems may arise if ecological taxes are classified as user taxes (on products). To reduce these problems, it may be considered to impose ecological taxes not on products but on production processes or emissions. ${ }^{63}$ It may also be considered to introduce ecological taxes at the level of the European community. The introduction of ecological taxation may also be considered for those European countries in which some important flaws can be noted in the use of direct regulation instruments. ${ }^{64}$

If ecological taxes are used as environmental policy instruments, problems may arise if these instruments do not accord with existing policy frameworks and generally accepted principles of environmental policy. ${ }^{65}$ The first aspect is related, among others, to whether or not it is possible for single countries to freely pursue environmental policies within the broader framework of specific national and supra national legislature (e.g. EU legislation). Member countries of the European Union, for instan$\mathrm{ce}$, are allowed to freely pursue environmental policies as long as these do not interfere with a free movement of goods, products, capital and services. ${ }^{66}$ If the European

${ }^{61}$ Hansjürgens (1992, p. 234).

62 Ibid.

63 Ibid., pp. 236-238.

64 Wilhelm (1990, p. 122) argues that this is especially the case for countries in the southern part of Europe.

${ }^{65}$ Relevant problems and possibilities for the use of taxes for ecological and other purposes in the Netherlands are further analyzed in chapters 6-11 within the institutional and policy framework for ecological taxation in this country.

66 See Becker (1991) for a further elaboration of the limitations of environmental policy by EC Member countries in the context of the strive for a free movement of goods, products, services and capital within the EC. 
Union is responsible for the policy area in question, however, environmental policies by single Member countries with regard to this area may be (severely) restricted. ${ }^{67}$

Further problems in using taxes and tax reforms for environmental policy purposes may occur if these instruments are unable to meet generally accepted environmental policy principles such as e.g. the precaution, the co-operation and the polluter pays principle. The precaution principle refers to the prevention of environmental problems. The co-operation principle refers to the possibilities for particular societal groups and those affected by particular environmental policy measures to $\mathrm{co}$. operate in environmental policies. ${ }^{68}$ Following the original formulation by the OECD, the polluter pays principle refers to the criterion that polluters should bear the expenses of carrying out measures decided by public authorities to ensure that the environment is in an acceptable state. There are, however, many different interpretations of the latter principle in practice. According to very strict interpretations of the principle, polluters should not only bear the expenses of carrying out measures decided by public authorities but also the environmental burden of remaining emissions. They only have to bear particular types of expenses under very broad interpretations of the principle. It can generally be stated that ecological taxes (partly) adhere to the polluter pays principle as formulated by the OECD. The main purpose of Pigouvian taxes, for instance, is to confront polluters with the external costs imposed upon society. Being indirectly aimed at making polluting behaviour more expensive, other types of ecological taxes can also be used to (partly) confront polluters with the environmental costs imposed upon society. In case ecollogical taxes are dynamically efficient in the sense that they stimulate environmentally friendly technologies, for instance, these taxes also adhere to the precaution principle. Generally, the adherence of ecological taxes to the precaution and the co-operation principle can only be assessed with great difficulties. This is because the principles themselves are usually difficult to operationalize in practice. ${ }^{69}$

In conclusion, it can be stated that, although the analysis has been restricted to some important general problems of ecological taxation, the use of taxes for ecological and other purposes can generally be considered an intricate matter. Different types of taxes are not only characterized by their own set of peculiarities but also have to be embedded into specific institutional or constitutional frameworks which sometimes are unfavorable to the use of these taxes. Several of the intricacies involved are summarized in Table 3.4 .

\footnotetext{
${ }^{67}$ See also WRR (1992, p. $111 \mathrm{ff}$ ) and von Weizsäcker (1989).

${ }^{68}$ See Knüppel (1989, p. 23).

69 See Knüppel (1989, p. 104).
} 


\begin{tabular}{|c|c|c|c|c|c|c|c|c|}
\hline 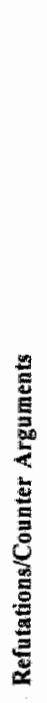 & 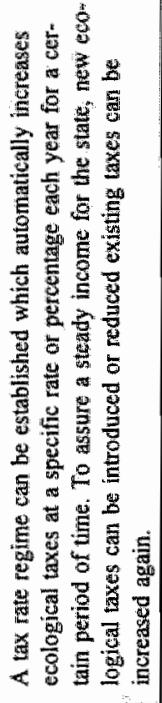 & 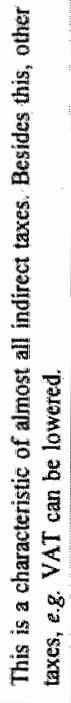 & 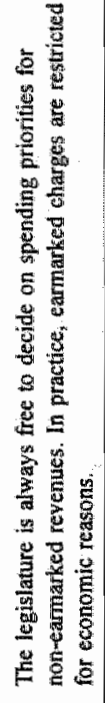 & 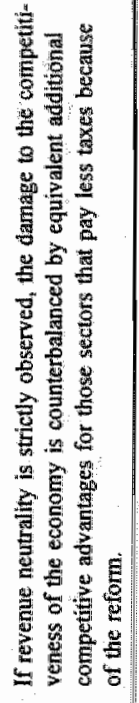 & 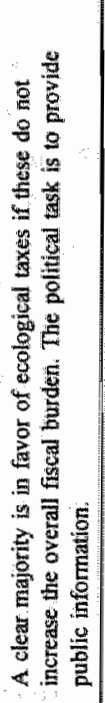 & 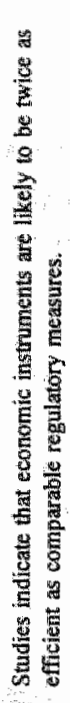 & 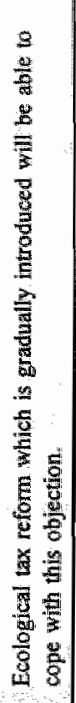 & 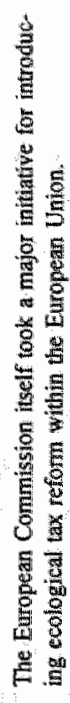 \\
\hline 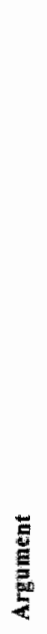 & 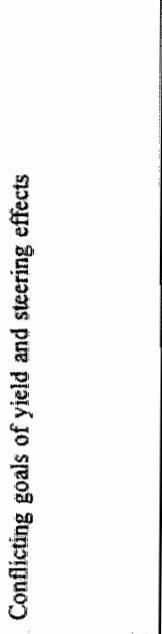 & 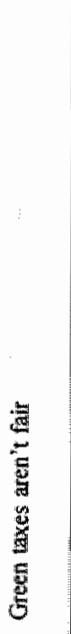 & 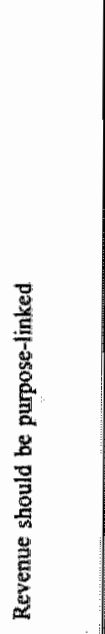 & 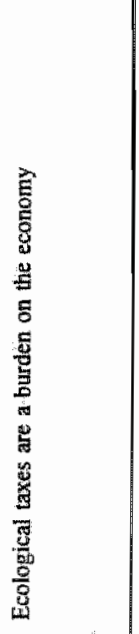 & 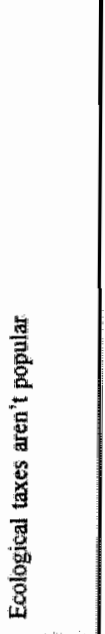 & 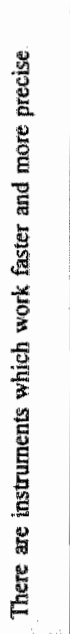 & 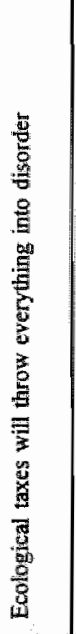 & 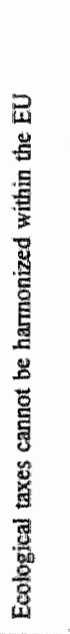 \\
\hline 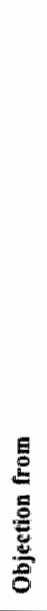 & $\frac{\hat{g}}{2}$ & $\begin{array}{l}\frac{a}{0} \\
\frac{a}{0} \\
\frac{a}{8}\end{array}$ & 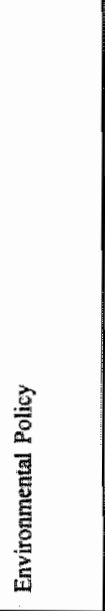 & 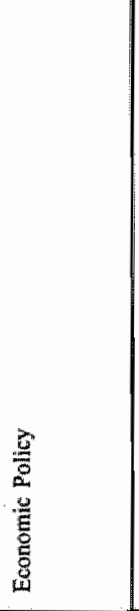 & $\frac{4}{5}$ & 恖 & 总 & 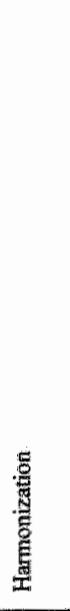 \\
\hline
\end{tabular}


Table 3.4, which is based on von Weizsäcker and Jesinghaus (1992) and Teufel (1989), ${ }^{\text {th }}$ shows a general set of objections and arguments which have been raised against ecological taxation and ecological tax reform. Several of these arguments have been previously described in this chapter (e.g. conflicting fiscal and steering effecis and the difficulties related to earmarking and tax harmonization within the EU). From these considerations and the other (counter) arguments mentioned in the table, it follows that each ecological tax option intended to be introduced in a particular country has its own set of problems and possibilities.

For Pigouvian taxes, the most important problems are related to the informational requirements and needs necessary to set the proper tax rate and to evaluate the expected effects of the tax on tax avoiding changes in behaviour. ${ }^{71}$ Analyzing different environmental policy instruments, Bovenberg et al. (1991, pp. 63-64) conclude that regulatory charges present an attractive option if governments have only limited information on the cost effectiveness of different alternatives by which pollution can be eliminated at the source of pollution. Since those who are liable for the charge, on the basis of the knowledge and creativity they possess, can select their optimal level of pollution reduction, the total costs of emissions control will be minimized. This, however, will only be the case if it is assumed that all polluters, when confronted with the tax, will behave rationally. Charges also present an attractive option in those cases in which the stimulation of environmentally friendly technologies and production processes is considered very important and the diffusion of technologies requires relatively large changes in production processes. ${ }^{72}$. These charges are also generally considered to be attractive if governments can collect all relevant information (e.g. on elasticities) and if the environmental burden per unit of pollution does not considerably vary through time or per source of pollution. Generally, and especially in comparison to direct regulation instruments, (regulatory) environmental taxes are considered to be suitable in those cases in which pollution can be easily measured and polluting behaviour is strongly affected by financial stimuli. In comparison to direct regulation instruments, attractive features of (regulatory) environmental taxes include the general compliance with the polluter pays principle and the fact that these instruments are flexible in the sense that they allow liable actors the freedom of choice between paying the tax or reducing polluting activities.

${ }^{70}$ Teufel is one of the authors of the UPI-proposals for ecological tax reform (see Umwelt- und Prognose Institut Heidelberg e.V., 1988).

71 Benkert et al. (1990, p. 82) argues that using tax allowances instead of Pigouvian taxes in order to relief desirable (i.e. environmentally friendly) behaviour is also complicated because a tax base has to be found which expresses this behaviour. Moreover, reliefs can only be provided for those who are liable for the specific tax into which the allowances are included.

${ }^{72}$ SERV (1992, p. 59). 
In the long run, these taxes are also usually effective from an ecological point of view and efficient in a dynamic sense. ${ }^{73}$

For ordinary revenue raising taxes, the most important problems are related to the possible conflicting fiscal and steering effects of these taxes. Revenue raising environmental taxes are considered to be an attractive option if relevant elasticities are low. Tax revenues can then be used to clean up existing pollution or to reduce existing taxes. Bovenberg et al. $(1991$, p. 64) also conclude that a clear relationship between the tax point and the point of pollution and the presence of possibilities to cheaply measure pollution, constitute important preconditions for the use of taxes and levies for ecological purposes. For earmarked taxes, the most important problems are related to the establishment of a clear relationship between that what is paid and that which is provided and funded by tax revenues. Ecological tax reform incorporates several of the problems which are characteristic for the other types of ecological taxes.

Following Hansjürgens (1992, p. 49-53) it can be stated that the instrument of taxes and tax reforms seems especially relevant in those cases in which different environmental policy instruments have a similar degree of ecological effectiveness and the rapidity by which particular ecological goals have to be met is less relevant. In these cases, ecological taxes and tax reforms can present viable options for meeting ecological targets at minimum costs and for continuously inducing an environmentally friendly behaviour. Further possibilities are also present in the case that ecological taxes comply with the polluter pays principle, while direct regulation instruments are inconsistent with the principle. This situation can arise if the latter is perceived as also including payments for remaining emissions. As previously demonstrated in the discussion of the different characteristics of ecological taxes and tax reforms, different problems are also inherent to these instruments. For Pigouvian taxes or regulatory charges, these problems are mainly related to possible conflicting fiscal and steering effects and the informational requirements necessary to set taxes and tax rates that are also ecologically effective. Besides this, ecological taxes and tax reforms generally seem less useful in those cases when the environment, ecosystems and the lives and health of humans are directly endangered or when particular allocational decisions have already been made (see Hansjürgens, 1992, p. $62 \mathrm{ff}$ ). For these and other cases, the use of non tax (environmental policy) instruments or a combined use of tax and non tax (environmental policy) instruments can be considered.

Based on his analysis of the problems and possibilities of using different types of taxes for ecological purposes, Hansjürgens (1992, p. $245 \mathrm{ff}$.) concludes that ecological taxes should ultimately be designed such that they are tailored to the relevant environmental problem(s), while being marked by a small tax base and a relatively high tax rate. According to Hansjürgens, such taxes would not only be more effective from an ecological point of view but, in comparison to ecological taxes that are

${ }^{73}$ See e.g. SERV (1992) and the references cited there. 
marked by a broad tax base and relatively low tax rates, would also enclose less severe conflicting fiscal and steering effects. Hansjürgens further concludes that, given the aim of finding a proper solution to environmental problems, ecological taxes should only supplement existing tax systems. An incorporation of environmental policies into the tax code or an introduction of ecological tax reform would not solve these problems. In the same sense, Hansjürgens argues that since the use of earmarked environmental taxes can be complicated from a fiscal and legal point of view and can also be associated with particular inefficiencies, ecological taxes of the ordinary revenue raising type could best be used to supplement the existing tax system. The latter type of taxes however also has its own set of problems. ${ }^{74}$ In an analysis of the merits of ecological taxation, Bergmann and Ewringmann $(1989$, p. 71$)$, on the other hand conclude that because conflicting fiscal and steering effects are an intrinsic feature of ordinary revenue raising environmental taxes, earmarked types of taxes can play a significant role in the use of taxes for ecological purposes.

Following von Weizsäcker and Jesinghaus (1992) it can be stated that realistic ecological tax designs and policy options include those options which are revenueneutral, easy to administer, which can be internationally harmonized, and which can be combined with measures to compensate for any negative social distribution effects. Besides this, realistic policy options include those options which can be introduced gradually and which are predictable. More specifically it follows that ecological tax bases and tax rates have to be properly chosen, i.e. among others in close connection with the relevant environmental problem, relevant elasticities and the purpose of the tax in question. The availability of information on short and long term elasticities and related tax avoiding changes in behaviour is also important for the ultimate design of ecological taxes. For the ultimate design of these taxes it is also important to know whether the tax is part of a package which includes different "smaller" ecological taxes. In those cases, it has to be questioned whether the same results can also be obtained with one "broad" ecological tax.

From an ecological point of view, it is also important to know how ecological taxes affect the environmental awareness of those confronted with these taxes. ${ }^{75} \mathrm{~A}$ related question in this respect is how ecological taxes can be made acceptable when

74 An additional problem of using ordinary revenue raising types of taxes for environmental policy purposes is related to the possible effects on existing financial relationships ("financiêle verhoudingen") between different levels of government in a particular country. These effects can especially be expected to occur in the case that particular existing taxes or grants are reduced or abolished in response to the introduction of ecological taxes (also see Ewringmann, 1990 , Wilhelm, 1990, p. 118 and Hansjürgens, 1992, p. 247).

${ }^{75}$ See Wilhelm $(1990)$ for a further elaboration of this question. 
they are intended to be used for environmental problems that are not or just indirectly "felt" by citizens (e.g. the greenhouse effect). ${ }^{76}$

To make the implementation of ecological taxes generally more acceptable, the OECD (1993a, pp. 7, 99, 115 and chapter 7) suggests and stresses the importance of:

- The adoption of simple and transparant taxes.

- The need to implement these taxes gradually and to monitor their effects.

- The introduction of financial compensatory measures to offset any undesirable social consequences of ecological taxes.

An introduction of ecological taxes as part of a package and explicitly linked to reductions in other taxes in order to produce a revenue neutral package.

Making environmental and taxation policies mutually reinforcing.

Analyzing ecological taxation within the proper institutional framework.

The introduction and use of ecological taxes which have only minor complications in view of the existing fiscal structures.

Assessing the administrative feasibility and the costs of introducing new ecological taxes.

A clear specification of the framework and the objectives of ecological taxes in order to enhance the understanding and participation of economic agents.

It follows from these suggestions that, in order to reduce the problems and make use of the possibilities offered by ecological taxation, ecological taxes and tax reforms should not only be carefully designed but also be embedded into a broader framework in which ecological taxation is accompanied by several accommodating measures.

\subsection{Ecological taxes and ecological tax reform: a checklist for design and imple- mentation}

In the following a checklist is derived which indicates the practical problems to be solved in order to arrive at a successful implementation of ecological taxes in practice. The main purpose of the checklist is to display the most important intricacies of ecological taxation, to show relevant decision points for policy makers and to indicate the preconditions for feasible types of ecological taxes. The questions mentioned in the checklist are related to relevant policy decisions prior to the design and implementation of the tax (questions 1a-lc), ecological taxes in the form of Pigouvian taxes (questions 2-8), ordinary revenue raising taxes (questions 9-11), earmarked taxes (questions 12-16) and to ecological tax reform (questions 17-23). The remaining questions (24-33) are related to the effects and evaluation of all types of ecological

${ }^{76}$ For a further elaboration of different features of an "ideal" ecological tax, see Wilhelm (1990), Nutzinger and Zahrnt (1989, 1990), Faber and Michaelis (1989), Benkert et al. (1990). 
taxation and to the decision whether or not to introduce the tax in question (question 34).

Checklist

Decisions prior to the design and implementation of the tax

1) What is the main purpose and/or function of the tax?

a) Allocational function. If so, continue with questions 2-8

b) Fiscal function. If so:

1) are revenues intended for general policy purposes?

If so, continue with questions $9-11$

2) are revenues intended for specific policy purposes?

If so, continue with questions 12-16

c) Changing the structure of tax raising. If so, continue with questions 17-23

\section{Pigouvian taxes}

Design

2) Is the tax base of the Pigouvian tax chosen in close connection with the desired behavioural changes, i.e. is there a clear linkage between the tax point, a point of choice and the point of pollution?

3) Are environmentally friendly alternatives available and offered, i.e. do Pigouvian taxes offer choices for those confronted with the taxes?

4) Does the ecological tax in the form of a Pigouvian tax, from the viewpoint of economic efficiency, lead to the desirable and ideal tax avoiding changes in behaviour?

\section{Implementation}

5) Is it possible to use or implement the right tax and administrating authority for ecological taxes in the form of Pigouvian taxes?

6) Is it possible for the taxing and administrating authority to acquire and provide information concerning the possibilities for alternative ways of behaviour? 
7) Is it possible for the taxing and administrating authority to formulate an accommodating policy that facilitates behavioural changes?

As follows from the previous questions (2-7), the most important intricacies of Pigouvian taxes are related to whether or not an affirmative answer can be formulated to the following question:

8) Does the ecological tax in the form of a Pigouvian tax exclusively fulfil an allocational function, that is to say can be expected that the ecological tax in this form leads to zero income for the state?

\section{Revenue raising taxes}

\section{Design}

9) Are tax elements set in such a way that a maximum amount of tax revenues can be raised, i.e. is the tax mainly used for fiscal ends?

\section{Implementation}

10) Is an ecological tax in the form of an ordinary revenue raising tax compatible with the existing tax system?

11) Does the use of revenue raising taxes for ecological purposes lead to a change in the structure of tax raising?

\section{Earmarked taxes}

\section{Design}

12) Is there a quid pro quo relationship between the earmarked taxes and the services provided by the government which introduces these taxes?

13) Can appropriate revenues and revenue raising sources be identified?

14) Are revenues raised from an identifiable group of individuals, activities or products and restricted to be used for the funding of specific or general environmental policies?

15) Is there a clear relationship between those who are confronted with paying the tax and those who benefit from the provisions which are funded from the revenues resulting from tax payments? 


\section{Implementation}

16) Can a policy framework be formulated by which tax revenues and expenditure requirements can be kept on the same line?

\section{Ecological tax reform}

\section{Design}

17) Are ecologically undesirable tax elements being removed from existing taxes?

18) Can marginal tax rates be differentiated in favour of activities that are considered desirable from an ecological point of view?

19) Is the bulk of the tax burden shifted from labour and capital to (the use of) natural resources and pollution?

20) Are (new) tax revenues used as a substitute for existing revenue raising taxes?

\section{Implementation}

21) Can ecological tax reforms be implemented fiscally neutral?

22) Provided there is a blueprint, is it possible to gradually introduce ecological tax reform?

23) Is ecological tax reform used in order to achieve an optimal use of natural resources, a reduction of pollution, a reduction in the use of environmentally unfriendly energy and aimed at achieving more labour intensive means of production?

\section{Ecological taxes and tax reform in general: effects and evaluation}

\section{Design}

24) Is the tax base chosen in close connection with the main purpose of the tax or tax reform?

25) Can ecological taxes and tax reforms be tailored to environmental problems? 


\section{Implementation}

26) Is it possible to formulate and finance an accommodating policy with which it is possible to compensate in case of undesirable side effects?

27) Are ecological taxes and tax reforms easy to administer?

28) Can ecological taxes and tax reforms be implemented so as to be fiscally neutral?

29) Is there a consensus in society on the implementation of the ecological taxes in question?

30) Is the ecological tax (reform) acceptable and feasible from an ecological, legal, political, institutional, economic and environmental policy point of view?

31) Does the ecological tax (reform) not stand in the way of attaining sustainable growth, i.e. are future generations also considered when formulating ecological tax policies?

32) Is it possible to indicate the direct and indirect economic and income redistribution effects of ecological taxes and tax reforms?

33) Do ecological taxes and tax reforms provide incentives to reduce emissions and steer technology in an environmentally friendly direction?

\section{Decision point}

34) Do the benefits of introducing a particular type of tax outweigh their costs?

From the checklist it follows that the phenomenon of an ecological tax comprises several complicated problems. These problems can be solved only if the ecological tax as a policy instrument is placed within a general policy framework. On the one hand this can be achieved by using an ecological tax in the form of a Pigouvian tax as an instrument of environmental policy. In this case it is important to formulate and search for an accommodating policy for behavioural alternatives. Outside the existing tax system, also new earmarked environmental taxes can be introduced. In this case it is important to find a proper relationship between the taxes, taxable individuals or agents and the provision of an ecologically relevant service. The possibility exists, on the other hand, to reform the entire tax system in order to stimulate an optimal use of natural resources. If ecological taxes of the ordinary revenue raising type are used, this in fact opens a political discussion on the entire tax system. From this it follows 
that ecological taxes are complicated, yet that in principle ecological taxes could be feasible. The foregoing list of questions indicates the preconditions for feasible ecological taxes and ecological tax reforms. From the checklist it also follows that the elements which determine the viability of ecological taxes that are intended to be used for various purposes (i.e. earmarked taxes, revenue raising taxes and ecological tax reform) differ from those which determine the viability of taxes that are solely intended for ecological concerns (Pigouvian taxes). The viability of the latter types of levies strongly depends on the incorporation of elements in the design of these taxes which further enhance their allocational function, and the presence of a framework in which information on behavioural alternatives is distributed to relevant actors. The viability of the former types of levies, strongly depends on their compatibility with the existing tax system and the determination of a clear destination of associated tax revenues. 


\section{The Imposition of Ecological Taxes and the Concept of Ecological Tax Units}

\subsection{Introduction}

In previous chapters of this study, different theoretical possibilities and problems of using taxes for ecological and other purposes have been discussed. Among others, it was shown that the viability of these levies differs for taxes that are designed under a double dividend approach and those that, in principle, are set on the basis of purely ecological concerns (e.g. Pigouvian taxes). In order to serve a meaningful purpose and be acceptable and feasible, ecological taxes not only have to be properly designed but also be levied by a proper taxing authority. In addition, these taxes have to be introduced on a proper level and be embedded into relevant institutional and constitutional structures. Institutional structures refer to arrangements which provide structures within which economic units can co-operate and/or compete (Williamson, 1993). Constitutional structures refer to a set of rules, or social institutions, within which individuals operate with one another (Brennan \& Buchanan, 1980, p. 3). Within this context, in the following several elements relevant for the imposition of ecological taxes are further discussed. The discussion of these elements is mainly embedded into the theory of constitutional environmental economics (see also Paulus, 1994c).

Following Backhaus (1994), constitutional environmental economics can be described as a branch of environmental economics that deals with the constitution of viable ecological units. Such units satisfy two criteria. First, there is an organizational unit which is built around an ecological unit and has a maximum overlap with that unit. Second, the organizational unit is also a decision making unit that is able to weigh policy options in the light of available resources, all related to the ecological unit in question. Defined as such, the concept of ecological units can be considered as being part of the afore mentioned ecological concerns approach. Within the context of the concept of ecological units, in this chapter, this approach is used to further explain several elements of the imposition of ecological taxation.

Building on this characterization of constitutional environmental economics, several elements relevant for the ecological circumstances of a particular region are briefly sketched in section 4.2 . Given these particular circumstances, several elements of different economic theories are used to determine the proper taxing authority, level and institutional context for ecological taxes. The main elements of these theories, which include the theory of fiscal federalism, the theory of clubs, Tiebout's theory of local expenditures, Brennan and Buchanan's theory of taxation within constitutional political economy and Wicksell's voluntary exchange approach, are described in section 4.3. The basic arguments and elements arising from these theories are then used to derive the necessary arrangements which allow a connection of taxes and tax 
systems to relevant ecological systems or circumstances. Such arrangements are discussed under the heading of ecological tax units. Several aspects of ecological tax units and the implications of the previous analysis for ecological taxation are further discussed in section 4.4 .

In sections 4.5 and 4.6 , the analysis of the previous sections is carried one step further. Confronting the ideal situation described in section 4.4 , these sections start from the conception that existing taxing authorities tend to be political units which most of the times do not fit the description of being clearly related to relevant ecolo: gical circumstances or eco-systems. The implications of the latter for the ecological effectiveness, practical feasibility and acceptability of ecological taxes are then further discussed. In section 4.5 , the river Rhine is used to illustrate the main elements and implications of the concept of ecological tax units. In section 4.6 , several elements by which it is possible to impose ecological taxes in close relationship to relevant ecological tax units are further discussed. The chapter ends with an overview of the implications for ecological taxation and with several conclusions and remarks (section 4.7).

\subsection{Ecological level and circumstances}

It was previously argued that markets can misallocate environmental resources and can allow environmental problems, among others, in case there are externalities and/or in case ecological circumstances contemplate the characteristics of a public or collective good. The latter characteristics include non-rivalry and non-excludability in case the good in question can be perceived as a purely collective good. According to Samuelson (1954), a purely collective good can be considered the exact opposite of a purely private good. The latter is characterized by strict rivalry and excludability.

In the intermediate range between purely private and purely collective goods, there is a range of goods that have a certain degree of "publicness" but that are neither purely collective nor purely private. ${ }^{\prime}$ Within the literature of public finance, these goods are more familiarly known as public goods. Goods that have excludable benefits but that are non-rival constitute a familiar example of these kind of goods. Although certain environmental problems or ecological circumstances represent the characteristics of a collective good (e.g. the climate or a landscape), other environmental problems or ecological circumstances either exhibit the characteristics of a public good or offer the possibility to tie in the consumption of a second good for which private incentives exist for the production and/or provision of the good. ${ }^{2}$ Often cited examples of the former include particular (polluted) waterways and of the latter certain nature regions or natural parks which can be visited but for which exclusion is

1 See, i.a. Buchanan (1965), Demsetz (1970) and Comes and Sandler (1986).

2 See Demsetz (1970, p. 306). 
possible via fences or via fees that have to be paid in order to enter these regions or parks. $^{3}$

Many environmental problems and ecological circumstances which have the character of public goods are local public goods, i.e. goods that are relevant for particular regions or zones. This circumstance may, for instance, arise in case the impact of environmental problems differs per region due to specific ecological circumstances. In this study, the ecological circumstances of a region are conceived as particularities that give the region (e.g. a country, an eco system) a typical character when considered from an ecological point of view. ${ }^{4}$ The typical character may be due, among others, to:

The extent to which the environment in the region in question is able to absorb environmental pollutants or pollution.

The existence of a particular relationship between the emissions and immission (i.e. environmental burden) of certain polluting substances within that region.

The specific nature of certain environmental problems within the region.

The specific (ecological) structure of one or more environmental compartments (e.g. soil, water or air) within the region in question.

Based on these and other ecologically relevant particularities, regions can be distinguished on the basis of ecological circumstances or, in other words, on the basis of the ecological level at which the environmental problems or circumstances in question occur (e.g. a local level or a fluvial level). The environmental problems or circumstances or particular elements thereof (e.g. the environmental quality) can then be considered public goods. Within different economic theories, it is questioned by which level and authority particular tasks with regard to these goods can best be performed. In the following, the main elements of several of these theories are further described and analyzed. These theories are then put into an environmental context in order to derive those elements that are relevant for the feasibility, problems, possibilities and imposition of ecological taxation in practice.

\subsection{Ecological taxation: taxing authority and level of introduction}

\subsubsection{The theories of fiscal federalism, clubs and local expenditures}

In economic theory, the question of how the public sector should be organized and which level of government should perform which task, in order to attain a particular

3 See also Cornes and Sandler (1986) who indicate different examples and applications of the theory of collective and public goods.

${ }^{4}$ For a more detailed definition of nature and environment, see Krabbe and Heijman (1986). 
welfare optimum, is the central theme of the theory of fiscal federalism. ${ }^{5}$ In case of complete (de)centralization, the (de)central level(s) of government execute(s) all functions of society, i.e. those related to allocation, distribution and stabilization. Both centralization and decentralization have some well known advantages. Oates (1972: 311) makes the point that a centralized government has the advantage of being more apt to perform functions related to distribution, stabilization and allocative functions in case of collective goods. ${ }^{6}$ An important advantage of decentralization is a quicker response to changing preferences. In this sense, decentralization offers the possibility to respond to spatial patterns and circumstances. Patterns, circumstances and preferences may differ geographically because of differences in needs, service costs, revenue ability and benefits, revenue burden and benefit incidences (see Bennett, 1980). According to Bennett (1980, p. 94), needs can differ among jurisdictions because of the existence of local public goods, externalities, indivisibilities (e.g. where joint needs cannot be disaggregated) and because of public welfare related needs (e.g. where joint social needs such as law and order and welfare institutions cannot meaningfully be divided between people). When the costs of environmental protection, technical factors, location etc. show geographical patterns, differences in service costs can also cause differences in preferences between jurisdictions. Revenue ability and benefits can differ among jurisdictions mainly because of differences in the canons of revenue raising, revenue sources and behaviour, the apportionment of revenue burdens and revenue capacities. Moreover, the geographical incidence of revenue burdens and the access to public goods can also lead to geographical differences (benefit incidence). ${ }^{7}$

In addition to the advantage of being able to respond to spatial patterns and circumstances, decentralization also has the advantage that competition between different levels of government encourages these levels to adopt the most efficient techniques to produce their goods (i.e. if it is assumed that there are no synergies to be exploited with non-competition). Moreover, an important advantage of decentrallzation is a more rational weighing of the costs and benefits of a specific government program. It can generally be stated that an optimal organization of the public sector is one which combines the advantages of the two extreme forms and minimizes possible disadvantages, which is what federalism tries to accomplish (see Oates, 1972, p. 14 ff.). From an economic point of view, a federal government can be defined as a public sector which has both decentralized and centralized levels of decision making. A central feature of a federal government is also the fact that choices of the provision of specific government services for each government level are determined by the demand for these services by citizens and others in the jurisdiction in question. The

5 See Oates $(1972)$.

6 See Wolfson (1988) for a critical remark on this statement by Oates.

7 For a more detailed analysis of these elements, see Bennett (1980). 
central matter is finding the suitable degree of decentralization for a specific government sector. "This as I see it, is the central theoretical problem of fiscal federalism: the determination of the optimal structure of the public sector in terms of assignment of decision-making responsibility for specified functions to representatives of the interests of the proper geographical subsets of society" (Oates, 1972, p. 19).

In an ideal situation, assuming a finite number of collective goods, the suitable degree of decentralization can be derived from Oates' decentralization theorem. Each collective good is characterized by the fact that the consumption of the good is defined over a specific geographical subset of the total population. This means that there is a public sector in which choices concerning the provision of public services are determined largely by the demands of the residents of the respective jurisdiction (Oates, 1972 , pp. $34-35$; p. 19). Furthermore, it is assumed that the geographical distribution of the population is fixed, so that citizens do not leave their residencies. Besides this, the costs of providing each good are assumed to be equal in every jurisdiction and for every level of government. Given these assumptions, the optimal. form of federal government which provides a finite number of collective goods is the one in which there is a level of government for each subset of the population. The boundaries of this subset are determined and defined by the consumption of the $\operatorname{good}(\mathrm{s})$ in question.

In an ideal situation each provision, in other words, is linked to that jurisdiction of which the spatial range corresponds with the actual use by citizens. ${ }^{8}$ From the decentralization theorem it then follows that for a particular collective good, given the afore mentioned conditions and assumptions, it is always more or at least as efficient to let local governments provide efficient levels of output for their jurisdictions than to let the central government provide a specific uniform level of output for all jurisdictions (Oates, 1972 , p. 35). In this sense, if the environmental quality in a region within a specific nation can be considered a local public good, under the afore mentioned conditions, it is always more or at least as efficient to let local governments provide the efficient level of environmental quality than to let the central government provide a non regionally differentiated level.

Since centralization offers no benefits of scale, since it is assumed that different levels of government face equal costs, the theorem in fact emphasizes a certain degree of decentralization. The incentive to decentralize increases when there are more different efficient levels of output between jurisdictions. This situation will arise in case the diversity of the individual demand in the entire country increases and if every geographical subset of the population becomes more homogeneous. In a non ideal situation, in which not all conditions of the theorem hold, a determination of the optimal form of the public sector becomes more complicated. ${ }^{9}$ Complications may

${ }^{8}$ See Wolfson, (1988, p. 347).

See, e.g. Oates (1972) for a further analysis of such situations. 
arise in case the consumption of the collective good in question is no longer defined over a specific geographical subset, in case of externalities and in case the population is mobile and can move to other jurisdictions.

One of the central assumptions of the theory of fiscal federalism is that the consumption of a collective good is clearly defined over a specific geographical subset. When the consumption of the good, however, is not clearly defined over this subset, an optimal size of the group which collectively consumes the good has to be determined. This is the central theme of the economic theory of clubs. The basis of this theory was first described by Buchanan (1965) ${ }^{10}$ The central theme of the theory is related to the most desirable cost and consumption sharing arrangement for those goods and services for which the optimal sharing group is more than one person or family but smaller than an infinitely large number (see Buchanan, 1965, p. 2). This theory, in other words, is related to the range of goods and services that are neither purely private nor purely collective.

To determine the most desirable cost and consumption sharing arrangements for these goods and services it has to be taken into consideration that the utility which an individual obtains from these goods and services also depends on the number of other persons with whom the benefits of the goods and services have to be shared (i.e. the club size). An individual will attain full equilibrium in club size if the marginal benefits that he secures from having an additional member in the sharing arrangement are equal to the marginal costs that he incurs from adding a member (Buchanan, 1965 , p. 5). Increasing the club size by adding an additional member may affect the costs of the good or service in question to any other member. Additional individual benefits, for instance, arise if, due to economies of scale, it becomes cheaper for individuals to consume the good or service together (i.e. if it is assumed that individuals share in the costs of providing the specific goods or services for groups of varying sizes). Increasing the club size, however, also imposes additional individual costs. The latter can be due to congestion and/or due to a decrease in the individual power over consumption levels of the good or service in question. To determine the optimal club size, therefore, both marginal costs and benefits of adding an additional member have to be taken into consideration.

In case there are externalities which go beyond the boundaries of the jurisdiction in question, the probability of which increases according as the size of this jurisdiction is relatively small, it seems desirable to internalize the externalities in such a way that the spatial range is in agreement with the actual use of the good. Among others, this can be achieved by increasing the size of the jurisdiction in question or by using intergovernmental grants for a reduction or abolishment of the inefficiencies

${ }^{10}$ Buchanan (1965, pp. 1-14). See Tollison (1972) and Cornes and Sandler (1986, part 4) for extensions and descriptions of the development of the theory of clubs since the original formulation by Buchanan. Extensions of club theory include $i . a$. discriminatory clubs, stability of club members
ship and intergenerational clubs. 
associated with externalities. " The latter solution can be traced back to the idea and suggestions of Pigou to use subsidies for the internalization of (positive) externalities, although Pigou did not explicitly refer to government units as the recipients of such subsidies. ${ }^{12}$ In this sense, fiscal federalism also emphasizes the importance of financial relationships ("financiële verhoudingen") between different levels of government. If the costs of collective decision making are also taken into consideration, attention has to be paid to the fact that, other than in the ideal situation, the higher the number of government levels, the higher the costs of creating and operationalising these levels (e.g. more administrative and electoral costs). Again, relevant costs and benefits of alternatives have to be weighed against each other.

If it is no longer assumed that the population is immobile, it has to be taken into consideration that citizens/households can move to other jurisdictions. This consideration is one of the central aspects of Tiebout's pure theory of local expenditures. ${ }^{13}$ The central question of this theory is whether at local levels of government any mechanism operates to ensure that expenditures on public goods approximate their proper level (p. 418). To find the solution to this question, Tiebout (1956) presents a local government model in which it is assumed that: ${ }^{14}$

1) Consumer-voters are fully mobile and will move to that community which best satisfies their preference patterns.

2) Consumer-voters have full knowledge of differences among revenue and expenditure patterns and are able to react to these differences.

3) There are a large number of communities in which consumer-voters may choose to live.

4) All persons are living on dividend income (i.e. employment opportunities are not considered).

11 Since mobility across national boundaries is generally much less than mobility within a nation, taxation by local governments is much more difficult than taxation by central governments because of the possible risks of fiscal leakages (see also section 4.3 .2 of this study).

${ }^{12}$ Generally, intergovernmental grants can be conditional and unconditional. The fomer include matching grants in which receiving governments have to match the grant they receive with a certain amount from their own revenues. Within the theory of fiscal federalism, the suggestions of Pigou to use subsidies in case of positive externalities are usually referred to within the context of matching grants.

13 Tiebout (1956, pp. 416-424).

14 Tiebout (1956, p. 419-420). By focusing on different communities which each offer their specific set of revenue-expenditure package to consumer-voters, this local government modell also implicitly stresses the importance of marking out and clearly defining the borders of the different communities. In practice, the latter is important i.a. for zoning issues. See e.g. Mishan (1968). 
5) The public services supplied exhibit no external (dis)economies between communities.

6) For every pattern of community services there is an optimal community size, with the optimum defined in terms of the number of residents for which this bundle of services can be produced, at the lowest average cost.

7) Communities below the optimum seek to attract new residents to lower average costs. Those above optimum size do just the opposite. Those at an optimum try to keep their population constant.

Given these assumptions and given particular revenue and expenditure patterns, a consumer-voter will move to that community whose local government best satisfies his set of preferences. The consumer, in other words, will "vote with his feet" and reveal his demand for a particular public good. The demands for public goods and the preferences regarding the desired package of provisions will, in this way, be reflected in the revenue-expenditure pattern of each local government. If mobility is costless, the production of local public goods is efficient. If accurate if not perfect information is available, an efficient outcome will result and each consumer-voter will be part of that jurisdiction which best satisfies his/her preferences. Specific costs (e.g. costs of congestion), however, may also arise due to mobility. The latter may again have certain consequences for the individual benefit of the good or service in question. ${ }^{15}$

From the previous considerations, it can be concluded that; ideally, the responsibility for a particular task or good can best be performed by that level of government of which the spatial range corresponds with the actual use by citizens. In this case, there are different levels of government, ".....each of which determines levels of provision of particular public services in response largely to the interests of its geographical constituency" (Oates, 1972 , p. xvi). Secondly, it can be concluded that in a non ideal situation the most suitable organization of the public sector can be determined with great difficulties only. In those situations,".....[T] an independent unit or level of government to provide a good must be weighed against the increase in costs due to a larger number of public agencies" (Oates, 1972, p. 49). If the costs outweigh their benefits, it is desirable to let a general purpose unit provide the particular service or good in question. ${ }^{16}$

It must have become obvious that within an environmental context, the previous considerations imply that the responsibility for ecological problems or circumstan-

15. See Mueller (1989, chapter 9) and the references cited there for descriptions of the empirical evidence on the Tiebout model and the possible complications of Tieboutian models. The latter are related, among others, to cases in which individuals earn part of their incomes outside the particular community in question and to whether or not an equilibrium distribution of the population among clubs exists and if so, whether or not this equilibrium is Pareto efficient.

16 These costs may outweigh benefits, for instance, if via the provision of public goods by general purpose units particular synergies can be exploited. 
ces ideally is a task for a level of government or authority which is clearly related to these circumstances. The latter is for instance the case if a level of goverment or decision making authority or arrangement has administrative responsibilities which coincide or correspond with the ecological level at which these problems or circumstances occur. Since specific choices concerning the organization of the public sector also determine the ideal financial or fiscal organization of that sector, the previous considerations also have implications for the use of taxes ${ }^{17}$ With regard to taxes, in case of a decentralized organization of the public sector, for instance, it has to be decided by which level(s) of government (or taxing authority) specific taxes have to be imposed.

In his dissertation on public finance aspects of polluter charges, Hansjurgens $(1992,211-217)$ analyzes the question of whether these charges have to be levied by national (i.e. central) or regional level(s) of government. Based on fiscal federalism theory, Hansjürgens describes, i.a., the pros and cons of a regional differentiation of polluter charges. Such a differentiation might be considered because:

The emission of polluting substances can result in different environmental burdens (or immissions) in different regions. Besides this, it is possible that, in some cases, a regional concentration of emissions and immissions occurs.

The absorptive and assimilative capacity of the environment may be different in particular regions, due to, for instance, prior environmental damages. Immission norms may therefore be differentiated according to the absorptive capacity of the particular region in question.

Citizen's preferences for environmental quality, damages and burdens may differ per region.

To be able to differentiate between regions via pollution charges, these regions have to be divided into specific charges zones, such as, for example, the current water boards in the Netherlands. For each zone, which ideally should be constructed for each source of emission, a particular authority has to be indicated which controls and imposes the pollution charge(s) in question. Constructing a charges zone for each source of emission, however, can be a difficult exercise in practice. According to Hansjürgens (1992, p. $215 \mathrm{ff}$ ), difficulties consist of among others the fact that a differentiation of pollution charges requires different and additional administrations, e.g. with regard to the control and measurement of emissions and immissions in particular regions. The extra costs that may be associated with these additional ad-

${ }^{17}$ See Wolfson (1988, p. 345). 
ministrations ${ }^{18}$ however should then be weighed against the benefits of a regional differentiation of polluter charges. These benefits can be considerable if information on ecological circumstances is also regionally differentiated. When relevant information is only available to regional authorities, a central government may not have all the information necessary to set the proper ecological taxes. In this case, the benefits. in terms of a gain in ecological effectiveness, when polluter charges are regionally differentiated, can be substantial. If relevant information on ecological circumstances, however, is also not available to regional authorities, a regional differentiation of polluter charges can be costly. In this case, the difficulties involved in measuring and expressing emissions in terms of immissions and the related problems in setting proper tax rates are faced not by one but by many authorities. It then follows that the desirability of a regional differentiation of polluter charges depends among others on the availability of relevant information to decision making authorities.

\subsubsection{Ecological taxation: economic level}

So far, ecological taxes have been discussed with an eye on the ecological level at which they could best be imposed. For taxing authorities and for those who are confronted with ecological taxes, however, the economic level at which these levies are imposed is also an important determinant for their ultimate feasibility and acceptability. The economic level refers to the market and the competitive position of those who are mainly confronted or affected by these taxes (see also WRR, 1992, p. 135). In general, several problems can arise when ecological taxes are intended to be imposed at a level which does not coincide with the proper economic level. In those cases in which taxes are set and used for ecological purposes in only particular jurisdictions, difficulties mainly consist of the fact that economic actors can be induced to move themselves or their polluting activities to jurisdictions in which lower or no taxes are levied..$^{19}$ Economic actors (including polluters) will be induced to leave the latter jurisdictions among others when mobility costs are relatively low and in those cases in which ecological taxes are dissociated from related environmental provisions. In addition, jurisdictions that separately introduce ecological taxes might discourage investments and the creation of new jobs in their jurisdictions. Consequently, in order to attract particular economic actors (e.g. investors), separate jurisdictions can even be encouraged to reduce their environmental standards and thus the related costs for

18 Whether there are extra costs depends i.a. on how much of the costs that are associated with a uniform imposition of polluter charges by the central government can be saved via the imposition of such charges by regional authorities.

${ }^{19}$ Within the context of the central subject of this study, only costs in terms of ecological taxes are taken into consideration. Generally, however, decisions by economic actors to move themselves or their activities to other jurisdictions depend on total costs (including other than environmental taxes, labour, resounces etc.). 
relevant decision makers. Competition between different jurisdictions may then even result in a level of environmental quality below the one which can be achieved when ecological taxes are imposed by one centralized jurisdiction. ${ }^{20}$ Within the context of an international trade model with two countries and assuming that environmental policies can not be introduced within the context of an international co-operative arrangement, Baumol and Oates $(1988$, p. 257 ff.) for instance show that environmental policies can affect a country's balance of payments, its employment level and its GNP (p. 262). Describing a situation for two countries, in which one country produces a particular commodity with a polluting production method, while the other country produces the same commodity by way of a non polluting production method, it is shown that in the short run, under certain assumptions, if the government of the former country decides to prohibit and eliminate polluting production processes, this may produce a deterioration in the balance of payments and an increase in domestic production. This, however, is not a forgone conclusion since, as the authors argue, "[w]ithout examining the relevant elasticities, it is never safe to argue that a rise in production cost and price will lead to a reduction in revenues and input demand" (p. 262). In the long run, particular specialization patterns may arise if one country decides to produce the commodity in question by means of a polluting production method. More specifically, this country will become specialized more than it would have otherwise in the production of items that generate pollutants (p. 265).

In analogy to the difficulties encountered by jurisdictions which plan to introduce ecological taxation within an international context, local governments face comparable difficulties in introducing and/or using taxes for ecological purposes. Although local governments, by varying environmental standards and policies among different local jurisdictions, can set standards and policies in accordance with different local environmental circumstances, setting and using taxes for ecological purposes in only particular jurisdictions can be difficult in case these taxes induce an interjurisdictional flow of products and/or economic actors. ${ }^{21}$ In this sense Oates (1972, p. 138-139) concludes that "..... where individual economic units are sensitive to local fiscal treatment in terms of locational decisions, it would appear wise for local governments not to depart too radically from at least rough approximations to benefit forms of taxation". The latter type of taxation includes the use of earmarked taxes, i.e. the use of taxes for which their is a direct association between the revenues of the tax and the provisions funded by these revenues.

It follows that ecological taxes preferably are imposed at the level at which ecological problems occur by taking into consideration the level which determines the

20 See Oates and Schwab (1988) for a more explicit analysis of the effects of competition between different jurisdictions on the resulting environmental quality in these jurisdictions.

21 For an alternative approach by which local communities, via a licencing procedure, can combine the enforcement of environmental standards against local producers and the end of furthering employment and economic prosperity, see Backhaus (1994, pp. 20-23). 
competitive or economic position of the jurisdiction in question and the related cost of control, information and transactions. In each separate case it has to be decided whether the benefits of setting environmental taxes on the basis of particular spatial circumstances outweigh the costs of discouraging new investments, the danger of encouraging economic actors to leave the particular jurisdiction in question and the disadvantages of possible reductions in environmental standards and environmental quality. The use of particular types of taxes, such as earmarked taxes, can be helpful in reducing the sensitivity of relevant actors to leave the jurisdiction in question. In section 4.3.3, earmarking is shown to be a central element of constitutional political economy.

\subsubsection{The imposition of ecological taxes: the political decision making process}

In the analysis of ecological taxation in this and the previous chapter(s), so far several design issues and the level of introduction for this type of taxation have been further discussed and analyzed on the basis of an a priori assumption that governments will use these taxes within their environmental policies. A proper design and level of imposition, however, does not necessarily imply that all ingredients necessary for the recipe of a feasible ecological tax are present. This is only true if there are no government failures in the sense that political actors are induced not to impose the tax in the way that it was originally designed. Although this is generally assumed in the socalled traditional or neoclassical approaches of taxation economics, this is not the case for specific positive approaches to taxation economics such as those presented by Brennan and Buchanan $(1980,1985)$ and Wicksell (1896). Within the latter approaches, the constitutional and institutional structures into which taxation is embedded, themselves are subject of analysis (see also chapter 1 of this study). In addition, within positive approaches to taxation economics, there generally is an association between tax policies and expenditures, while tax policy alternatives are tested on the basis of the principle of (quasi) unanimous consent. ${ }^{22}$

In a model in which a potential taxpayer-beneficiary is presumed to be ignorant about his future position and is confronted with a revenue maximizing "Leviathan"wise government, Brennan and Buchanan (1980, pp. 7-8 and p. 136) discuss the following questions: ${ }^{23}$

${ }^{22}$ See Cullis and Jones (1994, chapter 17$)$.

${ }^{23}$ For a further elaboration of taxation within the context of constitutional political economy (in comparison to "orthodox" fiscal economics and public choice theory), see i.a. the journal Constitutional Political Economy. This journal was founded in 1990. See also Brennan and Buchanan (1980 and 1985). The latter books are generally considered to be among the most important books that laid the foundation of constitutional political economy. 
What sort of tax institution would we expect a rational taxpayer-citizen to select in determining the constitution to which he is to be subject?

How may the potential taxpayer-beneficiary at the same time ensure that the revenues collected will be devoted to the financing of those goods and services that he values?

Brennan and Buchanan (1980) address these two questions in terms of the following equation: ${ }^{24}$

$\mathrm{G}=\alpha \mathrm{R}$

In the equation, $G$ represents the quantity of a (bundle of) public good(s), $R$ the total tax revenue collected and $\alpha$ the share or proportion of that revenue which is devoted to the outlay on the public good(s). Assuming $\alpha$ to be exogenously fixed, the first question boils down to determining the constitution which limits $R$. If it is assumed that tax revenues collected depend on the rate and base of the tax in question, limits on R might be exerted by the taxpayer-beneficiary by appropriately choosing constitutional restrictions on the revenue raising potential of the tax system, e.g. by opting for particular tax bases and rate structures. ${ }^{25}$ If it is no longer assumed that $\alpha$ is fixed, the second question can be addressed in terms of the following equations.

$Y_{k}=R-G$

$Y_{k}=(1-\alpha) R$

In equations (2) and (3), $Y_{k}$ represents the maximand ascribed to the behavioural or utility maximizing entity (e.g. a king or politicians-bureaucrats). To select tax institutions, within this framework, such that the utility maximizing entity directs a share of revenues to the provision of $G$ and not all of the tax revenues to the provision of benefits to the entity itself, Brennan and Buchanan show that if $\alpha$ can in some way be positively related to $R$, the maximization of $Y_{k}$ may not involve the minimization of $\alpha$. An above zero $\alpha$ may, therefore, be the case if, by supplying $G$, total tax revenues increase in such a way that $Y_{k}$ can also be sufficiently increased. This situation can arise if the tax base and tax rate are variable and broad enough to

24 The brief description of the model and following statements are based on Brennan and Buchanan $(1980$, chapters 3 and 7$)$.

${ }^{25}$ By viewing taxation within a constitutional context, efficient tax arrangements (choosen by those who do not know their own position) are defined as those that would emerge from agreement at a constitutional state of deliberation. This need not satisfy the criteria for efficient taxation in "orthodox" fiscal theory, where a lump sum tax would be the benchmark for an efficient revenue raising tax (see Brennan and Buchanan, 1980, footnote 3, chapter 3, p. 211). 
finance the provision of the public good and have a strong complementary relationship with thiss good. Brennan and Buchanan clarify their statements with an example of the provision of a highway or public road. It is supposed that the public good ( $\mathrm{C}$ in the model described above) in question is a road network. Assuming the utility maximizing entity to be a maximizer of the share of tax revenues and benefits to the entity itself, the question is how the rational taxpayer-beneficiary may at the same time ensure that a sufficient share of the revenues collected will also be devoted to the financing of the public good, i.e. to the road network he or she values. The rational taxpayer-beneficiary will select (at a constitutional stage) an enforcement mechanism to be built into the structure of tax raising. In this example, such a mechanism can be a general constitutional requirement that roads be financed exclusively by taxes levied on automobiles or perhaps on privately purchased road-inputs as gasoline, oill and tires (p. 144). By using a tax base (automobiles and/or road inputs) which has a strong complementary relationship with the public good in question (a road network), the utility maximizing entity can raise (additional) revenues by providing the public good. The mechanism in this way ensures that the revenues raised by the utility maximizing entity are primarily spent on the provision of the public good desired. ${ }^{26}$ It follows that if the public good in question offers the possibility to tie in the consumption of other private goods (in the example above, for instance, such private goods as gasoline, oil etc.), taxation of the latter goods can also provide for a significant part of the revenues necessary to fund the public good in question.

The self-enforcing mechanism built into the fiscal constitution as presented in the example of Brennan and Buchanan above, in fact, is a particular form of earmarking, as expressed in a tax base which induces governments to utilize revenues for the spending desired. ${ }^{27}$ Earmarking in this sense is important because "voters, or their representatives, are likely to choose outcomes more rationally, more efficiently, if they can compare costs and benefits for each separate activity rather than for a multicomponent budget" (p. 152).

The association between taxation and expenditure decisions, the constitutional and institutional context into which tax policies are embedded and the importance of earmarking are also central elements in the so-called voluntary exchange approach of Wicksell. In his voluntary exchange approach theory of the public economy, Wicksell $^{28}$ assumes that each and every public activity is considered separately and is accompanied by a specific cost sharing arrangement. An activity proceeds only when a unanimous consent is reached, i.e. when the activity or government action represents an improvement for all persons as measured by the preferences of the individuals

26. A part of the tax revenues raised has to be used to cover particular costs that are associated with the imposition of taxes. They entail $i . a$. the costs of administrating and obtaining these taxes.

${ }^{27}$ See Brennan and Buchanan (1.980, p. 136 and p. 150-152).

${ }^{28}$ Wicksell $(1896,1958)$. 
themselves. Individuals reveal their preferences through general agreements. ${ }^{29} \mathrm{Ap}$ plying the voluntary exchange theory to taxation, this theory stresses that taxes and tax finance expenditures should be linked, i.e. taxes and the use of tax revenues for certain expenditures should be looked at simultaneously. Based on the principle of voluntary consent, the voluntary exchange approach theory is concerned with taxes which find the agreement of those confronted with the tax. From an economic point of view, these taxes are to be preferred because they minimize the excess burden of the tax in question. By emphasizing the association of taxes and tax finance expenditures, the voluntary exchange approach theory also stresses the importance of earmarked taxes.

Building on the voluntary exchange approach of Wicksell, Backhaus (1992, p. 15) states that "[C]onsensual political decisions can be taken by a fraction of the entire population, and the administration in power can secure political profit by serving as an entrepreneur and organizer of a club-like arrangement through which, on the basis of voluntary exchange, a public good or service may be provided". The previous considerations on taxation agreement, and taxation within a constitutional setting are in this sense related to club-like arrangements in which members pay a member fee in order to enjoy the benefits of the club good or public good in question. Within this context, for example, if the environmental quality in a particular region can be considered a local public good, ecological taxation could be embedded into a governmental and/or club-like arrangement in which those who benefit from the tax policies of the responsible authority not only pay but also have a say in the policies of this authority. Possibilities and problems of these kinds of arrangements with regard to ecological taxation are further discussed in section 4.4.

\subsection{Ecological tax units}

In the following, the basic elements of the previously described theories are used to analyze within which institutional context or arrangement, on which level and by which taxing authority, ecological taxes could best be imposed in order to be ecologically effective, feasible and acceptable in practice. The analysis starts from the assumption that particular environmental problems, ecological circumstances and/or elements thereof (e.g. the related environmental quality) can be considered public goods, i.e. goods which are neither strictly private nor strictly collective. ${ }^{30}$ According

${ }^{29}$ Brennan and Buchanan (1980, p. 6-8),

30 Although environmental problems, ecological circumstances and/or elements thereof are considered as public goods in this chapter, it has to be taken into consideration that generally such problems and circumstances can also have collective good characteristics. This is especially the case if environmental problems are viewed in the context of future generations. In such cases, intergenerational clubs also have to be considered as possible institutional arrangements for ecological taxation (see e.g. Cornes and Sandler, 1986). 
to the theory of fiscal federalism, for each good or service in question, in an ideal case, there is a decision making unit of which the range is determined and defined over the consumption of the good or service in question. According to Tiebout, consumer-voters, under strict conditions (see above), choose to be part of that decision making unit of which the expenditures-revenues package 'offered' by this unit accords with their preferences. In this sense, a particular decision making unit consists of one or more consumer-voters who have the same preferences and who share in the benefits of the particular good or service provided by this unit. Following Buchanan, such a voluntary sharing arrangement can be considered a club. With the option of voting with their feet, consumer-voters or members of the club are always free to leave the club. If there are no externalities and thus only club members can benefit from the public good, the decision making unit can also exclude those who are not part of the sharing arrangement. In case there are several clubs, the range for each club has to be clearly defined and different 'club zones' have to be determined. Once part of a club, consumer-voters, by voluntarily paying a member fee, also share in the costs of producing or providing the club good. The payment of these fees by members of club-like arrangements can be related to the theories on taxation as presented by Wicksell and Brennan and Buchanan. A central feature of both theories is the close connection between taxes, the supply of relevant provisions and the consent of those who are confronted with these taxes. As argued by Wicksell, the latter requires a particular constitutional arrangement in which the members of a particular group or their representatives decide whether or not they want to contribute to the provision of the good in question.

From an ecological point of view, the previous considerations imply that, in an ideal case, ecological taxes are imposed by an authority, decision making unit or tax unit (political or tax unit) that has executive powers over a range that corresponds with the range of relevant ecological problems, circumstances or elements thereof (ecological unit). Such ideal cases can then be referred to as ecological tax units or E.T.U.. They represent institutional arrangements which create a direct connection of taxes of particular levels of government to relevant ecological systems. The importance of the latter kind of arrangements is also stressed by fiscal federalism theory. According to this theory, each provision (e.g. a particular environmental quality of eco-systems) should ideally be tied to that jurisdiction of which the spatial range corresponds with the actual use by citizens and others. In terms of the afore mentioned theories, the central features of ecological tax units include the following:

1) There is a political unit of which the range corresponds with an ecological unit, i.e. there is a unit which is constituted on the basis of relevant ecological
circumstances.

2) The political unit has the authority to impose taxes.

Ecological tax units represent the idea of club-like functional purpose arrange-
ments. 
4) Relevant actors can voluntarily decide whether or not to join the club-like arrangement (e.g. via voting with their feet).

5) When joining the club-like arrangement, members agree to pay a club-like fee. The fee is necessary in order to achieve a preset target.

6) The fees or 'taxes' are set by representatives who are chosen by those who join the club-like arrangement on the basis that there is a close relationship between those who pay the taxes, have a say in and benefit from the policies conducted by these representatives.

The latter feature, which is usually not explicitly treated within the theories on fiscal federalism, local expenditures and clubs, (partly) incorporates several of the suggestions of Wicksell (1896) and Brennan and Buchanan (1980, 1985). Being functional instead of general purpose units, the main advantage of ecological tax units is the related simplicity of policy making. Policy makers can direct all their policies towards one goal, for instance maintaining a particular environmental quality in a specific ecological system. Possible problems and inefficiencies associated with general purpose policy making can therefore be avoided. In comparison to general purpose decision making units, the members of functional units can more easily obtain the information necessary to evaluate and compare the performances of these units to those of other (functional) units. In comparison to units which are not constituted on the basis of ecological circumstances, the main advantage of ecological tax units is the optimal use of available information. This information is crucial in setting the proper tax rates and thus in setting taxes which are effective from an ecological point of view. In setting taxes which are also acceptable to relevant actors, an additional advantage of ecological tax units is the close relationship between those who impose, benefit from and pay for the taxes of the E.T.U. Furthermore, being club-like and competitive arrangements which can voluntarily be joined or left by relevant actors, ecological tax units also induce the creation of arrangements which correspond with existing preferences on the provision of particular goods or services. Since they are both functional and competitive, ecological tax units also have an incentive to provide goods and services in an efficient and least cost manner. The incentive is provided by the fact that, since they are functional, ecological tax units can specialize in the provision of the good in question.

Central to the concept of ecological tax units is the fact that they are functional decision making units. This means that they are functional as regards the ecological system on the basis of which they are constituted. Water authorities in the Netherlands are examples of such functional decision making units. These authorities control the quality and/or quantity of regional surface waters in this country. Their jurisdictions are determined on the basis of the regional aquatic eco-system in question. There are over a hundred of these functional water authorities in this country, which differ from general purpose decision making units (such as municipalities, provinces etc.) only in the sense that they have one particular task, i.e. controlling the quality and/or quantity of regional surface waters. In this sense, there are general purpose 
units which handle and make choices between different policy issues, while there are functional units which handle a single policy issue, i.e. a particular ecological issue. The formulation of policies on the basis of purely ecological issues is a central aspect of the ecological concerns approaches of ecological taxation.

For ecological tax units to function properly, it is important that they are constituted on the basis of the eco-system in question. This in order to prevent or minimize on possible ecological and other (e.g. economic) leakages. The minimization of these leakages is important in order to prevent externalities and thus possible interactions between the (effects of the) policies of ecological tax units and those of other (e.g. general purpose) units and vice versa. Such interactions can have particular effects in the sense that certain policy measures from different decision making units may counteract or reinforce each other. It thus follows that a proper constitution means that all relevant benefits and costs associated with the introduction of an ecological tax unit are taken into consideration. To assess these benefits and costs it is important that ecological tax units, besides being constituted on the basis of the ecosystem in question, are also constituted on the basis of the interests and the consent of all relevant parties, with an explicit recognition of all of the functions that are fulfilled by the eco-system in question.

The concept of ecological tax units as presented above (partly) corresponds with the idea of functional overlapping and competing jurisdictions (FOCl's) as discussed by Frey and Eichenberger (1994). More specifically, FOCI's are displayed (p. 2) as political units which extend over regions defined by the tasks to be fulfilled. The units are assumed to have enforcement power and can raise taxes. Since there are numerous tasks or functions to be fulfilled, this implies many different governmental units which extend over different geographical regions. It is assumed that individuals and/or communes may choose to what governmental unit they want to belong. Via initiatives and referenda these individuals and communes can also express their preferences.

A central aspect of the idea of FOCl's is the idea that jurisdictions should emerge in response to the geography of the function, task or problem in question (p. 3). FOCl's, in other words, emerge in response to the demand by individuals or communes (p. 5). ${ }^{31}$ Another central aspect is the possibility for individuals to vote (p. 4). The idea of FOCl's therefore explicitly emphasizes the political supply process. In this sense, the idea of FOCl's differs from fiscal federalism theory in which decision making processes within functional decision making units are not explicitly analyzed. The idea of FOCI's also differs from Tiebout's theory of local expenditures and the related concept of "voting with the feet", because the "political jurisdictions are

3ithin the context of the central subject of this chapter, only eco-systems and their particular problems and functions are relevant. In this sense, this study does not state that for each separate issue there should be a separate functional decision making unit. If that were the case, the interaction between separate issues and conducted policies should explicitly be taken into consideration. Within the context of the central subject of this study, however, only functional ecological units matter. 
exogenously given, are multi-purpose, do not overlap, and the political supply process is unspecified" (p. 4). Buchanan's theory of clubs is similar to the idea of FOCl's in the sense that the size of the club is endogenously determined by the benefits and cost of the club members. The idea of FOCI's, however, differs from the theory of clubs in the sense that clubs do not have jurisdictional power as FOCI's do and in the sense that the theory of clubs does not explicitly pay attention to the political decision making process. FOCI's also differ from clubs in the sense that clubs are purely voluntary while FOCI's not necessarily are (p. 8).

Since existing political units are usually general purpose units which perform duties with regard to many functions, these units are not designed to minimize functional spillovers and to maximally exploit economies of scale with respect to particular functions, which is the central goal of FOCl's (p. 5). According to Frey and Eichenberger ( $p .6$ ), the possibilities of the members of FOCI's to exit totally or partially from the jurisdictions in question and their possibility to vote the managers of FOCI's will serve as two important mechanisms by which these managers can be induced to conform as well as possible to their members' preferences. The latter kind of competition is necessary to induce governmental units or jurisdictions to act efficiently and can be achieved via a process in which citizens directly elect the persons managing the FOCl's and/or have a right to initiate referenda on specific issues (p. 7).

As one of the main disadvantages of a federal system of FOCI's, Frey and Eichenberger ( $p .13 \mathrm{ff}$ ) indicate that once jurisdictions are differentiated on the basis of functions, each individual will be a citizen of various jurisdictions. The individual will correspondingly be involved in different elections and referenda and might possibly be overburdened and respond by political abstinence. Whether this is also the case for the economic actors that are part of particular ecological tax units, depends i.a. on the factors which influence their participation to vote. Generally, participation depends on the influence a voter expects to have on the outcome. This expectation, in its turn, depends on the number of voters and the number of dimensions to be voted upon. It can generally be stated that, ceteris paribus, the smaller the number of voters and dimensions to be voted upon, the higher is the influence a voter expects to have on the outcome. Since ecological tax units are decision making units that are functional with regard to only specific ecological circumstances, the number of dimensions to be voted upon can generally be regarded as very small. In fact, if the specific function for which the ecological tax unit is constituted is the sole aspect to be voted upon, there is only one dimension. Within the context of ecological tax units, the number of voters depends mainly on whether citizens or particular representative bodies can vote on the specific dimension(s) of the ecological tax unit in question. With regard to large ecological systems (e.g. the river Rhine, see section 4.5), it can be expected that it is not the citizens themselves but the cities, provinces, water boards etc. of which they are part of, who can vote upon the issue(s) involved. In this sense, depending on the particularities and the size of the ecological system in question, the number of voters can be a restricted set of specific decision making authorities, which each have their own interest in maintaining a particular function of the 
ecological system in question. In the specific case of the river Rhine, for instance, each separate city, water district etc. along the river has a certain interest in maintaining (either) the ecological, shipping, recreational or other functions of the river. Each of these decision making bodies therefore has an interest in actually participating in the votings involved.

\subsection{The river Rhine: possibilities for the application of the idea of ecological tax units}

The central elements of the idea of ecological tax units can be briefly described by way of an example. The example represents the situation in which the environmental quality of a particular watershed can be controlled in various ways and on various levels. The river Rhine constitutes a clear example. Extending through different countries in Europe, the river is an ecological unit for which there is no corresponding organizational unit, i.e. a decision making unit which has a maximum overlap with the ecological unit. With the assumption that an efficient and sustainable management of the river can be considered desirable, within the context described above, the environmental control of the watershed could best be placed in the hands of an agency that has the authority to control and enforce particular policies over the range of this watershed. Depending on the possibilities and problems of establishing such an agency, given particular institutional and constitutional structures, different situations can arise. Among others, they include arrangements in which each separate jurisdiction or country decides on policy measures for the control of (part of) the environmental quality of the watershed. They also include arrangements in which several or all jurisdictions, by way of interjurisdictional co-operation arrangements agree, to coordinate their environmental control policies. In addition, they consist of an arrangement in which the jurisdictions in question or a relevant supra-national authority decide(s) on establishing an agency or arrangement responsible for the environmental quality of the watershed in question. When possible, jurisdictions can agree to grant this agency or arrangement the power to tax and enforce.

In the particular case that individual jurisdictions opt for unilateral policy controls, the level and instrument of control can vary per jurisdiction. Moreover, it is conceivable that particular countries (e.g. those located upstream) do not take any or just a restricted set of control measures. Consequently, economic and ecological leakages and inefficiencies can arise. Since watersheds are characterized by complicated aquatic relationships, controlling only part of the system is ineffective since particular relevant elements of the whole chain of elements which ultimately determine the environmental quality of the system are left unconsidered. Moreover, since separate jurisdictions can only ineffectively control the environmental quality of the watershed and unilateral actions carry the risk of economic leakages, jurisdictions can be induced to only take policy actions when other jurisdictions also take corresponding measures. 
Despite the fact that there is a high probability that unilateral policy actions will be accompanied by ecological and economic leakages, separate jurisdictions can still play an important role in the control of environmental problems which do not encompass the level of their jurisdictions. First, separate countries can play an important role in the implementation of surveyable environmental control policies. Surveyability is especially relevant for the practical feasibility of environmental policy instruments and can also fulfil a pioneering and experimenting function for the imposition of ecological taxes by higher or other levels of decision making. Second, the unilateral introduction of particular control measures can play an important intermediate role in the dynamic process of finding and creating a proper level of policy making, i.e. One that has a maximum overlap with the ecological unit in question. Third, separate jurisdictions can play an important role in the creation of interjurisdictional co-operation arrangements and thus in the creation of agreement and co-ordination of jurisdictional environmental policies.

The economic leakages between different jurisdictions, in case these decide to co-ordinate their environmental policies, will considerably be lower than in the case that jurisdictions decide to unilaterally introduce particular policies. These leakages can be minimized especially when co-ordination and agreement among jurisdictions results in the creation of interjurisdictional co-operative arrangements. Such arrangements can eventually result in the establishment of a particular interjurisdictional administrative body that is responsible for the environmental quality of the watershed. The establishment of such a body, however, strongly depends on the costs of bargaining and negotiation among separate jurisdictions. Moreover, difficulties can arise with the determination of the ruling relationships between jurisdictions themselves and the interjurisdictional administrative body and with regard to the proper revenues and expenditures of this body, the corresponding contributions by jurisdictions and possible compensation schemes. When these costs and difficulties are relatively low in comparison to the level of environmental quality which can be gained by co-operative and co-ordinated policies, there is room for negotiations on the establishment of an ecological tax unit. Although, in terms of a minimization of ecological and economic leakages, ecological tax units seem the most desirable institutional arrangements for ecological units, what is required to actually introduce these administrative bodies, is a constitutional framework which allows these units to be created. Establishing such a framework, however is difficult, costly and time consuming. It requires among others a proper definition and attribution of property rights, the creation of possibilities for jurisdictions to introduce functional and interjurisdictional administrative bodies and an associated process of negotiations, decision making processes and use and application of environmental diplomacy.

To conduct an analysis of the possibilities and problems of establishing ecological units, Backhaus (1994) suggests an approach that is based on constitutional environmental economics. The approach consists of the following analytical steps:

1) Defining the function of the ecological unit in question. 
2) Defining and describing the ecological and organizational unit which can best fullil this function.

3) Finding a legal counterpart to the organizational unit defined in this way.

According to Backhaus, the (constitutional) principle of subsidiarity, i.e. the principle that requires, whatever the purpose of a policy, that it be carried out within that context which is the smallest viable one in which the objective can successfully be attained, can be used to determine the organizational structure which can be built around the ecological unit in question.

Applying his approach to the river Rhine, a Rhine authority is shown to be a possible organizational unit for an efficient and sustainable management of the river. This authority is presented as a large independent body, which can be enjoined by all entities (including provinces, cities, water districts etc.) that enjoy riperian rights to the water resource. In the example, the authority is enjoined by these entities because current relevant states are not the proper constituting elements of such a Rhine authority. Under the current system of property rights, which treats the river as a common pool resource, the number of users is restricted only as far as water intake and discharges are concerned and unrestricted but strongly regulated as far as shipping and recreational use is concerned. Since there are different competing functions of the river, including an ecological and recreational function and the functioning of the river as an important waterway, a source of drinking water and a receptical of waste water, it is argued that, since there is no proper organizational unit, the river is subject to abuse, overuse and underutilization. By establishing a Rhine authority, the river can be made a restricted common resource, with the authority optimizing the different uses of the resource. To construct such an authority, however requires the presence of a constellation of interests among affected parties. According to Backhaus, both upstream and downstream cities can have an interest in joining an associative Rhine authority. Upstream cities need the river for commercial navigation, while downstream cities are interested in an increase in the quality of the water received and in maintaining commercial navigation on the river if the harbor belongs to its most important assets. At the end of section 4.3 .3 of this study, it was indicated that this interest is also an important element in the decision of these cities to participate in votings on the relevant dimensions of the ecological tax unit.

Increased possibilities for achieving constellation can be created by accompanying the establishment of a functional decision making authority by particular liability systems for those cases in which certain standards on discharges cannot be met. In addition, since this authority is a functional decision making unit, no separate sources of revenue other than those directly related to the decision making on resource use seem necessary. In this sense, revenues can be raised via charges on water intake and discharge and via charges for the purification of water, traffic surveillance, commercial and recreational shipping etc. As emphasized in section 4.3 .3 of this study, if a public goods offers the possibility to tie in the consumption of private goods, taxation 
of the latter goods can also provide for a significant part of the revenues necessary to fund the public good in question.

Within the context of the Rhine Action Programme 2000, which has the purpose of making the eco-system of the Rhine sustainable by the year 2000, the relevant states at this particular moment in time, have achieved considerable progress in meeting particular preset reduction standards. Diffuse discharges $e . g$. from agriculture, however, still present a problem. In this sense, relevant states located near the Rhine now opt for a broad ecological approach, to be formally laid down in a renewed Rhine Agreement. ${ }^{32}$ A central element of this approach is the concept of total ecology, which expresses that policies with regard to the river should include the entire eco-system and e.g. not only the quality of the water. The International Rhine Protection Commission has made the application of this concept in practice as one of its main purposes. The concept of total ecology as expressed in terms of the aquatic ecosystem strongly reflects one of the basic elements of ecological tax units and thus can serve as a starting point for negotiations on the actual introduction of such units. Section 4.6 describes the conditions under which such negotiations can be successful.

\subsection{From current political units to ecological tax units?}

The creation of a Rhine authority in practice, or any ecological tax unit in that matter, is intricate, especially within an international context when for instance watersheds encompass jurisdictions in different nations (e.g. the river Rhine, the river Meuse, the Lake of Geneva or the Lake of Konstanz). The intricacies that arise are mainly related to the fact that the greater part of existing taxing authorities tend to be political units, which do most of the times not fit the description of being clearly related to revelant ecological circumstances. Mostly, these political units also tend to be general purpose instead of functional units. If existing taxing authorities do not correspond or just partly coincide with the range of ecological systems, inefficiencies may arise. To be able to impose and use taxes (in)directly for the control of disturbances to ecological systems, taxing authorities need information, among others on the working and characteristics of the eco-systems in question, on particular disturbances to the systems, on the relationships between taxes, these activities and disturbances and on behavioural reactions to the taxes imposed. If the boundaries of existing tax units do not or just partly coincide with the boundaries of the relevant ecological unit, the feedback system looses some of the information required to impose the tax regime necessary to sustain a particular level of environmental quality. This has important consequences for the ecological effectiveness of ecological taxes and for their support, acceptability and feasibility. The possible disadvantages resulting from the imposition of ecological taxes by political units, which do not or just partly coincide with the boundaries of relevant eco-systems, should then be weighed against their possible advantages. The

${ }^{32}$ Staatscourant (1994, December 9, nr. 238). 
imposition of ecological taxes by other than ecological tax units (e.g. political units or separate national and/or sub national jurisdictions or arrangements), can be advantageous if ecological tax units experience high pressures from interest groups which force these authorities to impose particular taxes in exchange for support or if ecological tax units can shift part of their (environmental) problems to other regions or nations.

In each case, choices consist of those between existing political, general purpose structures and functional ecological tax unit structures. Such choices are a principal element of constitutional political economy, in which the central issue is to understand the workings of alternative political institutions so that choices among institutions (or structures of rules) can be more fully informed (Brennan and Buchanan; 1985 , p. xi). Constitutional changes are called for when a constitution better than the status quo one can be obtained at costs less than benefits (Mueller, 1990, p. 182). In a Wicksellian sense, such changes involve the (near) unanimous consent of the actors involved. A simple example can be used to illustrate the main ideas and the importance of choices that are made on the basis of (near) unanimous consent. The example is that of a proposal for the introduction of a garbage collection service in a city in which such a service is not yet offered but considered desirable. Suppose that at a city meeting, a citizen or his/her representative proposes a program to introduce a garbage collection service. The introduction of such a service, for instance, consists of buying a garbage truck, hiring the workers who collect the waste etc. In a Wicksellian sense, also a proposal for a scheme of taxes with which the program can be financed, has to be formulated. An example of such a tax scheme is, for instance, one in which each producer of waste (e.g. a household or a company) pays a fraction of the costs. In this sense, if the costs of the program are $\mathrm{X}$ and the number of waste producers $\mathrm{Y}$, each producer of waste pays fraction $\mathrm{X} / \mathrm{Y}$ of the costs. For those who produce a relatively low (high) amount of waste, the costs, as expressed in terms of the amount of taxes to be paid, are relatively high (low) in comparison to the benefits. Consequently, if the proposal would be submitted for vote to the citizens or their representatives, no uninamous consent could be expected to result. Consent and consensus then have to be build on the basis of further discussions, compromises and adjustments of the original proposals. Building on these discussions, an alternative tax scheme can be formulated. Such a proposal could, for instance, consist of a scheme in which taxes are paid in proportion to the amount of waste supplied. Since the benefits to all waste producers can be expected to exceed their costs, the proposal can also be expected to pass unanimously.

Unamity and consensus building such as in the previous simple example is difficult however in those cases in which the boundaries of existing political units are inconsistent with the boundaries of ecological units. ${ }^{33}$ Several intricacies can be shown by way of an example in which separate countries, sub national governments

${ }^{33}$ For an illustration of these difficulties with regard to the introduction of carbon and energy taxes, see Paulus (1994d). 
and water districts border a body of water. Suppose now that one of the sub national government bodies in question suggests a program by which the environmental quality of the body of water can be made sustainable. In addition, assume that this government body also pursues and employs strategies to build consensus ${ }^{34}$ and accompanies the suggested program by a relevant tax proposal. Several intricacies arise. First, the sub national government in question can only suggest the program and employ particular strategies to build consensus if this is allowed by the ruling administrative relationships in the country of which the sub national government is part of. Second, even if there are no intricacies as regards ruling administrative relationships, there generally is no transjurisdictional taxing authority by which the suggested taxes can be imposed on the jurisdictions in question and by which the associated tax revenues can be collected. Hoel $(1992$, p. $102 \mathrm{ff})$ indicates several other problems of multilateral tax systems. First, the unfamiliarity to policy makers of a multilaterally imposed tax which is administered by an interjurisdictional agency. Second, the difficulties that are related to agreeing on how total emissions of polluting substances should develop over time and how tax rates should be determined and readjusted accordingly. Third, the difficulties that arise on agreeing on reimbursement rules, i.e. on how the costs of emissions reductions and the net taxes between participating jurisdictions should be determined and divided. Reimbursement rules have to be such that jurisdictions voluntarily agree to join the arrangement. Fourth, for any jurisdiction that is part of the arrangement, it can be of interest to give distorted information on its emissions in order to prevent high tax payments. Given these general intricacies, consensus building in these cases first involves agreeing on bringing about institutional changes. Once these instutional changes are practicable, consensus building then involves a process of adjusting and building consensus on different proposals, until a proposal for constitutional change can be formulated from which all can benefit. In this particular case, the suggested constitutional change entails the establishment of an ecological tax unit structure, which is agreeable to all relevant actors.

When consensus building fails in one or both phases, separate jurisdictions can try to 'force' other jurisdictions to co-operate. Referring to an example in which several nations border a body of water, Baumol and Oates (p. 276-277) show that, in case there is no unanimous consent among the different countries on setting environmental standards with regard to this body of water, transnational resource charges (or pollution tariffs) can be imposed on the exports of polluting countries. In this sense, transnational resource charges can be part of a strategy in which one country threatens to undertake price-influencing measures that would be damaging to other countries in order to force these countries to adopt a more environmentally friendly

${ }^{34}$ For a more detailed discussion of such strategies, see e.g. WRR (1992, p. 9 and pp. 165-175) in which a process of purposeful environmental diplomacy is considered an important element of strategies that aim at introducing environmental policy instruments at levels that minimize ecological and economic leakages. 
behaviour (p. 276). Especially if polluting countries are confronted with these charges for many of their products and in many of their markets, they will be induced to take environmental protection measures. This is because these measures will ceteris paribus increase their sales.

Although Baumol and Oates recognize that one has to be careful in introducing restrictive trade measures under the heading of environmental protection, they state that "...the threat of such measures may help to facilitate the process of direct negotiation and may lead to cooperative steps that will be effective in controlling transnational pollution" (p. 277). ${ }^{35}$ From this it follows that transnational resource and pollution charges present an interesting policy option in those cases in which it is difficult to achieve consensus among affected parties. In practice, the use of these charges, however, is restricted because of the fact that they are generally inconsistent with existing institutional rules and structures (e.g. GATT/WTO-agreements). Given these difficulties, the authors conclude that ".....feasible and effective mechanisms for the control of transnational pollution will require cooperation and cost-sharing on the part of the victim nations as well as polluting countries" (p. 283).

From the previous considerations it can be concluded that constitutional changes, such as those from status quo structures to ecological tax unit structures, entail structural changes. For such changes to be successful, severable favorable conditions under which unanimity decision rules can be expected to operate have to be present. According to Mueller (1989, p. 105 ff.), these favorable conditions include situations in which the nature of the game is that of a co-operative, positive sum game, in which the nature of the issues involves allocative efficiency improvements from which all can benefit. These conditions also include a method of forming a committee (e.g. a committee of representatives) which is voluntary and in which individuals of common interests and like preferences can join and propose the choice of issues.

The following checklist shows the practical problems to be solved and the decisions to be taken in order to decide on and arrive at a successful imposition of ecological taxes under the ecological concerns approach in practice. The primary purpose of the checklist is to show the main intricacies of institutional and constutional changes in relation to ecological taxation. The questions mentioned in the checklist are related to the proposal for constitutional change and the institutional structures which allow such a proposal to be made (questions 1-9), the decisions to accept or reject this proposal (questions 10-19) and the issues that are relevant at the constitutional stage (questions 20-21).

${ }^{35}$ The use of transnational resource and pollution charges has to be carefully considered within the context of the General Agreement on Tariffs and Trade (GATT-agreement) and WTO. Under the ruling GATT-agreement, environmental charges can be imposed on products from 'environmentally unfriendly" countries only if it can be demonstrated that these products entail clear health risks. 
Checklist

\section{A. Institutional structure for the proposal of constitutional changes}

1) Does an institutional structure exist, which allows constitutional changes to be proposed by relevant actors? (If not continue with 2 , if so continue with 3 ).

2) Do the costs of creating an institutional structure and a committee which is voluntary and in which individuals of common interests and like preferences can join and can propose the choice of issues (i.e. constitutional change) outweigh their benefits? (if not continue with 3 , if so maintain status quo structure).

\section{B. Proposal for constitutional changes}

3) What are the ecologically relevant particularities of the ecological unit in question?

4) Which functions are fulfilled by the ecological unit?

5) To which degree are these functions mutually competitive?

6) Is it possible to detect an organizational unit which is closely related to the relevant ecological circumstances or ecological unit?

7) In case there is no such organizational unit, what is the existing arrangement of property rights?

8) Given the existing arrangement of property rights, what are the effects of the absence of an organizational unit which is closely related to the ecological unit?

9) Is it possible to re-define existing property rights in such a way that all relevant externalities can be internalized? (if so, suggest the proposal and continue with 10 , if not maintain status quo).

\section{Decision to accept or reject the proposal for constitutional change}

10) What are the proper sources of revenues for the relevant organizational unit (including the possibilities to tie in the consumption of private goods)? 
11) Are relevant parties willing to join an associative organizational unit, body and/or authority, i.e. is the nature of the game that of a co-operative positive sum game, in which the nature of issues involves allocative efficiency improvement from which all can benefit? (if not continue with 12 , if so continue with 13).

12) In order to build consensus, do the costs of re-formulating and re-adjusting the (original) proposal for constitutional change outweigh their benefits? (if $\mathrm{so}^{\text {, }}$ continue with 13 , if not maintain status quo structure).

13) Is the organizational unit a decision making unit that is able to weigh policy options in the light of available resources, that are all related to the ecological unit in question?

14) Does the organizational unit have tax raising authorities?

15) Is all the information necessary for the imposition of ecologically effective environmental taxes available to decision making authorities?

16) Can ecological and economic leakages be minimized?

17) Can actors voluntarily agree to join an associative organizational unit?

18) Does there exist a legal counterpart to the organizational unit defined in the previous steps?

19) Can the suggested constitutional change be obtained at costs less than benefits? (if so continue with 20 , if not maintain status quo structure).

\section{Constitutional stage: the formulation of the blueprint of ecological tax units}

20) Is there an enforcement mechanism which ensures that the tax revenues that are collected are devoted to the financing of those goods and services that are valued by potential taxpayers-beneficiaries, i.e. is there a particular form of earmarking?

21) Is there a clear connection between those who pay the relevant taxes, have a say in and benefit from the policies conducted by the decision making unit?

It follows from the checklist that if the answers to the formulated questions are such that the proposal is accepted, the outcome is a process of constitutional change. 
This process will result in an organizational structure for ecological taxation which reflects the elements of the concept of ecological tax units described in this chapter. As previously indicated, this concept is a central element of the ecological concerns approaches of ecological taxation.

\subsection{Conclusions}

It follows from the ecological tax unit approach of ecological taxation, that for the feasibility, ecological effectiveness and acceptability of taxes that are used for ecollogical purposes, it is important that they are embedded within a process of institutional and constitutional change. This process is necessary to create institutional arrangements which allow a connection of taxes and levies in particular and fiscal systems in general to relevant ecological circumstances. Depending on the particular type of ecological tax in question, ecological taxes can, from a theoretical point of view, best be imposed by an authority and/or government level which is clearly related to relevant ecological circumstances, problems or elements thereof. For this structure to be feasible, regions have to be constituted on the basis of strict ecological relationships, whille decision making arrangements and fiscal structures have to be based on citizen's and other's preferences for the provision of that good in the particular region in question. The latter implies that especially levies that contain an element of earmarking are relevant to be used for particular ecological purposes. The benefits in terms of a possible higher support for and acceptability of these types of taxes should however always be weighed against their costs in terms of limited application possibilities and possible inefficiencies.

Since generally, the boundaries of existing jurisdictions do not coincide with the boundaries of existing ecological circumstances, the establishment of ecological tax unit structures requires a process of constitutional change. The checklist formulated in section 4.6 of this chapter shows the practical problems to be solved and the decisions that have to be taken in order to decide whether or not to actually make such changes. It can generally be concluded from the analysis in this chapter that the imposition of ecological taxes in close relationship to relevant ecological circumstances is a very intricate matter. In order to arrive at a succesful imposition in practice, it requires an approach of ecological taxation which is more radical than the gradual strategies suggested in the double dividend approaches. 


\section{From Theory to Practice: an Analytical Framework}

\subsection{Introduction}

Since institutional, fiscal, environmental policy and other relevant structures for ecological taxation differ per country and per group of countries, the actual feasibility of this type of taxation can only be determined on the basis of a case by case approach. To determine and analyze the feasibility of ecological taxation in the Netherlands, which is the main purpose of the remaining part of this study, a framework has to be formulated by which it is possible to make an application of the theoretical considerations presented in previous chapters to the actual and intended use of taxes in this country. The formulation of such an analytical framework is the main purpose of this chapter. A central element of this framework is the development of ecological taxation. By analyzing ecological taxation in terms of a development process, several elements of the double dividend and the ecological concerns approaches of this type of taxation can be combined. This framework can then be used to conduct an analysis of the feasibility of ecological taxation in the Netherlands. After the introduction (section 5.1), several central features of the double dividend and ecological concerns approaches of ecological taxation are discussed and compared in section 5.2. These elements are mainly derived from the discussions of both approaches in the previous chapters of this study but also include new elements that arise from studies such as $\operatorname{OECD}(1993 \mathrm{a}, \mathrm{b})$. An analytical framework which incorporates these elements and which expresses the development of ecological taxation is described in section 5.3. The possibilities to use this framework for an analysis of the feasibility of ecological taxation in the Netherlands are further considered in section 5.4. The chapter ends with several conclusions and remarks.

\subsection{Different approaches of ecological taxation}

In the previous chapters of this study, it was argued that the feasibility of different types of ecological taxes is determined i.a. by their ecological effectiveness, the acceptability to those who are confronted with them (both tax payers and policy makers) and the availability of relevant pieces of information to taxing authorities. It was also argued that the ecological effectiveness, acceptability and feasibility of different types of ecological taxes depends among others on the design and the imposition of these taxes and the institutional, fiscal and constitutional structures into which they are embedded. The main features of the design, imposition and relevant accommodating structures for taxes that are set under a double dividend approach, however, likely differ from those that are set under an ecological concerns approach. Before the 
main differences between these two approaches and the implications of these differences for the feasibility of ecological taxation are further discussed, first the main issues which generally determine the feasibility of this type of taxation (i.e. irrespective of the approach taken), are further delineated.

\section{Feasibility: general issues}

In order to be ecologically effective, acceptable and feasible, it was argued in the previous chapters that the tax base of ecological taxes should be closely related to the purpose of the tax. In addition, the tax base should be determined on the basis of the possibilities to link the tax point, the point of pollution and a relevant point of choice. In this sense, taxes should be linked to the moment of decision, i.e. the moment or point at which relevant actors choose between environmental friendly and unfriendly activities. The importance of this link is further discussed below in relation to the ecological concerns approaches of ecological taxation. Preferably, tax bases are clearly related to the aim of the tax. For Pigouvian taxes, this implies a close connection between the tax base and relevant tax avoiding changes in behaviour. For revenue raising taxes, this implies the choice of a tax base, on the basis of which a desired amount of tax revenues can be raised. The latter implies the use of relatively inelastic and/or broad tax bases. Acceptability by those who are confronted with the tax slightly favours the use of broad tax bases. For ecological taxes of the earmarked type, tax bases should be closely connected to a relevant ecological service and to the desired amount of tax revenues.

Depending on the purpose of the tax, it can next be decided whether taxes have to be imposed on emissions or on inputs, throughputs, outputs or effects. The difficulties associated with defining, finding and/or measuring a proper tax base will in turn determine that what should be taxed. The choice of a particular tax base depends, among others, on the intricacies of the pollution problem(s) in question, the possibility to relate taxes to quantities, the manner in which the relationship between the tax base and pollution is affected by production technologies, the possibility to discourage pollution emissions from production processes via different types of taxes and the manner in which emission costs are affected by their location, concentration and their aggregate level (OECD, 1993a, pp. 53-57).

Following the OECD (1993b), it can be stated that generally, emission or effluent charges are particularly appropriate when emissions can be monitored and the number of stationary sources is restricted. If polluters are able to react to financial incentives, e.g. by way of technological innovations, emission charges can be efficient when marginal abatement costs vary across polluters. Product charges are considered to be potentially appropriate for products that have environmental consequences in the phase of consumption, that are identifiable and consumed in large quantities and in diffuse patterns.

The choice of a particular tax base also depends on the costs of administration, control and enforcement of the specific tax in question. As previously shown in 
chapter 3 of this study, effluent taxes usually lack a close compatibility with existing tax systems. In this sense, these taxes can be expected to be accompanied with relatively high administrative costs. The latter include the costs of measuring and assessing emission quantities, which in their turn depend on the measurement costs per source, the number of emission sources and the scope for integration with normal commercial activities (OECD, 1993a, pp. 51 ff.).

In order to be acceptable to those who are confronted with these taxes, ecologically relevant taxes can, at least in an initial phase, be best introduced with relatively low tax rates. Relatively low tax rates will ceteris paribus be more acceptable to those who are confronted with these taxes. Since low tax rates also incorporate the danger of being relatively ineffective from an ecological point of view, tax rates should preferably be increased gradually over time. In this sense, it is to be preferred that, over a particular time span, there be variable ecological tax rates. Tax rate differentiation is to be preferred in those cases in which polluting products can be replaced by simple identifiable, readily available and less polluting substitutes (see $\mathrm{OECD}, 1993 \mathrm{~b}$ ). In terms of administrative costs, incorporation of tax rate differentiations within existing tax systems is to be preferred over the introduction of completely new ecological taxes.

In order to be acceptable to those who are confronted with ecological taxes, particular types of ecological taxes (e.g. energy taxes) can best be introduced with tax exemptions for certain groups of emitters, polluters or others. These exemptions seem especially relevant in those cases in which taxes are intended to be introduced at a level which does not coincide with relevant ecological and/or economic circumstances and thus in those cases in which particular economic and/or ecological leakages can reasonably be expected to arise. In those cases, tax exemptions can increase the acceptability and practicability of these taxes.

Generally, the imposition of ecologically relevant taxes will generate particular tax avoiding changes in behaviour in the sense that those who are confronted with these taxes:

a) Will attempt to avoid the tax by fully or partly reducing that which is taxed through adjustments in terms of time, place or specific activities.

b) Will attempt to shift the payment of that part of the tax which can not be avoided to others.

c) Will adjust their behaviour in reaction to the lower income which ceteris paribus results from paying that part of the tax which can not be avoided or shifted to others (see Hansjürgens, 1992).

Depending on the purpose of the tax in question, tax avoiding changes can be considered more desirable in case the tax has an allocational purpose and less desirable in case the tax has a fiscal purpose. The degree to which tax avoiding changes 
in behaviour are acceptable and can also actually be made by relevant actors, depends among others on the structures by which the tax is accompanied. A tax which is accompanied by a structure which provides information on possible behavioural alternatives is likely to be more succesful in this respect than one in which such a structure is absent. The feasibility of ecological taxation also generally requires these taxes to be embedded into fiscal, institutional and constitutional structures which allow or facilitate the imposition of taxes that are ecologically effective and acceptable.

\section{Double dividend and ecological concerns approaches of ecological taxation}

With regard to the structures into which ecological taxation has to be embedded in order to be feasible, double dividend approaches generally emphasize the use of existing fiscal and institutional structures. Consequently, the ecological taxes that are suggested and emphasized under this approach include those which:

a) Can have both a fiscal and ecological function.

b) Because of the fiscal function assigned to them, can give an incentive to policy makers to maintain the source of revenues (e.g. externality generating activities).

c) Are imposed by general purpose decision making units.

The strength of double dividend approaches lies in the general coherence with existing fiscal and administrative structures and the emphasis of various purposes for which ecological taxes can be used. While the former feature minimizes the costs of institutional and fiscal changes that are necessary to introduce ecological taxation, the latter feature enlarges the political attractiveness of these approaches. By introducing taxes into existing structures, the weakness of the double dividend approach, however, lies in the potential interest of policy makers to maintain the source of revenues and in the fact that taxes are designed and imposed by decision making units that are not exclusively constituted on the basis of purely ecological concerns. Both features can have particular consequences for the ecological effectiveness of ecological taxes in the sense that policy makers can be induced to maintain polluting activities and/or to impose taxes at a level at which ecological leakages can not be minimized.

With regard to the structures into which ecological taxation has to be embedded in order to be feasible, ecological concerns approaches emphasize the use of structures that are closely related to relevant ecological circumstances. As part of the ecological concerns approaches, the taxes that are suggested and emphasized under the ecological tax unit approach include those which:

a) Have a clear ecological function.

b) Are characterized by a strong relationship between those who pay, have a say and benefit from the policies of the taxing authority. 
c) Have been agreed to by tax payers at a constitutional stage.

d) Are imposed by functional decision making units that are constituted on the basis of relevant ecological circumstances.

The strength of the ecological tax unit approach lies in the establishment of incentive and administrative structures which enhance the ecological effectiveness and acceptability of ecological taxes by those who are confronted with them (i.e. tax payers and policy makers). Within the context of these structures and the fact that tax payers, at a constitutional stage, can indicate their preferred type of tax scheme and at the same time can limit the opportunities of policy makers to use the revenues for other than ecological concerns, ecological leakages can be minimized. Given the status quo fiscal and institutional structures, the weakness of the ecological concerns approaches lies in the costs that are associated with radical policy changes. The establishment of the proper structures for ecological taxation, as suggested by this approach, generally requires constitutional changes.

As part of the ecological concerns approaches, the taxes and tax elements that are suggested and emphasized under the Pigouvian tax approach, include those which:

a) Have a clear ecological function, i.e. the internalization of environmental externalities.

b) Induce the making of structural behavioural changes, e.g. with regard to the use of environmentally friendly technologies.

c) Are closely related to a point of choice, i.e. a moment of decision.

d) Via tax credits, can induce externality generators to reveal their polluting activities.

The strength of the Pigouvian tax approach lies in the possibility to directly connect taxes to a point of choice and to induce externality generators to reveal their polluting activities. The importance of the former possibility is stressed, among others, by Buchanan (1969). Within his theory of choice, Buchanan describes the direct relationship between costs and the act of choice as the essential element in the concept of costs. According to Buchanan (1969, pp. 42-43), cost is that which the decision maker sacrifies or gives up when he makes a choice. "It consists in his own evaluation of the enjoyment or utility that he anticipates having to forego as a result of selection among alternative courses of action" (p. 43). Within the context of this concept, when imposed such that they kick in at the point of choice, Pigouvian charges can make environmentally unfriendly alternatives (e.g. environmentally unsound production processes) more expensive. As previously argued in chapter 2 of this study, this makes these alternatives ceteris paribus less attractive. The weakness of this option lies in the fact that to induce such structural changes, Pigouvian charges have to be accompanied by institutional structures and taxing authorities which can provide relevant actors with information on possible alternative ways of behaviour. At the same time, the approach requires the presence of information on polluting acti- 
vities and their effects. The information is necessary to be able to set the proper tax rates. Since this information is generally difficult to obtain in practice, to induce structural changes, this approach generally requires the use of other instruments such as particular tax credits. The latter e.g. entails the inclusion in the income tax of accelaterated depreciation possibilities for investments in environmentally friendly production processes. An important attractive feature of these options, is the incentive provided to actors to reveal information on environmentally friendly production processes to taxing authorities. A weakness of this option of the Pigouvian tax approach, however, is that tax credits and tax deductions can only be provided to those who are liable for the specific tax into which the allowances are included.

It follows that double dividend and ecological concerns approaches of ecological taxation each have their own strength and weaknesses. Since they generally require institutional and constitutional changes, ecological concerns approaches commonly entail more radical ecological tax policy changes. Since policy makers may develop a clear interest in maintaining polluting activities as a source of tax revenues, double dividend approaches, on the other hand, commonly entail a development of ecological taxation which is marked by gradual policy changes. It follows that the weakness of one approach can be the strength of the other. To utilize the strength of each approach, in the following section, ecological taxation is described within the context of a development process. Distinguishing between different development dimensions, it is shown that the degree to which EC and DD approaches are relevant for the development of ecological taxation, differs per dimension.

\subsection{The development of ecological taxation}

To describe and analyze ecological taxation within the context of a development process, it is assumed that the development of this type of taxation can be expressed in terms of two dimensions. The first dimension expresses the development of ecological taxation in terms of the elements that are relevant for the design of feasible ecological taxes. These elements have been identified in chapters 2 and 3 of this study and include $i . a$. the development of the tax base, tax rates, tax deductions, tax purpose and the use of the revenues of the ecological tax in question. Allongside this dimension, ecological taxes can be further developed, for instance, via a broadening of the tax base by including additional polluting activities and via an ecological differentiation of tax rates via the introduction of low (high) tax rates for environmentally (un) friendly activities. Examples also include the introduction or abolishment of environmentally relevant tax exemptions and tax deductions. The second dimension expresses the development of ecological taxation in terms of the elements relevant for the imposition of feasible ecological taxes. These elements have been identified in chapter 4 of this study and include the institutional and constitutional structures for ecological taxation and the level at which taxes are imposed. Alongside this dimension, ecological taxation can be further developed, for instance, via improvements in the institutional and constitutional structures for ecological taxation and, if the ecological cir- 
cumstances in question require this, via a broadening of the ecological level at which these taxes are imposed. The latter can, for instance, be achieved if different tax jurisdictions co-operate and jointly introduce a tax.

Table 5.1 portrays the afore mentioned dimensions. Alongside the vertical axis, the first dimension is represented. This dimension is therefore called the vertical dimension. Alongside the horizontal axis, the second dimension is represented. This dimension is therefore called the horizontal dimension. Both dimensions express the development of ecological taxation in the direction of thoroughly and carefully designed taxes (vertical dimension) and in the direction of proper structures and a proper level of imposition, given ecological circumstances (horizontal dimension). ${ }^{1}$

\begin{tabular}{|c|c|}
\hline $\begin{array}{l}\text { ECOLOGICAL } \\
\text { TAXATION }\end{array}$ & $\begin{array}{l}\text { Horizontal dimension }(H) \text { : enlarging relevant } \\
\text { institutional and constitutional structures and } \\
\text { the level of imposition } \\
\quad \rightarrow\end{array}$ \\
\hline $\begin{array}{l}\text { Vertical } \\
\text { Dimension }(V) \text { : } \\
\text { A broadening of the tax } \\
\text { design } \\
\qquad\end{array}$ & 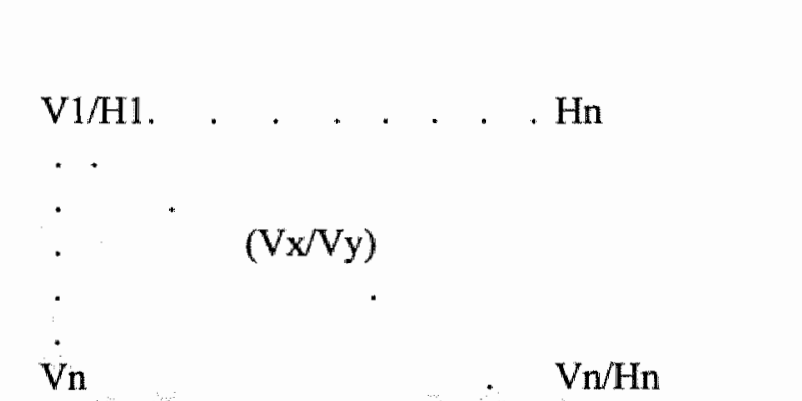 \\
\hline
\end{tabular}

Table 5.1 The development of ecological taxation

In Table 5.1, V1 and $\mathrm{Hl}$ represent the starting points for the development of ecological taxation alongside the vertical and horizontal dimension, respectively. These starting points indicate the ruling opinions and institutional and other relevant frameworks for ecological taxation within a particular unit (e.g. a country or level of government) at a particular point in time. $\mathrm{V} 1$ and $\mathrm{H} 1$, in other words, represent the current status quo in terms of the design and imposition of a particular ecological tax.

Although several elements as regards the feasibility of ecological taxation have been identified in previous chapters of this study, a two-sided dimensional framework is used in this chapter to indicate the main development features. By distinguishing between only these two dimensions, it is possible to emphasize the main differences between a development of ecological taxation within an existing institutional structure (vertical dimension) and a development of this type of taxation via a change in the institutional structure for taxation itself (horizontal dimension). 
Given this status quo, there are three directions which offer possibilities to further develop ecological taxation. First, within the given fiscal and institutional structures, the ecological tax in question can be further developed in terms of the design of these taxes. This development is expressed by the possibilities in the range V1-Vn. Second, the ecological tax in question can be further developed in terms of the institutional and constitutional structures and the level of imposition. This can be achieved via a move from status quo structures towards new institutional structures. This development is expressed by the possibilities in the range $\mathrm{H1}-\mathrm{Hn}$. A third possibility consists of further developing ecological taxation in terms of both the design and the imposition. This development is expressed by combinations in the range from $\mathrm{V} / \mathrm{HI}$ towards $\mathrm{Vn} / \mathrm{Hn}$. $\mathrm{Vx} / \mathrm{Vy}$ is a possible combination within this range. $\mathrm{Vn} / \mathrm{Hn}$ indicates a situation in which carefully designed ecological taxes have been developed in such a way that they are implemented at a level at which ecological and economic leakages are minimized, intended purposes are achieved and acceptability has reached it highest degree. In each case, a combination of $\mathrm{V}$ and $\mathrm{H}$ represents the most viable or feasible ecological tax at a particular point in time. Since the existing frameworks and ruling opinions on ecological taxation can be expected to differ per unit, the distances between $\mathrm{Vl}$ and $\mathrm{Vn}$ and between $\mathrm{Hl}$ and $\mathrm{Hn}$, which express among others the possibilities and problems of moving towards a structure for ecological taxation which differs from the existing structure, can also be expected to differ significantly per unit.

Although the development process for ecological taxation differs per unit, it is likely that each unit starts from the same basic idea, i.e. to introduce ecological taxation first in close connection with existing structures and then to decide whether or not to further develop this type of taxation. Depending on the marginal costs of (non) development, a viable option for ecological taxation can then be decided upon. ${ }^{2}$ The costs associated with further development, for instance, depend on how far relevant institutional frameworks allow this type of taxation to be actually introduced and developed by a specific unit alongside one or both of the dimensions. Depending on the relative costs involved, it is conceivable that at a particular point in time, the ecological tax most viable is represented by a tax which is ineffective from an ecological point of view but which is acceptable to those who are confronted with the tax. In this specific situation, an approach of ecological taxation which is not directly aimed at achieving a sole ecological purpose (such as e.g. the double dividend approach), can be a viable approach for the development of this type of taxation. In the same sense, it is conceivable that ecological taxation is only developed alongside one

2 For a description of the difficulties involved in assessing or measuring particular (environmental) costs and benefits, see Cropper \& Oates (1992) and Tietenberg (1992). Within the context of chapter 4 of this study, relevant benefits and costs (e.g. in terms of institutional changes and transactions) are determined by opportunities. In this sense the (relative) costs of remaining within a particular status quo structure are equal to the opportunities foregone in terms of institutional changes. 
particular dimension. This is for instance the case if the costs of introducing ecological taxes at an interjurisdictional level are relatively high while the costs of broadening the design of these taxes within a relevant jurisdiction are relatively low. In this particular case, it is then possible that ecological taxation develops alongside the vertical but not alongside the horizontal dimension indicated in Table 5.1.

In those cases in which changes in institutional, constitutional, fiscal and other relevant structures for ecological taxation are considered desirable in order to facilitate and ensure the ecological effectiveness and acceptability of these taxes, ${ }^{3}$ the ecological concerns approach can be used to analyze whether or not a move from the status quo towards a new structure, is feasible. More specifically, the EC approach can be used to determine whether the costs of acquiring the information necessary to set up the new institutional structures, the costs of actually introducing these structures and the costs of assessing and evaluating possible behavioural changes in response to these new structures, outweigh their benefits. The assessment of these costs and benefits can proceed on the basis of the checklist indicated at the end of chapter 4 of this study. Following Buchanan (1975, pp. 178-180), it can be stated that to the extent that there is mutuality of gain in prospect, agreement should be conceptually attainable.

By embedding ecological taxation within a broader process of development, it follows that the double dividend approach and the ecological concerns approach not necessarily have to be conceived as two opposite approaches. Within the development process, the two approaches merely present likely approaches in relation to a particular development dimension. If ecological taxation can only be further developed within the status quo structure (e.g. alongside the vertical dimension), either because the costs of institutional and constitutional change outweigh their benefits or because policy makers have developed an interest in maintaining the status quo structure, the double dividend approach can be used to indicate the relevant elements of design. If, on the other hand, institutional and constitutional changes are considered desirable (e.g. alongside the horizontal dimension), ecological concerns approaches can be used to analyze whether and how such changes are also actually feasible. A combination of both approaches can be used in those cases in which a further development of ecological taxes in terms of both their design and the institutional framework into which they are embedded, is considered desirable. ${ }^{4}$

I In his theory on the crisis of the tax state, Schumpeter (1953) presents a tax system as the fiscal expression of a society at a particular point in time. To be successful, tax systems have to reflect the social values of a society. Fundamental tax reforms (instead of incremental tax reforms via small changes in existing tax laws) are considered necessary in those cases in which tax systems fail to reflect such vallues.

4 For an application of the main ideas described in this chapter to the further development of taxes that are used for the internalization of externalities that are associated with the combustion of fossil fuels, see Paulus (1994d). 


\subsection{An analysis of the feasibility of ecological taxation in the Netherlands}

It follows that the possibilities, problems and costs of further developing ecological taxation alongside both dimensions, differ per decision making unit. As indicated, the associated costs, for instance, depend on how far relevant institutional frameworks allow this type of taxation to be actually introduced and developed by a specific unit alongside one or both of the dimensions. Since relevant institutional frameworks and the acceptability of ecological taxes vary from country to country and even from jurisdiction to jurisdiction, these costs also likely vary per country and per jurisdiction. They can therefore only be determined on the basis of a case by case approach. In the remaining part of this study (i.e. in chapters 7-11), such an approach is used to conduct an analysis of the feasibility of ecological taxation in the Netherlands.

Building on the previous considerations, the development of ecological taxation in the Netherlands is further described, determined and explained. In addition, the problems and possibilities to further develop ecological taxation in the Netherlands, within the context of the development process described in Table 5.1, are analyzed. To assess the viability of ecological taxation in the Netherlands, the subsequent analysis is carried out on the basis of the following steps:

- A determination of the existing relevant frameworks (i.e. the status quo structures) for ecological taxation in the Netherlands.

- A determination of the current use of ecologically relevant taxes in the Netherlands.

- A derivation of several features and trends in the use of ecologically relevant taxes within the frameworks identified.

- An incorporation of these features and trends within the theoretical framework presented in this chapter.

A determination, description and explanation of particular phases of development of ecological taxation in the Netherlands.

A determination of the possibilities and problems to further develop ecological taxation in the Netherlands alongside the vertical and horizontal dimensions described above.

- An assessment of the development and feasibility of ecological taxes in the Netherlands.

To conduct a feasibility analysis in terms of these steps, the actual use of environmental taxes within the current institutional structures in the Netherlands is first described in chapters 6 and 7 of this study. In chapters 8,9 and 10 , several trends, features and the difficulties and possibilities for a further development of ecological taxation in this country are described and explained. The policy implications that result from this analysis are discussed and summarized in chapters 10 and 11. 


\section{The Institutional, Fiscal and Environmental Policy Frame- work for Ecological Taxation in the Netherlands}

\subsection{Introduction}

Following Williamson (1993), an institutional framework can be described as an institutional arrangement which provides a structure within which economic units can co-operate and/or compete. The institutional framework into which ecological taxation is embedded can provide both opportunities and restrictions for the ecological effectiveness, acceptability and feasibility of this type of taxation. Within this context, the main purpose of this chapter is to describe and discuss several elements of the existing institutional, fiscal and environmental policy framework for ecological taxation in the Netherlands. This framework indicates, among others, the division of responsibilities for taxation and environmental issues between different governmental bodies in this country. The opportunities and restrictions for ecological taxation and the possibilities for different levels of government in this country to co-operate and compete can then be determined on the basis of this division of responsibilities. As argued in the last section of the previous chapter, the determination of the opportunities, possibilities and restrictions for ecological taxation that are provided by the institutional framework in the Netherlands, serves as the first step in the analysis of the feasibility of ecological taxation in this country (see also Paulus, 1994e). After the introduction (section 6.1), the administrative and financial relationships between different government bodies in the Netherlands are further discussed in section 6.2 . In section 6.3 , the main taxes and related charges which can be imposed by sub national government bodies in this country are briefly analyzed. The environmental policy framework for ecological taxation is discussed in section 6.4. Based on the results of the analyses in previous sections, the main opportunities, possibilities and restrictions for the use of ecological taxes in the Netherlands are presented in section 6.5.

\subsection{The institutional and fiscal context for ecological taxation in the Netherlands}

\subsubsection{Administrative and financial relationships between government bodies in the} Netherlands

The Netherlands are usually characterized as a decentralized unitary state, implying that local governments and/or public bodies have policy freedom as far as this freedom does not harm the unitary state. ${ }^{1}$ Decentralization of the unitary state can be

1 See e.g. Duchateau and Lok (1993, p. 1) and Stevens (1993, p. 21). In 1798, the Netherlands officially became a unitary state after having been a confederation from 1579-1795. 
territorial in the sense that sub national governments execute tasks for the public interest. The execution of such tasks by provinces and municipalities in the Netherlands presents a clear example. Decentralization of the unitary state can also be functional in the sense that public bodies execute tasks which are related to specific functions. The execution of particular environmental tasks by water boards in this country can be seen in this respect. In general, sub national governments and public bodies in the Netherlands can execute their tasks in autonomy or under co-government ("medebewind") with the central government. As an autonomous government body, a municipality, for instance, is authorized to conduct and govern those affairs which are not conducted by other governments. Under co-government, provinces or the central government require municipalities to co-operate in the execution of particular regulations. In the latter case, municipalities are thus more severely restricted in their formulation and execution of policies.

Since 1865, sub national governments and especially municipalities in the Netherlands have increasingly relied on central government grants as their main sources of revenues. This financial dependence especially increased during the last century and resulted, among others, in a strong reduction in the possibilities of municipalities to raise revenues by means of own taxation. ${ }^{2}$ The increased financial dependence of municipalities in fact started in 1865 , when it was no longer allowed to municipalities to impose excise taxes. At that time, these taxes were the main revenue sources for these governments. ${ }^{3}$ Prior to 1865 , different governments in the Netherlands each imposed their own set of taxes. To compensate municipalities for the loss of tax revenues from excise taxes, the central government distributed part of its tax revenues to municipalities.

In 1929, a municipality fund ("Gemeentefonds") was introduced in the Netherlands. On the basis of their number of inhabitants, municipalities received grants from this fund. The grants replaced the tax revenues that municipalities received from the central government. The revenues of the fund were raised by means of a municipality fund tax. ${ }^{4}$ At the same time that the municipality fund was introduced, the possibility for municipalities to raise revenues by means of income taxes was abolished. Since 1935 , the possibilities for municipalities to raise revenues by means of own taxation have been further reduced. ${ }^{5}$

After the second World War, the central government's influence on municipal policies further increased due to among others the attempts of the central government

2 Raad voor de Gemeentefinanciẻn (1986, pp. 1-3).

3 For a more detailed description of the reasons why the possibilities for municipalities to impose excise taxes were abolished, see Raad voor Gemeentefinanciën (1986, p. 57 ff).

Ibid., pp. 38-42.

s Ibid., p. 60ff. 
to completely equalize the capacity to provide a certain level of municipal provisions. ${ }^{6}$ Besides grants from the municipality fund, municipalities presently also receive specific (i.e. earmarked) grants directly from the central government. Unlike block grants which can freely be spent specific grants can only be spent by sub national government bodies under the conditions explicitly stated by the central government.

Block grants are provided to municipalities on the basis of certain division standards. These standards involve a basic grant which is equal for all municipalities and additional grants on the basis of the geographical size of the land of the municipality in question, the number of inhabitants, houses etc. For municipalities facing additional costs because of special circumstances (e.g. a specific state of the soil) refined grants can also be provided. Additional grants can be provided to those municipalities for which the block grants and the revenues raised by means of own taxation do not suffice to provide an adequate level of provisions. At present, the municipality fund is legally founded in the Act on Financial Relationships 1984 ("Financiële Verhoudingenwet $\left.1984^{\prime \prime}\right){ }^{7}$ As in the case of municipalities, provinces receive block and specific grants. Block grants are provided via a province fund ("Provinciefonds"). The distribution of the grants from this fund is legally founded in the Province Act. Provinces receive specific grants directly from the central government.

Specific grants are the most important sources of income for sub national governments and especially municipalities in the Netherlands. With regard to these grants, the central government explicitly describes the activities for which they should be used. The grants can only be received once or for a short period of time. Unlike block grants, specific grants are not provided by special funds but directly by the central government and thus via the central public budget. Duchateau and Lok (1993, p. 27) note that, in recent years, a "crawling" centralism can be detected in the Netherland, which, among others, is related to the increasing dependence of sub national governments on central government grants. For 1988, Table 6.1 shows the main sources of revenues for the municipality and province fund in the Netherlands. As can be noticed from this table, the main sources of revenues are provided by the taxes that are levied by the national level of government. These include income, wage and value added taxes.

16 For a more detailed description of the historical development of the financial and administratiwe relationships between municipalities and the central government in the Netherlands, see Raad voor Gemeentefinanciën (1986, chapter 1).

Ibid., pp. 43-44. 


\begin{tabular}{|c|c|c|}
\hline Tax/levy & $\begin{array}{l}\text { municipallity } \\
\text { fund }\end{array}$ & $\begin{array}{l}\text { province } \\
\text { fund }\end{array}$ \\
\hline income tax & 709 & 61 \\
\hline wage tax & 3866 & 336 \\
\hline $\begin{array}{l}\text { dividend } \\
\text { tax }\end{array}$ & 227 & 20 \\
\hline tax on garnes of chances & 10 & 1 \\
\hline wealth tax & 114 & 10 \\
\hline corporate income tax & 1718 & 149 \\
\hline death duties etc. & 116 & 10 \\
\hline motor vehicles tax & - & - \\
\hline value added tax & 3874 & 336 \\
\hline user taxes on cars & 270 & 23 \\
\hline excise taxes & 949 & 82 \\
\hline legal taxes etc. & 290 & 25 \\
\hline remaining & 5 & - \\
\hline Total & 12148 & 1053 \\
\hline
\end{tabular}

Table 6.1 Budget funds ( $\mathrm{m} / \mathrm{n}$ guilders, 1988). Source: Based on CBS data (Statistiek der Rijksfinanciën).

In general, the grants provided by the municipality (province) fund and the specific grants are considered substitutes for a significant part of the municipal (provincial) taxes. Consequently, the importance of these taxes as sources of revenue has steadily decreased over time. At present these taxes mainly serve to compensate for certain shortages which have not been fully met by block grants or specific grants. Allocational functions such as those performed by Pigouvian taxes are hardly ever fulfilled by these taxes. According to Stevens (1993), this can be explained in terms of the existing administrative relationships between different governments in the Netherlands. If an administrative structure allows sub national governments to also develop their own policies, assigning taxing capacities to these governments is functional. If these governments, however, only execute policies under co-government, they can not use these taxes for allocational purposes, in addition to fiscal purposes. ${ }^{8}$ In practice, even in case sub national governments do have the authority to impose taxes, central governments can still strongly influence the imposition of these taxes. The 
central government can, for instance, dictate the essential elements of the tax or levy in question or interfere in case the autonomy to tax has undesirable consequences for policies that are conducted by the central government (e.g. income redistribution policies)."

In theory, depending on the administrative structure, high or low tax sovereignties can be assigned to sub national governments. In case these sovereignties are low, the centrai government, for instance, imposes taxes and provides sub national governments with the necessary means to perform their tasks. This can be achieved, for instance, by means of block grants or specific grants. If sub national governments do have the authority to impose taxes, the autonomy to tax can be strict (= open system) or limited (= closed system). Strict autonomy arises if the central government does not limit the taxing powers of sub national governments. A limited autonomy arises if the central government assigns only limited powers to tax to the latter governments, which is the case for the Netherlands (see Stevens, 1993, p. 22). In the Netherlands, sub national governments only have a very limited taxing autonomy. They are only allowed to impose certain taxes that are indicated by the central government. There are also strict material and formal stipulations for the design of these taxes (Stevens, 1993, p. 23). Having the main elements of a closed system, the taxing autonomy of sub national governments in the Netherlands is clearly constituted and constrained by the legislation of the central government. Not surprisingly, given the limited taxing autonomy of these governments in the Netherlands, the share of taxes in the total revenues received by municipalities and provinces in the Netherlands is equally small (see Table 6.2).

Following Goedhart, Stevens (1993) explains this to be characteristic for a small open country, for which it is not accepted that the level of provisions is differentiated throughout the country. In this sense, the central government will restrict provincial and municipal autonomies via a reduction of the most noticeable inequalities in the local capacities to tax and to provide public goods and via a complete equalization of the local capacity to provide public goods by also taking into consideration certain spill-overs. The high value attributed to an equalization of the capacities mentioned above (which is also known as the equivalence principle) initially resulted in a strong reduction of the possibilities for municipalities in the Netherlands to raise revenues by means of own taxation. In 1930 , for instance, $92,7 \%$ of the revenues raised by municipalities were collected by means of own taxation, while $7,3 \%$ was collected by means of block grants. In 1955 , almost $20 \%$ of municipal revenues were raised by means of own taxation. The revenues raised by means of block grants in 1955 already amounted to $80,3 \% .^{10}$ In 1992 , approximately $10 \%$ of municipal revenues were raised through municipal taxes and related levies (see Table 6.2).

Ibid., p. 23 .

${ }^{10}$ Koopmans et al. (1991, p. 230). 


\begin{tabular}{|l|r|r|r|r|}
\hline Revenues & Munieipalities & Provinces & Total & $\%$ \\
\hline $\begin{array}{l}\text { Levies and char- } \\
\text { ges }\end{array}$ & 2872 & 284 & 3156 & 5,3 \\
\hline Own taxes & 3519 & 277 & 3796 & 6,1 \\
\hline Block grants & 15205 & 1271 & 16476 & 26,9 \\
\hline $\begin{array}{l}\text { Specific } \\
\text { grants }\end{array}$ & 331.88 & 4634 & 37822 & 61,8 \\
\hline
\end{tabular}

Levies and charges: municipalities: sewer(age) charges, refuse collection charges, water pollution charges, administrative charges, "precario or sufferance' dues, market charges, burial charges and parking charges.

Levies and charges: provinces: administrative charges, ground water charges, water pollution charge and surcharges on the contribution for broadcastings.

Taxes: municipalities: real estate taxes, dog taxes, tourist taxes, commuter taxes, building site and 'benefit' taxes.

Taxes: provinces: surcharges on the motorvehincles tax.

Table 6.2 Municipal and provincial revenues (1992, in million guilders).

Source: Stevens (1993, p. 27).

Since sub national government bodies in the Netherlands have only limited possibilities to raise revenues by means of own taxation, the share of these revenues in the total tax revenues raised in the Netherlands is equally low. Table 6.3 shows the revenues resulting from the imposition of direct and indirect taxes by different government bodies in the Netherlands. The table represents the situation for 1988 .

\begin{tabular}{|l|r|l||}
\hline Government body & $\begin{array}{l}\text { Received revenues from in- } \\
\text { direct taxes (in million guil- } \\
\text { ders) }\end{array}$ & $\begin{array}{l}\text { Received revenues from } \\
\text { direct taxes (in million } \\
\text { guilders) }\end{array}$ \\
\hline Central & 53360 & 63270 \\
\hline Public Industrial Organizations & 530 & -210 \\
\hline Provinces & 210 & 670 \\
\hline Water boards & 920 & 1680 \\
\hline $\begin{array}{l}\text { Municipalities and Municipal co- } \\
\text { operation arrangements }\end{array}$ & 2680 & 65830 \\
\hline
\end{tabular}

Table 6.3 Tax revenues different government bodies in the Netherlands. Source: Based on CBS data (Statistiek der Overheidsfinanciën). 
In 1986, the Council for Municipal Finance ("Raad voor Gemeentefinanciën") in the Netherlands pleaded for a strengthening of the financial and administrative position of municipalities in the Netherlands. A strengthening of this position was considered necessary and desirable in order to ensure an efficient and effective municipal government policy. ${ }^{11}$ Re-enforcement of the financial and administrative position of municipalities was considered to be possible via a re-enforcement of the municipality fund, via a replacement of earmarked central government grants by block grants and via extensions in the capacity of municipalities to raise revenues by means of own taxation (see section 6.2.2.). The re-enforcements were proposed by the Council on the basis of the recognition that, for their revenues, municipalities increasingly depended on central government grants.

\subsubsection{Changing administrative and financial relationships}

In the last decade and especially in recent years the financial and administrative relationships between governments in the Netherlands have been a subject of increasing discussion. Main discussion topics include the level of government by which a particular provision can best be provided and the level of government by which tax payers could best be confronted in order to finance this provision. Financial and administrative relationships between different governments in the Netherlands have recently also been influenced by several major government operations which included i.a. a decentralization and re-organization of administrative relationships in this country.

At the beginning of the eighties, decentralization plans were announced in the Netherlands. A strengthening of the position of sub national government bodies in this country was the main purpose of these plans. ${ }^{12}$ Discussions on changing the governmental division of responsibilities included a) the introduction of regional governments in the Netherlands in addition to the national, municipal and provincial governments b) an enhancement of further co-operation arrangements between municipalities and c) the merger of several municipalities. ${ }^{13}$

Since the beginning of the 1990's, the introduction of regional governments in the Netherlands has increasingly been discussed. In different policy Memoranda that have been published since the 1990 's, the introduction of regional governments for

${ }^{11}$ Raad voor de Gemeentefinanciên (1986).

${ }^{12}$ See Duchateau and Lok $(1993$, p. 28 ff.). Within the context of very strict restraints, public industrial organizations in the Netherlands are also allowed to impose particular levies. A levy on the use of pesticides for agricuitural purposes is one of these very limited possibilities. By permission of a minister, these public bodies are sometimes also allowed to impose earmarked environmental levies.

${ }^{13}$ Raad voor Gemeentefinanciën (1986, p. 11). 
regions that are located around seven large cities in the Netherlands are suggested. ${ }^{14}$ Cities include, among others, Rotterdam, Amsterdam, Utrecht and The Hague. For the actual introduction of these governments, co-operative agreements between government bodies are stimulated and a Framework Act for Changing Administrative Relationships, which offers the possibilities to gradually introduce regional governments, has been formulated. ${ }^{15}$ On the basis of the act, a gradual introduction of these governments first entails the introduction of a public body in the form of an intermunicipal co-operation arrangement for a maximum of four years. The central government can delegate particular tasks to this decision making body, e.g. such tasks as drawing up environmental policy plans or granting particular licences. After the initial four years, a regional authority can be introduced, also for a maximum of four years, before the actual regional government can be installed. In the course of this process, the central government can delegate additional tasks to the regional decision making authority, e.g. such tasks as the decontamination of soil. ${ }^{16}$ To avoid the introduction of a new (fourth) level of government in the Netherlands, regional governments are presented as "new style provinces".

Prior to the act in which regulations are laid down with regard to the introduction of new style provinces, a new Act on Joint Arrangements was introduced in the Netherlands in 1985. The act allows different governments to establish co-operative arrangements. At that time, approximately 1500 co-operation arrangements were operative in this country. In 1990, five years after the introduction of the new act, the number of arrangements was reduced to $592 .{ }^{17}$ In 1991, existing acts with regard to the merger of several municipalities were also extensively changed.

In the near future, one of the central aims of the central government in the Netherlands is to reduce the number of specific grants and to shift several of these grants to the municipality fund. ${ }^{18}$ Within this context, extended possibilities for sub national governments to raise revenues by means of own taxation (e.g. via an imposition of local, provincial or regional taxes and related levies) have also increasingly been discussed. Both financial arguments and arguments from an administrative point of view have been put forward in this context. ${ }^{19}$ One of the latter arguments is that sub national governments, with regard to their policies and associated costs, will have

${ }^{14}$ For a more detailed discussion of the Memoranda that were published on the subject of regional governments, see Duchateau and Lok (1993, pp. 285-286).

${ }^{15}$ Duchateau and Lok (1993, pp. 285-286).

${ }^{16}$ Ibid.

${ }^{17}$ See Duchateau and Lok (1986, pp. 274-275).

18 Duchateau and Lok (1993, p. 33).

${ }^{19}$ See Korff (1993, p. 12). 
to justify these costs and policies for citizens in a more comprehensive manner. This more comprehensive justification is also important for the financial arguments that have been put forward. A more comprehensive justification will expectedly result in a better weighing of the utility of a specific provision and the related sacrifice that has to be made by the tax payer. ${ }^{20}$ By expanding the possibilities for sub national government bodies to raise revenues by means of own taxation, these bodies also become less dependent on block grants and specific grants. In theory, expansions can be achieved through extensions of existing taxes or via the introduction of new taxes. In recent decades, the introduction of the possibility for municipalities in the Netherlands to impose real estate taxes, can be considered a first step in this direction.

In 1983, the so-called Christiaanse Commission ${ }^{21}$ submitted a report in which a doubling of the revenues that could be raised by municipalities by means of own taxation was considered a reasonable policy option. Increases in the revenues that could be raised by provinces, were also considered reasonable. ${ }^{22}$ As one of the preconditions for the feasibility of their proposals, the Christiaanse Commission indicated that extended taxing possibilities for provinces and municipalities should be accompanied by reductions in block grants and especially specific grants. ${ }^{23}$

In 1992, the so-called De Kam Commission ${ }^{24}$ also suggested several extensions in the possibilities for municipalities and provinces to raise revenues by means of own taxation. According to the Commission, in order to keep these changes fiscally neutral, these extensions should be accompanied by rellevant decreases in the taxes that are levied by the central government. The extensions were suggested because of the fact that provinces and municipalities in the Netherlands, at that time, only received $10 \%$ of their revenues from own taxation. About half of these total means were raised by way of ordinary revenue raising taxes. Real estate taxes and the surcharges on the motor vehicles tax constituted the main tax revenue sources for municipalities and provinces, respectively.

${ }^{20}$ Discussions on extending the possibilities for sub national governments to raise revenues by means of own taxation are usually conducted on the basis of the premise of revenue neutrality. On the basils of this premise, discussions on the afore mentioned possibilities generally also entail possibilities for reducing particular taxes and related levies imposed by the national government and/or reductions in assigned grants to sub national levels of government. For a more extensive discussion of the pros and cons of these different possibilities, see the report of the De Kam Commission (Commissie de Kam, 1992, pp. 27-31).

2" Commissie Christiaanse (1983).

${ }^{22}$ In 1990, also another Commission examined the possibilities of such extensions for provinces, see Commissie Haks (1990).

${ }^{23}$ Raad voor gemeentefinanciën (1986, pp. 66-67).

${ }^{24}$ Commissie de Kam (1992). 
With regard to revenue raising taxes (levies, charges etc. were not taken into consideration) the Commission more specifically analyzed how municipal and provincial tax revenues could be raised by $150 \%$ and $300 \%$, respectively. The Commission presented several options. Among others, the Commission suggested to partially transfer some of the taxes that are levied by the central government to provinces and municipalities. They mainly include the taxes that are not used by the central government for income redistribution or stabilization purposes. In addition, the Commission suggested an extension of the possibilities for municipalities and provinces to levy surcharges on the taxes currently imposed by the central government. The introduction of new taxes and revenue sharing were also presented as possible options. In the latter option, municipalities and provinces are provided with a direct share in central government taxes. The share can be based on that part of the central government taxes that has been raised in the particular jurisdiction(s) in question.

The Commission stated (pp. 8-9) that extensions could be considered feasible if they resulted in reasonable stable tax revenues. In addition, extensions could be considered feasible if perception and administrative costs allowed the actual introduction of these taxes and if it could be expected that these extensions/taxes would explicitly be recognized as sub national government taxes. To be considered a feasible policy option, the Commission also indicated that economic and income redistributions effects should be acceptable and moderate. In addition, these extensions were considered to be feasible in case there was a reasonable consensus and in case these extensions/taxes could be incorporated into existing intergovernmental relationships in the Netherlands.

Within the context of these preconditions, the Commission proposed several extensions in the possibilities for municipalities and provinces to raise taxes by means of own taxation. The main aspects of these extensions are summarized in Table 6.4. With the aim of extending municipal and provincial taxes with 5 and 0,75 billion guilders, respectively, the Commission indicated that municipalities could opt for a particular combination of the latter three options mentioned in Table 6.4. Provinces could opt for one of the first three options. The transfer of taxes on ground water and waste substances is considered an additional option for provinces. The Commission indicates that only minor changes in existing laws and acts are necessary for most of the possibilities shown in Table 6.4.

Following de Groot et al. (1993), Stevens (1993) describes the adjustments in financial relationships that have to be made in response to the changing intergovernmental relationships. There are several possible responses (p. 18-19):

1) Adjusting the status quo, i.e. adjusting the existing closed system instead of introducing an open system.

2) Making block grants more common.

3) Extending the possibilities for provinces, municipalities and regional governments to raise revenues by means of own taxation. 


\begin{tabular}{|c|c|c|}
\hline $\begin{array}{l}\text { Taxing authority or decision } \\
\text { making body }\end{array}$ & Proposed extension & $\begin{array}{l}\text { Expected tax revenues (in } \\
\text { million guilders) }\end{array}$ \\
\hline Provinces & $\begin{array}{l}\text { 1) Introduction of a surtax of } \\
0,23 \text { cents on the wage and income } \\
\operatorname{tax}\end{array}$ & 760 \\
\hline Prowinces & $\begin{array}{l}\text { 2) An increase in the surcharges on } \\
\text { the motor vehicles tax (approx. } 70 \\
\text { points) }\end{array}$ & 750 \\
\hline Provinces & $\begin{array}{l}\text { 3) Introduction of an inhabitants tax } \\
\text { of fl } 70,00 \text { per adult }\end{array}$ & 818 \\
\hline Provinces & $\begin{array}{l}\text { 4) Transfer of the suggested tax on } \\
\text { ground water and waste substan- } \\
\text { ces.* }\end{array}$ & 475 \\
\hline Municipalities & $\begin{array}{l}\text { 5) Introduction of } 1 \text { surtax on the } \\
\text { wage and income tax }\end{array}$ & 3180 \\
\hline Municipalities & $\begin{array}{l}\text { 6) Introduction of an inhabitants tax } \\
\text { of fl } 100,00 \text { per adult }\end{array}$ & 1169 \\
\hline Municipalities & $\begin{array}{l}\text { 7) A shift of the transfer tax } \\
\text { ("overdrachtsbelasting") from the } \\
\text { central government to municipali- } \\
\text { ties. Existing tax exemptions will be } \\
\text { abolished and the tax rate will be } \\
\text { reduced to } 3 \% \text { or } 4 \% \text { ** }\end{array}$ & 1750 \\
\hline $\begin{array}{l}\text { This proposal is consic } \\
\text { Transfer taxes can be i } \\
\text { other than on the basis } \\
\text { nomic value. }\end{array}$ & $\begin{array}{l}\text { d optional } \\
\text { osed in case particular real estate in } t \\
\text { inheritance. The tax rate now consist }\end{array}$ & $\begin{array}{l}\text { Netherlands is obtained } \\
\text { of } 6 \% \text { of the assessed eco- }\end{array}$ \\
\hline
\end{tabular}

Table 6.4

The proposals of the De Kam Commission. Source: Commissie de Kam (1992, p. 8; ch. 5).

The latter response includes the options suggested by the De Kam-Commission (Commissie de Kam, 1992) and de Groot et al. (1993). De Groot et al. (1993) also suggested an increase in existing provincial and municipal tax revenues by $300 \%$ and $150 \%$, respectively. ${ }^{25}$ The increase in tax revenues should be accompanied by the

${ }^{25}$ In general, several municipalities and provinces in the Netherlands can extend their revenues from own taxation by making use of the possibilities that are offered by the Municipality and Province Act. Not all municipalities and provinces actually impose the taxes that they are allowed to impose on the basis of these acts. Studies indicate that almost 2 billion guilders of municipal taxing capacities remain un-utilized. For provinces, approximately one hundred million guilders of these capacities remain un-utilized (Commissie de Kam, 1992, p. 27). In the report of the De Kam Commission, it is for instance shown, that approximately 136 municipalities impose parking taxes and 
introduction of a so-called "equalization grant" ("vereveningsuitkering"). The main purpose of this grant is to reduce the difficulties that arise if governments differ in their capacities to tax. These differences can, for instance, occur as a result of different average incomes.

The municipal parking taxes that were introduced in 1991, can be considered one of the first steps in the direction of extending the possibilities of sub national governments to raise their revenues from own taxation. ${ }^{26}$ The new Municipality Act that was introduced in 1992, can be considered a second step. Among others, the act re-enforces the position of municipalities with regard to other governments. ${ }^{27}$ Within the context of the current institutional structures for taxation by different levels of government in this Netherlands, in the following the main aspects of the different taxes that can be imposed by sub national governments are further described.

\subsection{Taxation by sub national governmental bodies in the Netherlands}

\subsubsection{Taxes and related levies which can be imposed by provinces in the Netherlands}

Besides supervising water boards and municipalities, provinces in the Netherlands have limited tasks in the areas of traffic and water. In recent years, provinces in the Netherlands also received increasing responsibilities in the areas of environmental protection and physical planning. ${ }^{28}$ Having the status of public bodies, provinces in the Netherlands, of which there are twelve in total, however have very limited possibilities to impose taxes. Provinces are allowed to only impose the following taxes:

- $\quad$ Surcharges on the principal sum owed of the motor vehicles tax.

- Administrative and/or other charges for the use of provincial possessions, works and installations ("inrichtingen") destined for public services

'Precario' dues.

Charges which can be levied on the basis of special acts such as the water pollution charge and the ground water charge. The revenues of both charges are earmarked.

approximately 308 municipalities impose 'precario' dues (precario-rechten). There are over 600 municipalities in this country.

${ }^{26}$ Duchateau and Lok (1993, p. 34).

27 Since intergovernmental relationships can change, it follows that the financial and other relationships between governments have to be considered in a dynamic sense. (Also see Koopmans et al., 1991, chapter 10).

${ }^{28}$ See Andriessen et al. (1990). 
The taxes which can be imposed on the basis of the Province Act include the surcharges on the head sum of the motor vehicles tax and legal and other charges for the use of provincial possessions and services. The surcharges are levied from the inhabitants of the province in question. On the basis of special acts, including specific environmental acts, provinces are also allowed to impose particular environmental levies, including the water pollution charge and a ground water tax. The tax revenues raised are usually restricted to be used for the funding of related goods, services or provisions.

\subsubsection{Taxes and related levies which can be imposed by municipalities in the Nether- lands}

In the Netherlands, there are over 600 municipalities. ${ }^{29}$ Of the total revenues that are received by these municipalities, about $5 \%$ is raised through the imposition of taxes and related levies. The most important tax revenue source is the real estate tax. Besides taxes and related levies that can be imposed on the basis of the Municipality Act, municipalities in the Netherlands are also allowed to impose taxes or related levies on the basis of special acts. These acts allow numerous taxing possibilities, including among others the options for municipalities to introduce a water pollution charge and a waste disposal charge. Municipal taxes and levies are further described in municipal tax decrees (By Laws or "belastingverordeningen"). These decrees can differ per municipality. The taxes which can be levied on the basis of the Municipality Act are the following: the real estate tax ("ortroerende zaakbelasting"), the "benefit" tax ("baatbelasting"), the building site tax ("bouwgrondbelasting"), the dog tax ("hondenbelasting"), the advertising tax ("belasting op openbare aankondigingen/reclamebelasting"), the commuter tax ("belasting ter zake van het houden van nachtverblijf of het hebben van een gemeubileerde woning"), the tourist tax ("toeristenbelasting"), the parking tax ("parkeerbelasting"), the administrative or legal charges ("leges") and other charges ("rechten"): ${ }^{30}$

Administrative or legal charges can be subdivided into:

1a) Fees for certificates ("uittreksels, afschriften etc. uit gemeentelijke registers").

1b) Fees for subscriptions ("abonnementen uit deze registers").

2) Copy fees ("leges voor het verstrekken van copieën").

3) Fees for archival services ("inzage in archieven").

4) Fees for licences (wettelijk gebaseerde vergunningen).

${ }^{29}$ In May 1994, there were 636 municipalities in this country.

${ }^{30}$ Sio (1991, p. 13) and De Man (1987, part 6, pp. 136-139). 
The other charges can be subdivided into:

1) User charges ("gebruiksretributies"): charges for using municipal possessions intended for public services such as roads, streets, bridges and markets.

2) Service charges ("genotsretributies"): charges for municipal services such as refuse collection charges and sewerage charges.

3) 'Entertainment' charges ("vermakelijkheidsretributies"): charges for using provisions offered by the municipality in those cases in which the provisions are related to having amusements on places open to the public.

4) 'Sufferance or 'precario' dues ("precariorechten"): dues for having boards, rails, petrol pumps up, above or under land or water owned by municipalities. The most important due is an outdoor advertising tax.

The basic elements of most municipal taxes and levies in the Netherlands are described in the Municipality Act. On the basis of this act, municipalities in the Netherlands are free to set the level of tax rates, to describe particular tax exemptions and, under particular restrictions, tax bases (see BZW/MICON study, 1993, p. 15). In the same act (art. 277), an overview is provided of the taxes, levies and charges which can be levied by municipalities in this country. With regard to charges, both user and service charges can be distinguished. User charges are related to the use of municipal possessions and/or the use of installations or works intended for public services and that are under the control of the municipality. Charge rates have to be related to the use by the one liable for the charge in question. Service charges can only be imposed if the municipality renders a service and if the one who is liable for the charge actually benefits (i.e. is not forced to benefit) from the service.

Almost all of these charges are characterized by the existence of a quid pro quo relationship, in the sense that for the charges paid, a service etc. is rendered by the government. In this sense, these charges differ from ordinary revenue raising taxes for which there is no quid pro quo relationship. Since 1989 , the revenues of the administrative and other charges can cover a maximum of $100 \%$ (but not more) of the costs which are related to these charges. Profits, i.e. revenues above those needed to defray the costs, are not allowed by law. Municipal tax regulations will not be approved in case such profits can reasonably be expected (BZW/MICON study, 1993, p. 16, p. 21).

The real estate tax is the most important revenue source for local governments. The real estate tax is the successor of, among others, the land and personal tax in the Netherlands. ${ }^{31}$ Since 1970 , the real estate tax can be levied on the actual users of the real estate and/or the current owner of the real estate. Mostly, the tax is levied on the basis of the economic value of the real estate. Tax rates vary per municipality. The assessment value for the real estate tax is also used for other forms of levy. Water

${ }^{31}$ See Sio (1991) for a further elaboration of the levies mentioned in this part of the section. 
boards, for instance, base their own assessments on the assessment for the local real estate tax. The assessment value of the same tax is also used as a norm for the local 'benefit' and building site taxes. The local 'benefit' tax is based on the idea that a lot of real estate in certain parts of a municipality is "benefitted" by provisions made by or in co-operation with the local government. Due to this benefit the local government, for a period of up to thirty years, can levy an annual tax (as a means to achieve a reasonable contribution in the costs from those provisions) on the real estate, payable by its owners. The tax is based on the taxable revenue or surface. Tax rates differ per municipality. The local building site tax is imposed within the context that, in case provisions are made by or in co-operation with the local government, it is possible for real estate to become more suitable or more advantageous for building. Due to this side effect, the local government can levy a tax on the real estate. Liable are those who use the real estate. The tax is based on the surface or length of the real estate alongside public roads. Tax rates differ per municipality. Examples of the provisions made by or in co-operation with the local government are the obtaining and the placing at one's disposal of real estate. Building site taxes and 'benefit' taxes can not be levied at the same time. Building site taxes can already be levied before the actual provisions are wholly prepared. This is not possible for 'benefit' taxes. The latter taxes, however, are broader than building site taxes in the sense that they also incorporate the preparation of sites for building. 'Benefit' taxes, in their sense, however, again are limited because they can only be imposed in order to receive a reasonable contribution. ${ }^{32}$

'Precario' dues can be levied from those objects up, above or under land or water owned by the local governments. Liable are those persons who are permitted to have such objects, who own such objects, or whose objects are found up, above or under municipal land or water. There are various tax rates, which can be differentiated according to surface or piece. A due essentially is an ordinary revenue raising tax. In practice, this tax is mainly applied to outdoor advertising but its potential goes far beyond this application. 'Precario' dues, for instance, must be paid for rails, petrol pumps, cab ranks, balconees, porches, etc. Sewerage charges are municipal charges that are imposed on the users and/or owners of real estate ("pand") in order to defray the costs of constructing and exploiting sewerage systems. Tax rates can differ for those who own or use the lot. There can also be different tax rates for companies. In order to defray the costs of collecting household waste at least once a week, municipalities in the Netherlands are allowed to impose either refuse collection charges or waste disposal taxes. Refuse collection charges can be imposed on those who use, i.e. benefit from services rendered by the municipality. They can also be imposed on the use of municipal possessions, works or installations intended for public service.

Municipalities in the Netherlands can also impose a waste disposal tax which is an ordinary revenue raising tax and thus not a charge. This tax differs from the refuse

${ }^{32}$ For the most important differences between the two taxes, see Sio (1991). 
collection charges in the sense that there is no quid pro quo relationship and in the sense that the tax is used with regard to waste substances from households only.

\begin{tabular}{|c|c|c|c|}
\hline Levy/tax/charge & $\begin{array}{l}\text { Revenues in } \\
\text { million } \\
\text { guilders } \\
\text { (1991) }\end{array}$ & $\begin{array}{l}\text { Revenues in } \\
\text { million guilders } \\
\text { (1992) }\end{array}$ & $\begin{array}{l}\text { Number of munici- } \\
\text { palities actually in- } \\
\text { posing the levy in } \\
\text { question (1991) }\end{array}$ \\
\hline \multicolumn{4}{|l|}{ A. Municipal taxes } \\
\hline $\begin{array}{l}\text { real estate taxes } \\
\text { (user part) }\end{array}$ & 1290 & 1412 & 647 \\
\hline $\begin{array}{l}\text { real estate taxes } \\
\text { (benefit part) }\end{array}$ & 1865 & 1933 & 647 \\
\hline dog taxes & 65 & 68 & 513 \\
\hline $\begin{array}{l}\text { commuter taxes } \\
\text { ('woonforensenbelasting') }\end{array}$ & 14 & 15 & 200 \\
\hline tourist taxes ("toeristenbelasting') & 71 & 79 & 293 \\
\hline benefit" taxes & 11 & 11 & 290 \\
\hline building site taxes & 0 & 1 & 36 \\
\hline \multicolumn{4}{|l|}{ B. Leviles and Charges } \\
\hline sewerage charges & 584 & 689 & 526 \\
\hline charges for the disposal of waste & 980 & 1289 & 608 \\
\hline water pollution charge & 70 & 78 & 2 \\
\hline 'precario' dues & 95 & 105 & 278 \\
\hline burial charges & 73 & 78 & 523 \\
\hline administrative charges for building & 220 & 240 & 647 \\
\hline other administrative charges & 143 & 143 & 647 \\
\hline parking charges & 161 & 198 & 129 \\
\hline market charges & 49 & 52 & 492 \\
\hline Total: $\mathbf{A}+\mathbf{B}$ & 5691 & 6392 & \\
\hline
\end{tabular}

Table 6.5 Municipal taxes and charges (in million guilders). Source: Based on CBS data (Statistiek der Gemeentebegrotingen). 
One of the main differences between the waste disposal tax and refuse collection charges is the fact that the former tax can be imposed by municipalities only on the basis of special acts (e.g. Waste Substances Act and Environmental Protection Act. ('Wet Milieubeheer'). Refuse collection charges, on the other hand, can be imposed on the basis of the Municipality Act. Contrary to waste disposal taxes, this means that refuse collection charges can only be imposed on those who actually make use of the service offered by the municipal government. Prior to 1979, when the Waste Substances Act came into operation, only refuse collection charges could be used by municipalities in order to defray the costs of collecting waste. The main revenues with regard to some of the charges raised by municipalities in the Netherlands in 1991 and 1992 are summarized in Table 6.5. Table 6.5 also provides an overview of number of municipalities that actually imposed these levies in 1991.

\subsubsection{Water boards}

Water boards are public bodies like municipalities and provinces. Contrary to provinces and municipalities, however, water boards are functional government bodies. This means that these bodies have a limited task in the sense that they are only involved in the embankment of water, the control of the quantity and quality of water and the control of waterways and roads. Those who benefit from the execution of these specific tasks by water boards are usually those who own land, houses or other real estate. These owners also pay the taxes that are used to fund these tasks and choose their own government board. In this sense, contributions of block grants via the national or provincial government are considered undesirable. In order to defray the costs associated with their tasks, water boards therefore impose a water quantity assessment, payable by those who benefit from the tasks executed by the authority.

Besides water quantity assessments, water boards can also impose particullar charges, 'precario' dues and, based on special acts; water pollution charges. The revenues from the latter charges can be used to defray the costs associated with measures to prevent or reduce the pollution of surface waters. While there were 238 water boards in the Netherlands in 1986, the number of water boards had decreased to 141 in 1990 . A few decades ago there were over 2000 of these authorities in this country. Water boards execute their control in a particular control region. It is possible that there are more water boards for one and the same region. Each water board then performs a separate task, e.g. the embankment of water or the control over the quantity and/or quality of water. The execution of these tasks is usually delegated to water boards by provinces. Only the provinces of Groningen, Frisia and Utrecht execute particular tasks with regard to the control of the quality of surface waters. The municipality of Amsterdam itself also performs particular tasks with regard to the purification of surface waters. Besides a water quantity assessment and a water pollution charge, water boards are also allowed to impose 'precario' dues and charges ("rechten"). Within the framework of the Surface Waters Pollution Act, administrative charges can also be levied for the treatment of requests for the granting or changing 
of licences that are required by the Surface Waters Pollution Act (Belastingwetgeving, 1993). ${ }^{33}$

\subsection{The environmental policy context for ecological taxation in the Netherlands}

As previously shown, the existing administrative relationships between the central government and sub national governments in the Netherlands are also reflected in a particular division of authorities and responsibilities with regard to taxation. A similar division of authorities and responsibilities with regard to policies on specific environmental issues between different governments can also be noticed. Several features of the latter kind of division between governments in the Netherlands are further described below.

\subsubsection{Environmental policy in the Netherlands: general features}

Policies with regard to the environment in the Netherlands, as a Member country of the EU and the OECD, have been strongly influenced by and found a basis in particular developments and ideas of the past. At the beginnings of the 1970 's, for instance, OECD countries accepted the polluter pays principle. Since then, both the Netherlands and the European Community have accepted the principle that "the polluter should bear the expenses of carrying out measures decided by public authorities to ensure that the environment is in an acceptable state. The measures concern pollution prevention, encouraging rational use of scarce resources and avoiding distortions in trade and investments". ${ }^{34}$ The polluter pays principle is formally laid down in article 130R of the European Treaty. ${ }^{35}$ Likewise at the beginning of the 1970 's, in the famous report for the Club of Rome, ${ }^{36}$ warnings were made against an overuse of natural resources and against pollution of the environment. Since an overuse of natural resources and pollution could have detrimental effects on (future) human life, in the report a plea

${ }^{33}$ On the basis of the revenues of the water quantity assessments and the water pollution charge, in 1990, 141 water boards could be classified: (CBS, 1992a)

Size ( $\$ 1000$ guilders):

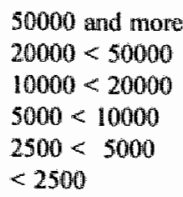

12 water boards
7 water boards
17 water boards
21 water boards
38 water boards
46 water boards

34 Which is the original definition of the OECD as provided in a OECD study of 1972. The quotation here stems from SERV (1992, p. 17).

${ }^{35}$ See SER (1989b, pp. 27-28).

${ }^{36}$ See Meadows (1972), who re-emphasizes these warnings in Meadows et at. (1992). 
was made for a drastic change of the idea that progress should be based on economic growth. ${ }^{37}$ Confronted with increasing environmental problems and a related worseming of the natural state of the environment, the central theme of the greater part of recent environmental policies entails finding a proper balance between economic growth and a natural state of the environment which fulfils the needs of both present. and future generations. At the beginning of the 1970's, the ideas of the Club of Rome, which also influenced environmental policy in the Netherlands, eventually resulted in a legal basis for this kind of policy in this country. ${ }^{38}$ Since then, until the end of the 1970 's, environmental policy in the Netherlands mainly incorporated the elimination of negative environmental effects of particular activities. This found expression in, for instance, a decontamination of soil, water and air. At the end of the 1970 's and the beginning of the 1980's, the focus of environmental policy in the Netherlands was no longer the cleaning and elimination of environmental pollution but prevention of pollution. ${ }^{39}$ In the second half of the $1980^{\prime}$ 's, also the World Commission on Environment and Development (WCED) emphasized the importance of preventive environmental policy. ${ }^{40}$ This kind of policy was considered one of the main aspects of attaining what the WCED termed a sustainable development, i.e. a "process of change in which the exploitation of resources, the direction of investments, the orientation of technological development and institutional change are all in harmony and enhance both current and future potential to meet human needs and aspirations". ${ }^{41}$ In order to achieve a sustainable development, what is necessary is: ${ }^{42}$

A renewed economic growth (3-4\% for developed countries and 5-6\% for less developed countries per year).

A change in the quality of economic growth.

A provision of essential needs (e.g. labour, food, water).

A sustainable size of the population.

Maintaining and improving the environment and maintaining natural resources. Re-orientation of technology.

Integration of economic and ecological interests within decision making.

37 Also see WRR (1992, p. 20).

${ }^{38}$ Ibid.

${ }^{39}$ Ibid., p. 20.

${ }^{40}$ WCED (1987). The report of this commission is also known as the Brundtland report.

${ }^{41}$ Definition as formulated by the SERV $(1992$, p. 16).

${ }^{42}$ See Socio-Economic Council (SER, 1989, p. 11). 
At the end of the 1980 's, with the environment as a subject of great public concern and environmental policy as one of the cornerstones of government policy, sustainable development became the central goal of environmental policy in the Netherlands. ${ }^{43}$ Since the Netherlands, due to its geographical position, is very susceptible to pollution also from outside the country, one of the cornerstones of Dutch environmental policy is recognition of the fact that environmental problems are interrelated. In order to develop a consistent approach, it was decided to draw up an environmental policy plan every four years. The first plan, properly called the National Environmental Policy Plan (NEPP), was published in May 1989. The analysis and the recommendations of the WCED and the concept of sustainable development provided the starting points for the NEPP. ${ }^{44}$ An upgraded and more ambitious version of the NEPP, the National Environmental Policy Plan Plus (NEPPP), was published in June 1990 (see also SER, 1990). Both plans indicate the main lines of future environmental policy in the Netherlands and aim at accomplishing a sustainable environmental development in this country within the duration of one generation. In December 1993, the environmental policy plan for the period 1995-1998 (NEPP-2) was published. With the main purposes of the previous environmental policy plans unchanged, the NEPP-2 describes the main lines of policy actions, necessary to keep these purposes within reach. Table 6.6 provides a brief overview of several environmental policy targets. The table also shows the related and expected (long term) results of the environmental policy measures that are mentioned in the national environmental policy plans.

A central aspect of all environmental plans in the Netherlands is that to explain the environmental system and the effects of disruptions through human interventions, a classification of local, regional, fluvial, continental and global levels is made. Specific (environmental) problems occur at each level but they are all interrelated. In order to reflect the integral approach to environmental policy, problems and solutions are described in terms of eight key themes covering the most important environmental problems. These themes include climatic change and the depletion of the ozone layer, acidification, eutrophication, diffusion, waste disposal, other disturbances such as excessive noise, dehydration and the "squandering" of natural resources.

Besides using key themes for environmental policy, it was also decided to identify several important target groups. Target groups are defined as sets of actors who not only cause environmental pollution by their actions but who also form communities and which therefore can be tackled as a group. These groups include farmers, traffic and transport companies, industries, electricity and gas companies and consumers. The central objective is to work out environmental policies in co-operation with the target groups and the authorities concerned.

${ }^{43}$ VROM-ministry (1992). For a more detailled application of the sustainability principle to the Netherlands, see Hueting (1974) and Hueting et al. (1992).

${ }^{44}$ See SER (1989b, p. 7). 
Relevant frameworks

\begin{tabular}{|c|c|c|c|c|c|c|}
\hline $\begin{array}{l}\text { Enviran- } \\
\text { mental Pro- } \\
\text { blemt }\end{array}$ & Unit & $\begin{array}{l}\text { Actual } \\
\text { situation in } \\
1990\end{array}$ & $\begin{array}{l}\text { Targer to be } \\
\text { achioved in } \\
2000\end{array}$ & $\begin{array}{l}\text { Target to be } \\
\text { achileved tis } \\
2010\end{array}$ & $\begin{array}{l}\text { Eupected } \\
\text { results in } \\
2000 \text { on the } \\
\text { basis of } \\
\text { NEPP-2 }\end{array}$ & $\begin{array}{l}\text { Expected } \\
\text { reswhts in } \\
2010 \text { on the } \\
\text { bosis of } \\
\text { NEPP-2 }\end{array}$ \\
\hline $\begin{array}{l}\text { Emission of } \\
\mathrm{CO}_{2}\end{array}$ & $\begin{array}{l}\begin{array}{l}\text { billion } \\
\text { kilogram }\end{array} \\
\end{array}$ & 184 & $173-177$ & & 177 & \\
\hline $\begin{array}{l}\text { Usage of } \\
\text { CFCs }\end{array}$ & $\begin{array}{l}\text { million kilo- } \\
\text { gram }\end{array}$ & 7,7 & 0 & & 0 & \\
\hline $\begin{array}{l}\text { Emission of } \\
\mathrm{NH}_{3}\end{array}$ & $\begin{array}{l}\text { million kilo- } \\
\text { gram }\end{array}$ & 216 & 82 & $25-50$ & 86 & 70 \\
\hline $\begin{array}{l}\text { Emission of } \\
\mathrm{NO}_{\mathrm{x}}\end{array}$ & $\begin{array}{l}\text { million kilo- } \\
\text { gram }\end{array}$ & 576 & $238-243$ & $60-120$ & 366 & 227 \\
\hline $\begin{array}{l}\text { Emission of } \\
\mathrm{SO}_{2}\end{array}$ & $\begin{array}{l}\text { million kilo- } \\
\text { gram }\end{array}$ & 207 & $75-90$ & $50-100$ & 92 & 75 \\
\hline $\begin{array}{l}\text { Acid deposi- } \\
\text { tion } 2000\end{array}$ & $\begin{array}{l}\text { acid equiva- } \\
\text { lent per hec- } \\
\text { tare }\end{array}$ & 4500 & $<2400$ & 1230 & 2600 & 2000 \\
\hline $\begin{array}{l}\text { P discharged } \\
\text { to surface } \\
\text { water }\end{array}$ & $\begin{array}{l}\text { million kilo- } \\
\text { gram }\end{array}$ & 25 & 8 & $3 \times 8$ & 15 & 14 \\
\hline $\begin{array}{l}\text { N discharged } \\
\text { to surface } \\
\text { water }\end{array}$ & $\begin{array}{l}\text { million kilo- } \\
\text { gram }\end{array}$ & 258 & 75 & $25-75$ & 160 & 125 \\
\hline $\begin{array}{l}\text { Priority sulb- } \\
\text { stances }\end{array}$ & index & 80 & $<40$ & & 50 & \\
\hline $\begin{array}{l}\text { Enission of } \\
\text { volatile orga- } \\
\text { nic substan- } \\
\text { ces (VOC) }\end{array}$ & $\begin{array}{l}\text { million kilo- } \\
\text { gram }\end{array}$ & 459 & 193 & 117 & 255 & 230 \\
\hline Waste & $\begin{array}{l}\text { billion } \\
\text { kilogram }\end{array}$ & 22,5 & 14,5 & 14 & 14 & 14 \\
\hline $\begin{array}{l}\text { Noise } \\
\text { muissance road } \\
\text { traffic }\end{array}$ & $\begin{array}{l}\text { \% seriously } \\
\text { annoyed }\end{array}$ & 20 & 19 & 0 & 15 & 11 \\
\hline $\begin{array}{l}\text { Dellydration: } \\
\text { ground water } \\
\text { depletion }\end{array}$ & $\begin{array}{l}\text { depleted land } \\
\text { area index }\end{array}$ & 100 & 75 & - & 80 & 67 \\
\hline $\begin{array}{l}\text { Enwironmen- } \\
\text { tal costs }\end{array}$ & $\%$ of GNP & 2,0 & . & - & 3,1 & 2,7 \\
\hline
\end{tabular}

Table 6.6 Environmental policy in the Netherlands: targets and (expected) results. Source: National Enwironmental Policy Plan-2 (1993, p. 16). 
An important feature of Dutch environmental policy is the two track policy, i.e. it is directed both at sources and effects of environmental problems. Besides key themes and targets groups; the third feature of environmental policy in the Netherlands is the orientedness of this policy towards specific regions. The central idea of region oriented environmental policies in the Netherlands is that by setting regional targets in those cases in which national targets do not suffice for particular environmental problems, the effectiveness of environmental policies can be increased. The effectiveness can be increased by taking into consideration the fact that there are differences in the emissions, vulnerability and functions of different regions. This is what a region or region oriented environmental policy tries to accomplish. Besides for environmental problems that occur within the borders of a specific region (e.g. those related to dehydration, disturbances, eutrophication of ground and surface waters and ammonia resulting from agricultural activities), region oriented environmental policy in the Netherlands is also directed towards regions in which there are (or will expectedly be) important differences between the desired and actual environmental quality. ${ }^{45}$

More specifically, with a general environmental quality norm as a basic point of reference, different types of regions can be distinguished ${ }^{46}$ First, there are regions that fulfil special functions, which can only be maintained by environmental conditions that are higher and/or stronger than the general environmental quality norm. Second, there are regions for which the environmental or spatial quality is already higher than the general environmental quality norm but for which this quality can only be maintained via additional measures. Finally, there are regions that have so many environmental problems that the general environmental quality norm can not be met. Additional measures are necessary to maintain these regions. On the basis of the Environmental Protection Act ('Wet Milieubeheer'), the national and provincial level(s) of government in the Netherlands, within their environmental policy plans, can indicate particular regions, that are considered to be in need of a special protection.

In 1990, a so-called "action plan region oriented environmental policy" was formulated. ${ }^{47}$ Within this action plan, attaining the environmental conditions that are necessary for a sustainable development of the living environment is described as the central aim of region oriented environmental policies in the Netherlands. In this country, there are sectoral and integrated region oriented environmental policies. Sectoral region oriented environmental policy is aimed at one aspect of the environmental quality or at one function of the region in question. In the former case, the local or regional environmental quality is so low or so high that a special environ-

45 For a more elaborated description of the main elements of region oriented environmental policy in the Netherlands, see Backes et al. (1992).

46 Schoof (1991, p. 468).

47 Tweede Kamer der Staten-Generaal, Vergaderjaar 1990-1991, 21896 , nirs 11-2. 
mental protection seems necessary (e.g. silence regions or soil protection regions). In the latter case, a specific function demands a special protection either because the environmental burden is too high or because the function is very sensitive to the burden in question (e.g. ground water protection regions). Integrated region oriented policy is aimed at several functions and at more than one aspect of the environmental quality. This policy seems desirable in case a particular region fulfils several functions or copes with several regional or fluvial environmental problems, which demand an integrated region oriented approach (e.g. ROM regions, North Sea, particular river basins etc.).

\subsubsection{Environmental policy by sub national public bodies in the Netherlands}

A significant part of environmental policy in the Netherlands is executed by provinces, municipalities and water boards. Besides licencing, sub national governments in this country also have important environmental tasks as regards the decontamination of soil and sound, the prevention and disposal of waste, sewerage, the purification of water, the protection of particular regions, energy savings and environmental education. ${ }^{48}$

Although sub national governments in the Netherlands administer and enforce a significant part of environmental policies, these policies can not be considered outside the context of the national environmental policy plans (NEPP's). In 1990, after the publication of the first NEPP, for instance, the national government and the representative organizations of the provinces, municipalities and water boards in the Netherlands decided that, as far as possible, environmental policies would be executed together. This agreement has had important consequences for the environmental policies that, since then, have been pursued by sub national governments in this country. In the national environmental policy plans it is stated, that the basic principle of environmental policy in the Netherlands is the translation of goals with regard to environmental themes into targets for target groups. ${ }^{49}$ This translation then provides the starting points for behavioural changes. Due to this central principle, a translation of goals with regard to environmental themes into provincial or regional targets only occurs if special circumstances require such a translation. In the second NEPP a translation to provincial or regional targets is considered necessary only for those environmental problems that are related to dehydration, disturbances, eutrophication of ground and surface waters and ammonia resulting from agricultural activities. In those cases in which national targets do not suffice for particular environmental problems, regional targets can be formulated within the environmental policy plans of provinces.

48 Tweedle Kamer der Staten-Generaal (1993), Milieuprogramma 1994-1997 (p. 120-121).

49 The groups include agriculture, industries, oil refineries, energy companies, 'retail trade', traffic, consumers, building sector, waste disposal plants, drink water companies, sewerage and water cleansing industries. 
Under these specific circumstances, provincial and regional targets can be set and be further translated into specific targets for companies or industries.

Besides translating targets with regard to specific environmental themes into provincial and regional targets, provinces, regional government bodies (i.e. water boards) and local government bodies (i.e. municipalities) in the Netherlands also have important tasks with regard to the execution of environmental policy and environmental policy acts, e.g. the Environmental Protection Act. A central aspect of the Environmental Protection Act, which was passed in March 1993, is the planning of environmental policy. On the basis of the act, the national government and provinces are obliged to publish an environmental policy plan every four years. Likewise these levels of government are obliged to yearly publish an environmental program. The program monitors the progress of the environmental policy plan. Municipalities are not obliged to publish an environmental policy plan. In the Environmental Protection Act (see Aalders, van et al, pp. A 1-16/A 1-17) it is stated that municipalities are obliged to yearly draw up a municipal environmental program. A main element of this program is an overview of the activities that need to be conducted by municipalities within the context of the environmental tasks appointed to these governments by law. Besides a representation of the financial consequences of these activities, municipalities are also obliged to draw up a sewerage plan for a particular period of time. The sewerage plan indicates, among others, the sewerage(s) present in the municipality, the expected date at which sewerage(s) should be replaced and the related financial consequences.

Although the environmental policies conducted by sub national government bodies in the Netherlands can not be considered outside the context of the national environmental policy plans, there is no hierarchical relationship between the NEPP's and the environmental plans of provinees (and municipalities). The environmental policy plans of provinces incorporate elements which influence zoning arrangements and the plans of water boards with regard to the control of the quality and quantity of water. Provincial environmental policy plans also function as a hinge for the environmental plans and/or programs of municipalities. In the second National Environmental Policy Plan (NEPP-2), several important environmental policy tasks are mentioned for sub national governments in the Netherlands. The main tasks for provinces include: ${ }^{50}$

1) The drawing up of policy plans in which:

a) Provinces indicate how the main purposes with regard to the environmental themes mentioned in NEPP-2 can be translated for the particular province in question. 193).

${ }^{50}$ Tweede Kamer der Staten-Generaal (1993), Nationaal Milieubeleidsplan 2 (NEPP-2, pp. 192- 
b) Provinces indicate for which regions in the province in question there are specific environmental quality demands.

c) Provinces further detail on their roles with regard to the removal of waste.

d) Provinces further indicate how they handle specific executive powers with regard to policies for the relevant environmental target groups.

2) The drawing up of provincial decrees or regulations for the protection of the environment.

3) The granting of licences or permits. Within the context of the Environmental Protection Act, provinces can make demands on the (production of) waste and the use of raw materials, resources and energy by institutions or plants etc. ${ }^{5 !}$

4) The enforcement of licence conditions and general regulations.

5) The drawing up of executive programmes in which the execution of powers is indicated via plans. Provinces have also, together, drawn up a program for the execution of relevant elements of the National Environmental Policy Plan in question.

6) The implementation of region oriented policies. This task includes the drawing up of regional plans and a 'region oriented' translation of the main targets with regard to the environmental themes mentioned in NEPP-2.

7) The provision of facilities designed to change behaviour especially with regard to the extraction of water and the prevention and disposal of waste.

The main tasks for municipalities or intermunicipal co-operation arrangements mainly include the granting and enforcement of licences. More specific environmental tasks include the execution of specific laws others than those related to licencing, the drawing up of policy and executive plans especially with regard to the disposal of household waste, municipal sewerage and the saving of energy (see NEPP-2). Further tasks include an 'environmental' adaptation of plans (e.g. within location and parking policies and zoning plans) and the introduction of e.g. environmental traffic charts. An additional task for municipalities is the stimulation, communication and provision of information on environmentally relevant subjects, for instance on how to arrive at a proper protection of the environment (e.g. in the case of energy savings).

The main tasks of water boards include the granting and the registration of licences/permits. In addition, they include policy measures with regard to dehydration,

51 In the environmental programme for the period 1994-1997, it is stated that the level of maintenance and licencing by provinces should be adequate by 1995 . 
the drawing up of policy plans and the consultation with municipalities on the drawing up of municipal sewerage plans. ${ }^{5 !}$

For the period 1995-1998, provinces have indicated that their policies will be especially directed towards the industries target group, the problem of waste and towards environmentall policies for specific regions ("buitengebieden"). In order to protect the environment, provinces are obliged to lay down particular decrees (by laws or "verordeningen"). These decrees contain (Aalders, van et al., 1993, pp. A 1-16):

- Regulations with regard to the manner in which particular waste substances should be disposed of.

An indication of the municipalities which should co-operate in the disposal of waste substances and the introduction of regulations by which co-operation can actually be realized.

- Regulations with regard to the protection of the quality of ground water in view of the production of drinking water.

- Regulations with regard to the prevention and reduction of noise nuisance in particular indicated regions.

- Regulations on the composition and working methods of the provincial environment commission.

Water boards have indicated that they will direct their (future) policies mainly towards the reduction of dehydration and the decontamination of (water) soils. Besides this, their policies will also be directed towards the maintenance of the Surface Waters Pollution Act and the execution of existing policy plans, including the NEPP's. Municipalities have decided to give priority to the maintenance of the continuity of municipal policies.

In several areas and sectors that are important from an environmental point of view, sub national government bodies in the Netherlands now play a significant role. The representative organizations of sub national government bodies in this country have come to voluntary agreements with the industries target group. It has been agreed that those industries that are unwilling to produce an environmental plan for their industry will be confronted with higher requirements for relevant permits or licences. In the area of traffic and transport, more than 70 municipalities have introduced environmental traffic charts. The charts indicate the local air pollution and the excessive noise created by car traffic in the municipality in question. In the area of waste, provinces "steer" the direction of the collection of waste substances by way of provincial environmental policy plans, environmental decrees and licences. Municipalities play a crucial role in the actual collection of waste substances.

It follows that sub national government bodies in the Netherlands have important responsibilities for particular environmental problems. For local (1 and 2$)$ and

${ }^{52}$ NEPP-2 (1993, p. 195). 
regional levels of government ( 3 and 4 ), the main environmental policy purposes are related to:.$^{53}$

1) The prevention of soil and water related environmental problems, local air pollution and excessive noise.

2) Achieving a sustainable living environment in rural and non rural municipalities

3) Repairing the functions of the environment for the provision of drinking water, sustainable types of agriculture, living in rural regions and for recreation.

4) Creating possibilities for the development and the preservation of landscapes and nature.

\subsubsection{Environmental policy instruments in the Netherlands}

To achieve the policy targets described above, governments in the Netherlands use different environmental policy instruments. The most important categories of environmental policy instruments include the instruments that are based on public law and the instruments that are based on private law. The former include direct regulation instruments (e.g. the setting of environmental laws and requirements, environmental planning, the granting of licences) and financial regulation instruments (e.g. environmental levies, subsidies and compensation payments). The latter include voluntary agreements and liability arrangements for environmental damages.

For the administration and/or enforcement of environmental pollicy, governments in this country mainly use legal or direct regulation instruments such as, for instance, environmental laws, provincial and municipal environmental regulations and the issuing of environmental licences. An activity which has particular consequences for the environment is prohibited in the Netherlands unless there is a licence for it. In this sense, the purpose of the granting of licences is not to prohibit particular activities but to regulate these activities by means of licences. In the NEPP-2 (1993) it is stated that, in the near future, the number of activities for which licences are required will be reduced. In addition, different licences will be bundled into one integrative environmental licence, while licencing procedures will be simplified. Whether this all can be achieved and thus whether licencing in the Netherlands can be further improved, depends among others on the further development of the Environmental Protection Act.

Within the context of the central subject of this study and from an economic point of view, the decision to further improve non tax instruments such as licencing, also depends on whether or not tax instruments can be further improved. Compared to economic instruments such as taxes, non tax instruments such as licences are generally considered to be static, inflexible and ecologically and economically inefficient (Op-

${ }^{53}$ Ibid., p. 30 
schoor \& Vos, 1989, p. 24). The inability to respond to changed circumstances is related to the fact that licences generally are in force for a particular designated period of time. Technologies by which emissions can be reduced and the environmental circumstances by which economic actors (e.g. firms) are confronted, however, constantlly change. In addition, the instrument of licencing generally provides no incentives to firms to further develop new and cheaper technologies by which polluting emissions can be reduced ${ }^{54}$ Since, after a designated period of time, emission standards on technologies can be expected to be tightened after the discovery of new technologies, firms will be induced to conceal their discoveries from the control authority (Tietenberg, 1992, p. 374). As argued in chapters 2 and 5 of this study, tax instruments such as Pigouvian taxes, on the other hand, provide an incentive to polluters to search for environmentally friendly technologies. By adopting such technologies, firms can reduce the amount of taxes to be paid. Tax instruments such as tax credits, in addition, provide an incentive to firms to reveal the discovery of new environmentally friendly technologies. By revealing the discovery of such technologies to the control authority, firms can obtain a tax credit and therefore, for instance, a reduction in the (corporate) income tax. In comparison to tax instruments, the use of licences and other direct regulation instruments is generally preferred in practice. This is because control authorities are generally more familiar with command and control instruments (see Bohm and Russell, 1985 and Opschoor and Vos, 1989). Taxes are also generally considered to be intricate, while they may add to inflation (because of price increases) and can be associated with uncertainties as regards tax revenues and environmental effects. In addition, in comparison to direct regulation instruments, taxes are generally considered to be instruments which can only indirectly regulate polluting activities (see Bohm and Russell, 1985 and Opschoor and Vos, 1989). It follows that for each environmental issue, a comparative analysis has to be made of the use of non tax and tax instruments. In addition, possibilities to further combine the attractive features of each set of instruments also have to be analyzed (see Opschoor and Vos, 1989, p. 25 in this respect).

The administrative environmental law in the Netherlands offers governments the legal instruments that can be employed for the use of environmental policies. The administrative environmental law in the Netherlands can be divided into three main parts (see Drupsteen, 1991, pp. 253-271). First, there is the Environmental Hygiene Law. This law includes such acts as the Environmental Protection Act and the Surface Waters Pollution Act. The law and acts are mainly directed towards the protection of the non-biotic environment. Second, there is the Environmental Protection Law. This law includes such acts as the Forestry Act and Nature Protection Act which are mainly directed towards the protection of the biotic environment. Third, there is the Physical Planning and Construction Law. This law which is mainly directed towards

${ }^{54}$ An alternative licencing procedure by which polluting firms can also be induced to search for new environmentally friendly technologies is described in Backhaus (1994). 
the so-called artificial environment consists of, for instance, the Act on Physical Planning.

At this point in time, Environmental Law in the Netherlands mainly consists of Environmental Hygiene Law. In recent decades, Environmental Law in the Netherlands has slowly been developing from a sectoral towards a more integrated Environmental Law. ${ }^{55}$ In 1980, the introduction of the WABM Act, a general environmental provision act in which general regulations with regard to environmental hygiene are formulated, formed the starting point for a more integrated Environmental Law in this country. The WABM Act was introduced in order to bring more unity in certain parts of the environmental legislation in this country. Originally, the act only contained procedural directions which were intended to be specified with those aspects that are common to various laws or which, due to general characteristics, could not be dealt with in a separate sectoral acts or laws. After 1980, the WABM Act was extended, among others, with financial regulations, i.e. with financial subjects that were common to various sectoral acts. Several of these financial subjects were harmonized and/or were further put into uniformity. More specifically, changes involved a replacement of several environmental levies by one levy on fuels; arrangements with regard to the assignment of compensation payments; arrangements with regard to the Air Pollution Fund and arrangements with regard to deposit-refunds.

In 1993, the WABM Act was renamed and changed into the Environmental Protection Act ('Wet Milieubeheer'). Important (future) elements of the Environmental Protection Act include environmental policy, licencing, environmental planning and environmental quality requirements. Serving as an integrative environmental law, the Environmental Protection Act $^{56}$ incorporates (elements) of several environmental acts in the Netherlands, including the Mining Act 1903, the Act on Nuclear Energy, the Act on Waste Substances, the Act on Noise Nuisance, the Ground Water Act, the Air Pollution Act, the Surface Waters Pollution Act, the Pollution of Sea Water Act, the Act on Chemical Waste Substances, the Act on Environmentally Hazardous Substances and the Soil Protection Act. ${ }^{57}$

Besides direct regulation instruments, financial and social regulation instruments are also used for the administration and enforcement of environmental policy in this country. Although financial regulation instruments are usually embedded into a particular law or legal framework, these instruments are usually distinguished from legal or direct regulation instruments because they only indirectly influence the behaviour of citizens (see Drupsteen, 1991). The use of financial and fiscal regulation instruments for (in)direct ecological purposes in the Netherlands are more explicitly

\$5 This section is mainly based on Drupsteen (1991, pp. 253-271).

s6 This part of the section is mainly based on Aalders, van et al. (1993/1994).

57 The Act on Waste Substances and the Act on Chemical Waste Substances fell into decay in 1994. 
discussed in chapter 7. In recent years, instruments based on private law such as voluntary arrangements, have become increasingly important for environmental policies in the Netherlands. Liability arrangements, based on civil liability law, have also become increasingly important. In the near future, supporting provisions, with which it is possible to (further) enhance the effectiveness and efficiency of these instruments; will also be introduced. Supporting provisions include information, the monitoring of the results of changes in environmental behaviour by different target groups and the use of marketing techniques for the execution of environmental policies. In the Environmental Program for 1994-1997 (p. 113), the fact that the environment can be considered a problem of information, awareness, organization and governance, is mentioned as the point of departure for the design of social instruments. In chapter six of the NEPP-2, the further development of environmental policy instruments in the Netherlands is described. In the near future, it can be expected that existing instruments will be further improved and that additional policy instruments will be introduced. These instruments can be expected to be embedded into a clearly formulated framework of instrumental choice and be supplemented by supporting provisions which increase the effectiveness and efficiency of different instruments. More specifically, it can be expected that the development will be aimed at stimulating self regulation, ${ }_{9}^{58}$ at improving the application of a mixed set of instruments, at stimulating the internalization of the use of the environment into prices and at improving the quality of different types of instruments (p. 179).

\subsection{Implications for the use of taxes for ecological purposes in the Netherlands}

It follows from the previous considerations that the existing administrative, financial and environmentall policy framework in the Netherlands provides both restrictions and opportunities for the use or introduction of ecologically relevant taxes in this country. Especially sub national governments in this country face particular restrictions and inflexibilities as regards the introduction or (further) use of ecological taxes. The existing administrative and financial relationships between different governments in the Netherlands allow only very limited taxing autonomies to sub national governments. These governments can only impose those taxes that are explicitly laid down by the central government in specific acts and laws. In addition, the design of these taxes is also usually committed to stringent regulations by the central government. To respond to relevant local ecological circumstances by way of taxes generally requires the consent of the central government and the establishment of Special Acts. In addition, the existing administrative and financial relationships between different governments in the Netherlands allow only very limited opportunities for sub national go-

58 The stimulation of self regulation via particular instruments, involves the enlargement of the options for target groups, governments, organizations and citizens to bear their own responsibilities with regard to the environment. 
vernments to impose taxes which can also be used for allocational instead of fiscal ends. Moreover, existing administrative and financial relationships only marginally allow inequalities in the capacities of these governments to tax or to provide particular public goods. For the use of taxes for ecological purposes in the Netherlands, this implies that the existing administrative and financial framework provides particular inflexibilities and restrictions on the level and/or authority by which these taxes can be imposed, on the design and purpose of these taxes and on the possibilities to differentiate the imposition of ecological taxes throughout the country.

In recent years, the changing intergovernmental and financial relationships in the Netherlands have also provided several opportunities for the introduction or use of taxes which can be more clearly related to relevant ecological circumstances and ecological levels. More specifically, these developments and related opportunities include the introduction of regional governments in response to the changing responsibilities between governments in the Netherlands and the intention to strengthen the financial independence of sub national governments. The latter is expressed by the intention to increase the possibilities of these governments to raise revenues by means of own taxation. In addition, developments and opportunities include the intention to further enhance co-operation arrangements between different governments in this country and the fact that, in recent years, provinces have gained increasing responsibilities for environmental protection.

Opportunities to further relate taxes to relevant ecological circumstances are also provided by the existing environmental policy framework in the Netherlands. More specifically these opportunities involve the recognition by environmental policy that certain environmental problems occur at a specific ecological or economic level, which should constitute the basis for environmental policies and the input of particular policy instruments. In addition, opportunities consist of the orientation of environmental policy towards specific environmentally relevant regions and the recognition by environmental policy that preventive environmental policies and an internalization of environmental externalities into prices can play an important role in achieving sustainable growth. In recent years, also the execution of a significant part of environmental policies in the Netherlands has been delegated to provinces, municipalities and water boards. These governments mainly perform environmental tasks that are related to the decontamination of soil and sound, the prevention and disposal of waste, sewerage, the purification of water, protection of particular regions, energy savings and environmental education (see section 6.4). It follows that although, at present, there are strict rules for sub national governments in the Netherlands to impose and use taxes and levies for particular ecological purposes, these governments at the same have increasing opportunities to use these taxes for these purposes in the near future. These opportunities are due to changing intergovernmental and financial relationships and the incorporation of particular conceptions within the existing environmental policy framework. Within the context of these opportunies and restrictions, in the following chapter(s) an overview is provided of the present and potential future use of environmental taxes in the Netherlands. 


\section{Ecological Taxation in The Netherlands}

\subsection{Introduction}

The main purpose of this chapter is to describe the current use of ecologically relevant taxes in the Netherlands in order to determine the most important features of ecological taxation by different levels of government in this country. After the introduction, section 7.2 provides an overview of the main environmentally relevant levies and taxes currently imposed in this country. This overview also includes particular tax provisions that are used in this country and that have particular (un)desirable effects on the environment. The chapter ends with several conclusions and remarks.

\subsection{An overview of environmentally relevant levies in the Netherlands}

\subsubsection{Environmental levies}

In the Netherlands, environmentally relevant levies include those that are used as an environmental policy instrument in order to achieve particular environmental policy purposes and those that are used as a fiscal instrument in order to raise tax revenues. The main environmental levies and related charges that can be imposed by the national government in the Netherlands include (see also Paulus, 1994b):

- $\quad$ Environmental user taxes on fuel such as taxes on mineral oils, LPG, coal, gas and fuel used by the natural gas and chemical industry.

Regulatory environmental user taxes on leaded and unleaded light oil.

A noise charge on civil aviation.

A charge on surplus manure.

A livestock fodder charge.

A water pollution charge for national waters.

Sub national governments in the Netherlands can impose:

A water pollution charge for regional waters (provinces, municipalities and water boards).

A charge for soil protection (provinces).

A ground water charge (provinces).

A waste disposal tax (municipalities).

Refuse collection charges (municipalities).

Sewer(age) charges (municipalities).

Water quantity assessments (water boards). 


\begin{tabular}{|c|c|}
\hline Environmental levies & $\begin{array}{l}\text { Authority permitted to introduce, change or } \\
\text { abolish environmental levies }\end{array}$ \\
\hline (Regullatory) charges on mineral oils & General tax service ("Rjjksbelastingsidienst") \\
\hline Environmental user charges on fuels & $\begin{array}{l}\text { Minister of Finance (prior to } 1992, \text { Minister of } \\
\text { Physical Planning and the Environment) }\end{array}$ \\
\hline Noise charge on civil aviation & $\begin{array}{l}\text { Minister of Traffic and Public Works in co- } \\
\text { operation with those who exploit the airport }\end{array}$ \\
\hline National water pollution charge & $\begin{array}{l}\text { Minister of Traffic and Public Works. For the } \\
\text { collection of the charge, co-operation is possible } \\
\text { with the general tax service. }\end{array}$ \\
\hline Provincial water pollution charge & $\begin{array}{l}\text { The Provincial Executive ("Provinciale Staten") } \\
\text { of the province in question }\end{array}$ \\
\hline Municipal water pollution charge & Municipality in question \\
\hline Water board: water pollution charge & Water board in question \\
\hline Charge for soil protection & The Provincial Executive \\
\hline Waste disposal tax and refuse collection charges & Local Council ("Gemeenteraad") \\
\hline Ground water charge & The Provincial Executive \\
\hline Charge on surplus manure & $\begin{array}{l}\text { Minister of Agriculture, Nature Preservation and } \\
\text { Fishery }\end{array}$ \\
\hline
\end{tabular}

Table 7.1 Authorities permitted to introduce, change or abolish particular environmental levies. Source: Based on Boele et al. (1992, chapter 9, pp. 195-204).

Except for refuse collection charges and sewer(age) charges, all environmental levies can be imposed on the basis of a specific environmental act. Refuse collection charges and sewerage charges can be imposed by municipalities on the basis of the Municipality Act. Generally, there are different decrees or regulations for the introduction, change or abolishment of different environmental levies. Table 7.1 summarizes the main features. In general, environmental levies can be introduced, changed or abolished by law. For levies that are imposed by sub national governments, there are strict regulations. If the imposition of a particular environmental levy by sub national governments is allowed for by law, the actual introduction, change or abolishment of this levy requires a provincial, municipal or water board tax regulation or decree ("belastingverordening"). The main elements of the levies and charges indicated in Table 7.1 are further discussed below. The discussion mainly represents the situation prior to the introduction of the Environmental Protection Act in 1993. Prior to the introduction of this act, the legal basis for the imposition of environmental levies in the Netherlands was provided by the WABM Act (see section 7.2.2 below). 
Since 1993, the Environmental Protection Act and a new Act on Environmental User Taxes form the legal basis for the imposition of these levies in this country. Where possible and relevant, the implications of the introduction of the Environmental Protection Act for the imposition of environmental levies are also considered in the following sections.'

\subsubsection{Environmental user charges on fuels and regulatory charges on mineral oils}

Prior to 1988, the system of environmental levies in the Netherlands was a so-called sectoral system, i.e. a system in which the imposition of environmental levies is mainly based on different sectoral environmental acts, e.g. the Air Pollution Act, the Act on Waste Substances, the Soil Protection Act etc. In 1988, with the introduction of earmarked charges on fuel (the so-called WABM fuel charges), part of this sectoral system was replaced by a more integrated system of environmental levies. Besides structurally changing the existing system of charges, the introduction of these fuel charges also changed the way in which particular environmental policies in the Netherlands had, until then, been financed. The new fuel charge was introduced as a single replacement of charges that could previously be imposed on the basis of the Air Pollution Act, the Act on Waste Substances, the Act on Noise Nuisance, the Act on Chemical Wastes and the Soil Protection Act. ${ }^{2}$ The Air Pollution Act allowed the imposition of levies with regard to apparatus/machines ("toestellen"), fuels and installations ("inrichtingen"). Since 1972, only a levy on fuels had been imposed on the basis of this act. The Act on Waste Substances permitted the imposition of levies with regard to goods, motor vehicles, car wrecks and licensees. No levies on the basis of this act have ever been introduced in the Netherlands. The Act on Noise Nuisance allowed the imposition of levies with regard to apparatus or machines, installations, motor vehicles and mopeds and fuels. On the basis of the act, only a levy on particular fossil fuels and a levy on installations had been imposed since 1981 and 1982, respectively. The Act on Chemical Wastes permitted the imposition of levies with regard to licensees, the application of chemical processes and with regard to mineral lubricating and system oil. On the basis of the act, a levy on mineral lubricating and system oil had been imposed since 1979. A levy on chemical waste substances had been imposed since 1981. The Soil Protection Act is further discussed in section 7.2 .5 .

I In the tax law of 1994 (Belastingwetten 1994) and in Aalders, van et al. (1993/94), in which the environmental regulations for the Netherlands are described, the environmental levies which can be imposed on the basis of the Environmental Protection Act are not yet explicitly mentioned.

2 See Boele ef al. (1992, pp. 39-40). The part of the section which describes the development of WABM fuel charges and the replacement of these taxes by environmental user taxes is based on chapter 2 of Boele et al. (1992). 
The revenues of the charges that had actually been imposed at that time (i.e. prior to 1988) covered only one-third of total environmental policy expenditures in the Netherlands. The greater part of these revenues (approximately $75 \%$ ) was raised by levies on fuell (Opschoor and Vos, 1989). This and the fact that almost none of the charges had incentive effects, resulted in a replacement of these charges by one general fuel charge in 1988. The general fuel charge is partly a mineral oil excise duty and partly a levy (see Opschoor and Vos, 1989). The main features of the general fuel charge and the resulting changes of the then existing sectoral system of environmental levies are shown in Table 7.2.

\begin{tabular}{||l|l|l|l||}
\hline Previous system & & New Fuel Charge & \\
\hline Charge & Revenues (1985: Ecu) & Target groups & $\begin{array}{l}\text { Revenues (1988: Ecu } \\
\text { expected) }\end{array}$ \\
\hline Chemical waste & 0,9 million & Industry & 28,4 million \\
\hline Industrial noise & 9,9 million & Traffic & 82,6 million \\
\hline Lubricating oil & 0,9 million & Households and others & 18,1 million \\
\hline Fuell (Air pollution) & 40,9 million & - & - \\
\hline Fuel (Traffic noise) & 27,9 million & - & - \\
\hline Total & 80.5 million & Total & 129.1 million* \\
\hline $\begin{array}{l}\text { * The revenues of the general fuel charge were (at that time) expected to increase from } 286 \text { million } \\
\text { guilders in 1989 to } 1543 \text { million guilders and } 2209 \text { million guilders in } 1992 \text { and 1994, respectively } \\
\text { (see Boele et } \text { al. 1992, p. 36). }\end{array}$ \\
\hline
\end{tabular}

Table 7.2 The new general fuel charge in the Netherlands. Source: Opschoor and Vos $(1989$, p. 59$)$.

The general fuel charge was introduced in 1988 by including financial regulations into the WABM Act. The charge was introduced as an earmarked charge. The revenues could be used as funding sources for direct environmental expenditures as prescribed in the WABM Act. The revenues from ordinary revenue raising taxes provided the funding sources for indirect environmental expenditures. The introduction of the general fuel charge in 1988 followed several discussions that had been held in the Netherlands ever since the mid seventies. During the seventies, environmental levies and alternative financing schemes for environmental policy had been discussed in different Policy Memoranda, including a Memorandum on instruments, one on environmental levies and one on alternative funding schemes. ${ }^{3}$ The first two Policy Me-

3 See Boele er al. (1992) for a more elaborate discussion of the following Memoranda: -Tweede Kamer der Staten Gieneraal (1974/75), Nota instrumenten millieuhygienisch beleid, heffingen en fysieke reguleringen, Bijlage bij Kamerstukken II 1974/75, 13100, hoofdstuk XVII, nr. 2. 
moranda drew attention to the use of specific instruments for environmental policy purposes within the context of a specific interpretation of the polluter pays principle. Following these two Memoranda, the Policy Memorandum on alternative funding schemes described the basic disadvantages of a sectoral system of environmental levies. The fact that, under such a system, different levies could be imposed on one and the same product was considered one of the main disadvantages of the system. At the same time, since such a system requires the presence of a structure in which many small levies can be imposed and be introduced in different application areas, the relatively high administrative costs that are related to such a system were considered another important disadvantage.

Against this background, four alternative funding schemes were considered. ${ }^{4}$ First, a categorical system in which levies are imposed on different categories of polluters (e.g. industrial installations, traffic and transport and products). Under this system, revenues can be used to defray the costs of reducing the pollution produced by the category in question. Second, a financing system with levies on basic products. In this system, levies can be imposed on raw materials, intermediate goods and fuels. Third, a system in which environmental policies are funded by general means and finally, a system with levies on fuel.

A categorical system of environmental levies was considered undesirable because of the difficulties related to the determination of the emissions resulting from industrial processes and with regard to selecting the installations and pollution components liable for taxation. In addition, it was expected that a categorical system would be associated with high perception costs..$^{5}$ A funding system with levies on basic products was considered a simple but undesirable system, mainly because of expected technical and administrative problems and a high burden for only a very small part of producers. A system in which environmental policies were funded by general means was considered undesirable because of the inconsistence with the polluter pays principle.

Within the previous context, a funding system based on levies on fuel was considered the most desirable system, although such a system would also not be fully consistent with the polluter pays principle. The main advantages of the system, however, were considered to be the fact that the greater part of different categories of polluters could be confronted with one general levy, whille further information could

-Tweede Kamer der Staten Generaal. (1979), Nota Milieuheffingen, Kamerstukken II, 1978/79, 15658 .

-Tweede Kamer der Staten Generaal (1984/85), Notitie altematieve financieringsstelsels, Kamerstukken II, $1984 / 85$, UCV 107.

4 See Boele et al. (1992, p. 43-46).

5 Ibid, p. 44 
The revenues of the charges that had actually been imposed at that time (i.e. prior to 1988) covered only one-third of total environmental policy expenditures in the Netherlands. The greater part of these revenues (approximately $75 \%$ ) was raised by levies on fuel (Opschoor and Vos, 1989). This and the fact that almost none of the charges had incentive effects, resulted in a replacement of these charges by one general fuel charge in 1988 . The general fuel charge is partly a mineral oil excise duty and partly a levy (see Opschoor and Vos, 1989). The main features of the general fuel charge and the resulting changes of the then existing sectoral system of environmental levies are shown in Table 7.2.

\begin{tabular}{|l|l|l|l|}
\hline Previous system & & New Fuel Charge & \\
\hline Charge & Revenues (1985: Ecu) & Target groups & $\frac{\text { Revenues (1988: Ecu }}{\text { expected) }}$ \\
\hline Chemical waste & 0,9 million & Industry & 28,4 million \\
\hline Industrial noise & 9,9 million & Traffic & 82,6 million \\
\hline Lubricating oil & 0,9 million & Households and others & 18,1 million \\
\hline Fuel (Air pollution) & 40,9 million & - & - \\
\hline Fuel (Traffic noise) & 27,9 million & - & - \\
\hline Total & 80.5 million & Total & 129.1 million* \\
\hline $\begin{array}{l}\text { * The revenues of the general fuel charge were (at that time) expected to increase from } 286 \text { million } \\
\text { guilders in } 1989 \text { to } 1543 \text { million guilders and } 2209 \text { million guilders in } 1992 \text { and } 1994, \text { respectively } \\
\text { (see Boele et al., } 1992, \text { p. } 36 \text { ). }\end{array}$ \\
\hline
\end{tabular}

Table 7.2 The new general fuel charge in the Netherlands. Source: Opschoor and Vos (1989, p. 59).

The general fuel charge was introduced in 1988 by including financial regulations into the WABM Act. The charge was introduced as an earmarked charge. The revenues could be used as funding sources for direct environmental expenditures as prescribed in the WABM Act. The revenues from ordinary revenue raising taxes provided the funding sources for indirect environmental expenditures. The introduction of the general fuel charge in 1988 followed several discussions that had been held in the Netherlands ever since the mid seventies. During the seventies, environmental levies and alternative financing schemes for environmental policy had been discussed in different Policy Memoranda, including a Memorandum on instruments, one on environmental levies and one on alternative funding schemes. ${ }^{3}$ The first two Policy Me-

3 See Boele et al. (1992) for a more elaborate discussion of the following Memoranda: - Tweede Kamer der Staten Generaal (1974/75), Nota instrumenten milieuhygienisch beleid, heffingen en fysieke reguleringen, Bijlage bij Kamerstukken II 1974/75, 13100, hoofdstuk XVII, nr. 2. 
moranda drew attention to the use of specific instruments for environmental policy purposes within the context of a specific interpretation of the polluter pays principle. Following these two Memoranda, the Policy Memorandum on alternative funding schemes described the basic disadvantages of a sectoral system of environmental levies. The fact that, under such a system, different levies could be imposed on one and the same product was considered one of the main disadvantages of the system. At the same time, since such a system requires the presence of a structure in which many small levies can be imposed and be introduced in different application areas, the relatively high administrative costs that are related to such a system were considered another important disadvantage.

Against this background, four alternative funding schemes were considered. ${ }^{4}$ First, a categorical system in which levies are imposed on different categories of polluters (e.g. industrial installations, traffic and transport and products). Under this system, revenues can be used to defray the costs of reducing the pollution produced by the category in question. Second, a financing system with levies on basic products. In this system, levies can be imposed on raw materials, intermediate goods and fuels. Third, a system in which environmental policies are funded by general means and finally, a system with levies on fuel.

A categorical system of environmental levies was considered undesirable because of the difficulties related to the determination of the emissions resulting from industrial processes and with regard to selecting the installations and pollution components liable for taxation. In addition, it was expected that a categorical system would be associated with high perception costs. ${ }^{5}$ A funding system with levies on basic products was considered a simple but undesirable system, mainly because of expected technical and administrative problems and a high burden for only a very small part of producers. A system in which environmental policies were funded by general means was considered undesirable because of the inconsistence with the polluter pays principle.

Within the previous context, a funding system based on levies on fuel was considered the most desirable system, although such a system would also not be fully consistent with the polluter pays principle. The main advantages of the system, however, were considered to be the fact that the greater part of different categories of polluters could be confronted with one general levy, while further information could

-Tweede Kamer der Staten Generaal (1979), Nota Milieuheffingen, Kamerstukken II, 1978/79, 15658.

-Tweede Kamer der Staten Generaal (1984/85), Notitie altematieve financieringsstelsels, Kamerstukken $11,1984 / 85$, UCV 107.

4 See Boele et al. (1992, p. 43-46).

5 Ibid, p. 44. 
be obtained on the environmental tax burden for polluters. ${ }^{6}$ An additional advantage was seen in the fact that, under such a system, particular environmental taxes could be closely related to existing excise taxes on mineral oils. This makes the system relatively simple. In addition, a funding system based on fuel levies was expected to be accompanied by relatively low perception costs.

Besides the introduction of fuel charges of which the revenues could be used to fund particular environmental policies, in the Policy Memorandum also the introduction of regulatory product charges was emphasized. These charges could be used to induce environmentally friendly behaviour and production processes. Regulatory charges were considered desirable for those cases in which there was no need to prohibit completely that which would be taxed, in which environmentally friendly alternatives were present at relatively low costs and in which there were low perception costs. In addition, regulatory charges were considered to be desirable in those cases in which regulatory charges would not hinder international competitiveness and in which particular environmental problems were mainly related to (the use of) products. Regulatory charges on installations were considered undesirable for technical, administrative and enforcement reasons.

The general fuel charge system, in which charges are imposed on different fuels according to their carbon and energy content ( $50 \%$ each), was introduced in the Netherlands in April 1988. The fuels which can be taxed include light oils, semi heavy oils, light and heavy fuel oil, LPG, coal and gas. Specific fuels that are used by installations which produce more than a stated amount of natural oil or chemical products are also included in the charge. The general fuel charge was intended to be levied on the basis of the amount of fuel used. Since the charge was introduced as an earmarked charge, tax rates were determined on the basis of the required amount of revenues. These revenues were used to defray the costs of direct environmental expenditures. Precise tax rates were described in the WABM Act. Those who used, created, produced or imported the fuel in question were liable for the general fuel charges. Since the introduction of the general fuel charge in the Netherlands, basic elements of the charge have been discussed on different occasions and in different acts. During these discussions, several points of criticism have been made. Among others, questions were raised in relation to the difficulties involved in distinguishing direct from indirect environmental expenditures. Further questions were raised on the questionable relationship of the charge with the polluter pays principle, on the lack of a proper calculation of the exact rates of the charge and on the uncertain relationships between those who paid the charge and those who benefitted from the use of the revenues of the charge. ${ }^{7}$

In 1992, following these discussions, the earmarked general fuel charge was converted into a user tax on fuel. The conversion was formally laid down in the Act

6 Ibid, p. 45 .

7 See Boele et al. (1992, p. 50-56). 
on Fuel User Taxes with an Environmental Tax Base, which came into operation in July 1992. Although the basic elements of the general fuel charge (i.e. tax base, energy/carbon content etc.) did not change, the user tax on fuel differed from the general fuel charge in the sense that revenues were no longer earmarked to be used for environmental policy measures. Instead, revenues could be used to fund general and not necessarily environmental policy measures. In 1992, also the regulatory user charges were converted into regulatory user taxes. Since the introduction of the user taxes on fuel, possibilities to further broaden the tax base of these taxes have been discussed. In 1992, the introduction of an Act on Environmental User Taxes was proposed. One of the central elements of this act is an extension of the user taxes on fuel with user taxes on ground water and waste. This act was introduced in 1995.

\subsubsection{Noise charge on civil aviation}

Noise charges on civil aviation can be imposed on the contribution to the nuisance of noise by airplanes in particular "noise" zones. Liable are those who own, keep or use an air craft which lands on particular airports in the Netherlands. For an air craft which weighs less than 6000 kilograms, no taxes have to be paid. The imposition of these levies is formally laid down in several acts. In a bill of 1986, in which it is suggested that the imposition of noise charges should be included in the Air Traffic Act, these levies are presented as (earmarked) taxes. In the bill, the users of an air craft are no longer considered liable for these levies. In addition to a fixed basic levy, which is based on the amount of revenues needed to defray the costs of insulation, taxes are also based on the contribution to the production of total noise by a single air craft. The basic tax rate is set at approximately fl 35,00 . Since part of the revenues of the noise charges is used for insulation, they also finance part of the environmental policy in the Netherlands (see Boele et al., 1992, p. 65).

\subsubsection{Water pollution charge}

Following Boele et al. (1992), the organization of the control of surface waters in the Netherlands can be categorized in terms of three dimensions: 1) the controlling authority (the central government or sub national government bodies); 2) the subject to be controlled (the quality or quantity of water); 3) the manner of control (active or passive). The central government only passively controls national surface waters. Regional control authorities both actively and passively control regional surface waters. Provinces can delegate their control tasks to water boards. Water boards can be assigned to control the embankment of water, the quality and/or quantity of surface waters and roads and waterways (see Schuddeboom, 1990). ${ }^{8}$ The passive control of

B Schuddeboom (1990) also indicates that for a reduction of diffuse discharges, the Surface Waters Pollution Act in the Netherlands is less suitable if not unsuitable. 
the quality of surface waters is related to licencing and the levying of water pollution charges. The active control of this quality is related to the installation and control of, for instance, sewage treatment plants ("RWZI's"). To indicate the main elements of their control policies, control authorities are obliged to draw up a so-called water quality plan on the basis of the Surface Waters Pollutions Act. The latter act was passed in the Netherlands in 1970 . This act provides both the legal instruments to control the quality of surface waters in this country and a system to finance the necessary control measures. The latter include measures that are necessary to protect aquatic ecological systems and the use of surface waters for the preparation of drinking water.

To defray the costs of measures that prevent or reduce the pollution of surface waters, the national government and provinces and authorized public bodies (e.g. municipalities, water boards or intermunicipal co-operation arrangements) can impose water pollution charges on those who (in)directly emit polluting substances into these waters. These charges can also be imposed on those who control a related installation or public work (e.g. a sewerage). In order to defray the costs of preventing the pollution of surface waters, the latter bodies themselves can impose a fee ("bijdrage") on those who are connected directly or indirectly to this installation or work. Since a licence is required for each discharge into surface waters, also administrative charges can be imposed. The revenues of these administrative charges can be used to defray the costs of licencing.

The tax base of the water pollution charges and fees is the amount or the quality or capacity of polluting or harmful waste substances that are emitted into surface waters or related installations or works. For the national government, tax bases are related to different substances. With regard to oxygen-binding (bio-degradable) substances, taxes are imposed on the basis of the average burden on surface waters per 24 hours. This burden is expressed in terms of 'inhabitants equivalents'. For other substances, taxes are based on the number of units of weight of the substances that are emitted into surface waters in the relevant year. These units are expressed in 'polluting equivalents'. 10

Tax rates are determined by the costs of controlling the quality of relevant surface waters and by the natural and aquatic circumstances of the control region (i.e. water board district) in question. Since the national government only passively controls the quality of surface water, tax rates differ from those that are set by sub national government bodies. For the control of regional surface waters, the latter tax rates are determined by dividing the total control costs by the number of polluting units discharged into the control region in question. The national government uses

9 One 'inhabitant equivalent' is equal to the use of 136 gram oxygen per 24 hours.

10 One "polluting equivalent" represents:

* 1 kilogram of the following substances: led, copper, nickel, zinc and chrome.

* 0,1 kilogram of the following substances: mercury ("kwik"), cadmium and arsenicum. 
different tax rates for discharges into fresh and salt water (Boele et al., 1992, chapter 4). In 1992, charges of fl 42,50 and fl 39,50 were imposed per inhabitant equivalent for fresh and salt water, respectively. For sub national governments, tax rates varied between fl 42,24 and $\mathrm{fl} 120,00$. The water pollution charge can be considered an earmarked charge in the sense that there is a relationship between those who pay the charge and those who benefit from the use of the revenues of the charge. In practice, the charge has also raised some important steering effects (see e.g. Schuurman, 1988)

In Boele et al. (1992), several features of a possible future water pollution charge in the Netherlands are described. Since the present charge is imposed on oxygen binding substances and heavy metals by regional controlling authorities and on only the former substances by the central authority, expected features of such a future charge entail a charge on heavy metals to be imposed by the central authority, a charge on the discharges of phosphates into national and regional surface waters and a charge on organic micro pollution. More specifically, possible options for a future water pollution charge entail: ${ }^{11}$

- An incorporation of all substances discharged into surface waters via an extension of the existing tax base of oxygen-binding and (partly) heavy metals with phosphates, organic micro-pollution and other substances.

Leaving the water pollution charge unchanged but defraying all the costs (including those not incorporated in the existing tax base) associated with the quality of surface waters with the revenues of this charge.

Introducing a new tax base for the water pollution charge, e.g. by way of a water quality assessment in which those who benefit from the control of the water board pay accordingly.

Developing standards for a separate incorporation of different substances into the existing water pollution charge as long as this is efficient. As far as the revenues of the charge do not suffice to defray the costs of the control of the quality of water, the introduction of a water quality assessment can be considered. The water quality assessement should preferably be paid by those who have a specific interest in the control of this quality.

In a Policy Memorandum on water management, in which the polluter pays principle is described as one of the basic principles of the future water pollution charge, preferences with regard to the latter option are expressed. ${ }^{12}$ The introduction

${ }^{11}$ See Boele et al. (1992, chapter 4).

12 Tweede Kamer der Staten Generaal (1989/1990), Water voor nu en later (Derde Nota Waterhuishouding), Kamerstukken WI, 21250 , nrs. 1-2,3. 
of a water pollution charge which taxes households according to their actual use of water or according to the number of persons within the household is generally considered undesirable in this country (see Boele et al., 1992, chapter 4).

\subsubsection{The charge for soil protection}

The Soil Protection Act in the Netherlands provides different instruments to prevent or restrain six groups of human activities that (can) lead to a pollution or affection of the soil in its various functions. These activities include the depositing of substances into or on the soil to stay there permanently; the influencing of the structure and quality of the soil; working in/on the soil; transporting substances that can contaminate or pollute the soil; activities which indirectly affect the soil and other activities leading to, among others, an erosion of the soil. ${ }^{13}$

The Soil Protection Act was passed in 1987. Since the beginning of the seventies, the protection of soil and ground water had been formally laid down in different acts, including the Chemical Waste Act, the Act on Waste Substances and the Nuisance Act. On the basis of the Soil Protection Act, which is a framework act which can be filled in with Orders of Council ("Algemene Maatregelen van Bestuur"), provinces can indicate ground water protection regions and soil protection regions. ${ }^{14}$ Ground water protection regions are regions for which a more than general protection of the quality of ground water is needed in order to prepare drinking and industrial water, in case a general protection level does not suffice to properly fulfil this task. The regions can be indicated in a so-called ground water protection plan. Via provincial regulations or decrees on ground water protection, policy intentions can be translated into binding rules. These rules can not be overruled by regulation of the central government in so far as the provincial regulation takes place under co-government (see also chapter 6 of this study). Soil protection regions are regions that have special soil characteristics, which makes them valuable in the sense that, for instance, a particular landscape can be preserved.

To provide additional protection to the ecological value of the soil or the quality of ground water for the fabrication of drinking water, provinces in the Netherlands are thus allowed to indicate so-called soil and ground water protection regions. In the Netherlands, the quality of the soil and ground water have steadily deteriorated due to an overuse of manure substances and pesticides and the discharge of polluting substances, especially in urban and industrial regions. With the option of indicating soil and ground water protection regions, provinces in the Netherlands can offer a

${ }^{13}$ See Vereniging Maastrichtse Juristen voor Milieubehoud/Werkgroep Limburgse Milieuproblematiek (1989, pp. 136-140).

14 Note that provinces are also allowed to indicate regions in which the soil is saturated with phosphates. 
more than general protection to certain regions in their provinces. ${ }^{15} \mathrm{~A}$ general protection can be offered on the basis of Orders in Council following the basic policy lines as described in the relevant environmental policy plans. The Orders in Council which have already been drawn up by provinces in the Netherlands, entail, among others, those related to the use of manure and organic substances and those related to particular discharges of waste water. In order to offer a general protection to soils that are already contaminated, requirements with regard to the quality of the soil can also be set. ${ }^{16}$

It follows from the above that via Orders in Council or via provincial decrees, particular soil polluting or disturbing activities can be restricted. On the basis of the Soil Protection Act (1987) and since 1993 on the basis of the Environmental Protection Act, provinces are authorized to impose a so-called charge for soil protection. ${ }^{17}$ The charge for soil protection is collected from individuals who benefit from the fact that they operate within an environmental protection region, e.g. those who extract ground water for the fabrication of drinking water in a ground water protection region. For each ground water protection region, a charge for soil protection can be imposed. Charges are levied on the basis of the amount of extracted ground water. The revenues of these charges are earmarked and are destined to be used for the compensation of those who suffer from the extra protection, e.g. those who can no longer use specific manure substances or pesticides due to the stricter rules that are in force in ground water protection regions. Revenues are also used to finance the research which has to be conducted in response to the requests for compensations. The decrees that are necessary to implement the charge are introduced within the same year that compensations are granted (see Boele et al., 1992).

Although provinces are allowed to impose a charge for soil protection, none of the provinces in the Netherlands has decided to actually introduce the charge. The charge is considered to be too complicated. Moreover the charge is inconsistent with the polluter pays principle because, in a sense, polluters receive compensation. In Boele et al. (1992) it is stated that the execution of the charge for soil protection is too complicated also because a charge decree ("verordening") has to be implemented for each ground water protection region. In the near future, therefore, further changes of the Soil Protection Act can be expected.

${ }_{15}$ Prior to the introduction of the Environmental Protection Act in 1993, a more than general protection of soil could be offered, among others, on the basis of the Soil Protection Act, the Nuisance Act, the Act on Waste Substances, the Ground Water Act, the Physical Planning Act and the Nature Protection Act (see Intentieprogramma Bodembescherming Limburg, 1991).

${ }^{16}$ See e.g. Intentieprogramma Bodembescherming Limburg (1991).

${ }^{17}$ The precise financial regulations with regard to the imposition of charges for soil protection were laid down in the WABM Act. For a more explicit description of the use of soil protection taxes as a policy instrument for an effective land use policy, see Backhaus and Paulus (1993). 


\subsubsection{Waste disposal charges and refuse collection charges}

In order to defray the costs of collecting household waste, municipalities in the Netherlands are allowed to impose either refuse collection charges or waste disposal taxes. These levies cannot be imposed at the same time. Besides defraying the costs of collecting waste, the revenues of these charges can also be used to defray the costs associated with the reduction of waste. Municipalities are also allowed to use different tax bases for refuse collection charges and waste disposal taxes.

Refuse collection charges can be imposed on those who use, i.e. benefit from the services rendered by the municipality or on the use of municipal possessions, works or installations intended for public services. The charges are used to defray the costs of the collection and burning of waste. The charge is one of the most important service charges in the Netherlands (BZW/MICON, p. 20). Refuse collection charges can be imposed on the actual collection of household and non-household waste. The charge can be considered a user charge, in case the relevant waste is collected via waste containers. The charge rates of refuse collection charges depend on the amount and frequency of waste collection. Municipalities in the Netherlands can also impose a waste disposal tax, which is an ordinary revenue raising tax and thus not a charge. This tax differs from refuse collection charges in the sense that there is no quid pro quo relationship between tax payments and the services provided by the government and because the tax is used with regard to waste substances from households only. The waste disposal tax is based on the lot where household waste is periodically produced and collected. Liable are those who own or use the lot. The revenues of the tax are used to defray the costs associated with the collection of household and related waste. The revenues of the tax are not allowed to be higher than these costs.

Although most municipalities in the Netherlands impose a fixed tax rate, certain differentiations in these rates are allowed. With regard to the waste disposal tax, differentiations according to the number of persons within a household or the frequency of collection are allowed. Differentiation on the basis of the ability to pay ${ }^{18}$ and the actual use of the service of waste collection is not allowed. Differentiation of the tax rate according to the amount of waste supplied, although allowed for refuse collection charges, is not allowed for waste disposal taxes. With regard to refuse collection charges, differentiations on the basis of the number of bags or waste containers, the content of these containers and the number of persons within a household are also allowed. In 1990, seven municipalities in the Netherlands used tax rate differentiations that were based on the amount of waste supplied. Tax rate differentiation is usually considered a means to induce households to supply less waste or to split up different types of household waste.

${ }^{18}$ Differentiation of municipal charges on the basis of the ability to pay is only allowed for municipal dog taxes. For other municipal charges such a differentiation is not allowed because these charges are primarily based on the benefit principle. Local governments in the Netherlands, with a few exceptions, are also not allowed to conduct income (re)distribution policies. 
One of the main differences between the waste disposal taxes and the refuse collection charges is the fact that the former taxes can be imposed by municipalities only on the basis of Special Acts (e.g. the Waste Substances Act and the Environmental Protection Act). Refuse collection charges, on the other hand, can be imposed on the basis of the Municipality Act. Contrary to the waste disposal taxes, this means that refuse collection charges can only be imposed on those who actually make use of the service offered by the municipal government. Prior to 1979 , when the Waste Substances Act came into operation, only refuse collection charges could be used by municipalities to defray the costs of collecting waste.

\subsubsection{Sewer(age) charges}

Sewerage charges are municipal charges that are levied on the users and/or owners of real estate ("pand"). The revenues of the charges are used to defray the costs of constructing and exploiting municipal sewerage systems. Tax rates can differ for those who own or use the lot. There can also be different tax rates for companies. More specifically, municipalities in the Netherlands are allowed to impose (BZW/MICON, p. 19):

1) A sewerage charge on the use of a public sewerage. In this case this charge is a user charge ("rioolafvoerrecht"). In case of a sewerage user charge, a clear relationship has to exist between the benefit that users have of the sewerage and the costs that are related to the use. The user charge can be based on the use of water. The charge rate can be fixed or variable.

2) A sewerage charge on the use of the service rendered by the municipality ("rioolaansluitingsrecht"). In case of a sewerage service charge, the tax rate is usually a fixed amount of guilders per year determined on the basis of the sewerage connection. The charge can not be levied on the basis of the amount of waste water.

3) A sewerage charge on the use of sewerage (1) and the use of the service rendered by the municipality (2).

Depending on what is taxed and according to which rates, in the Netherlands, a large spreading of sewerage charges can be noticed among different municipalities. In this sense, industries, companies and citizens in different municipalities face different costs. ${ }^{19}$

${ }^{19} \mathrm{~A} \mathrm{BZW} / \mathrm{MICON}$ study (1993) indicates that the same holds for refuse collection cllarges ("reinigingsrechten") and administrative charges ("rechten"). Most studies, however, do not indicate whether the spreading in different environmental charges is also the result of differences in the services offered. 


\subsubsection{Ground water charges}

In 1982, the Ground Water Act was passed in the Netherlands. This Act provides regulations with regard to the extraction of ground water from soil and the infiltration of water. The act, in order words, is especially concerned with the quantity of ground water. On the basis of the Ground Water Act, provinces are obliged to draw up a ground water plan. The main elements of the control of the quantity of ground water have to be indicated in this plan. Both the central government and provinces can impose a ground water charge on those who keep registered installations for the extraction of ground water. The charge is based on the amount of extracted ground water per cubic metre. The revenues are earmarked and are mainly used to defray the costs associated with research considered necessary for the control of ground water and for compensation payments (Schuddeboom, 1990). Since the revenues of the charges are earmarked, tax rates are set accordingly. Revenues may not be higher than the associated costs of controlling the quantity of ground water. In 1992, tax rates were set at an average of 0,01 guilders per cubic metre of ground water extracted in the different provinces in this country.

\subsubsection{Charge on surplus manure}

In 1986 the new Fertilizers Act came partly into operation in the Netherlands. The purpose of the act is to protect the soil and to guard the quality and trade of manure. The act only provides a framework which has to be further filled in with Orders in Council and decrees. The latter can then be differentiated for different regions and companies. The Fertilizers Act consists of the following regulations: ${ }^{20}$

Regulations with regard to the transport, storage and trading of animal manure substances.

A manure accounting system, which can be used to determine the excess of manure.

The introduction of a Manure Agency ("mestbank"). This agency can buy or take excesses of manure and can mediate in the trading and marketing of these excesses. There are several regional manure agencies and one national Manure Agency in the Netherlands.

The introduction of a charge on surplus manure.

The prevention of an extension in the production of animal manure substances.

With regard to the production of manure waste substances, a charge on surplus manure can be imposed in order to defray the costs of, among others, appliances of manure agencies and the creation of infrastructural provisions for the transport, sup-

${ }^{20}$ Boele et al. (1992, p. 164). 
ply, treatment or destruction of manure excesses. Above a certain basic amount of manure, the charge is based on the amount of animal manure that is yearly produced. The charge can be imposed on the companies where (animal) manure substances are produced. The charge is imposed on the amount of manure substances, expressed in kilograms of phosphates, per unit of time. Per kilogram of phosphate, the tax rate is as follows:

$\begin{array}{lll}\text { - for a total production between } 0-125 \text { kilograms: } & \text { f } 0,- \\ \text { - } & \text { for a total production between } 125-200 \text { kilograms: } & \text { f } 0,25 \\ \text { - } & \text { for a total production of more than } 200 \text { kilograms: } & \text { f } 0,50 \text {. }\end{array}$

For certain manure substances, differentiated tax rates (e.g. lower tax rates for dry manure from poultry) are also possible. The legal basis for levies on surplus manure is provided in the Fertilizers Act (1986). To determine the charge, farmers have to keep a manure accounting system. The charge is imposed and revenues are collected by a special agency ("Bureau Heffingen"). The charge on surplus manure is accompanied by a charge on livestock fodder.

\subsubsection{Water quantity assessments}

Water boards are public bodies like municipalities and provinces, who are authorized to impose particular levies. Water boards, however, differ from municipalities and provinces in the sense that they have only one particular task, i.e. controlling regional water affairs. The latter, for instance, includes controlling the quantity and/or quality of regional ground and/or surface water. ${ }^{21}$ To perform this task, water boards operate within a specific "control region" which is constituted on the basis of the task of the water board in question. One of the main characteristics of water boards in the Netherlands is the existence of a close relationship between those who pay the levies imposed by the water board and those who benefit from the provisions and policies of this authority. Those who have a clear, direct and permanent interest in the execution of the task by water boards do not only pay but also have a say in the policies of these authorities. To fund their expenditures, water boards are allowed to impose water quantity assessments, legal and other charges and, in some cases, the water pollution charge. ${ }^{22}$

Water quantity assessments are levied on those who own or use real estate such as houses, offices and land within the control region (see e.g. Havekes et al, 1991 and Belastingwetten 1993). Taxes are based on the surface of the real estate for real estate which is unrelated to buildings or on the tax base of the local real estate tax for

${ }^{21}$ See Havekes et al. $(1991,28 \mathrm{ff})$.

${ }^{22}$ See Havekes et al. $(1991,96 \mathrm{ff})$. 
real estate which is related to buildings. ${ }^{23}$ The tax rate, which can be differentiated, is a certain amount of guilders per hectare of real estate. The tax rate is set by the water board in such a way that (approximately) that amount of revenues can be raised which is necessary to defray the costs of executing its tasks (e.g. controlling the quantity of surface water). The general committee of the water board decides whether or not a particular water quantity assessment has to be introduced, changed or abolished. The committee also decides whether or not it is necessary to impose separate assessments for each task conducted by the water board. In this sense it is, for instance, possible that a water board imposes separate assessments for the embankment of water and for the control of the quantity of water (Havekes et al., 1991). Water quantity assessments are yearly determined on the basis of the budget of the costs of the authority in question. Generally, the total costs are divided by the number of liable persons, on the basis of their proportional benefit from the execution of specific tasks. by the water board in question.

\subsubsection{Environmental taxation: main features}

The previous considerations were intended to demonstate that ecological taxation in the Netherlands mainly involves the use of revenue raising taxes for fiscal and ecological purposes. Studies indicate that, in total, the tax revenues that have been raised by environmental levies in the Netherlands amount to some 3 billion guilders. This is less than $2,5 \%$ of the total tax receipts in this country. ${ }^{24}$ Table 7.3 provides a brief overview of the development of the revenues of environmental levies in the Netherlands during the period 1975 to 1988 . Table 7.3 shows that, until 1988 , water effluent charges and user charges on municipal waste constituted the most important charges in terms of tax revenues. In the Netherlands, water effluent charges mainly consist of the water pollution charges that are imposed by different levels of government. The charges imposed by water boards and sub national governments are the most important water effluent charges in this country. These charges are imposed on households and firms. While households and small firms pay a standard charge, medium firms pay a charge on the basis of a table of coefficients with unit rates for different industries. Large firms usually pay on the basis of monitoring. ${ }^{25}$

${ }^{23}$ Real estate unrelated to buildings etc. includes arable/crop/agricultural land, woodland and lots. Real estate related to buildings includes houses, offices, industrial buildings, erc.

24 See OECD (1993a).

${ }^{25}$ See Opschoor and Vos (1989). 


\begin{tabular}{|c|c|c|c|c|c|c|}
\hline $\begin{array}{l}\text { Environmental le- } \\
\text { vies }\end{array}$ & 1975 & 1980 & 1985 & 1986 & 1987 & 1988 \\
\hline $\begin{array}{l}\text { Water pollution } \\
\text { charge (national) }\end{array}$ & 105 & 179 & 104 & 13l & 114 & 116 \\
\hline $\begin{array}{l}\text { Water pollution } \\
\text { charge (provinces) }\end{array}$ & 36 & 103 & 156 & 146 & 169 & 171 \\
\hline $\begin{array}{l}\text { Water pollution } \\
\text { charges (water } \\
\text { boards) }\end{array}$ & 216 & 556 & 850 & 853 & 893 & $94 \mathbb{1}$ \\
\hline $\begin{array}{l}\text { Water pollution } \\
\text { charges (municipa- } \\
\text { lities) }\end{array}$ & 53 & 76 & 109 & 115 & 126 & 65 \\
\hline Sewer charges & 127 & 235 & 313 & 371 & 369 & 397 \\
\hline $\begin{array}{l}\text { Noise charges on } \\
\text { civil aviation }\end{array}$ & - & - & 7 & 9 & 12 & 20 \\
\hline Air pollution charges & 50 & 62 & 92 & 87 & 106 & 52 \\
\hline $\begin{array}{l}\text { Charges on chemical } \\
\text { substances }\end{array}$ & - & - & 3 & 2 & 4 & 3 \\
\hline $\begin{array}{l}\text { Charges on lubricant } \\
\text { oil }\end{array}$ & - & 2 & 4 & 2 & 2 & 1 \\
\hline $\begin{array}{l}\text { Charges on traffic } \\
\text { noise }\end{array}$ & - & - & 78 & 85 & 90 & 35 \\
\hline $\begin{array}{l}\text { Charges on industrial } \\
\text { noise }\end{array}$ & - & - & 20 & 22 & 23 & 12 \\
\hline $\begin{array}{l}\text { WABM fuel char- } \\
\text { ges* }\end{array}$ & - & - & - & - & - & 160 \\
\hline $\begin{array}{l}\text { Charges on surplus } \\
\text { manure }\end{array}$ & - & - & - & - & - & 24 \\
\hline $\begin{array}{l}\text { Waste disposal char- } \\
\text { ges }\end{array}$ & 220 & 398 & 597 & 616 & 657 & 688 \\
\hline
\end{tabular}

Table 7.3 Environmental Levies: Revenues 1975-1988 (in million guilders). Source: CBS (1991, p. 33), CBS (1992b, p. 288). 
The charges are generally considered to be effective, moderately efficient in economic terms and highly efficient in administrative terms. ${ }^{26}$ As described before, user charges on municipal waste are used to defray the costs associated with the collection of solid waste.

The main taxes and tax provisions used for ecological purposes in this country during the period 1991-1993 are summarized in Table 7.4. Table 7.4 shows that in the Netherlands, levies, earmarked charges as well as ordinary revenue raising taxes and tax provisions are used for environmental policy purposes. The latter provisions include accelerated depreciations and differentiations in the special taxes on motor vehicles and the excise taxes on oil. They also include tax reliefs for owners of nature regions. Accelerated depreciations are allowed for certain categories of means of production by which environmental problems can significantly be reduced. In certain cases, a one hundred percent depreciation is allowed for. Differentiations of the excise taxes on oil products and of the special tax on motor vehicles are used to encourage the use of environmentally friendlier or "cleaner" cars. Special taxes on motor vehicles are reduced for cars which meet particular emission conditions (e.g. a particular cylinder capacity). Within the wealth tax, transfer tax and municipal immovable real estate taxes there are several tax reliefs for owners of nature regions. Protection of these regions is the main purpose of these tax reliefs.

Table 7.4 shows that the national government in the Netherlands offers several ecological tax provisions including tax reliefs for owners of nature regions and accelerated depreciations for those investing in environmental production processes or machineries. Besides differentiating tax rates for environmental purposes, the national level of government in the Netherlands also imposes environmental user taxes, noise charges on civil aviation and taxes on surplus manure.

Table 7.4 also shows that several ecological taxes in the Netherlands are imposed by sub national governments, i.e. by provinces, municipalities and water boards. These levels of government, more specifically, impose ecological taxes which are related to the disposal of waste and the mistreatment and protection of soil, ground and surface water. To fund specific policies with regard to the disposal of waste and the mistreatment and protection of soil, ground and surface water, the revenues of these taxes are earmarked or restricted to be used for only these purposes. Under the current institutional framework in the Netherlands (see chapter 6 of this study), sub national governments are restricted as regards the use of taxes for allocational purposes.

In an analysis and evaluation of the fiscal instruments that are used with regard to the environment in the Netherlands, Oosterhuis and De Savornin Lohman (1994), distinguish between taxes that are designed for environmental purposes and taxes and provisions that may have desirable or undesirable environmental side effects. ${ }^{27}$ With

26 Ibid.

27 Oosterhuis and De Savomin Lohman (1994, pp. 7-50). 
regard to the former taxes and for the period 1989-1990, several 'performances' are shown (see Table 7.5).

\begin{tabular}{|c|c|c|}
\hline Ecological tax or tax provisions & Function & $\begin{array}{l}\text { Level of government im- } \\
\text { posing the tax }\end{array}$ \\
\hline $\begin{array}{l}\text { Enwironmental user taxes including: } \\
\text { user taxes on fuel (including Pigouvian } \\
\text { taxes on light oil) and } \mathrm{CO}_{2} \text { charge }\end{array}$ & $\begin{array}{l}\text { Revenue } \\
\text { Incentive } \\
\text { Revenue }\end{array}$ & $\begin{array}{l}\text { National } \\
\text { National }\end{array}$ \\
\hline Noise charge on civil aviation & Revenue & National \\
\hline $\begin{array}{l}\text { Taxes on waste disposal and municipal } \\
\text { refuse collection charges }\end{array}$ & Revenue & Municipal \\
\hline Water pollution charge & $\begin{array}{l}\text { Revenue (in practice: } \\
\text { Incentive) }\end{array}$ & $\begin{array}{l}\text { National, Provincial, } \\
\text { Municipal, Water Boards }\end{array}$ \\
\hline Charges for soil protection & Revenue & Provincial \\
\hline Ground water charge & Revenue & Provinciall \\
\hline Charges on surplus manure & Revenue & National \\
\hline Accelerated depreciation & Incentive & National \\
\hline $\begin{array}{l}\text { Differentiation of special tax on motor ve- } \\
\text { hicles }\end{array}$ & Incentive & National \\
\hline $\begin{array}{l}\text { Differentiation in excise taxes on oil pro- } \\
\text { ducts }\end{array}$ & Incentive & National \\
\hline Tax relief for owners of nature regions & Incentive & National \\
\hline Water quantity assessments & Revenue & Water Boards \\
\hline 'Precario' dues & Revenue & $\begin{array}{l}\text { Provincial, Municipal, Water } \\
\text { Boards }\end{array}$ \\
\hline
\end{tabular}

Table 7.4 Ecological Taxes in the Netherlands: 1991-1993. Sources:

OECD, 1993a, p. 88, from F.H. Oosterhuis and A.F. de Savornin Lohman (1991), Taxation and Environment: Case Study on the Netherlands in: "Taxation and Environment: Four Case Studies", OECD, Paris, 1993.

Boele (ed.) et al., 1992.

Belastingwetten 1993. 


\begin{tabular}{|c|c|c|c|}
\hline Taxes & $\begin{array}{l}\text { Tax revenues ( } \mathrm{m} / \mathrm{n} \\
\text { guilders) }\end{array}$ & Function & $\begin{array}{l}\text { Performance as envi- } \\
\text { ronmental policy in- } \\
\text { strument }\end{array}$ \\
\hline $\begin{array}{l}\text { Environmental charge } \\
\text { on fuels }\end{array}$ & 926.3 & $\begin{array}{l}\mathbb{R} \\
\text { I (charge on low- } \\
\text { octane gasoline) }\end{array}$ & + \\
\hline $\mathrm{CO}_{2}$ charge & 150.0 & $\mathrm{R}$ & + \\
\hline $\begin{array}{l}\text { Noise charge on cuvil } \\
\text { aviation }\end{array}$ & 17.0 & $\mathrm{R}$ & 0 \\
\hline $\begin{array}{l}\text { Waste disposal tax } \\
\text { and refuse collection } \\
\text { charge }\end{array}$ & 810.0 & $\mathrm{R}$ & + \\
\hline $\begin{array}{l}\text { Water pollution } \\
\text { charge }\end{array}$ & 1301.0 & $\mathrm{RI}$ & + \\
\hline $\begin{array}{l}\text { Charges for soil pro- } \\
\text { tection }\end{array}$ & 0.0 & $\mathbb{R}$ & not yet applied \\
\hline Ground water charge & 4.0 & $\mathbf{R}$ & 0 \\
\hline $\begin{array}{l}\text { Charge on surplus } \\
\text { manure }\end{array}$ & 38.0 & $\mathrm{R}$ & + \\
\hline $\begin{array}{l}\text { Accelerated deprecia- } \\
\text { tion }(1992)\end{array}$ & 8.0 & 1 & 0 \\
\hline $\begin{array}{l}\text { Differentiation in } \\
\text { special tax on motor- } \\
\text { wehicles }\end{array}$ & 500.0 & $\mathbb{I}$ & + \\
\hline $\begin{array}{l}\text { Differentiation in } \\
\text { excise on oil }\end{array}$ & 150.0 & I & + \\
\hline $\begin{array}{l}\text { Tax relief for owners } \\
\text { of nature regions }\end{array}$ & $?$ & $\llbracket$ & 0 \\
\hline
\end{tabular}

Table 7.5 The Netherlands: performances of taxes designed for environmental purposes. Source: Oosterhuis and De Savornin Lohman (1994, p. 28).

From Table 7.5 and from the previous considerations, it must have become obvious that the main function of environmental levies and charges in the Netherlands is primarily a fiscal one. Although environmental levies in the sense of Pigou have hardly been introduced in this country, there are environmental levies which, perhaps in spite of their original intent, have (had) strong steering effects (e.g. the water pollution charge). For the greater part, these environmental levies are set on the basis 
of a double dividend approach, with a clear destination of the use of tax revenues. In terms of the revenues raised by these environmental \evies, it has also been shown that they constitute only a very small part of total tax revenues despite of the fact that most of these levies are not of the Pigouvian tax type. 


\section{Ecological Taxation in the Netherlands: Development Stages}

\subsection{Introduction}

Building on the results of the previous two chapters of this study, one of the central purposes of this chapter is to derive several features and trends in the use of ecological(ly relevant) taxes in the Netherlands. Based on the results of this analysis, an additional aim of the chapter is to incorporate and confront these results with(in) the theoretical framework provided in earlier chapters of this study in order to derive, determine, describe and explain the development stages of ecological taxation in this country. After the introduction (section 8.1), in section 8.2, the use of environmentally relevant taxes and charges in the Netherlands is compared to the use of such levies in other OECD countries. After this, the trends and main features of ecological taxation in the Netherlands are further discussed in section 8.3. In section 8.4, the actual use of ecologically relevant taxes and levies in the Netherlands is confronted with the theoretical considerations provided in previous chapters of this study. On the basis of these results, among others, the stages of development of ecological taxation are further indicated. The chapter ends with several conclusions and remarks.

\subsection{The use of taxes and charges for ecological purposes in OECD countries}

In this section, the use of taxes and charges for ecological purposes in the Netherlands is compared to the average use of these levies in OECD Member countries. On the basis of different OECD studies, including the studies by Opschoor and Vos (1989) and the $\operatorname{OECD}(1993 \mathrm{a}, \mathrm{b})$, the main features of the use of ecological taxes and levies in OECD countries are further described. Generally, in the overviews provided in OECD studies, the main features of ecological taxes are discussed in terms of the type of tax (e.g. effluent charges, user charges, product charges, tax differentiations and administrative charges), the purpose of the tax (a fiscal or incentive function) and in terms of the actual impact of these levies.' Since the actual impact of these levies may differ from their stated purposes, different types of ecological levies are distinguished. They include levies that are intended to have an incentive function and that operate as such (II levies) and those that are intended to have an incentive function but operate mainly as revenue raising instruments (IF levies). They also include levies that are aimed at raising revenues and that operate as such (FF levies) and those that are aimed at raising these revenues but that have a substantial incentive impact (FI charges).

1 See Opschoor and $\operatorname{Vos}(1989$, p. 14) and OECD $(1993 \mathrm{~b}$, p. 17). 


\section{Different charge systems}

In their study of the use of environmental levies by OECD Member countries prior to 1988, Opschoor and Vos (1989) provide an overview of different charge systems. A summary of this overview is presented in Table 8.1. Table 8.1 shows that effluent charges are mainly applied in the field of water protection and noise abatement by several European countries and the United States. User charges are applied in (almost) all OECD Member countries, while product charges and tax (rate) differentiations are mainly used by a number of European countries, in particular the Scandinavian countries.

\section{Evaluation}

On the basis of an evaluation of these different charge systems, Opschoor and Vos (1989, pp. 113-116) conclude that effluent charges play a minor role in the field of controlling air pollution and managing waste. The economic significance of noise (abatement) charges, which have been introduced in several OECD countries, is relatively low. In terms of their fiscal purpose, effluent charges in the field of water pollution control policy can be rated successful. The efficiency and effectiveness of these charges however require higher charge rates. If due to these changes, the administrative efficiency of these charges decreases, the use of taxes that are more intricate but economically more efficient has to be weighed against the use of relatively simple and from the point of view of administration effective but economically inefficient taxes. Effluent charges are also compatible with the polluter pays principle.

User charges play a significant role especially with respect to the collection and treatment of municipal waste and with regard to waste water discharged into sewers. Since the charges are primarily introduced to defray particular costs, the economic and administrative efficiency of these charges is considered more important than the ecological effectiveness of these charges, although a closer relationship between the charge rates and actual pollution would be more compatible with the polluter pays principle.

Product charges are mainly imposed on potentially harmful products in order to cover particular environmental expenditures. In so far as those who are liable for particular product charges also pay for the damage or for preventive measures, the compatibility of these charges with the polluter pays principle is considered quite good.

Administrative or legal charges are considered to be compatible with the polluter pays principle if part of the financial burdens are laid on polluters instead of the general public. Although they can be embedded into existing tax systems, tox differentiations are only limitedly applied in practice. Their administrative efficiency is generally perceived as considerable to relatively high. According to Opschoor and Vos (1989), tax differentiation is also compatible with the polluter pays principle. 


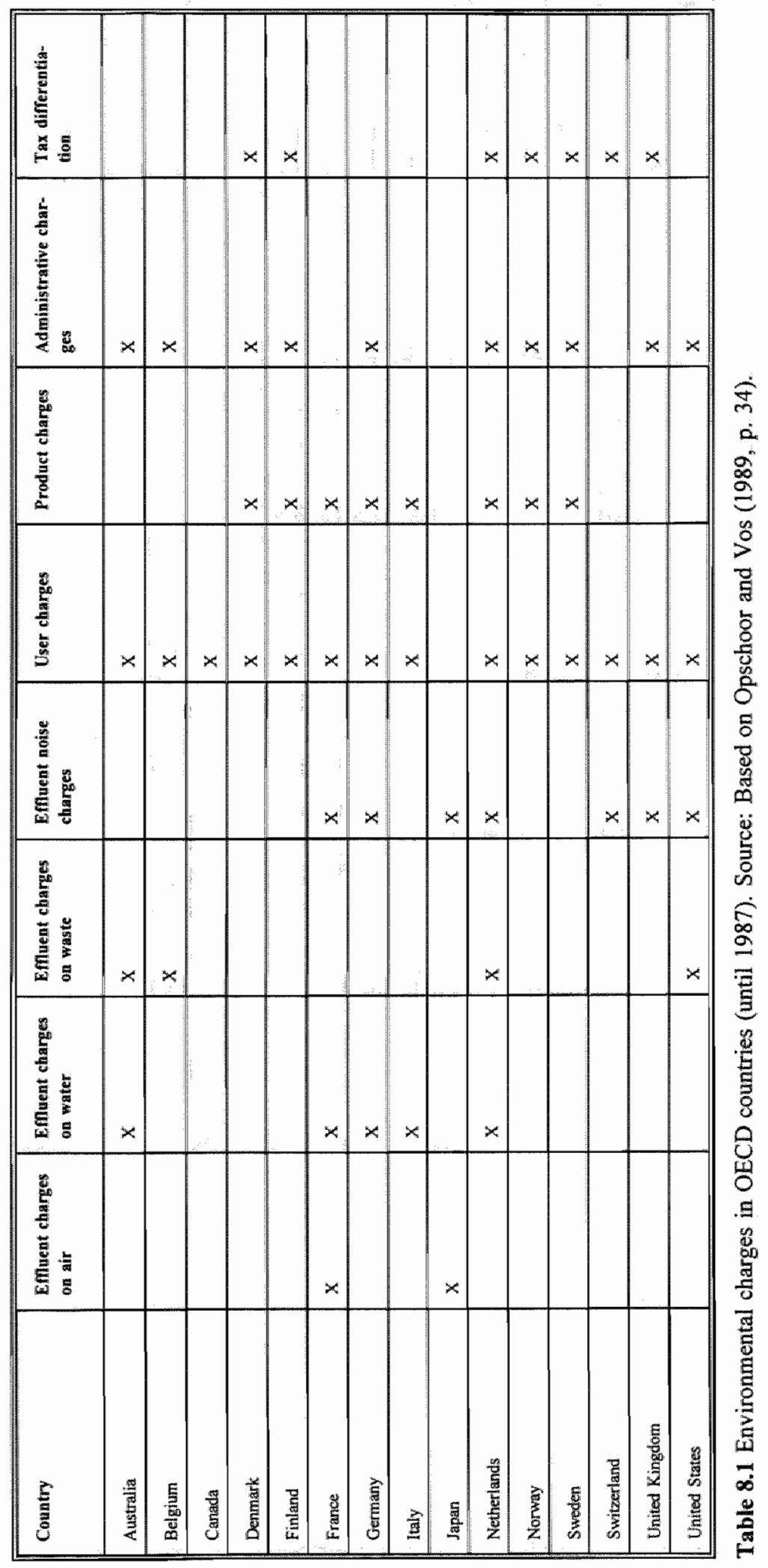




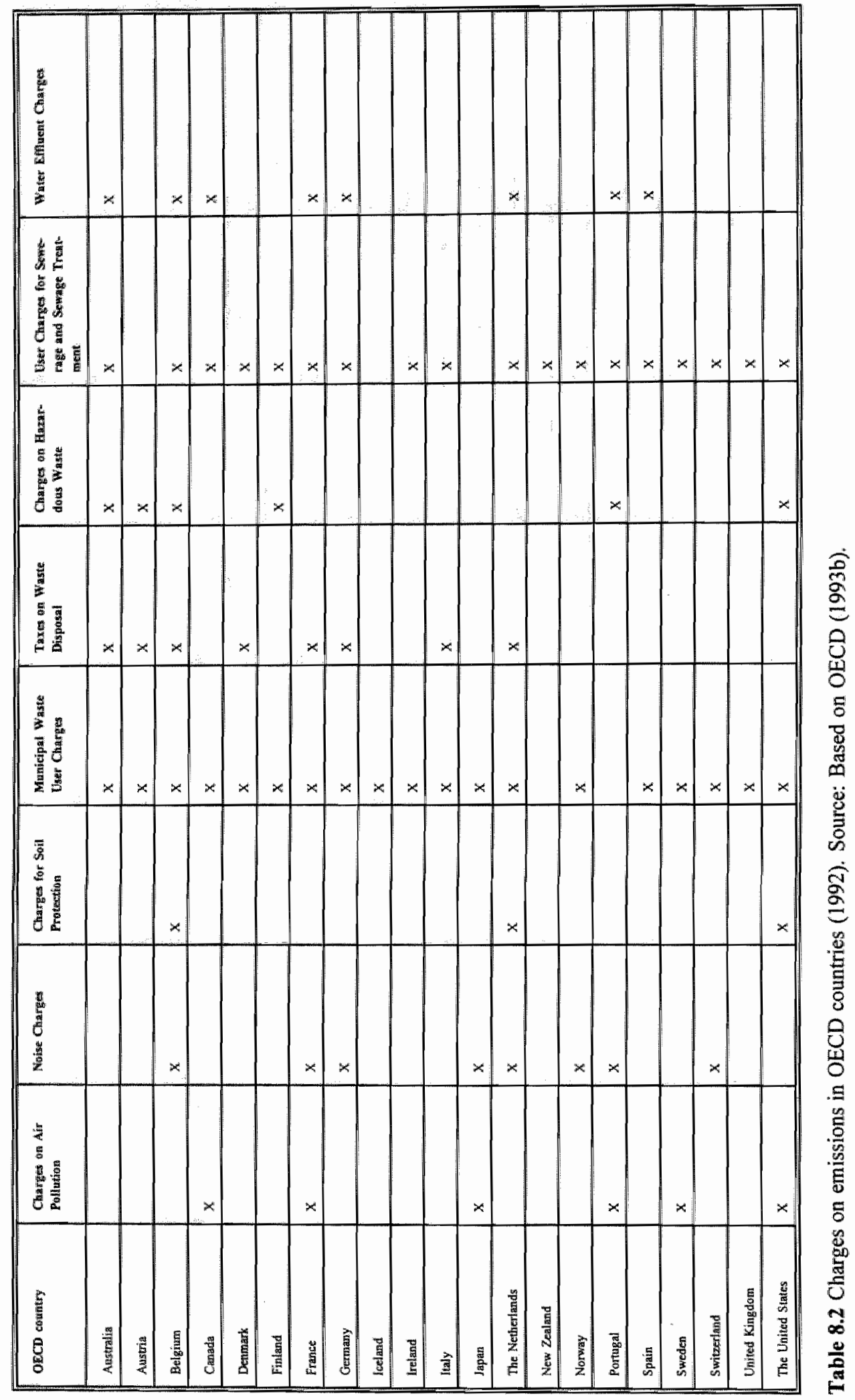


Although the use of a total of 150 economic instruments, including approximately 80 charges were documented in the OECD study performed by Opschoor and Vos (1989), the authors indicate that OECD countries did not employ market based instruments on a significant scale in 1987. These instruments were mainly used in addition to existing command and control instruments. Between 1987 and 1993, the use of charges, taxes and deposit refunds almost doubled. ${ }^{2}$ Tables 8.2 and 8.3 provide an overview of the most important charges in this period. ${ }^{3}$ Table 8.2 shows that emission charges are mainly related to emissions in air, soil, water and to emissions of waste and waste water. While almost all OECD countries impose user charges on municipal waste and sewerage treatment, only a few countries impose charges on emissions in air, soil and water. OECD Member countries that do impose the latter charges include Belgium, France, Germany, Japan, Portugal and the Netherlands.

Table 8.3 shows that charges on products and tax differentiations are mainly used in relation to cars, fuels and products that are used in agriculture. While the greater part of the OECD countries have introduced tax differentiations for leaded and unleaded petrol and car sales tax differentiation, charges on particular products have been introduced by a relatively minor part of these countries. It can generally be noticed from Tables 8.2 and 8.3 that revenue raising charges are mainly used for ecological purposes by several countries of the European Union and by Norway. It can also generally be noticed that Scandinavian countries make a relatively extensive use of ecological taxes as an instrument of environmental policies. ${ }^{4}$ In Tables 8.4 and 8.5 , the fiscal and steering effects of the different charges that are imposed on emissions and products as they have been identified in a study by the OECD (OECD, 1993b), are further detailed. The authors indicate, among others, that the revenues of the greater part of these charges are earmarked to be used for environmental expenditures. For taxes and charges on emissions, for instance, of the 33 charges that were identified (i.e. not taking into account II charges and proposed charges) 27 had earmarked tax revenues. Of the six remaining charges, the revenues of 3 charges were used for general policy purposes, while the spending of the revenues of 3 charges remained unknown. It follows that earmarking the revenues of environmental charges can be considered a general practice in most OECD countries.

2 See OECD (1993b, p. 3).

3 OECD (1993b, chapter 3).

* For a more detailed description of the use of several financial environmental policy instruments, see also DHV/VROM (1992). 


\begin{tabular}{|c|c|c|c|c|c|c|c|c|c|c|c|c|c|c|c|c|c|c|c|c|c|}
\hline 堡 & & + & & $x$ & $\times$ & $\infty$ & & & $-\infty$ & & & $\times$ & & $\star$ & & & & $x$ & & & $*$ \\
\hline 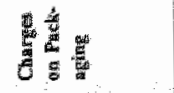 & & & $x$ & $\propto$ & $x$ & $x$ & & & & & & & & & & $x$ & $*$ & $*$ & & & $x$ \\
\hline 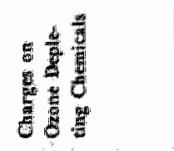 & $x$ & 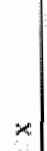 & & & $x$ & & & & & & & & & & & & & & & & $x$ \\
\hline 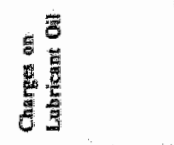 & & & & & & $*$ & $x$ & & & & & $x$ & & & & $x$ & & & & & $x$ \\
\hline 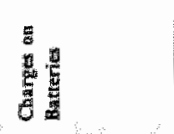 & & & & $\approx$ & $\times$ & & & & & & & & & & & 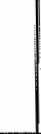 & $x$ & $x$ & & & \\
\hline 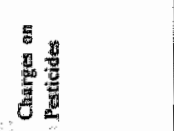 & & & & & & & & & & & & & & & & $x$ & . & $x$ & & & \\
\hline 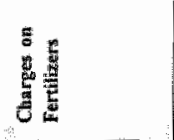 & & $\infty$ & & & & $\times$ & & & & & & & & & & $x$ & & $\star$ & & & \\
\hline 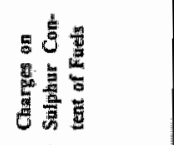 & & & & & & & & & & & & & & & & 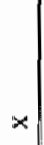 & & $x$ & & & \\
\hline 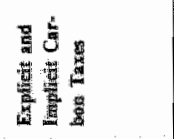 & & & & & $x$ & $\times$ & & & & & & $*$ & & $x$ & & $*$ & & $\times$ & & & \\
\hline 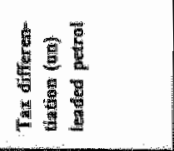 & & $*$ & $*^{*}$ & $x$ & $\times$ & $*$ & $x$ & $x$ & & $\times$ & $x$ & & & $\times$ & $x$ & $\times$ & $\times$ & $x$ & $\times$ & $\times$ & \\
\hline 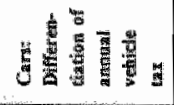 & & $x$ & & & $x$ & & & $x$ & & & & & & $x$ & & & & & & & \\
\hline 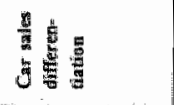 & & & $x$ & 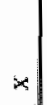 & & $\times$ & & $x$ & 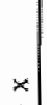 & & & & $x$ & $\times$ & & $\approx$ & & $\times$ & & & $x$ \\
\hline $\begin{array}{l}5 \\
5 \\
5 \\
5 \\
8 \\
8\end{array}$ & 啮 & 墨 & 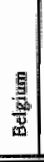 & 昜 & ह & 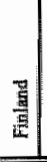 & 量 & S & $\begin{array}{l}8 \\
5\end{array}$ & $\frac{\mathrm{g}}{\mathrm{g}}$ & $\frac{\underline{t}}{\underline{2}}$ & 焉 & : & 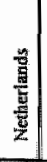 & 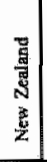 & ह & 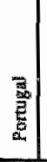 & $\begin{array}{l}\mathrm{g} \\
\mathrm{E}\end{array}$ & 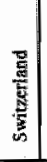 & 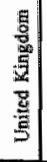 & 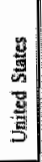 \\
\hline
\end{tabular}




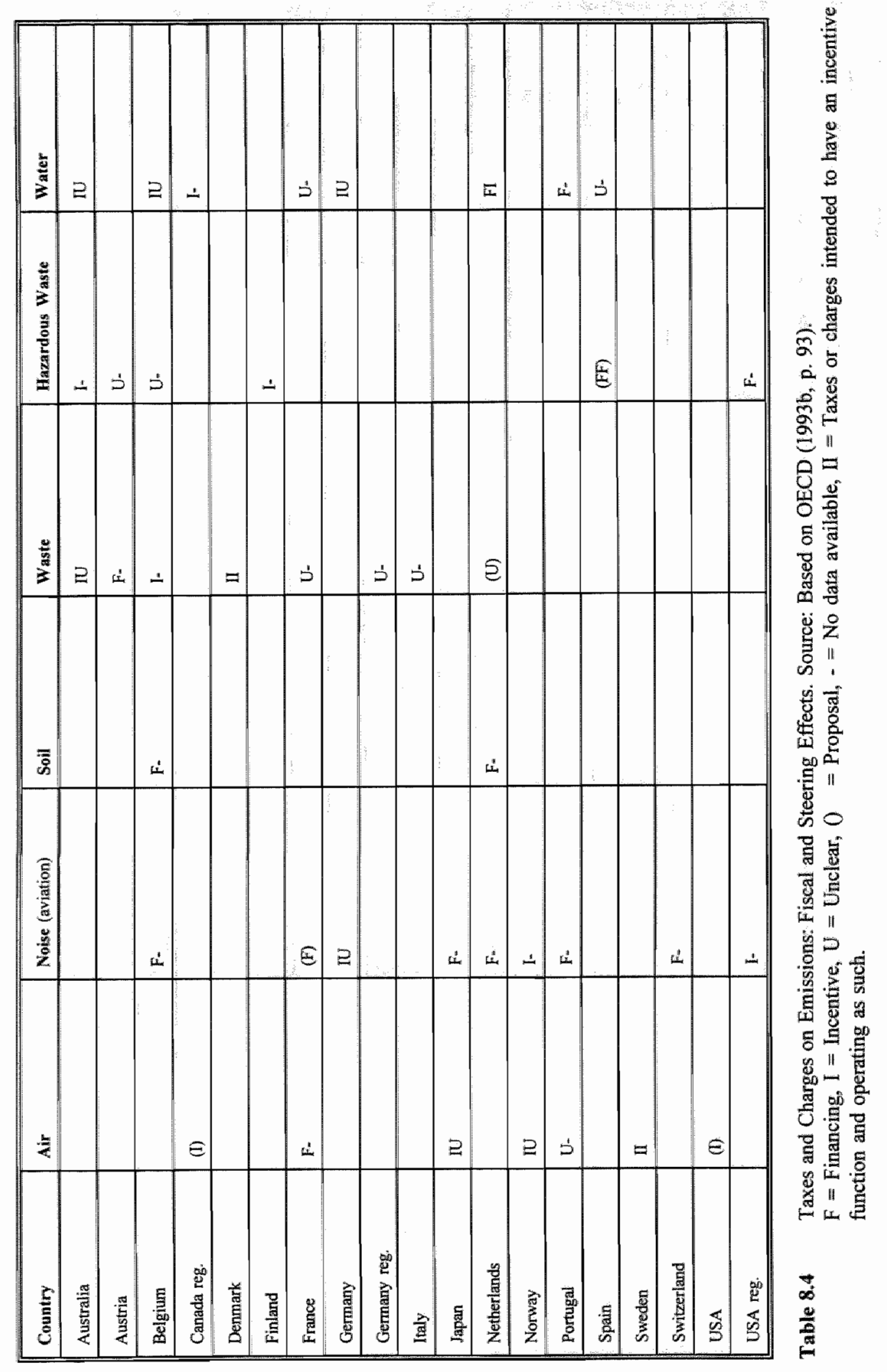




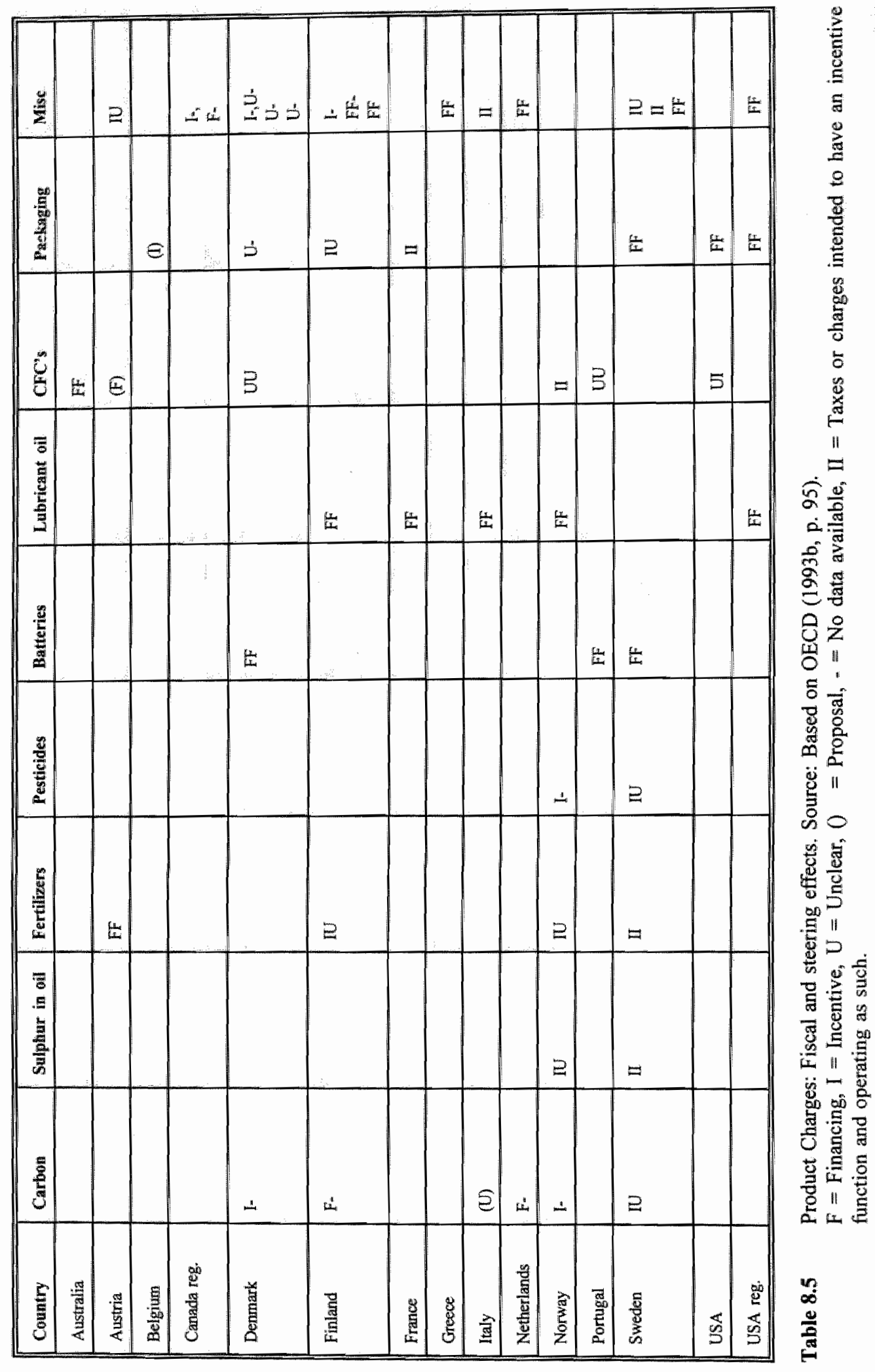


As regards the incentive effects of the different charges mentioned in Table 8.4 and Table 8.5, it follows from a OECD study (OECD, 1993b) that, aithough relevant data are not always available, there are relatively few charges that actually have their intended incentive effect. This conclusion holds for both emission charges and product charges (see Table 8.6).

\begin{tabular}{|l|l|l|l|l|}
\hline \hline & $\begin{array}{l}\text { Emission } \\
\text { charges: } \\
\text { incentive } \\
\text { effect inten- } \\
\text { ded }\end{array}$ & $\begin{array}{l}\text { Emission } \\
\text { charges: } \\
\text { actual in- } \\
\text { centive } \\
\text { effects }\end{array}$ & $\begin{array}{l}\text { Product } \\
\text { charges: } \\
\text { incentive } \\
\text { effect } \\
\text { intended }\end{array}$ & $\begin{array}{l}\text { Product } \\
\text { charges: } \\
\text { actual in- } \\
\text { centive } \\
\text { effects }\end{array}$ \\
\hline Yes & 15 & 3 & 21 & 7 \\
\hline Inconclusive & 8 & 7 & 7 & 10 \\
\hline No & 12 & - & 23 & 20 \\
\hline No data & - & 25 & - & 14 \\
\hline
\end{tabular}

Note: Inconclusive means that the evidence is inconclusive, mainly because the charge is applied in combination with other policy instruments.

Table 8.6 Incentive effects of emission charges and product charges. Source: Based on OECD (1993b, pp. 94 ff).

Comparing the actual use and effects of ecologically relevant levies, charges and taxes in OECD countries with the use and effects of these types of levies in the Netherlands, it can be noticed from the previous considerations that:

1) In comparison to other OECD Member countries, there is a relatively extensive use of effluent charges in the Netherlands.

2) In the Netherlands, the use of product and user charges, tax differentiations and administrative charges is comparable to that of other OECD countries and especially to that of the Scandinavian countries.

3) In comparison to several other OECD countries, there is a relatively restricted use of taxation within the context of air pollution in the Netherlands.

4) The fiscal and steering effects of ecological levies on emissions, except for those on emissions in surface waters, are comparable to those in other OECD countries. 
From the previous considerations, it can therefore be concluded that generally the use of different types of ecologically relevant taxes in the Netherlands is comparable to the use of these taxes in other OECD countries, especially the Scandinavian and particular other European countries. In the Netherlands, however, relatively more effluent charges are imposed. These seem to have above average steering effects when imposed on emissions in regional surface waters.

\subsection{Trends and main features of ecological taxation in the Netherlands}

Although the use of taxes for ecological purposes in the Netherlands is on average comparable to that of other European OECD Member countries, several specific features of ecological taxation in this country can still be detected. Describing several features of this type of taxation in this country, Opschoor and Vos (1989), for instance indicate that the Netherlands have taken a more pragmatic approach towards environmental policy which is expressed in a restructured charges system with respect to air, noise and hazardous waste. At the same time, the country has shifted from a sectoral towards a more integrated approach of environmental charges (see also section 7.2.2 in this study). In addition, a tendency towards a more decentralized approach of environmental policies, which further enhances the role of municipalities and provinces in the implementation of environmental policies, can be observed. Together with a tendency towards deregulation and a shift from curative towards more preventive environmental policies, the two authors conclude that: "In line with these tendencies, existing charges will keep their function of raising revenues for financing direct environmental programme costs. New charges with an incentive function are likely, in particular regulatory product charges, of which the lead in gasoline charge is a first example" (p. 108).

In terms of the development process described in chapter 5, a likely introduction of new types of environmental levies in the near future in the Netherlands could present the beginning of a new stage in the development process of ecological taxation in this country. In order to identify particular stages in this process, in the following, several trends and features of the current use of ecological taxes in the Netherlands are described. For particular ecological taxes, this use is then compared to their expected future use.

\section{Current Use}

In Table 8.7, specific trends and features of ecological taxation in the Netherlands are summarized in terms of several elements of the design, imposition and the institutional structures in which this type of taxation in this country is embedded. The trends and features represent the general elements of all ecological taxes in the Netherlands. Specific elements of separate ecological taxes are discussed in relation to the expected future use of these taxes. 


\begin{tabular}{|c|c|}
\hline Main Features & Ecological taxation in the Netherlands \\
\hline Tax base & $\begin{array}{l}\text { Relatively broad tax bases in terms of the } \\
\text { number of actors liable for the taxes. Emis- } \\
\text { sions as well as inputs and outputs serve as } \\
\text { tax bases. }\end{array}$ \\
\hline Tax rates & $\begin{array}{l}\text { There are only minor tax rate differentiations. } \\
\text { Tax rates are relatively low in terms of indu- } \\
\text { cing considerable steering effects. }\end{array}$ \\
\hline Tax provisions & $\begin{array}{l}\text { Although there are certain tax provisions in } \\
\text { the taxes that are not primarily intended to be } \\
\text { used for ecological purposes, ecological tax } \\
\text { provisions play only a minor significant role. }\end{array}$ \\
\hline Level of imposition & $\begin{array}{l}\text { The greater part of ecological taxes are } \\
\text { imposed by municipalities, provinces or water } \\
\text { boards (i.e. on a local or regional level). }\end{array}$ \\
\hline Taxing authority & $\begin{array}{l}\text { National as well as sub national government } \\
\text { bodies. }\end{array}$ \\
\hline Revenue effects & $\begin{array}{l}\text { Moderate. Environmental tax revenues cur- } \\
\text { rently constitute less than } 3 \% \text { of total tax } \\
\text { revenues in the Netherlands. }\end{array}$ \\
\hline Steering effects & $\begin{array}{l}\text { Almost none, except for the regional water } \\
\text { pollution charge. }\end{array}$ \\
\hline Relevant institutional frameworks & $\begin{array}{l}\text { Existing division of responsibilities with } \\
\text { regard to taxation and environmental issues } \\
\text { between different levels of government in the } \\
\text { Netherlands. }\end{array}$ \\
\hline Type and purpose of the tax & $\begin{array}{l}\text { Mainly earmarked taxes. Almost all environ- } \\
\text { mental taxes in the Netherlands are aimed at } \\
\text { raising an amount of revenues that can be } \\
\text { used to fund environmental expenditures or to } \\
\text { lower the tax burden of other taxes. }\end{array}$ \\
\hline
\end{tabular}

Table 8.7 Main features of ecological taxation in the Netherlands

In chapter 7 of the previous chapter it was shown, that ecological taxation in the Netherlands involves the use of particular types of ecological levies in relation to environmental problems that are associated with (the use of) fuels, soil and ground

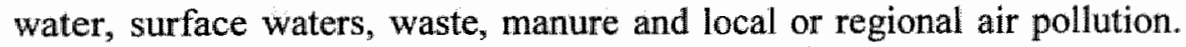

The greater part of the levies that are used within the context of these environmental problems are levies of the earmarked type of which the tax revenues are used to fund relevant environmental provisions and to defray the costs of relevant environ- 
mental expenditures. Environmental levies that are aimed at inducing tax avoiding changes in behaviour have hardly been introduced in this country, while ordinary revenue raising taxes, except for the environmental user taxes, have so far only marginally been used for these purposes. The latter is generally explained in terms of the fact that these taxes are inconsistent with the polluter pays principle.

Both emissions and products serve as important tax bases for environmental levies in the Netherlands. The former taxes include those on water, waste and noise. The latter, those on lubricant oils, fossil fuels and car fuels. The rates of these environmental levies are relatively low. Accordingly, the regulatory or steering effects of most environmental levies are also relatively low. Although the main purpose of the charge is primarily a fiscal one, the strongest steering effects are shown by the regional water pollution charge. Generally, however, the rates of most environmental levies in the Netherlands have been too low to induce strong incentive effects. Since 1988, the environmental user taxes and the (regional) water pollution charge are the most important levies, in terms of the amount of tax revenues raised. In some cases, the environmental tax revenues that are raised are not enough to cover all relevant environmental costs. With regard to the environmentally relevant tax deductions, credits and provisions that have been introduced in the Netherlands, it has been argued in the previous chapter that these only play a minor significant role in Dutch environmental policies.

With regard to the idea of ecological tax reform, it can generally be stated that, besides some exceptions, this type of reform has so far hardly been introduced in the Netherlands. In fact, several elements of the existing tax system which induce side effects that can be considered undesirable from an ecological point of view have not yet been removed. Significant regulatory environmental levies have also not been recently introduced, while existing taxes and levies on labour have not yet been replaced by particular environmental taxes.

With regard to the taxing authority and the imposition of ecological taxes, it can generally be stated that the greater part of environmental levies in the Netherlands, especially those which are related to the problems of waste and soil and water polluting substances and activities, have been imposed by sub national governments, i.e. by provinces, municipalities and water boards. Only the water quantity assessments that are imposed by water boards in this country come close to representing the idea of ecological tax units. The national government imposes environmental levies which are related to fuels, transport and traffic. In terms of the amount of tax revenues raised, the most important environmental levy (i.e. the environmental user tax) is imposed by the national government.

With regard to the frameworks and contexts into which ecological taxation is embedded in the Netherlands, it follows from chapter 6 that the existing institutional and fiscal framework imposes important restrictions on the introduction and/or further use of ecological taxes by sub national governments in this country. The existing environmental policy framework on the other hand provides several opportunities for 
the imposition of these taxes by these governments mainly because of its orientation towards environmental policies for particular environmentally relevant regions.

From the brief description of the main features and trends of ecological taxation in the Netherlands it follows that the greater part of the ecologically relevant levies that are currently used in this country share the characteristic of being relatively small earmarked types of taxes that have relatively low tax rates and a main purpose of raising a proper amount of tax revenues necessary to fund relevant environmental expenditures. Within the theoretical framework provided in earlier chapters of this study, the use of earmarked types of taxes and of ecological taxes that have relatively low tax rates can be explained in terms of the expected higher public support for and acceptability of these kind of taxes. The latter is usually attributed to the existence of a more or less direct relationship between those who are confronted with (paying) the $\operatorname{tax}$ and those who benefit from the provisions which are funded from tax revenues. Earmarked types of taxes also play a central role within the concept of ecological tax units as they, when they are properly designed, present an option to tax and raise revenues in close relationship to those who benefit from the taxes.

From the brief description of the main features and trends of ecological taxation in the Netherlands it also follows that with regard to the imposition of ecologically relevant taxes, only the imposition of ecologically relevant levies by water boards in this country closely reflects the idea of ecological tax units. Being functional decision making units, these units have only the particular task of controlling regional water affairs, e.g. the quantity and/or quality of regional ground and/or surface water(s). ${ }^{5}$ To perform this task, water boards operate within a specific "control region" (i.e. a water board district). This region is constituted on the basis of the task of the water board in question. If its task is to control the quality of a regional surface water, the control region is constituted on the basis of the natural boundaries of this surface water. The control region of water boards, in other words, is constituted purely on the basis of the function of the water boards in question. This function, in its turn, is determined by ecological (i.e. aquatic) relationships. This closely resembles the concept of ecological tax units in the sense that responsible decision making units are not only functional but are also closely related to relevant ecological circumstances. Not unlike ecological tax units, one of the main characteristics of water boards in the Netherlands is also the existence of a close relationship between those who pay the levies imposed by the authority and those who benefit from the provisions and policies of this authority. Those who have a clear, direct and permament interest in the execution of the task by water boards not only pay but also have a say in the policies of these authorities. To fund their expenditures, water boards are

5 See Havekes et al. $(1991,28 \mathrm{ff})$. 
allowed to impose water quantity assessments, legal and other charges and, in some cases, the water pollution charge. ${ }^{6}$

\section{Expected Future Use}

So far, several main features of the current use of ecological taxation in the Netherlands have been discussed in general terms. In the following, several expected future uses of ecological taxation in this country are further described. These expected future uses are then compared to current uses, in order to derive particular trends and stages of development of ecological taxation in the Netherlands in general and of separate taxes in particular.

In chapter 7, which provided an overview of the most important ecological taxes that are currently imposed in the Netherlands, for several of these taxes also expected future elements were briefly indicated. It was indicated among others that since the introduction of user taxes on fuel in 1992, further extensions of these taxes have been discussed. In addition to the existing taxes on fuel, policy makers have especially opted for the introduction of environmental user taxes on ground water and waste substances. In November 1993, a proposal to introduce such taxes in the Netherlands was approved by the Second Chamber. Although, several objections have since then been raised against the introduction of additional taxes on ground water and waste substances, and several elements of the original proposals have been changed and fine tuned, environmental user taxes on ground water and waste were actually introduced in this country in January 1995. Besides ground water and waste, a small environmental user tax on uranium was also included. This tax will be introduced in 1996. With a tax of fl 34 cents per cubic metre of ground water extracted and of $\mathrm{fl}$ 28,50 guilders per ton of disposed waste, tax revenues of approximately 600 million guilders are expected. The greater part of these revenues stems from the taxes that are imposed on ground water. With an enlargement of the tax base of the existing environmental user taxes, which prior to 1995 consisted of only fuel taxes, it seems that a first step is taken in the direction of actually introducing the idea of ecological tax reform in this country. ${ }^{7}$

With regard to the water pollution charge, the previous chapter indicated that the tax base of the existing charge can be expected to be broadened and changed. Currently the tax base consists of oxygen binding substances and heavy metals for regional controlling authorities and of only the former substances for the central

6. See Havekes et al. (1991, $96 \mathrm{ff})$.

7 The idea of ecological tax reform as expressed in an increase in taxes on the use of the environment and natural resources and a decrease in taxes on labour has been extensively discussed in the Netherlands in recent years. For an overview of the main elements of discussion, see e.g. Backhaus \& Paulus (1991), Bakker \& Bleijenberg (1991), Bovenberg \& de Mooij (1993), van Driel (1992), Groen Links (1991), Stuurgroep Regulerende energieheffingen (1992) and Wasch (1990). 
authority. For the near future, the option that seems to be currently preferred by policy makers is a separate incorporation of different substances into the existing water pollution charge. As far as the revenues of the charge do not suffice to defray the costs of the control of the quality of water, a water quality assessment is also considered a possible future option. With regard to the charges for soil protection, it was indicated in the previous chapter that since the execution of the current charges is too complicated, mainly because it requires the implementation of a charge regulation or decree ("verordening") for each ground water protection region, in the near future, further changes of the Soil Protection Act can be expected. In this sense, the institutional and constitutional framework into which these taxes are embedded, can be expected to change in the near future. For several other sub national government taxes (especially waste disposal taxes, refuse collection charges and sewerage charges) it can be expected that tax rates will be (further) differentiated in order to enhance the steering effects of these environmental levies. Generally, it can also be expected that, in the near future, a more significant role will be assigned to environmental tax provisions. The reason for this is the recent recognition by policy makers that it is relatively easier to incorporate environmental elements into existing levies than to introduce new environmental levies. In their review of environmental levies for OECD countries, Opschoor and Vos (1989) also indicated further possibilities to use tax differentiations and tax provisions for environmental purposes in the Netherlands. Among others, they suggested to 1) differentiate car prices (i.e. tax advantages for cleaner cars), 2) to introduce tax differentiations for leaded/unleaded gasoline and 3) to differentiate value added tax rates on the basis of the environmental soundness of particular products and services, and 4) to introduce a variabilization of car costs via an increase of indirect taxes on car fuels and a decrease in the annual motor vehicles tax or road tax for cars. While the former two tax differentiations are currently operative in the Netherlands, the latter two differentiation systems have recently been heavily discussed.

In December 1993, the second NEPP, which is the environmental policy plan for the Netherlands for the period 1995-1998, was published. ${ }^{8}$ With the main purposes of the previous environmental policy plans unchanged, the NEPP-2 describes the main lines of policy actions necessary to keep these purposes within reach. These actions consist of readjusting and supplementing existing environmental policy measures. With regard to the (further) use of taxes and levies or elements thereof for ecological purposes in the Netherlands, the plan emphasizes, among others an increase in the excise taxes for traffic, a differentiation of tax rates in the motor vehicles tax and an introduction of a regulatory energy tax to be imposed on the smaller users of fuel and electricity by 1995 if such a tax is not introduced within the European 
community by the end of $1994 .^{9}$ In recent years, especially the introduction of regulatory energy taxes has been strongly debated in this country.

Since 1993, climate change policies in the Netherlands have been mairily directed towards international environmental diplomacy. Prior to 1993, awaiting international consensus formation on these types of policies, the Netherlands mainly focused on domestic policy formation. The introduction of a tax on the carbon and energy context of fossil fuels constitutes one of most important elements of policy formation. In 1992, the Steering Committee Regulatory Energy Levies (the so-called Wolfson Committee) published a report in which the possible effects of regulatory levies on energy, in terms of energy savings and economic effects, were examined. ${ }^{10}$ To determine these effects, the committee analyzed three variants of regulatory energy levies.

The first variant consists of a fixed levy on oil products, natural gas, coal and uranium to be introduced at the level of the OECD, with taxes based on the carbon and energy content of these fuels. The tax rates are equal to an increase in the costs of energy by $50 \%$ and by $100 \%$. With a tax rate of $100 \%$, the Committee calculated a tax revenue of more than 40 billion guilders. Compared to a reference path, such a tax could increase the energy efficiency by $5 \%-10 \%$ in the year 2015 . The analysis of this variant also shows that an important part of the energy intensive industry is expected to move to areas or countries outside the OECD when a regulatory charge is actually introduced. For the Netherlands, the imposition of such a charge would result in significant reductions in economic and employment growth.

The second variant consists of a fixed levy on oil products, natural gas, coal and uranium to be introduced in the Netherlands, with taxes based on the carbon and energy content of these fuels. The tax rates and the expected revenue effects are assumed to be similar to the previous variant. In comparison to a reference path, this levy is expected to increase the current energy efficiency by $5 \%-10 \%$ in 2015 with a $50 \%$ tax rate and by $10 \%-15 \%$ in 2015 with a $100 \%$ tax rate. It is also expected that an important part of the energy intensive industries in the Netherlands will shut down immediately in response to the charge. In this particular case, tax revenues will approximately be $50 \%$ lower than expected. In comparison to the reference path, real wages and labour costs are expected to grow at a lower rate, eventually resulting in a more labour intensive economy. Although employment can then be assumed to increase, the level of growth is expected to be below the one indicated in the reference scenario for the year 2015 . The third variant consists of a fixed levy on the use of energy in the Netherlands with exemptions for the levy for the energy intensive industries that operate internationally. In this variant, the energy levy is mainly imposed on the smaller users of gas (i.e. those who use less than one million cubic metres). Motor fuels are not included in the levy. Tax rates are similar to those in the

9 Ibid.

${ }^{10}$ Stuurgroep regulerende energieheffingen (1992). 
previous variants. With a tax rate of $100 \%$, tax revenues of approximately 15 billion guilders are expected. The energy efficiency is expected to increase by $3,5 \%$ in 2015 for a tax rate of $50 \%$ and by $5 \%$ in 2015 for a tax rate of $100 \%$. The long run macro economic effects are expected to be modest.

On the basis of these results, the Committee concluded that regulatory energy levies, depending on the variant chosen, can be expected to result in a movement of a smaller or greater part of the energy intensive industries to countries outside the Netherlands or the OECD. A regulatory energy levy introduced in only the Netherlands is expected to have severe economic consequences. Although the Committee did not make any policy recommendations as regards the actual introduction of regulatory energy taxes in the Netherlands, the study was used by several policy makers and lobbyists to emphasize that such taxes could better not be introduced in the Netherlands. ${ }^{11}$ Recently, however, within the context of the failure to introduce such taxes at the level of the European Union, it has been decided that energy taxes will be introduced in this country by $1996 .^{12}$ This will be done irrespective from the decision of other countries to also introduce these taxes, although a joint introduction together with several other countries is still preferred. The tax that will be introduced in 1996 in the Netherlands will be imposed on the smaller users of energy. The tax, which will be set at 11 cents per cubic metre of gas and 4 cents per kilo watt hour of electricity, is expected to raise revenues in the order of 1,4 to 2,7 billion guilders. Due to prior arrangements, Shell and ESSO will receive $5 \%$ of these tax revenues. Policy makers have indicated that the revenues of the tax will be shifted back to the tax payers via decreases in other taxes. The energy use is expected to decrease by 0,5 to $1,25 \%$. No taxes have to be paid for the first 800 cubic metres of gas and for the first 800 kilo watt hours of electricity. To safeguard against competitive disadvantages, beyond a certain maximum ceiling of energy use, energy intensive industries and horticulture are excluded from the tax. Calculations indicate that on average households will pay a tax equal to 210 guilders per year. Only in the initial stage, i.e. the period that the tax is introduced, households will pay a tax of approximately 100 guilders per year.

Besides regulatory taxes on energy, the introduction and adjustment of several other environmental levies have also been discussed in the Netherlands. Several of these elements are indicated in a review which was published in September 1992 and which evolved from action point A 106 of the first National Environmental Policy

11 For a more detailed discussion of energy taxation, see e.g. Driel van (ed.) (1992).

12 To actually introduce the tax in the Netherllands, first requires a formal decision by the Dutch cabinet. The decision then has to be further described in the form of a law proposal, which takes approximately two to four months. The proposal then has to be presented to the council of ministers and then has to be approved by the State Council ("Raad van State") and the Parliament. This approximately takes one year. After that, the proposal has to be approved by the European Commission. 
Plan (NEPP). In the report, several options to use the existing fiscal system for ecological purposes are further described. ${ }^{13}$ The review starts from the conception that the nature of the fiscal system in the Netherlands is such that it is especially usefull to be employed in a general and generic i.e. non specific ("generieke") manner: This is also true for the use of the system for environmental purposes. In the review it is stated that it is preferable to use the fiscal system for environmental purposes in the Netherlands via adjustments in existing taxes and levies instead of via the introduction of completely new taxes and levies. Adjustments are possible via alterations in the tax bases and tax rates of existing taxes. New taxes can be introduced via the introduction of taxes that have an environmental tax base. Further possibilities include the introduction of new taxes on basic substances or inputs and taxation of emissions and waste flows or outputs. Examples of the former taxes include those on the extraction of ground water and the use of pesticides and of the latter those on waste substances. By simultaneously decreasing other taxes, e.g. those on labour, possible undesirable side effects of these environmental taxes can be kept within range. The possible future uses of the fiscal system for ecological purposes in the Netherlands, as suggested in the review, are summarized in Table 8.8 . In the review it is concluded that there are several options and possibilities to further use fiscal instruments for environmental policy in the Netherlands. At the time the review was finished, the introduction of environmental user taxes on ground water and waste substances and a differentiation of the motor vehicles taxes and user taxes on cars were seriously considered. In the second National Environmentall Policy Plan, which emphasizes particular elements of environmental policy in the period 1995-1998, several of the afore mentioned environmental levies are again stressed. In addition to a differentiation on the basis of environmental considerations of the motor vehicles tax and the new tax imposed on those who have a car ("houderschapsbelasting") (pp. 142-146), the NEPP2 also stresses the use of financial economic incentive instruments with regard to pesticides $^{14}$ and the fiscal stimulation of environmentally sound investments (pp. 182-183). Since August 1994, the tax allowance schemes for environmental investments (VAMIL) allows all businesses that pay (corporation) income taxes, the unrestricted depreciation of capital goods in the field of environmental protection. Depreciation is only possible for the costs of the purchase or production of particular apparatus. Before August 1994, only accelerated depreciations were allowed and depreciations could not be postponed to forthcoming time periods. An important element of the tax allowance schemes for environmental investments in the Netherlands is that the government sets a particular limit. Once the costs of all depreciations, in terms of tax revenues lost, exceed this limit, the tax allowance scheme ceases for a particular period of time.

13 Tweede Kamer der Staten-Generaal (1992), Financiêlle instrumenten in het milieubeleid, 22779 , urs. 1 en 2.

14 NEPP-2, pp. 109-113. 


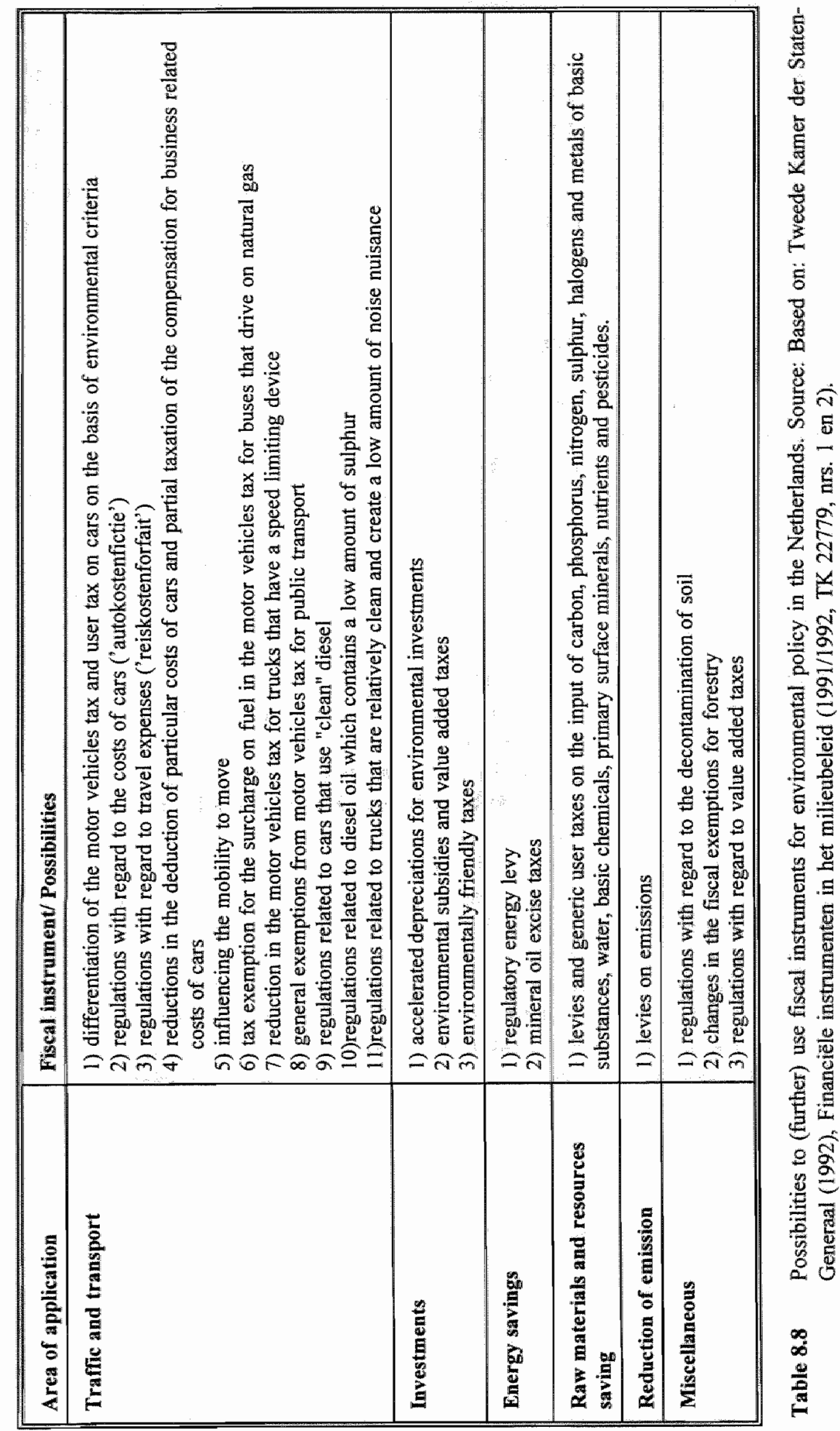


To fund the recycling of particular car elements, also a car disposal charge ('verwijderingsbijdrage') will be introduced in the Netherlands in 1995. The charge, equal to 250 guilders, has to be paid by the buyers of a new car. The revenues are put into a so-called 'car-wreck' fund. The fund can be used by demolition and car companies to finance the disposal and recycling of car wrecks. The fund can also be used to finance the disposal or recycling of consumed or used oil and particular synthetics in the most environmentally sound manner.

With regard to the use of fiscal and financial instruments in the Netherlands, ${ }^{15}$ it can generally be stated that a shift from taxes on labour to taxes on environmentally unfriendly activities (so the idea of ecological tax reform) has an increasing priority in this country. A first application of this priority can be seen in the introduction of taxes on fuel, ground water and waste and the intended introduction of a tax on uranium. The expected continuation of the input of financial instruments in the field of energy can be considered a second step in this direction. In order to stimulate energy savings, future options in the Netherlands also include a fiscal stimulation of energy savings via real estate taxes. ${ }^{16}$ The regulatory energy tax which is intended to be introduced in the Netherlands in 1996 is also part of this input. Within the discussions of energy taxes in this country so far, the major stumbling block seems to be the possible undesirable effects of these taxes on the distribution of income between different groups of people and industries. Decisive for the actual implementation of these taxes, therefore, at this point in time (i.e. at the end of 1994), seems to be the question whether or not and how it is possible to use and shift tax revenues back to tax payers. Since considerable income redistribution effects are usually considered undesirable in this country, it can be expected that the tax will be introduced in a revenue neutral manner. The latter can be achieved by introducing the tax in the form of an incremental surcharge on the costs of energy with possible revenues shifted back to tax payers via reductions in social security payments and taxes on labour. In this sense, at least at the national level, a shift from the tax burden on labour towards pollution seems to be a desired stage in the future development of ecological taxation in this country.

In conclusion, given the current set of ecological taxes, the future development of ecological taxation in the Netherlands can be expected to consist of readjustments of these taxes via changes in tax bases, provisions and tax rates. In addition, the introduction of new ecological taxes that are accompanied by a clear establishment of the use or shift of tax revenues for or to tax payers can be expected. For sub national

15 Ever since the publication of the first NEPP it has been agreed to that, yearly, the role and the application of financiall instruments in practice will be described in each Environmental Program. In this respect, see e.g. Tweede Kamer der Staten-Generaal (1993), Milieuprogramma 1994-1997, 23405, nrs. 1 and 2 (2॥ September 1993). nrs. $1-2$

${ }^{16}$ See Tweede Kamer der Staten Generaal (1993), Verwolgnota Energiebesparing, TK 23561, 
governments in the Netherlands, further developments can be expected to consist of a broadening of existing tax bases and of a further introduction of tax differentiations in relation to existing earmarked environmental taxes.

\subsection{Ecological taxation in the Netherlands: stages of development}

In chapter 5 of this study, both a vertical and horizontal dimension of the development of ecological taxation were distinguished. In short, the vertical dimension expresses the development of ecological taxation in the direction of thoroughly and carefully designed taxes. The horizontal dimension expresses the development of ecological taxation in the direction of a proper level of imposition, given ecological circumstances. It was argued in the same chapter, that the development process of ecological taxation alongside these two dimensions differs per country, level of government or even per jurisdiction. Generally, however, it can be expected that each of these units initially introduces elements of ecological taxation in close relation to existing institutional, ecological and other relevant structures, such as for instance the existing tax system. In subsequent stages, taxes can then be gradually broadened along the afore mentioned dimensions.

In the Netherlands, the introduction of several sectoral environmental levies in the period between 1970 and 1988 can be marked as one of the first stages in the development of ecological taxation in this country. ${ }^{17}$ A distinctive feature of ecological taxation in this period is the introduction of earmarked environmental levies. Resulting tax revenues are used for the funding of policies with regard to one particular environmental compartment, e.g. the air, the soil or a particular type of water. In 1988, after the recognition of the fact that environmental problems are interrelated and therefore not necessarily restricted to one particular environmental compartment, the introduction of a more integrated system of environmental levies marks a subsequent stage in the development of ecological taxation in this country. In this stage, the introduction of a broad integrated earmarked fuel charge by the national level of government can be considered one of the main characteristics of the development. At approximately the same time, sub national governments in this country gradually increase the tax rates of several of their environmental levies, including the waste disposal taxes, the refuse collection charges and the sewerage charges. For these levies, several of these governments also introduce tax rate differentiations. Since the 1990 's, the beginning of a new stage of development of ecological taxation in this country can be noted. This stage mainly consists of a broadening of existing ecological taxes and the introduction of new ecological taxes, with the aim of shifting part of the tax burden away from labour and in the direction of pollution and the use of natural resources. The introduction of environmental user taxes on ground water and

17 The imposition of water quantity assessments, however, has a much longer history. Water boards alleady exist for centuries in this country. 
waste substances (both in 1995) and on uranium in 1996 and the (intended) introduction of a regulatory tax on energy in 1996 can be considered first steps in this direction. Despite the introduction of new user taxes and the intended introduction of regulatory energy taxes, the current tax system does not develop towards a system which systematically focuses on moments of decision. According to the Pigouvian tax approaches described in chapters 2 and 5 of this study, a clear connection between taxes and moments of decision, is however necessary to induce structural behavioural changes (e.g. in order to induce a structural use of environmentally friendly production processes). In the near future, it can be expected that, under the current double dividend approaches of ecological taxation, additional steps in the direction of introducing ecological tax reform in this country will be taken. Table 8.8 shows that preferred steps in this direction include an extension of particular environmental tax provisions, the reduction of environmentally unfriendly elements from the existing tax system and the introduction of new environmental taxes on inputs.

The afore mentioned stages in development of ecological taxation in the Netherlands indicate a general overview for all environmental taxes in this country. For separate environmental levies, however, also particular stages of development can be noticed. In Table 8.9 several of such stages are indicated for the most important environmental levies in this country. The table portrays the situation at the beginning of 1995. For the horizontal dimension mentioned in this table, three consecutive stages of development are used as a benchmark. They include an initial stage in which ecological taxes are first introduced on a surveyable level and consecutive stages in which the level of imposition is gradually broadened in the direction of the ideal image of ecological tax units. For the vertical dimension, five consecutive stages are used as a benchmark. They include an initial stage in which ecological taxes are first introduced in relation to existing fiscal and other relevant structures and consecutive stages in which the tax base is gradually broadened, tax rates are differentiated and the character and the purpose of the taxes are gradually changed.

Table 8.9 shows that separate ecological taxes in the Netherlands mainly develop alongside the stages that are used as a benchmark in the vertical dimension. Only noise charges, charges for soil protection and ground water charges have not really undergone major changes since their introduction. In the near future however, it can be expected that the character of the noise charge will be changed. The charge, which now has the character of an ordinary revenue raising tax, can be expected to be converted into an earmarked charge. For the imposition of charges for soil protection, institutional changes can be expected to be related to changes of the Soil Protection Act. Changes in the current ground water charges can be expected to occur in co-ordination with the environmental user taxes on ground water that have recently been introduced. Table 8.9 also shows that environmental levies that have faced some gradual changes in terms of broadened tax bases and differentiated and increased tax rates enclose municipal environmental levies, the water pollution charge and the charge on manure substances. In the near future, further changes in the taxation of manure substances can be expected, since recently proposals for a regulatory charge 
on pesticides have been launched. Of all the taxes mentioned in Table 8.9 , environmental levies on fuel have probably undergone the most important changes. Being introduced in the form of separate fuel charges that could be imposed on the basis of the Air Pollution Act, the Noise Nuisance Act and the Act on Chemical Wastes in the period from 1972 till 1988, these levies were than integrated into one integrated WABM fuel charge in 1988. In 1992, the character of this earmarked charge was changed and replaced by a user tax on fuel. In 1995, the tax base of this user tax was broadened. Taxes can now be imposed on ground water, waste substances and, in a later stage (i.e. expectedlly by 1996) on uranium. In addition, in 1996, a regulatory tax on energy will be introduced.

\begin{tabular}{|c|c|c|c|c|}
\hline \multicolumn{3}{|c|}{ Horizontal Dimension $\rightarrow$} & & \multirow{7}{*}{ Vertical Dinnension } \\
\hline $\begin{array}{l}\text { 1. Ecological taxes } \\
\text { that are mot impo- } \\
\text { sed at a level which } \\
\text { is closely related to } \\
\text { relewant ecological } \\
\text { circumstances }\end{array}$ & $\begin{array}{l}\text { 2. Ecological taxes that, } \\
\text { are imposed at a level } \\
\text { which is relatively closely } \\
\text { related to relevant ecolo- } \\
\text { gical circumstances }\end{array}$ & $\begin{array}{l}\text { 3. Ecological taxes } \\
\text { that are imposed at } \\
\text { a level which is } \\
\text { related to relevant } \\
\text { ecological circum- } \\
\text { stances }\end{array}$ & , & \\
\hline & $\begin{array}{l}\text { Charge for soil protection } \\
\text { - Ground water charge } \\
\text {-Noise charge on civil } \\
\text { aviation }\end{array}$ & & $\begin{array}{l}\text { 1. Ecological taxes } \\
\text { that are levied in } \\
\text { close relation to } \\
\text { existing fiscal and } \\
\text { other structures }\end{array}$ & \\
\hline $\begin{array}{l}\text {-Environmental user } \\
\text { taxes }\end{array}$ & $\begin{array}{l}\text {-Charge on surplus manure } \\
\text {-Water pollution charge } \\
\text {-Waste disposall taxes } \\
\text {-Refuse collection charges } \\
\text {-Sewerage charges }\end{array}$ & $\begin{array}{l}\text { Water quantity asses- } \\
\text { sments }\end{array}$ & $\begin{array}{l}\text { 2. Eceloglcal taxes } \\
\text { that are gradually } \\
\text { being clianged wia a } \\
\text { broadening of their } \\
\text { tax base, via the } \\
\text { introduction of tax } \\
\text { rate differentiation } \\
\text { or via the abolish- } \\
\text { ment of particular } \\
\text { tax provisions. }\end{array}$ & \\
\hline $\begin{array}{l}\text {-Ewwironmental user } \\
\text { taxes. (including those } \\
\text { on ground water and } \\
\text { fraste substances) }\end{array}$ & -Disposal charges & & $\begin{array}{l}\text { 3. New revelue } \\
\text { raising emvironmela- } \\
\text { tal toxes are intiro- } \\
\text { duced }\end{array}$ & \\
\hline \multirow[t]{2}{*}{$\begin{array}{l}\text {-Regulatory energy } \\
\text { taxixes: }\end{array}$} & & & $\begin{array}{l}\text { 4. New regulatory } \\
\text { environmental taxes } \\
\text { gre introduced }\end{array}$ & \\
\hline & & & $\begin{array}{l}\text { 5. The tax revenues } \\
\text { of existing taxess are } \\
\text { used to shif the } \\
\text { burden of taxation } \\
\text { awsy from fabour } \\
\text { and in the direction } \\
\text { of polltution and the } \\
\text { use of natural re- } \\
\text { sources }\end{array}$ & \\
\hline
\end{tabular}

Table 8.9 Development stages environmental levies in the Netherlands. 
On the basis of the brief sketch of the main features and tendencies of ecological taxation in the Netherlands, it can be concluded that this kind of taxation in this country is gradually developing, via a stepwise process, from a system in which different sectoral environmental levies are introduced within a relatively unco-ordinated manner towards a more structured system, in which environmental levies are more thoroughly designed and co-ordinated. At the beginning of 1995 , this system serves as an important financing scheme for environmental policies and at the same time offers opportunities for the introduction of (additional) ecologically relevant taxes and tax elements that are not primarily intended to be used for revenue raising purposes. For the near future it can be expected that both the financing system and the new ecologically relevant tax elements that are introduced serve as the starting point for a gradual introduction of the idea of ecological tax reform in this country. The latter reform constitutes one of the major ellements of the double dividend approach of ecological taxation. It can also be concluded that the development of ecological taxation in the Netherlands is still in the initial phases of the process described in chapter 5 of this study. Although current institutional, administrative and financial changes create increasing possibilities for the use of an ecological circumstances approach (see section 6.5 of this study), they do not enhance the development towards a tax system which systematically focuses on moments of decisions or ecological or economic levels of imposition. 


\section{Development of Ecological Taxation: Vertical Dimension}

\subsection{Introduction}

In this study so far, it has been argued that carefully and thoroughly designed ecological taxes that are imposed on a proper level and that, given ecological circumstances, are embedded into relevant institutional and other structures, allow and facillitate the ecological effectiveness and acceptability of these taxes. It has also been argued that the latter structures likely vary from country to country and consequently provide different opportunities and problems to different levels of government to further develop ecological taxation. In the Netherlands, relevant structures for ecological taxation have so far allowed this type of taxation to be mainly developed along certain stages of the vertical dimension, but still in close relationship to existing fiscal structures. Environmental levies have mainly been introduced for revenue raising purposes, with tax revenues used to fund particular or general environmental policy measures.

Building on the general trends and features of ecological taxation in the Netherlands, the main purpose of this chapter is to identify possibilities and problems of further developing this type of taxation alongside the vertical development dimension described in chapter 5 of this study. Since the roles that can be played by sub national governments in this development process are generally overlooked within the existing body of literature on the subject, the subsequent analysis especially focuses on the role of these governments in the process of introducing ecological tax reform. After the introduction (section 9.1), several problems and possibilities to further develop ecological taxation alongside the afore mentioned vertical dimension are further described. For sub national governments and the national government, several problems and possibilities to relate current levies to environmental elements are described in sections 9.2 and 9.3, respectively. The possibilities and problems for different levels of government in the Netherlands to introduce ecological tax reform are further described in section 9.4. The chapter ends with several conclusions and remarks.

\subsection{Sub national governments and the development of ecological taxation via the incorporation of environmentally relevant elements into existing taxes}

\subsubsection{Analytical framework}

In the previous chapter, several environmental levies that are currently imposed by different levels of government in the Netherlands were classified by way of benchmark stages in the development process of ecological taxation. Alongside the vertical dimension, benchmark cases included the broadening of tax bases and the incorpo- 
ration of environmental elements into existing levies, and the use of tax revenues to shift the bulk of taxation towards pollution and the use of natural resources. On the basis of these benchmark stages, in the following several possibilities, problems and costs of moving towards particular (subsequent) development stages are further indicated. The analysis, which is mainly focused on the possible role that can be played by sub national governments, is based on the following questions:

1. Given the taxes and related levies that can presently be imposed by different levels of governments in the Netherlands, what are the possibilities for these governments to (further) use existing taxes and related levies for ecological purposes?

2. Given the restriction that ecological taxation can be introduced by different levels of governments in the Netherlands if introduced revenue neutral, what are the possibilities for these governments to introduce and use additional taxes, related levies and tax provisions for ecological purposes?

The first question is addressed in sections 9.2 and 9.3 for sub national governments and the national government, respectively. The second question is addressed for both levels of government in section 9.4. On the basis of an analysis of these questions, several options and problems for different levels of government to use taxes and related levies for ecological purposes in the Netherlands are then presented.. Where possible, the expected revenue and incentive effects of these additional or alternative actions are indicated. Required changes in laws and existing relationships and possible restrictions with regard to these actions are also, as far as possible, indicated. These effects, required changes and restrictions then express part of the costs for different levels of government in this country to further develop ecological taxation.

\subsubsection{The use of existing taxes for ecological purposes: sub national governments}

In order to conduct an analysis of the previous questions for sub national governments, first the main environmental policy tasks and instruments for these governments are further specified. In the previous chapters it was shown that the main environmental policy tasks for sub national governments in the Netherlands entail a) the prevention, control and/or decontamination of soil and water related environmental problems, excessive noise and local air pollution; b) the development of a sustainable living environment in rural and non rural regions; c) the restorement of the functions of the environment for the provision of drinking water and the creation of sustainable types of agriculture, recreation and living in natural regions; and d) the development of possibilities for the preservation of landscapes and nature. The division of responsibilities between provinces, municipalities and water boards with regard to these and other environmental tasks are shown in Table 9.1. 


\begin{tabular}{|c|c|c|c|}
\hline Environmental task & Provinces & Municipalities & Water boards \\
\hline $\begin{array}{l}\text { execution of environmental policy and en- } \\
\text { vironmental policy acts }\end{array}$ & $x$ & $\mathrm{x}$ & $x$ \\
\hline drawing up of environmental regulations & $\mathrm{x}$ & & \\
\hline $\begin{array}{l}\text { drawing up of environmental policy plans } \\
\text { and/or programmes }\end{array}$ & $\mathrm{X}$ & $x$ & \\
\hline granting of licences & $\mathrm{X}$ & $\mathrm{X}$ & $\mathrm{X}$ \\
\hline $\begin{array}{l}\text { translation of goals with regard to enwi- } \\
\text { ronmental themes into local/regional tar- } \\
\text { gets* }\end{array}$ & $\mathrm{X}$ & $\mathrm{X}$ & \\
\hline protection of particular natural regions & $x$ & & \\
\hline decontamination of soil and noise & $X$ & $\mathrm{X}$ & \\
\hline prevention of waste & $x$ & $\mathrm{X}$ & \\
\hline disposal/removal of waste & $x$ & $\mathrm{X}$ & \\
\hline sewerage & & $\mathrm{X}$ & \\
\hline purification of water & $x$ & & $\mathrm{x}$ \\
\hline $\begin{array}{l}\text { savings of energy with regard to local air } \\
\text { pollution }\end{array}$ & & $X$ & \\
\hline environmental education & & $x$ & \\
\hline making of environmental provisions & $X$ & $\mathrm{X}$ & $\mathrm{X}$ \\
\hline \multicolumn{4}{|c|}{$\begin{array}{l}\text { With regard to dehydration, disturbances, eutrophication of ground and surface waters and } \\
\text { ammonia resulting from agricultural activities. }\end{array}$} \\
\hline
\end{tabular}

Table 9.1 Sub national governments in the Netherlands: main environmental tasks.

To perform the specific environmental tasks mentioned in Table 9.1 , sub national governments in the Netherlands use different environmental policy instruments. Direct regulation instruments such as licencing, environmental planning and environmental regulation constitute the main part of these instruments. Social and financial regulation instruments such as education and environmental levies are mainly used in addition to direct regulation instruments. With regard to environmental taxes and related levies, existing sub national governments in the Netherlands mainly impose taxes and levies that are related to waste and soil and activities and substances that affect and pollute the soil and different types of water (see Table 9.2). 


\begin{tabular}{|c|c|c|c|}
\hline $\begin{array}{l}\text { Environmenital faxes and levieg/related policy } \\
\text { feld }\end{array}$ & Provinces & Municipalities & Water bararis \\
\hline $\begin{array}{l}\text { Water pollution charge for regional watters } \\
\text { /Quallity of surface waters }\end{array}$ & $x$ & $\mathrm{x}$ & $\mathrm{x}$ \\
\hline $\begin{array}{l}\text { Charge for soil protection } \\
\text { fQuality of soil and ground water }\end{array}$ & $\mathrm{x}$ & & \\
\hline $\begin{array}{l}\text { Waste disposal hax } \\
\text { /Prevention and disposal of waste }\end{array}$ & & $\mathrm{x}$ & \\
\hline $\begin{array}{l}\text { Ground water charge } \\
\text { Quantity of ground water }\end{array}$ & $x$ & & \\
\hline $\begin{array}{l}\text { Refuse collection charges and waste disposal taxes } \\
\text { /Prevention and disposal of waste }\end{array}$ & & $\mathrm{x}$ & \\
\hline $\begin{array}{l}\text { Sewer(age) charges } \\
\text { /Sewerage }\end{array}$ & & $\mathrm{x}$ & \\
\hline $\begin{array}{l}\text { Water quantity assessments } \\
\text { /Quantity and/or quality of regional surface waters }\end{array}$ & & & $x$ \\
\hline
\end{tabular}

Table 9.2 Sub national governments in the Netherlands: The use of environmental taxes and levies.

The purpose of the environmental levies and taxes mentioned in Table 9.2 is primarily a fiscal one. The revenues of these levies and taxes are used to fund specific or general policy measures. From the previous considerations it can be concluded that, within the framework of particular environmental policies, environmental taxes and levies are used by sub national governments in the Netherlands only in certain policy fields, i.e. with regard to the quality and quantity of surface water, the quantity of ground water, the quality of soil and ground water, sewerage and the disposal and/or prevention of waste. For several environmental areas for which sub national governments also have specific responsibilities, taxes and levies are not included in the set of environmental pollicy instruments. These areas include energy savings; excessive noise; local air pollution; (partly) the environmental problem of eutrophication as a consequence of agricultural activities; (partly) the development of a sustainable living environment in rural and non rural regions; (partly) the prevention of waste and the development of possibilities for the preservation of landscapes and nature. To determine whether it is possible for sub national governments to (further) relate the taxes they currently impose to relevant tasks and environmental problems, several possibilities to relate environmental ellements to the existing tax code are further delineated in section 9.2.2.1.

\subsubsection{Relating environmental elements to the existing tax code}

To determine the possibilities for sub national governments to relate environmentally relevant elements to existing taxes and levies, it is assumed that the existing administrative, financial and institutional context for the imposition of these taxes will not or 
can only slightly be changed. In this sense, it is possible to restrict the subsequent analysis to the given set of taxes and levies that are currently imposed by these governments. This set is summarized in Table 9.3. The taxes and levies mentioned in Table 9.3 can be imposed on the basis of the Municipality Act, the Province Act, the Water Board Act and on the basis of Special Acts. To determine whether the levies mentioned in Table 9.3 provide startingpoints to (further) relate them to ecological elements, e.g. via the introduction of tax provisions, tax deductions or a particular use of tax rates, in the following, first the main elements of the levies in terms of the tax base, tax rates etc. are described. Given the institutional framework for this type of taxation in the Netherlands, possibilities to relate these different levies to relevant ecological elements are then further discussed.

\begin{tabular}{|c|c|c|}
\hline $\begin{array}{l}\text { Taxes/Levies } \\
\text { Municipalities }\end{array}$ & Taxes/Levies Provinces & $\begin{array}{l}\text { Taxes/Levies } \\
\text { Water boards }\end{array}$ \\
\hline 1. Real estate tax & $\begin{array}{l}\text { 12. Surcharges on the } \\
\text { motorvehicles tax }\end{array}$ & 19. Water quantity assessments \\
\hline 2. 'Benefit' tax & 13. Administrative charges & 20. Legal charges \\
\hline 3. Building site tax & $\begin{array}{l}\text { 14. Other charges for the use } \\
\text { of provincial possessions, } \\
\text { work, installations destined } \\
\text { for public services }\end{array}$ & $\begin{array}{l}\text { 21. "Precario" dues and other char- } \\
\text { ges }\end{array}$ \\
\hline 4. Dog tax & 15. Water pollution charge & 22. Water pollution charge \\
\hline 5. Advertising tax & 16. Ground water charge & \\
\hline 6. Commuter tax & $\begin{array}{l}\text { 17. Surcharges on the contri- } \\
\text { butions for broad castings }\end{array}$ & \\
\hline 7. Tourust tax & $\begin{array}{l}\text { 18. Charges for soil protec- } \\
\text { tion }\end{array}$ & \\
\hline \multicolumn{3}{|l|}{ 8. Parking tax } \\
\hline \multicolumn{3}{|l|}{$\begin{array}{l}\text { 9. Administrative or legal } \\
\text { charges including charges for } \\
\text { licences }\end{array}$} \\
\hline \multicolumn{3}{|l|}{$\begin{array}{l}\text { 10. Other charges and taxes } \\
\text { including user charges, servi- } \\
\text { ce charges and 'precario' } \\
\text { dues }\end{array}$} \\
\hline 11. Water pollution charge & & \\
\hline
\end{tabular}

Table 9.3 Taxes and levies which can be imposed by sub national governments in the Netherlands. 


\section{Real estate, 'benefit' and building site taxes}

Real estate taxes can be levied on the actual users and/or the current owners of real estate. The taxes imposed on owners may not be higher than $125 \%$ of those imposed on the actual users of the real estate. Taxes imposed on owners can be levied on the basis of the assessed economic value of the real estate or on the basis of the lot size of the real estate by taking into consideration the nature or condition, position, quality and sort of use. 'The latter factors include, for instance, the position of the real estate determined by such aspects as parking space, availability of certain provisions and pollution of the soil; the sort of use, e.g. a factory or an office; and the quality of the real estate as determined by age and conservation of the real estate (Sio, 1991, p. 34).

The taxes that are based on the lot size of the real estate will probably be abolished before the end of this century. At that time, real estate taxes can only be levied on the basis of the assessed economic value. The latter value is determined by the property of the real estate, mortgages etc. excluded. The value is related to the condition of the real estate at the moment that someone decides to take it over or use it. Since the value of the real estate can depreciate, both technical and functional depreciations are taken into consideration in the assessment of the value of the reall estate (see Sio, 1991, p. 33). Technical depreciations incorporate the depreciation of the real estate over time and depreciation due to the use of this estate. Functional depreciations consist of reductions in value due to economic and other developments and can incorporate among others environmentally related considerations such as energy savings.

Tax rates are fixed for a particular interval of economic value, e.g. a fixed tax rate per fl 3000 or per fl 5000 guilders of assessed value. In the Municipality Act, certain exemptions for the real estate tax are allowed. They include churches, particular types of cultivated land, nature regions, public roads and rail tracks. ${ }^{2}$ At present, real estate taxes can also be imposed on moveable real estate such as caravans and house-boats. ${ }^{3}$ In recent years, revenues from the real estate tax have almost doubled (see Sio, 1991, p. 11). In 1993, these revenues amounted to more than three billion guilders. The real estate tax is an ordinary revenue raising tax for which there is no quid pro quo relationship between the taxes paid and the services provided by the municipal government.

"Benefit' taxes ("Baatbelastingen") can be used as a means to achieve a reasonable contribution in the costs from provisions made by or in co-operation with the local government. The taxes can be imposed on those who own real estate. Building site taxes can be imposed on those who use real estate in the instance that the real

1 Belastingwetten 1994 (p. 705 , art. 220 Gemeentewet).

2 See Duchateau and Lok (1993, p. 209).

3 See Duchateau and Lok (1993, p. 210). 
estate becomes more suitable or more advantageous for building in case of provisions made by or in co-operation with the local government. Several similarities can be detected between benefit and building site taxes. The most important similarity is that of real estate which is benefitted by such provisions as the construction of roads, parking provisions and parking spaces, sewerage, bridges, tunnels, green spaces etc. (see Sio, p. $53 \mathrm{ff}$ ). Mainly because of their similarities, on the basis of the new Municipality Act, several elements of 'benefit' and building site taxes have been integrated into a new style 'benefit' tax. Taxes can now be imposed in such a way that one hundred percent of the relevant costs can be covered (see Duchateau and Lok, p. 210211). The taxes, however, can not be imposed when real estate is not benefitted by the relevant provisions. Although municipalities are free to determine the tax base of the 'benefit' tax new style, the real estate tax often serves as the basic starting point.

In the proposals of the De Kam Commission (Commissie de Kam, 1992), extensions of the present real estate taxes in the Netherlands were considered one of the possibilities for increasing the policy freedom of municipalities with regard to taxation. ${ }^{4}$ Policy freedoms could be increased by abolishing certain exemptions from the real estate tax, by expanding the $125 \%$ limit on the real estate taxes that are imposed on owners and by differentiating real estate tax rates. As described before, the present real estate tax in the Netherlands allows exemptions for churches, particular types of cultivated land, nature regions, public roads and rail tracks. According to the De Kam Commission (Commissie de Kam, 1992) almost all of these exemptions could be abolished, including those for cultivated land. Exemptions for this kind of land had been included into the real estate tax in order to avoid increased tax burdens for those who owned this kind of land and were already (heavily) taxed by way of water quantity assessments. Instead of tax exemptions for those who own cultivated land, the Commission suggested the introduction of differentiated real estate tax rates, including a possibility to use a low or zero real estate tax rate for agricultural companies. With regard to the $125 \%$ limit, the Commission suggested to increase the limit to $140 \%$ or $150 \%$. The Commission also strongly favoured a further differentiation of existing real estate tax rates on the basis of the tax objects (between houses and other real estate) and the type of company, location and business sector.

From an ecological point of view, several suggestions of the De Kam Commission are interesting as they present options for the incorporation of particular environmental policies into the tax code of the real estate taxes. A first option is presented by the possibility to restructure the current tax base of these taxes by incorporating into the economic value certain elements which express the environmental (un)friendliness of the real estate in question. The environmental (un)friendliness of the real estate can, for instance, be expressed in terms of:

4t It is stated by the Commissie de Kam (1992, p. 53) that below national governments attain higher policy freedoms in case particular exemptions can be abolished or changed, tax limits can be changed and/or in case tax rates can be differentiated. 
- The degree of energy savings which can be related to the insulation of houses. In this case the real estate taxes can, for instance, be used for the fiscal stimulation of energy savings.

The environmental (un)friendliness of the way in which the particular real estate in question was constructed, e.g. in a durable or non durable manner.

Enhanced functional depreciations of the real estate by further including environmental aspects such as the pollution of the soil or the degree of local air pollution near parking spaces.

A further option is presented by differentiating the real estate tax rates according to the environmental (un)friendliness of this estate. The latter can be expressed in terms of such factors as the type and the location of the real estate. Examples include higher real estate tax rates for polluting companies or polluted land. A subsequent option is presented by enhanced tax exemptions, which could be introduced for particular natural regions. Abolishing the exemptions for cultivated land, as suggested by the De Kam Commission (Commissie de Kam), seems appropriate from an ecological point of view in case the land is cultivated in an environmentally unsound manner (e.g. because of the use of too many pesticides or eutrophying substances). From an ecological point of view, tax exemptions for land which is cultivated by way of durable farming seems undesirable.

Besides the possibility to restructure the tax base, to differentiate real estate tax rates and to enhance the use of tax exemptions, an alternative option is presented by the proposal of Henry George (see chapters 2 and 3 of this study). On the basis of this proposal, real estate taxes could be reformed in such a way that the value of the real estate is assessed on the basis of the surplus of the rent of the real estate. In the sense of Henry George, by taxing the rent of land (or real estate in this case), an optimal use of the land can be stimulated.

Both 'benefit' and building site taxes are based on the economic value of the real estate. These taxes are therefore related to the tax base of the real estate tax. This implies that changes in the tax base of the latter tax, e.g. via an incorporation of environmentally relevant elements, can also influence and change the 'benefit' and building site taxes. There are several options to also directly include specific environmental elements into the existing 'benefit' and building site taxes. These options consist of the inclusion of the environmental costs of making the soil ready for building (e.g. decontamination costs) into the existing building site taxes and the inclusion of the nature and location of particular provisions within the existing 'benefit' taxes. The possible non adherence with the polluter pays principle in the former case and the danger of cumulating effects with the real estate taxes in the latter case, however, present important restrictions for the actual introduction of such changes in the Netherlands. Suggested tax changes should therefore always be viewed within the context of the entire existing fiscal system, in order to avoid undesirable cumulating effects of different taxes and related levies. 
In conclusion, it can be stated that, from an ecological point of view, the real estate tax offers different starting points for the incorporation of environmental aspects. Changes in the real estate tax base, differentiations of the tax rates and further enhancements of tax exemptions can be used to further stimulate energy savings and an optimal use and cultivation of land. Existing 'benefit' and building site taxes and the future new style 'benefit' tax present only minor possibilities for the incorporation of environmentally relevant elements. Possibilities include the incorporation of the nature, location and costs of provisions. These possibilities, however, at the same time present the danger of being inconsistent with the polluter pays principle and bear the danger of cumulating with the effects of the real estate taxes.

\section{Dog taxes}

Dog taxes can be imposed on those who keep dogs. The taxes are based on the number of dogs kept. The tax rate can be fixed or progressive. Since the taxes were introduced with the purpose of regulating the number of dogs in order to keep the city clean, dog taxes, which have been levied since 1851, are sometimes presented as the first environmental taxes ever introduced in the Netherlands. "The taxes, however, never achieved their intended incentive effects. From an ecological point of view, dog taxes present no direct starting points for the incorporation of environmental aspects. Only tax rates can be increased in order to protect or improve the cleanliness of the city and thus to discourage undesirable behaviour.

\section{Advertising taxes and 'precario' dues ${ }^{6}$}

Advertising taxes can be imposed on advertising signs which are visible from the public highway. Liable are those who have a direct interest in the public announcement (see Sio, 1991). Tax rates can be differentiated according to size, time and type of advertising. Tax rates are usually based on the size or space occupied by the public announcement. No taxes have to be paid for advertising in magazines and papers.

'Precario' dues essentially are ordinary revenue raising taxes (i.e. there is no quid pro quo relationship between the taxes paid and the services provided) which can be imposed on those who have boards, rails, petrol pumps etc up, above or under municipal land or water. 'Precario' dues can only be imposed if the land or the water in question is actually owned by the municipality. 'Precario' dues can not be imposed on rented soil. The most important due is an outdoor advertising tax. Depending on the nature of the objects and the use involved, the tax rates of 'precario' dues can differ significantly. Sio (1991) indicates that tax rates can e.g. differ per (square) metre of occupied space, per period of time or per degree of interest. In this sense it

5 See Ilsink (1990, p. 48).

6 See also Gieskes (1993). 
is possible that a due can be collected from the owners of a petrol pump according to the amount of fuels provided, while at the same time tax rates can be differentiated according to place, e.g. according to whether a street is busy or not (p. 60). Advertising taxes and 'precario' dues are not based on a quid pro quo relationship and in this sense can not be considered charges as in the case, for instance, of legal or other municipal charges. Since there is no quid pro quo relationship with regard to "precario' dues, there is not tax revenue limit. Tax rates can also be freely set by municipalities. In this sense, for instance, more intensive uses can be more heavily taxed by way of higher tax rates. For equal uses, however, equal 'precario' dues have to be paid. ${ }^{7}$

From an ecological point of view, advertising taxes only provide minor starting points. Not unlike dog taxes, advertising tax rates can be increased in order to protect and improve specific features of the city, such as the cleanliness of the city. ${ }^{8}$ Another option is to further differentiate these rates on the basis of the environmentally friendliness of the type of advertising, e.g. higher tax rates for types of advertising that require a high input of energy, electricity or specific substances (plastics). Differentiation of tax rates is also one of the options that can be used to incorporate particular environmental elements into the 'precario' dues. Since these dues can directly be related to the use of municipal soil and water, options include a differentiation of tax rates according to the type of use, the object involved, the location of the use etc. Differentiation of outdoor advertising tax rates, however, should be carefully considered, in order to avoid a cumulation of 'precario' dues with ordinary advertising taxes. Since there is no quid pro quo relationship between the 'precario' dues and the services provided, while tax rates can also be freely set by municipalities, in principle, the potential to (also) use these taxes for ecological purposes is relatively high. Since 'precario' dues are directly related to the use of municipal land and water, in principle tax bases, tax rates and tax exemptions can be differentiated on the basis of ecological concerns.

\section{Commuter taxes and tourist taxes}

Commuter taxes can be imposed on those who, per tax year, reside more then 90 times in a particular municipality without being a citizen of that municipality. The purpose of these taxes is to let those who do not reside but who do benefit from the provisions of the municipality in question pay for (part of) the costs of these provisions. These taxes can therefore be seen as compensations for municipalities that are confronted with the free riding behaviour of citizens of other municipalities. The tax can be based on the duration of the stay, the rental value of the rented house or on

7 Most of the conditions, remarks and expected future developments are based on Sio (1991, pp. 62-74).

Also see Stevens (1993). 
the economic value, the tax base of the real estate tax or simply as a fixed amount per dwelling place. ${ }^{9}$ There are tax exemptions for those who are ill, helpless and/or old or for those who visit the municipality for a meeting of a public body or for those who temporarily fill a public place. Tax revenues are not earmarked and also are not restricted in the sense that tax revenues should only cover $100 \%$ of relevant costs.

Tourist taxes can be imposed on those who are not enlisted by the population registry office of the municipality in question. In this sense, taxes can, for instance, be imposed on tourists or those who offer a dwelling place for tourists, e.g. those who own a hotel, a camping etc. In the latter case, taxes can only be levied on those that have a financial interest in non residents or tourists. ${ }^{10}$ The burden of taxation that arises because of this tax, however, can be shifted from those who offer a dwelling place to those in need of such a place. The tax rate can be fixed (e.g. per vacation house or berth) or be based on e.g. the number of days or nights. Tax rates differ per municipality. Tourist taxes can also be imposed on tourists who use municipal water e.g. via boats (the so-called water tourists). More then half of all municipalities in the Netherlands impose tourist taxes. The taxes can also be imposed on those who visit the municipality in question for non touristic purposes, e.g. for business. Revenues, which amount to more then one hundred million guilders, can freely be used by municipalities and are not earmarked. ${ }^{11}$ Not unlike commuter taxes, the purpose of tourist taxes is to let those who do not reside but who do benefit from the provisions of the municipality in question pay for (part of) the costs of these provisions. The latter is considered reasonable in the sense that only for residents, municipalities receive a contribution from the municipalities fund. It can also be considered reasonable in order to compensate for the free riding behaviour of those who benefit from the provisions of the municipality in question but who do not reside in this municipality. In the act on tourist taxes no specific tax exemptions are mentioned. Generally, however, tax exemptions are offered to those who are sick, helpless or old, who use caravans or who are already liable for commuter taxes or water tourist taxes. ${ }^{12}$

From an ecological point of view, tourist taxes present an interesting case in the sense that by restructuring these taxes, particular elements that are relevant from this point of view can be taken into consideration. These include an increase or differentiation of the tax rates of tourist taxes according to the region or location in question (e.g. higher tax rates for those who camp in regions or locations that are considered important from an ecological point of view) and the possibility to differen-

9. Belastingwetten 1994 (p. 708) and Duchateau and Lok (1993, p. 211-212).

10 Plante-Failé (1993, p. 22-23).

11 Plante-Faile (1993, p. 11). Tourist taxes, however, cannot be imposed on those who wisit a recreation park for one day.

12 Plante-Failé (1993, p. 35). 
tiate tax rates for those who use the water and those who use the land for recreational purposes. Further differentiations of tourist tax rates, other than on the basis of the location or the recreational use in question, may be difficult to achieve in practice due to the intricacies that are involved in assessing those who are liable for the tax in question. The same difficulties also arise for commuter taxes, which on the whole hardly provide any starting points for the incorporation of environmental aspects.

\section{Parking taxes}

Parking taxes can be imposed on the basis of the parking of a motor vehicle at a certain place, time and manner or on the basis of a parking licence granted by the municipality for parking a vehicle at a prescribed place or manner. The former tax is paid immediately at parking metres or, if the tax is not immediately paid, can be imposed by means of a post tax assessment. The latter tax is paid at the moment the licence is obtained. Tax rates can be set according to the type of vehicle, the location where the vehicle is parked and the duration of parking. The purpose of the parking tax is to make it possible for municipalities to better maintain municipal regulations with regard to parking. Parking taxes are thus not primarily aimed at raising revenues. ${ }^{3}$ From an ecological point of view, parking taxes could be restructured in such a way as to include or incorporate certain elements of the environmental problems that are related to transport and traffic such as, for instance, the problem of local air pollution. Interesting options include further increases in parking tax rates for parking in the inner city, in order to induce the use of other means of transport to drive to or within the inner city. Tax rate differentiations for private and public transport or the introduction of tax exemptions for public transport also present options that can be used with regard to this purpose. Further increases or differentiations of parking tax rates for different types of motorvehicles, on the basis of the environmentally friendliness of these vehicles, also present interesting options.

\section{Legal and other charges}

Administrative or legal charges include charges for certificates, subscriptions, copies, archival services and licences. They can only be imposed in case a service is provided. The revenues of these charges are used to defray the costs that are directly associated with licencing. Revenues can therefore, for instance, not be used to defray the costs that are associated with the preparation of particular policies. Tax rates differ per municipality. The tax rates of most environmental administrative charges are based on the composition, the size and the nature of installations. Most municipalities in the Netherlands impose legal charges that cover less than $100 \%$ of the costs that

${ }^{13}$ Duchateau and Lok (1993, p. 212-214). 
need to be defrayed by the revenues of these charges ${ }^{i 4}$ In the near future, legal and administrative charges will no longer be distinguished from other charges. Legal charges will then be considered service charges, i.e. as long as there is an (individual) quid pro quo relationship.

Other municipal charges include user and service charges. User charges can only be imposed in case it can be shown that for the entertainment in question (e.g. a soccer match), specific provisions or additional costs have been made (e.g. municipal supervision). ${ }^{15}$ User charges can be levied on the basis of the use of municipal possessions that are intended for public services, such as roads, streets, bridges and markets. User charges can only be imposed if the user actually and individually uses municipal possessions and/or installations. Differentiation of tax rates is only allowed for the degree of use or the size of related benefits of use. ${ }^{16}$

Service charges can be levied for municipal services such as refuse collection and sewerage. All of these charges are marked by a quid pro quo relationship. The revenues of municipal charges may not be higher than the costs of the relevant provision or service. Service charges can only be imposed in case a service is actually provided and can be used individually. The charges can not be imposed if the individual is obliged to make use of the service or if he refuses to make use of this service. One of the most important service charges is the refuse collection charge. This charge can be levied on the basis of the actual collection of waste substances. For the use of containers, user charges can be imposed. With regard to refuse collection charges, different tax rates can be imposed on waste from households and companies. For companies, tax rates are determined on the basis of the amount of waste supplied.

Sewerage charges can be imposed in the form of user charges and/or in the form of service charges. These charges can thus be imposed on the connection to a sewer or on the use of the sewer. In case the connection to a sewer is already taxed by way of 'benefit' taxes, sewerage charges related to the connection to a sewer can not be imposed. Those who are liable for sewerage charges because they are connected to a sewer, usually pay a fixed amount per year. These charges, however, cannot be based on the amount of waste water. In case sewerage charges are imposed on users, these charges have to be related to the individual benefit that users have of the sewer and to the costs that are related to the use of the sewer. The revenues of the charges can be used to defray the costs of constructing and exploiting municipal sewerages. Sewerage charges that are imposed on users can be based on a fixed amount or on the use of water in combination with a fixed amount. User charges can

\footnotetext{
${ }^{14}$ See Sio $(1991$, pp. 62-74).

${ }^{25}$ Plante-Failé (1993, p. 11).

${ }^{16}$ Ibid
} 
only be imposed on the actual use of the sewer and thus e.g. not on the emissions of water in surface waters. ${ }^{17}$

Also provinces can impose particular user and service charges. These charges are generally considered as provincial taxes. The revenues of these charges/taxes may not be higher than an amount which provides a moderate profit to provinces. ${ }^{18}$

From an ecological point of view, especially user and service charges present interesting starting points for a (further) incorporation of environmental aspects. Interesting options include a further differentiation of the tax rates of sewerage charges, refuse collection charges and waste disposal taxes. The latter two types of levies can be differentiated according to the weight of the waste supplied (per household or group of households), the unit of volume (per bag, garbage can, frequency of supply etc.) and the type of waste substance (household waste or industrial waste). Interesting options also include a broadening of the tax base, e.g. by including different waste substances and the production, import, dumping and burning of waste into the tax base. Environmental legal. charges provide no additional starting points for the incorporation of environmental aspects.

\section{Sub national government environmental charges}

The water pollution charge, the ground water charge, the charge for soil protection and the water quantity assessments that are currently imposed in the Netherlands are also used within the framework of environmental policies in this country. Nevertheless, these levies also provide starting points for an incorporation of additional environmental elements. Mainly, these entail:

1) A broadening of the tax base of the water pollution charge by including additional substances such as phosphates, (partly) heavy metals, organic micro pollutants and discharges from agricultural businesses.

2) An increase in the tax rates of the charge for soil protection and the ground water charge in order to also use these taxes for the encouragement of a more environmentally friendly extraction of ground water.

3) As with real estate taxes, the introduction of tax exemptions for particular real estate in the water quantity assessments. Tax exemptions, however, should be carefully provided in order to prevent such a decrease in tax revenues that relevant costs can no longer be defrayed.

\footnotetext{
17 This section on sewerage charges is mainlly based on Sio (1991, pp. 62-74).

18 Belastingwetten 1994 (p. 701).
} 


\section{Surcharges on motor vehicles tax and on the contributions for broadcastings}

Since 1982, provinces in the Netherlands are allowed to impose surcharges on the principal sum owed of the motor vehicles tax. The latter tax is intended to be changed into a tax for those who keep motor vehicles ("houderschapsbelasting"). ${ }^{19}$ Surcharges can be imposed on the inhabitants of the province in question. By law, provinces are only allowed to impose a maximum rate of surcharges. In 1992, for instance, provinces were allowed to impose a surcharge of 34,2 cents. The rate of the surcharges is equal for all motor vehicles. Surcharges on the contributions for broadcastings can be imposed on residents who are liable for broadcasting fees on the basis of the Media Act. Surcharges on the contributions for broadcastings provide no additional starting points for the incorporation of environmental policies into their tax code. Surcharges on the principal sum owed of the motor vehicles tax can only very indirectly provide such starting points as their revenues could be raised by increasing the surcharge to 70 points (see the proposal of the Commissie de Kam, 1992). The additional revenues (approx. 750 million guilders) could then be used to stimulate the use of environmentally friendly motor vehicles. No further starting points for the incorporation of environmental aspects are however provided by these surcharges.

With regard to the taxes and related levies that are currently imposed by sub national governments in the Netherlands, several options have been indicated for a further incorporation of environmental aspects. Options range from a restructuring and broadening of existing tax bases to increasing and differentiating tax rates and abolishing or introducing particular tax exemptions or provisions. The policy alternatives that have been discussed for sub national governments in this respect are summarized in Table 9.4. With regard to the municipal taxes and related levies that are mentioned in Table 9.4, starting points are provided mainly by real estate and 'benefit' taxes, tourist taxes, parking taxes, user and service charges and 'precario' dues. With regard to the levies and taxes that are imposed by provinces and water boards, additional starting points are provided by the charges that are also currently being used within the field of environmental policy. By incorporating particular environmental elements, sub national governments in the Netherlands have an opportunity to use taxes and levies as (additional) environmental policy instruments for those policy fields and environmental tasks for which they currently use other instruments (e.g. direct regulation).

${ }^{19}$ See Commissie de Kam (1992, p. 53). 


\begin{tabular}{|c|c|c|c|}
\hline $\begin{array}{l}\text { Taxes and related } \\
\text { llevies of sub national } \\
\text { governments }\end{array}$ & $\begin{array}{l}\text { Options: } \\
\text { Restructure of the } \\
\text { tax base or incorpo- } \\
\text { ration of environmen- } \\
\text { tal costs in tax base }\end{array}$ & $\begin{array}{l}\text { Options: } \\
\text { Differentuating or } \\
\text { increasing tax rates }\end{array}$ & $\begin{array}{l}\text { Options: Introducing } \\
\text { or abolishing tax } \\
\text { exemptions or provi- } \\
\text { sions }\end{array}$ \\
\hline Real estate taxes & $x$ & $x$ & $\mathrm{X}$ \\
\hline $\begin{array}{l}\text { "Benefit" and building } \\
\text { site taxes }\end{array}$ & $\mathrm{X}$ & & \\
\hline Dog taxes & . & $x$ & \\
\hline Adwertising taxes & & $x$ & \\
\hline \multicolumn{4}{|l|}{ Conmuter taxes } \\
\hline Tourist taxes & & $\mathrm{x}$ & $\mathrm{X}$ \\
\hline Parking taxes & & $\mathrm{x}$ & $\mathrm{x}$ \\
\hline \multicolumn{4}{|l|}{$\begin{array}{l}\text { Administrative or } \\
\text { legal charges (inclu- } \\
\text { ding charges for licen- } \\
\text { ces) }\end{array}$} \\
\hline $\begin{array}{l}\text { Other charges inclu- } \\
\text { ding user and service } \\
\text { charges }\end{array}$ & $x$ & $\mathrm{x}$ & \\
\hline "Precario' dues & $\mathrm{x}$ & $\mathrm{x}$ & $\mathrm{x}$ \\
\hline Water pollution charge & $\mathrm{x}$ & & \\
\hline Ground water charge & & $\mathrm{X}$ & \\
\hline $\begin{array}{l}\text { Surcharges on the } \\
\text { principal sum of the } \\
\text { motor vehicles tax }\end{array}$ & & $\mathrm{X}$ & \\
\hline $\begin{array}{l}\text { Charges for soil pro- } \\
\text { tection }\end{array}$ & & $x$ & \\
\hline $\begin{array}{l}\text { Water quantity assess- } \\
\text { ments }\end{array}$ & & $\mathrm{X}$ & \\
\hline
\end{tabular}

Table 9.4 Options for the incorporation of environmental aspects in taxes and related levies of sub national government bodies in the Netherlands.

More specifically, the analysis shows that:

* Real estate taxes can be used to fiscally stimulate energy savings. This can be achieved by incorporating the environmental (un)friendliness of the real estate (e.g. 
the degree of insulation, the source of heat, the usage of water) into the real estate tax base, i.e. the economic value of this estate.

* Parking taxes can be employed to discourage the use of particular transport and vehicles in the inner cities. In this sense these taxes also provide an option of being used as instruments for policies with regard to local air pollution and the development of a sustainable living environment in cities.

* By broadening the tax base of the water pollution charge, e.g. by including particular phosphates, specific agricultural activities that are important with regard to the environmental problem of eutrophication might also be incorporated into this charge.

* By providing particular tax exemptions or provisions, real estate taxes and water quantity assessments can also be employed for the stimulation of particular ways of cultivating land. The latter may also be important for policies towards environmental problems that arise from the cultivation of land and/or related agricultural activities. Additionally, these levies can also be employed for the development of a sustainable living environment in rural regions.

* By differentiating tax rates, user and service charges can be used as instruments for policies that are aimed at the prevention of waste and the stimulation of an optimal use of water.

* Since they are directly related to the use of soil and water, while there is no relationship between the taxes and services provided, the tax base, tax rates and the tax exemptions of the 'precario' dues can be differentiated on the basis of ecological concerns.

It follows that with regard to several environmental tasks, particular options exist for sub national governments to also or additionally use taxes and levies as instruments of environmental policy. Fields of application entail the environmental tasks that are associated with energy savings, local air pollution, eutrophication as a consequence of agricultural activities, the development of a sustainable living environment in rural and non rural regions and the prevention of waste. With regard to the problems of excessive noise and the preservation of particular landscapes, existing taxes and levies of sub national governments in the Netherlands do not provide any direct starting points.

\subsubsection{Expected effects, restrictions and required changes in law}

From the previous considerations it follows that there are different policy alternatives for sub national governments to further use existing taxes and related levies for environmental policy purposes. Whether these options are also actually feasible within 
the institutional context of the Netherlands has however not yet been discussed. In order to discuss several of the elements that are relevant for the practical feasibility of these policy alternatives, it is assumed in the following that the introduction of these options can be considered desirable from an ecological point of view. It is thus assumed that as a result of the introduction of several or all of these options, the current or future state of the environment will not deteriorate but can be maintained or possibly even be improved. To assess the viability of policy alternatives such as those indicated above, in the following first a general analysis of several expected effects, problems and restrictions is presented. The discussion is general in the sense that only the elements that are shared by all sub national governments are discussed. The adjustments in laws that are necessary to introduce these options are also discussed within such a general framework. Following this general analysis, several effects, restrictions and problems of one particular option mentioned above (i.e. the use of differentiated tax rates in relation to the disposal and/or prevention of waste) are more explicitly assessed by way of a case study.

\section{General analysis}

Within the context of the existing financial and intergovernmental relationships in the Netherlands; it has already been argued in the previous chapters of this study, that the imposition of taxes and levies by sub national governments and especially municipalities in this country is severely restricted. Sub national governments in the Netherlands, for instance, commonly levy taxes on the basis of explicitly enabling legislation. In this sense, sub national governments can not introduce new taxes nor impose taxes that are not explicitly mentioned in these acts and laws. Further restrictions for sub national governments are related to the limited authorities of these governments to set tax rates. In addition, also for the collection of taxes and related levies, municipalities in the Netherlands have to explicitly consider particular acts and laws. Further restrictions are related to the fact that the decisions to introduce, change or abolish particular municipal taxes or related levies have to be taken by the Local Council (see Duchateau and Lok, 1993, p. 200 ff.). The introduction or abolishment of municipal regulations or decrees with regard to taxes and related levies also have to be approved by the Minister of Internal Affairs, while changes in tax rates have to be approved by the Provincial Executive (i.e. "Gedeputeerde Staten"). A further restriction is provided by the fact that municipal taxes, levies or elements thereof (i.e. tax rate, tax exemptions etc.) may not be based on the principle of ability to pay. Policies with regard to the (re)distribution of income are considered to be solely a task for the central government. For provinces and water boards similar limitations hold. It follows that changes in existing taxes and related levies or the introduction of new taxes can only take place after relevant changes have been approved by different authorities and after these changes have been explicitly laid down in relevant laws and acts (e.g. the Province Act, the Municipality Act, the Water Board Act and several tax laws). Generally, the incorporation of environmental elements into existing taxes, requires 
less stringent changes in relevant laws and acts than the introduction of new ecological taxes. Within the ruling administrative framework in the Netherlands, the required changes and approvements allow only limited opportunities for a strongly decentralized environmental and taxing policy by sub national governments in the Netherlands.

Of the previously suggested options, five entail a restructuring of the existing tax base via an incorporation of environmentally relevant elements into the tax base or via an extension of this base. Examples include the incorporation of the environmentally (un)friendliness of real estate in the real estate tax base and the inclusion of phosphates in the tax base of the water pollution charge. Ceteris paribus, a broadening of the tax base, with additional taxes imposed on environmentally unfriendly substances and activities, will result in higher tax revenues. Due to unexpected tax avoiding changes in behaviour or cumulating effects of different taxes, however, increases in tax revenues can be lower than expected. This might for instance be the case if a broadening of the tax base augments the tax burden for those who are already liable for the tax in question. In this respect, for instance, if the emitters of phosphates are also liable for the emission of other polluting substances in surface waters, inclusion of phosphates into the water pollution charge base, can increase the tax burden of those who already liable for the charge. This can induce tax avoiding changes in behaviour and consequently can result in lower than expected tax revenues. Depending on the increase in the tax burden that arises as a consequence of a broadening of the tax base, the indicated changes can also be associated with particular steering or incentive effects. With regard to these effects, however, the same uncertainties arise as with regard to expected fiscal effects. In general, steering effects are strongly associated with the degree or the differentiation of tax rates.

Approximately ten of the suggested options entail an increase of existing tax rates and/or a differentiation of these rates on the basis of relevant environmental ellements. The former, for example, encompasses increases of the ground water charges and the charges for soil protection. Examples of the latter encompasses the differentiation of waste disposal taxes and sewerage charges on the basis of the environmentally (un)friendliness of particular substances, activities etc. Ceteris paribus, higher or differentiated tax rates increase the incentive effects that are associated with these charges. Depending on the strength of these steering effects, the resulting total amount of tax revenues can be higher or lower than expected. Generally, higher tax revenues will arise in case that which is taxed is relatively inelastic and associated tax avoiding changes in behaviour are relatively low. In conclusion, it can therefore be stated that although, from a theoretical point of view, the effects of higher or differentiated tax rates on total tax revenues are indeterminate, the steering effects that are associated with these changes, can be expected to be positive.

Four of the options suggested above, entail the introduction or abolishment of tax exemptions or tax provisions. The abolishment of real estate tax exemptions for the cultivation of land, in case it can reasonably be expected that this cultivation is accompanied by environmentally unfriendly agricultural activities, constitutes a clear example. Tax exemptions will ceteris paribus result in lower tax revenues due to the 
fact that particular substances, activities etc. are excluded from taxation. In this sense, the abolishment of existing tax exemptions can be expected to result in higher tax revenues. Likewise, the introduction of particular tax provisions can be expected to ceteris paribus result in lower tax revenues. Generally, the introduction of additional environmental tax exemptions and provisions can be expected to result in higher steering effects.

In conclusion, it can then be stated that the introduction of the indicated policy options for sub national governments in this country can be expected to be associated with particular steering effects, in the sense that tax avoiding changes in behaviour will arise. Although, depending on the strength of these effects, total tax revenues can be expected to change, the ultimate direction of change is indeterminate. In this sense, the viability of these options, from the point of view of fiscal and steering effects, is also indeterminate, although generally steering effects can be considered desirable from an ecological point of view. Since the fiscal and steering effects can be expected to differ for each policy alternative, the viability of these options can only be determined on the basis of a case by case approach. In following up on this approach, and in order to determine whether the expected theoretical effects are allso consistent with actual effects, in the following, one of the indicated options is further detailed and analyzed.

\section{Case study: tax rate differentiations with regard to waste substances}

The indicated option which is further detailed and analyzed below is related to the use of differentiated tax rate systems with regard to waste substances. Commonly, differentiated tax rate systems with regard to these substances are aimed at inducing relevant actors (i.e. those who produce waste: households, firms etc.) to produce less waste or to collect different types of wastes. In this sense positive steering effects are usually expected. Differentiated systems are normally considered to be especially relevant with regard to household waste. Generally, two main types of differentiated systems with regard to household waste substances can be distinghuished. They entail systems in which taxes are differentiated on the basis of the amount of waste supplied and systems in which taxes are differentiated on the basis of a particular unit of volume. In a study of different systems for the collection of household waste, two subtypes of the former and three sub types of the latter system are distinghuished. ${ }^{20}$

Of the former systems, sub types include the system in which taxes are differentiated on the basis of the amount of waste supplied per household and the system in which this differentiation takes place on the basis of the amount of waste supplied per group of households. Under the first system, the waste collection service taxes households on the basis of the weight of the waste supplied, which is weighed electroni-

20 VROM (1993), Ministerie van Volkshuisvesting, Ruimtelijke Ordening en Milieubeheer, Directoraat-Generaal Milieubeheer (1993/9) 
cally. The amount to be paid is usually determined by a multiplication of the cumulated amount of waste with a particular tax rate. In the second system, the only difference consists of the fact that taxes are based on the amount of waste supplied by a group of people, e.g. those within a specific area, a group of buildings or a block of flats.

Of the latter systems, sub types include the systems in which taxes are differentiated on the basis of garbage bags, the frequency of supply or the number or size of garbage cans. With an expensive bag system, the costs of the collectment and treatment of waste is divided among the suppliers of waste via additional charges on the price of garbage bags. Those who supply waste are usually obliged to use these specific bags. Under a system in which taxes are related to the number of pick ups, tax rates can be based on e.g. the number of cans offered during a particular period of time. Those who supply waste pay a fixed amount per can collected. Under the system of tax differentiation per unit of volume on the basis of the number or size of cans, taxes can be differentiated according to the number or size of available cans.

In an analysis of the systems of tax differentiation that were actually used in practice at the beginning of 1993 , in the same study the effectiveness of these systems in terms of steering effects, the effects on the distribution of income, the costs that are associated with the execution of such systems for household waste and the illegal dumping of waste were also examined. The tax systems that were taken into consideration in the survey included the systems used in 14 municipalities in the Netherlands and different systems used by different levels of government in Germany, the USA, Liechtenstein and Australia. The main features of the tax differentiation systems with regard to household waste in the Netherlands are summarized in Table 9.5. From the analysis it can be concluded that, in comparison to a situation in which there are no differentiated tax systems, the introduction of an expensive bag system by municipalities results in a lower amount of waste produced. A comparison of different tax differentiation systems shows that the reduction in the amount of waste produced is highest under an expensive bag system. As regards the purposes pursued with the different tax systems, the analysis shows that the effectiveness and steering effects of most systems are high and do not diverge from expected effects. As regards the distribution of the burden of the tax, which indicates the distribution of the relationship between the amount of waste supplied and the amount of taxes paid, the survey shows that actual effects in this respect do not diverge from their expected effects.

Generally, systems in which taxes are differentiated on the basis of the amount of waste supplied per household or on the basis of expensive bags, show the strongest relationship between the individual tax burden and the amount of waste supplied. 


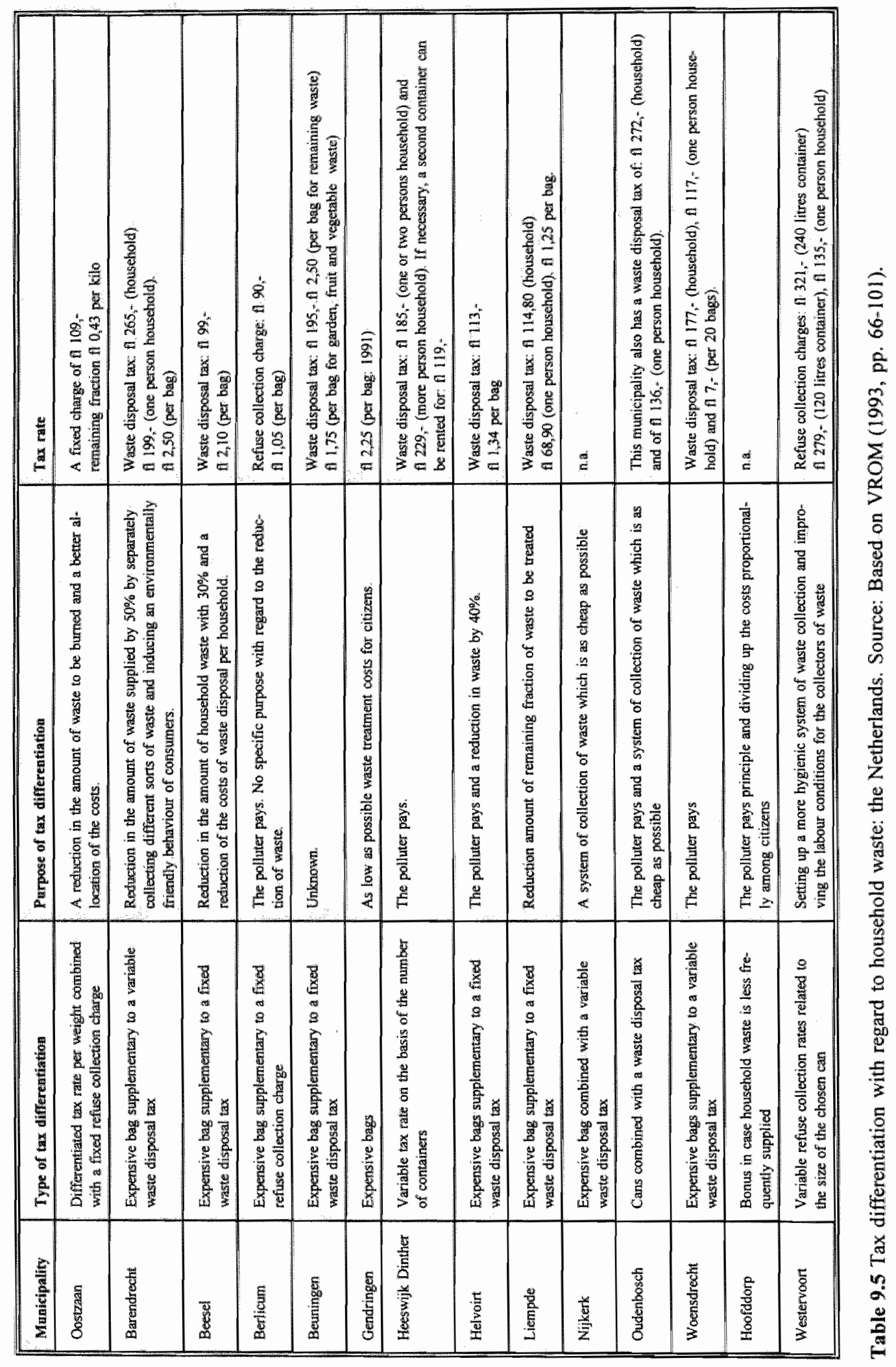




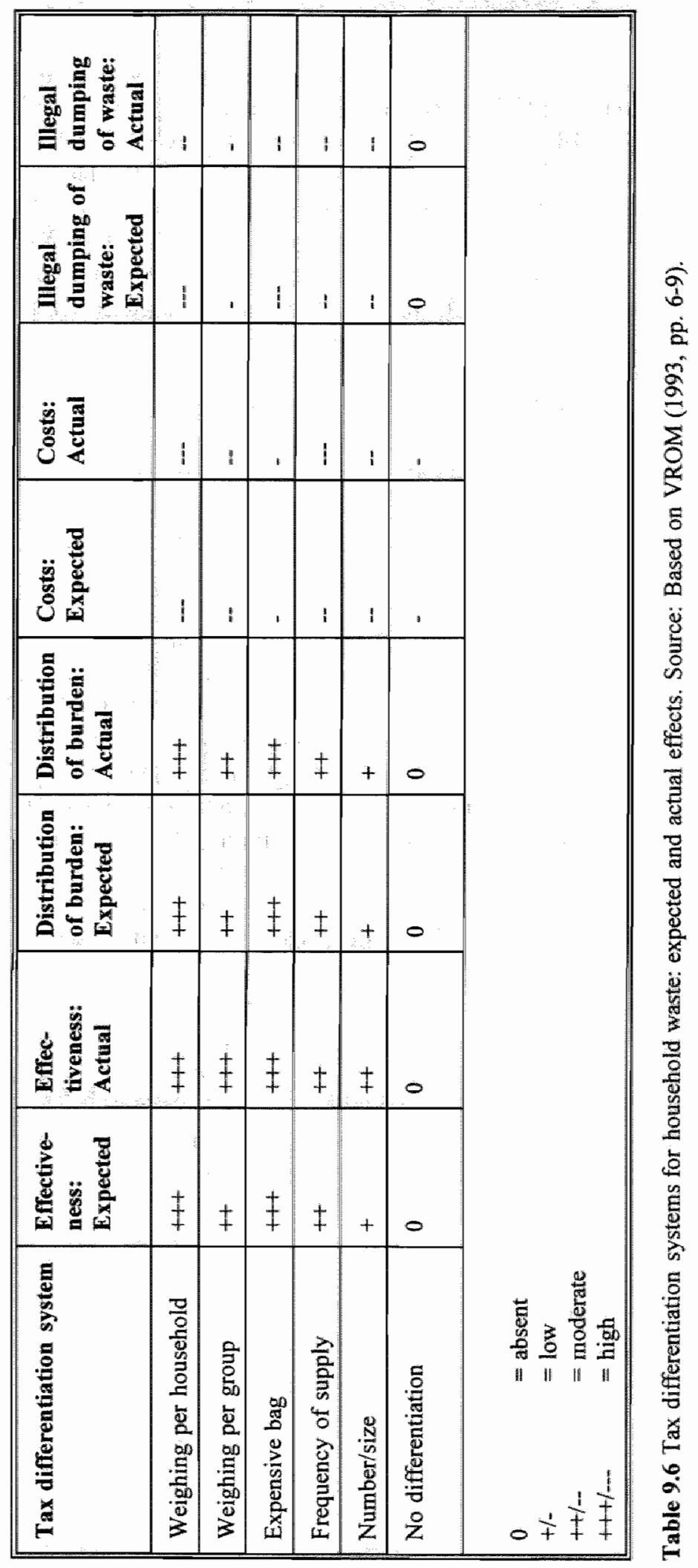


This relationship is relatively weak for systems that are based on the number or size of cans and relatively modest for other differentiated tax systems. The costs that are associated with the collection of waste are relatively high for systems in which the amount of waste supplied is weighed per househould or on the basis of the frequency of supply. The incentive to illegally dump waste is moderate for all systems, except for those that are based on the amount of waste supplied per group of households. The most important differences between the expected and actual effects of the differentiated tax systems with regard to household waste are summarized in Table 9.6.

The experiences with and possibilities of different financial instruments with regard to waste substances in Europe and the USA are also discussed in another survey that was conducted by the Ministry of Housing, Physical Planning and Environment in the Netherlands. ${ }^{21}$ In this survey, which was published in 1992, the effects of different charges on waste are discussed. For different countries and states in Europe and the USA, the survey indicates that, in practice, charges are mainly imposed on waste substances via taxes on the production, import, dumping or burning of household or industrial waste or on products via taxes on basic products and end products. ${ }^{22}$

Representing the state of the art up to July 1990, Table 9.7 shows the main features of charges on different waste substances, as they have been identified in the survey in terms of the environmental effectiveness, unintended side effects, legal and administrative feasibility and the political acceptability of these charges. It can be noted from this table that the acceptability of these charges to those who introduce and pay these charges strongly depends on the destination of associated tax revenues. In comparison to other charges, charges that are imposed on household waste, impose relatively few intricacies. Based on the features mentioned in this table, in the survey also several implications for the use of charges with regard to waste (substances) in the Netherlands are discussed. ${ }^{23}$ More specifically it is argued, with regard to industrial waste charges, that in order to prevent the exportation of waste to other regions or countries, the Netherlands should only consider a unilateral introduction of these charges in those cases in which the costs of the collection and treatment of waste and related charge rates are substantially lower than elsewhere. In all other cases, charges on industrial waste could best be embedded into co-ordinated EU policies. In the survey it is also stated that industrial waste charges should only be implemented in those cases in which they can be easily controlled and enforced.

21. VROM (1992), Ministerie van Volkshuisvesting, Ruimtelijke Ordening en Milieubeheer。 Directoraat-Generaal Milieubeheer (1992/6).

${ }^{22}$ Ibid., p. 8.

${ }^{23}$ Ibid., pp. 39-44. 


\begin{tabular}{|c|c|c|c|}
\hline 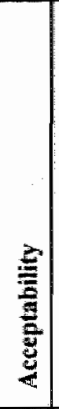 & 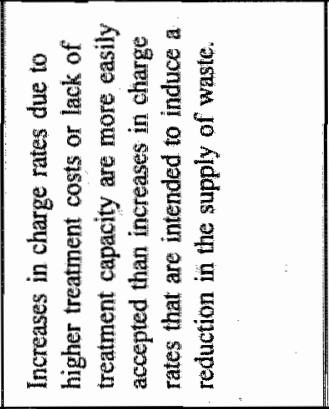 & 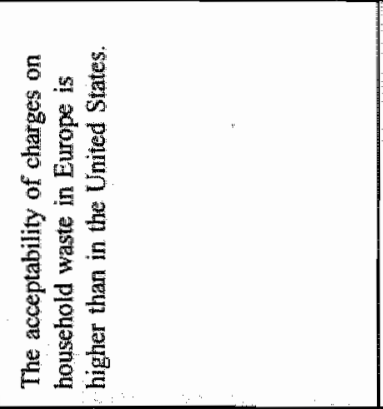 & 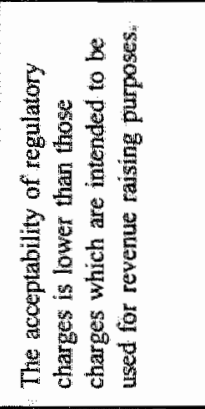 \\
\hline 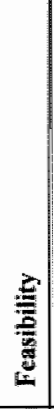 & 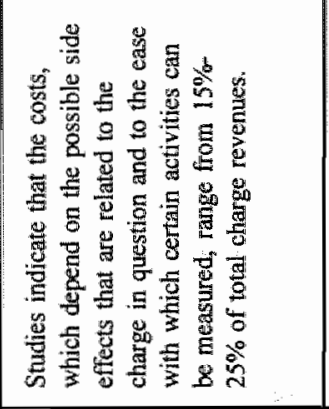 & 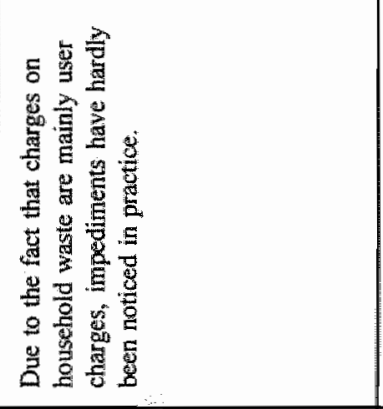 & 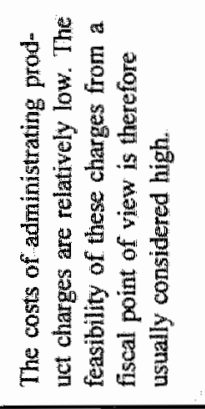 \\
\hline 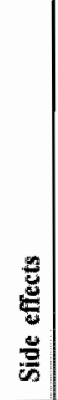 & 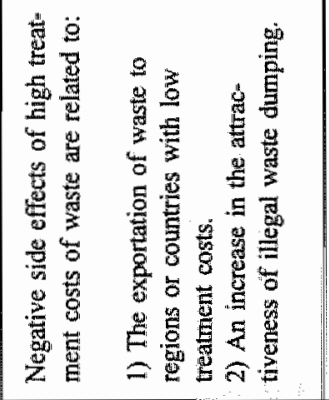 & 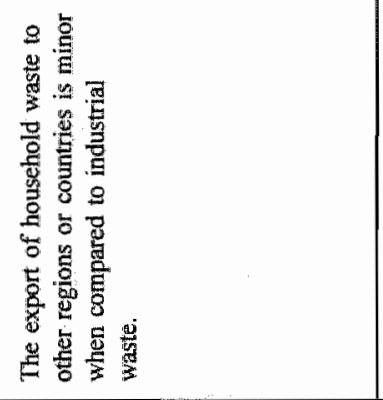 & 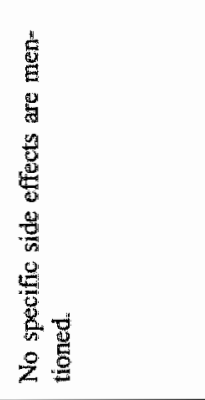 \\
\hline 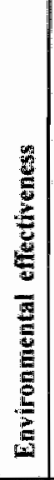 & 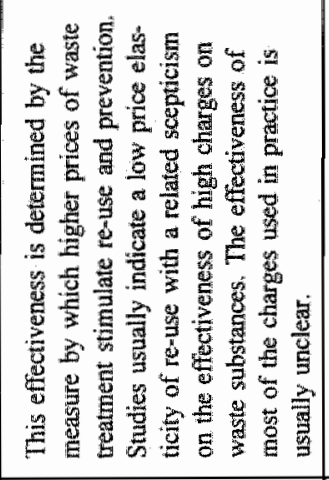 & 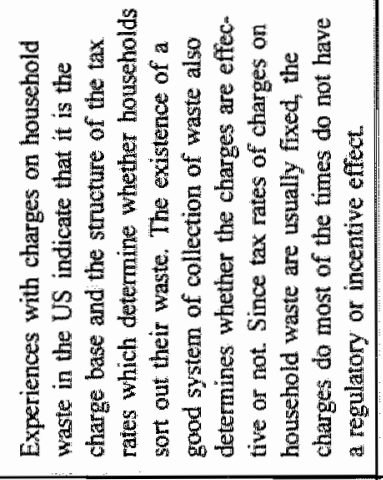 & 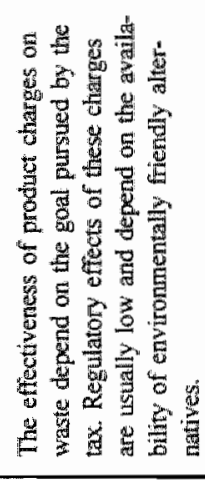 \\
\hline & 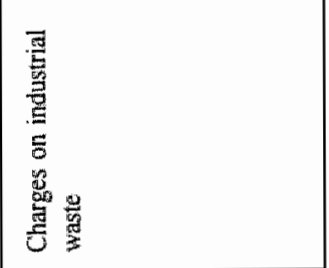 & 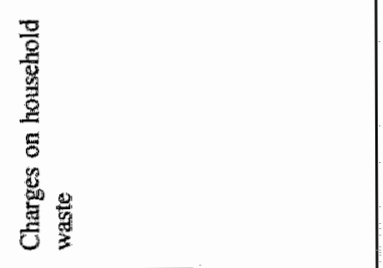 & 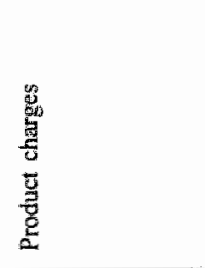 \\
\hline
\end{tabular}


Additionally, if charges on household waste confront municipalities with higher treatment rates and costs, differentiation of tax rates on the basis of the type of waste supplied is considered a feasible alternative. With regard to the use of regulatory product charges, it is indicated that these charges are preferably imposed in relation to products for which there is a clear environmentally friendly alternative. According to the survey, the use of regulatory product charges should however always be weighed against the use of a deposit refund system for waste substances.

On the basis of the results of the afore mentioned studies, it can be concluded that, for municipalities in the Netherlands, differentiated tax systems with regard to waste substances present an interesting option to further use current waste disposal taxes and refuse collection charges for ecological purposes. These systems are interesting especially because they present viable policy options for these governments, in the sense that they usually comply with the polluter pays principle, induce economic actors to less polluting behaviour and, in addition, have already actually been introduced by several municipalities in this country. The latter experiences with differentiatied tax systems show that, within the context of the ruling administrative framework, an expensive bag system presents one of the most viable options for municipalities in this country. The same framework however also allows the introduction of systems that differentiate taxes on the basis of the frequency of waste collection and the number of persons per household and, although in a more restrictive sense, systems that differentiate taxes on the basis of the amount of waste supplied or collected.

\subsection{The national government and the development of ecological taxation via the incorporation of environmentally relevant elements in existing taxes}

In the previous section, several possibilities for sub national governments to further relate currently imposed local and regional levies to relevant ecological elements, were indicated. In short, these possibilities entail a broadening of the tax base, the abolishment of tax elements that are undesirable from an ecological point of view, the ecological differentiation of tax rates and the introduction of relevant tax deductions and tax credits. To show that the same possibilities are also relevant for the national government, in this section several policy alternatives are also discussed for this level of government. Since sub national governments are the main focus of this chapter, the indication of these policy alternatives for the national government is brief and general. In the Netherlands, the national level of government mainly imposes taxes on income, profits and net wealth and taxes which increase prices. Taxes on income, profits and net wealth mainly consist of taxes on income, wages, dividends, business income, net wealth, inheritances and games of chances. Taxes which increase prices include import duties, value added taxes, excise duties, taxes on legal transactions, transfer and insurance taxes, capital duties, the motor vehicles tax and taxes on private cars and motorcycles. 


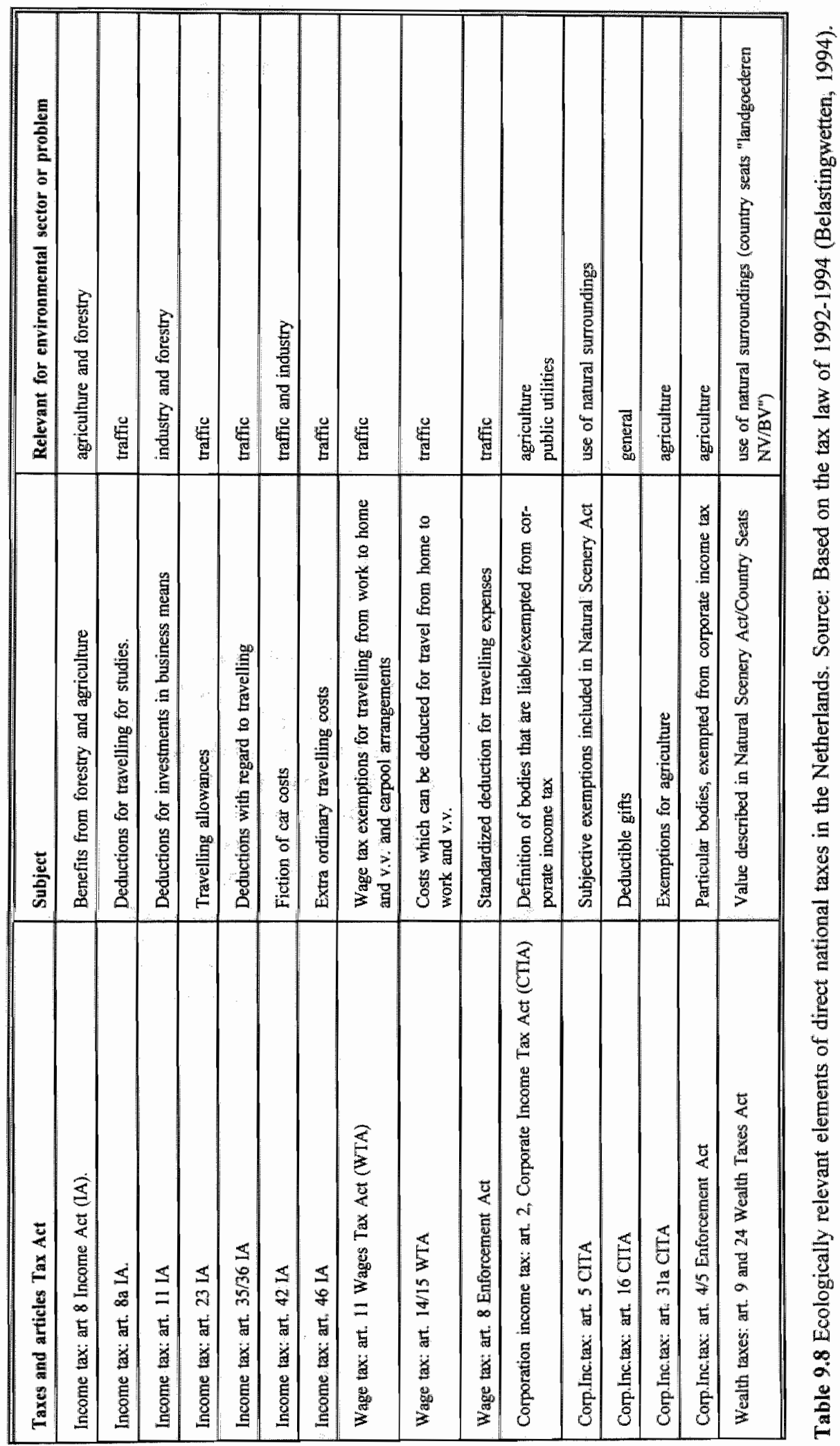




\begin{tabular}{|c|c|c|}
\hline Trues and articles Tax Act & Sulbjext & $\begin{array}{l}\text { Relevant for enwrommental sec- } \\
\text { tor or problem }\end{array}$ \\
\hline $\begin{array}{l}\text { Value tadded thxes art } 27,29 \text { Vallue fuded } \\
\text { Trixes Ad (VATA) }\end{array}$ & $\begin{array}{l}\text { Regulations with neggard to agricil- } \\
\text { ture }\end{array}$ & forestry and agriculture \\
\hline Vat art S0 WATA & User tax on cars & traffic and use of fuel \\
\hline Vat: arti. 9 VATA & $\begin{array}{l}\text { Division of vallue added tax rates } \\
\text { for speciffe goods and services }\end{array}$ & e.g. agriculture \\
\hline Excise taxes: Diverse Acts & Exctse tax on mineral oils & traffic and the use of fivel \\
\hline Molor vehicles tax: Diverse Acts & $\begin{array}{l}\text { Regulations with regard to (speci- } \\
\text { fic) motorvehicles }\end{array}$ & traffic \\
\hline
\end{tabular}

Table 9.9

Ecologicalty relevant elements of indirect national levies in the Netherlands. Based on the tax law of 1992-1994 (Belastingwetten, 1994).

Although they are primarily intended for other than environmental purposes, several of these taxes also contain elements that are important from an environmental point of view, e.g. because they can have a desirable or non desirable impact on the environment. Based on the tax law for 1992-1994 (Belastingwetten, 1994), Tables 9.8 and 9.9 illustrate several of such elements for direct and indirect taxes, respectively.

Table 9.8 shows that the income tax, for instance, allows certain tax exemptions for profits from forestry and agriculture. Within the same tax, limited tax deductions are included for travelling between home and work, for the use of company cars, for transport by car (other than by taxi) and for the accommodation of individuals outside their dwelling place. Travelling allowances for courses, congresses etc. are also incorporated in the income tax. Within the same tax, accelerated depreciations for environmentally friendly investments are also included. In the wage tax, a special tax treatment for the international transport of employees is allowed for, while, not unlike the income tax, tax allowances are also available for travelling expenses. Car pool arrangements are also an important element of wage taxes in this country.

The corporate income tax also contains several elements that can have a desirable or undesirable impact on the environment. Among others, there are tax exemptions for corporations mentioned in the Act on Natural Scenery. Other exemptions include those for international transport, for profits that arise out of agriculture and for institutions active in the field of agriculture. Deductions for specific investments are also allowed for in the corporate income tax. Wealth taxes incorporate certain tax exemptions that are based on the Act on Natural Scenery and special arrangements for country seats ("Landgoederen $\mathrm{NV} / \mathrm{BV}^{\mathrm{m}}$ ). Table 9.9 shows that also indirect taxes contain different elements that are relevant from an ecological point of view. Value added taxes, for example, contain specific tax arrangements for the use of certain materials and for public transport and cabs. Special user charges are imposed on cars and motor vehicles, while taxing arrangements are available for farmers and tobacco 
manufacturers. Although there is a general VAT rate of $17,5 \%$, a reduced rate of $6 \%$ is used for particular products and activities such as articles of food, grain and pulse(s), seeds, cattle, sheep, goats and pigs, pharmaceutical specialties, water, books, magazines, gas and mineral oil used for the heating and stimulation of products from horticulture; seeds for agriculture and horticulture; fertilizer and pesticides for use in agriculture; certain types of wood; cattle-fodder; specific tools used in agriculture, horticulture, forestry and cattle-breeding; advertising; transport of persons per ship or air craft within the Netherlands; camping; and services provided to $e . g$. farmers and cattle-breeders. It follows that several direct and indirect taxes, although they are primarily intended for other than ecological purposes, contain elements by which they can also positively or negatively affect the environment. In the previous section it was shown that also particular taxes and charges that are imposed by sub national governments in the Netherlands contain such elements. For elements in several local, regional and national taxes and charges, Oosterhuis and De Savornin Lohman (1994) indicate the direction of the expected impact on the environment (see Table 9.10).

Table 9.10 shows the situation for 1991. The table shows that although for several elements, the impact on the environment is uncertain, both positive and negative environmental effects can be expected from the greater part of these elements. As can be noted from the table, these effects mainly arise from travelling costs arrangements, arrangements with regard to the use of cars for private and business purposes and from the presence of specific tax deductions and special tax rates and arrangements for forestry, horticulture, agriculture, cattle-breeding and natural scenery. From the point of view of further developing ecological taxation in the Netherlands alongside the vertical dimension, the cleaning of environmentally unfriendly elements from existing tax measures (such as those mentioned in Tables 9.8, 9.9 and 9.10) can be considered a first step. According to Wasch (1990), the cleaning of such elements from existing tax measures can be considered an initial stage in the process of introducing ecological tax reform. Consecutive stages in this process consist of introducing and further enhancing environmentally friendly tax measures and of readjusting existing tax rates on the basis of ecological considerations. ${ }^{24}$ As examples of such measures, Wasch $(1990$, p. 31) mentions among others abolishing the standardized deduction ('forfait') for travelling expenses, abolishing the existing threshold for gifts to environmental institutions and organizations and abolishing the existing deduction for car costs.

24 For further elaborations of the possibilities and problems of introducing ecologically differentiated VAT systems, see Groen Links (1992) and LMO (1988). 


\section{Chanter 9}

\begin{tabular}{|c|c|c|}
\hline $\begin{array}{l}\text { Produlut } \\
\text { Acitivity }\end{array}$ & Trax medsures & $\begin{array}{l}\text { Potential effects or } \\
\text { performance: positi- } \\
\text { ve, negative or un- } \\
\text { certain effect on the } \\
\text { environment }\end{array}$ \\
\hline rutells & Excinse & +10 \\
\hline \multirow[t]{11}{*}{ Transpourt } & Fitcal facilities for commuting costs & - \\
\hline & Fiscal facilities: preferential treatment for public transport and carpooling & + \\
\hline & Transfer tax & 0 \\
\hline & Deductibility of moving casts & 0 \\
\hline & Municipal commuters tax & 0 \\
\hline & Tax on private use of business car & 0 \\
\hline & Limit to deductibility of business trip costs & + \\
\hline & Motor vehicle tax & + \\
\hline & Special tax on passenger cars and notorcycles: & + \\
\hline & VAT: differentiation between private and public transport & + \\
\hline & Parking tax & * \\
\hline \multirow[t]{3}{*}{ Agriculture } & Exemption from corporate taxation for small farms & 0 \\
\hline & Exemption from transfer tax in case of land consolidation & - \\
\hline & Low VAT rate for pesticides and fertilizers & . \\
\hline \multirow[t]{2}{*}{ Forestry } & Exemption from income and corporate tax & 0 \\
\hline & Exemption from municipal immowable property tax & 0 \\
\hline $\begin{array}{l}\text { Hunting and } \\
\text { fishing }\end{array}$ & Hunting and fishing licence fees & 0 \\
\hline $\begin{array}{l}\text { Nature con } \\
\text { siensution }\end{array}$ & $\begin{array}{l}\text { Deductibility and tax reduction of gifts and legacies to environmental and } \\
\text { nature protection orgtanizations }\end{array}$ & 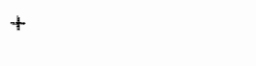 \\
\hline \multirow[t]{5}{*}{ Other } & Dog tax & + \\
\hline & Advertising tax & + \\
\hline & $\begin{array}{l}\text { Allowance of reservations and liability entries for envirommental expen- } \\
\text { ditures }\end{array}$ & + \\
\hline & Deductibility of environmental fines & - \\
\hline & Import duties & 0 \\
\hline
\end{tabular}

Table 9.10 Environmentally relevant taxes and tax provisions in the Netherlands. Source: Oosterhuis and De Savornin Lohman (1994, p. 29). 
Other options include disallowing the deduction of travelling expenses for the purpose of study and taxing environmentally unfriendly products. ${ }^{25}$. In Nentjes \& de Vries (1990, pp. 66-67), the potential impact of the reduction and abolishment of standardized deductions for travelling expenses is further analyzed. The study shows that, as a result of these policies, car mobility can be expected to decrease. More specifically, it is shown that if all standardized deductions and fiscal regulations for travelling between home and work would be abolished and if the compensations for travelling costs would be taxed, car mobility would decrease by 5,6 billion kilometres. As a result, 650 million guilders of the tax revenues that are now spent on travelling expenses can be saved. These savings can be used, for instance, for the improvement of public transport and the stimulation of car pool arrangements. If it is assumed that the abolishment of the threshold for gifts to environmental institutions, induces more gifts, which are then used for the protection or improvement of the environment, the abolishment of this threshold can be expected to have a positive impact on the environment (see Table 9.10).

Several of the options mentioned by Wasch (1990) are also suggested in the second NEPP and in the review which evolved from action point A 106 of the first NEPP ${ }^{26}$ In both publications, it is emphasized that ecological taxation can be further developed especially within the area of traffic and transport. Possibilities entail i.a. increases in the excise taxes for traffic, the introduction of tax rate differentiations (e.g. in the motor vehicles tax and the user taxes on cars); changes in the tax measures with regard to travelling expenses; a reduction in the taxes that are imposed on environmentally sound uses of transport and the introduction of tax exemptions for the surcharge on fuel in the motor vehicles tax for buses that drive on natural gas.

For all of the fiscal measures suggested with regard to traffic and transport, it is important to clearly distinguish between those that aim at raising a particular amount of revenues and those that make sense from an ecological point of view. Although traffic and transport as such are vital for a modern economy and should therefore be stimulated, it is important to distinguish between sound and unsound uses of forms of transportation. Certain forms of transportation pose more of a burden on the environment than others. From an ecological point of view, the use of the former types of transport should be discouraged, while the use of the latter should be induced. Within this context, the introduction of tax provisions in the motor vehicles tax for environmentally sound forms of transport makes sense from an ecological point of view. Increases in the excise taxes for traffic, on the other hand, are generally more attractive from a fiscal than from an ecological point of view. Since these

${ }^{25}$ In Wasch $(1979,1983)$, also several options to use the tax system for ecological purposes are described. Among others, they include the introduction of a general energy tax to be imposed on those products and production processes that proportionally consume a lot of energy.

${ }^{26}$ Tweede Kamer der Staten-Generaal (1992), Financiële instrumenten in het milieubeleid, 22779, nrs. 1 en 2. 
taxes are usually not differentiated on the basis of the environmental soundness of the form of transport, they are usually intended to serve only a fiscal purpose. The use of particular tax provisions such as tax credits and special tax deductions can generally be considered to be attractive not only from an ecological point of view, but also from the point of view of the European harmonization process. ${ }^{27}$ Generally, this process does not affect the use of such tax provisions. Within the context of this process, the use of user taxes and charges seems more complicated, since they are either infeasible from a practical point of view or impossible within the European Union.

From the brief considerations of the possibilities for the national government to further develop ecological taxation, it can be concluded that this level of government has several options to relate environmentally relevant elements to existing taxes. Generally, these options belong to either one of following categories: 1) abolishment of environmentally unfriendly elements from current taxes; 2) introduction of environmentally friendly elements into current taxes; 3) the introduction of tax rate differentiation and 4) the introduction of tax provision such as tax credits and special deductions. It follows that possibilities to further relate direct taxes to relevant environmental elements mainly include the use of options that belong to the former two categories. For indirect taxes, these possibilities mainly include the use of the third option. Possibilities that belong to the last category, i.e. the options that make use of certain tax provisions within particular direct or indirect taxes, however, can generally be regarded as the most desirable options from an ecological point of view.

\subsection{Ecological tax reform and the roles that can be played by different levels of government}

The possibilities to further develop ecological taxation, such as those presented in the previous section, are generally considered a first step in the chain of steps necessary to introduce the idea of ecological tax reform. In most studies on the subject, consecutive steps include the introduction of new ecological taxes and a shift of the burden of taxation from labour towards pollution and the use of natural resources. Also in the Netherlands, several suggestions have been made in this respect. Generally, however, these suggestions represent the main ideas of the double dividend approaches of ecological taxation, emphasizing the introduction of additional environmental taxes by the national government, to be accompanied by a reduction in taxes on labour. The role that can be played by sub national governments in the process of introducing ecological tax reform however is generally overlooked. Likewise, the consequences of such reforms for the financial and intergovernmental relationships are generally overlooked.

27 For a more elaborate description of the possibilities and problems that are related to the use of ecologically relevant taxes and tax elements within the framework of the European Union, see e.g. de Wit (1992, 1994). 
Within this context, in the following, several possibilities for different levels of government to further develop ecological taxation in the direction of ecological tax reform are further described. For all levels of government, it is assumed initially that viable options are represented by those that can be introduced in a revenue neutral manner.

\section{National government}

In the summer of 1989 , the political party "Groen Links", a green left party in the Netherlands, introduced what they described as a new instrument of environmental policy, i.e. the green tax (see e.g. Groen Links, 1990). In a report which was published in October 1991, this political party presented a proposal for the introduction of ecological tax reform in the Netherlands. ${ }^{28}$ The aim of the report was to stimulate discussions on ecological taxation and ecological tax reform in this country. To introduce such a reform, the party suggested a periodic increase in the prices of natural gas and electricity. The taxes and the expected prices are mentioned in Table 9.11.

\begin{tabular}{|l|l|l|l|l||}
\hline & 1992 & 1993 & 1994 & Prices \\
\hline $\begin{array}{l}\text { Natural gas per } \\
\mathbf{m}^{3} \text { for uses > } \\
\mathbf{8 0 0 m}^{\mathbf{3}^{*}}\end{array}$ & 0,125 & 0,25 & 0,50 & 0,54 \\
\hline $\begin{array}{l}\text { Electricity per } \\
\text { kilowatt-hour }\end{array}$ & 0,037 & 0,075 & 0,15 & 0,18 \\
\hline $\begin{array}{l}\text { * For those unable to work and for households of persons older than } 65, \text { a quotum of } 400 \mathrm{~m}^{3} \\
\text { is granted in addition to the quotum of } 800 \mathrm{~m}^{3} .\end{array}$ & \\
\hline
\end{tabular}

Table 9.11 Ecological tax reform: a first step. Source: Groen Links (1991).

Expecting the incentive effect of the periodical increases in prices to be such that $35 \%$ of energy can be saved, the structural revenues are estimated to be more than 17 billion guilders. According to the party, 15 billion guilders of these revenues can be used to decrease the financial burden for citizens, e.g. via reductions in other taxes. The remaining part of the revenues can be used to compensate the government for a resulting reduction in natural gas revenues. More specific details of the shift of the burden of taxation on labour towards the use of the environment are represented

${ }^{28}$ Groen Links (1991), "Op weg naar een groene belastingheffing. Een voorstel om een begin te maken met ecologische belastingheffing ten gunste van milieu en werkgelegenheid". 
in Table 9.12. It is suggested that a shift of the tax burden from labour to the environment, in this particular case, can be accompanied by a change in the determination of rents for houses. In this sense, for instance, a differentiation of rents on the basis of the degree of insulation of these houses is suggested. For houses that are badly insulated and thus induce a higher use of natural gas, rents should be decreased, in order to induce those who let out houses to take energy saving measures. Although the proposal by the green left political party in the Netherlands is one of the first proposals for ecological tax reform in this country, the attractiveness of the taxation of gas use, from an ecological point of view, can be questioned. Generally, in order to induce structural changes in behaviour, not the use of gas has to be discouraged, but the use of environmentally friendly production processes (e.g. heating apparatus) has to be stimulated. As previously argued in chapters 2 and 5 of this study, tax credits and tax deductions for the use of environmentally friendly production apparatus incorporated in e.g. the income tax, can be used for this purpose.

\begin{tabular}{|c|c|c|}
\hline Specific detaills & Decrease finaneiall burden & Increase financiall burden \\
\hline $\begin{array}{l}\text { Increase in prices of natural gas and } \\
\text { electricity for households }\end{array}$ & & 3,5 \\
\hline $\begin{array}{l}\text { Increase in bassic tax deduction with } \\
\text { ff } 1500 \text {, - }\end{array}$ & $4 ; 15$ & \\
\hline $\begin{array}{l}\text { Increase in prices of natural gas and } \\
\text { electricity for industries }\end{array}$ & & 11,7 \\
\hline $\begin{array}{l}\text { Decrease in particular social security } \\
\text { premiums and decrease in the tax } \\
\text { rate for the first income bracket }\end{array}$ & 7,8 & \\
\hline $\begin{array}{l}\text { Accelerated depreciations for envi- } \\
\text { ronmental inwestments and subsidies } \\
\text { for entergy savings and durable } \\
\text { energy }\end{array}$ & 3,5 & \\
\hline Total & 15,45 & 15,5 \\
\hline
\end{tabular}

Table 9.12 The destination of possible revenues (in billion of guilders). Source: Groen Links (1991).

In 1990 , prior to the publication of the ecological tax reform proposal by Green Left, in Nentjes \& De Vries (red., 1990), a large scale application of financial environmental policy instruments was suggested. Proposals were formulated in reaction to the then recently published NEPP-plus, in which only restricted opportunities for the introduction of such instruments were offered. 


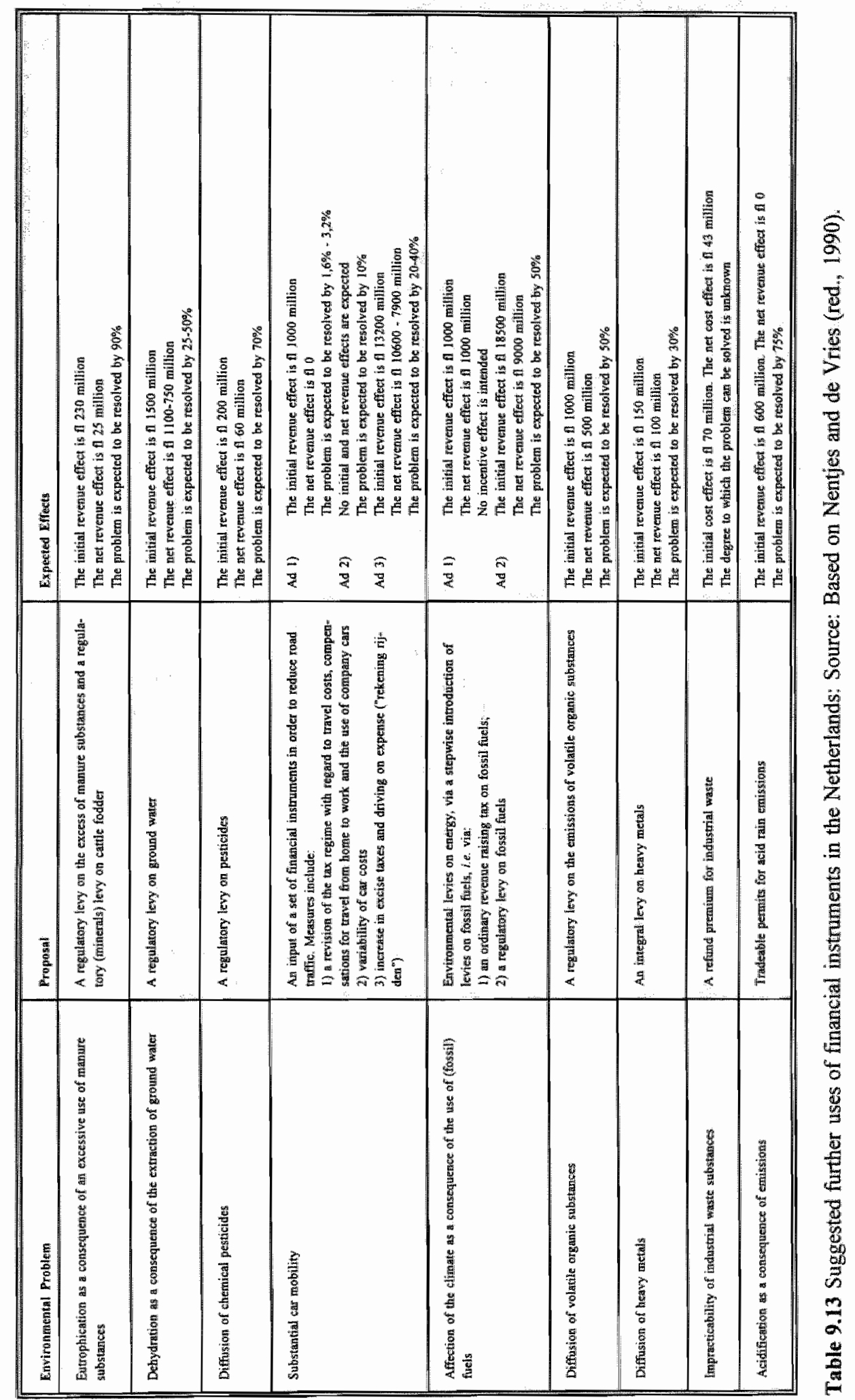


Opportunities that were provided, included regulatory charges on particular products such as certain packages, light bulbs and turpentine based paint. ${ }^{29}$ In reaction, in Nentjes \& De Vries (red., 1990), several proposals for the introduction of financial environmental policy instruments in the Netherlands were formulated. The proposals were formulated in relation to nine environmental problems. Regulatory charges on emissions and products comprise the greater part of these suggestions. The main elements of the proposals and their expected effects are summarized in Table 9.13. Table 9.13 shows that regulatory charges on emissions and products can have considerable fiscal and steering effects, that are also partly interrelated. Initially, when liable actors have not yet been able to adjust completely to the charges, relatively high tax revenues can be expected. In later stages, when the initial adjustment time has passed, it can be expected that, in order to avoid paying part of the charges, liable actors change (part of) their behaviour. Consequently, it can be expected that the significance of steering effects will increase over time, with associated decreases in tax revenues. So far, not one of the proposals summarized in Table 9.13 has already actually been introduced in this country, although regulatory levies on manure substances and energy and the use of financial instruments for the problem of car mobility have been widely discussed. Regulatory levies on energy can be expected to be introduced in the Netherlands at the beginning of 1996.

Besides the proposals formulated by Green Left and Nentjes \& De Vries (red., 1990 ), since the late 1980 's, a numerous amount of publications has emerged on the subject of ecological taxation in the Netherlands. They include writings by Schuurman (1988, 1990), Wiersma (1989), Vollebergh (1990, 1992a, 1992b), Vollebergh \& De Vries (1990, 1994), Cnossen \& Vollebergh (1991), Bakker \& Bleijenberg (1991), Bovenberg \& De Mooij (1993), Smith \& Vollebergh (1993), Van Ierland (1993) and De Savornin Lohman (1994). It can be noted from most of these writings on ecological taxation that generally the idea of introducing ecological tax reform in the Netherlands has gained more popularity in recent years. Due to the double dividend features that are expected to be associated with ecological tax reforms, the introduction of such reforms by the national government in the near future in the Netherlands is commonly held viable, under the condition that these reforms do not induce significant changes in the existing distribution of income in this country.

\section{Sub national governments}

In section 9.2, it was shown that several local and regional taxes, that are currently imposed by sub national governments in the Netherlands, can be related to relevant environmental elements. The possibilities and problems for sub national governments to introduce additional environmental levies and the possible role of these governments within the process of developing the idea of ecological tax reform, however,

${ }^{29}$ Vollebergh \& De Vries (1990). 
have not yet been explicitly discussed. Since it can generally be expected that the introduction of new ecological taxes by sub national governments in the Netherlands is accompanied by an increase in the amount of tax revenues raised by these governments, changes in the current financial and intergovernmental relationships in this country can also be expected to arise. Only in the specific case that sub national governments can introduce additional environmental levies without raising their total amount of tax revenues, minor changes in the existing financial and administrative relationships between different levels of government can be expected to arise. Since such cases can generally be considered the exception and not the rule, the introduction of additional environmental levies by sub national governments can be expected to be accompanied by changes in the relationships between different levels of government. In this sense, it is possible that an increase in the tax revenues raised by sub national governments is accompanied by a simultaneous reduction in other national or sub national government taxes, in order to introduce these changes in a revenue neutral manner. It is also possible that an increase in these revenues is accompanied by corresponding reductions in the block grants and/or specific grants received by sub national governments in the Netherlands. Due to the possibility that central government grants are reduced, once new (environmental) taxes are introduced, sub national governments in this country can be discouraged to introduce such taxes. In this sense, in comparison to the national governments, sub national governments can face additional disincentives for the introduction of new environmental taxes.

The introduction of the idea of ecological tax reform via revenue neutral shifts in the taxes imposed and/or the benefits granted or received by different governments is not a new concept in this country. The quid pro quo reductions ("profijtkortingen") in the block grants for municipalities in the eighties can, for instance, be considered clear representatives of this idea. In this specific case, reductions in block grants were brought on by the national government in order to re-enforce the application of the quid pro quo principle by sub national governments. By re-enforcing the use of this principle, sub national governments could compensate for the reductions in block grants received. Sewerage and the disposal and treatment of waste were considered the areas most suitable for such enhanced applications of the quid pro quo principle by sub national governments in the Netherlands. ${ }^{30}$

Given the possibility that changes in the existing financial and intergovernmental relationships in the Netherlands are likely to arise when sub national governments introduce additional environmental levies and given the restriction that ecological taxation and ecological tax reform seem viable in the Netherlands when introduced in a revenue neutral manner, in the following several possibilities, problems and the role of sub national governments in the process of further developing the idea of ecological tax reform are described. The subsequent analysis starts with an indication of the possibilities for sub national governments to introduce additional regulatory

${ }^{30}$ Koopmans et al. (1991, p. 232). 
environmental levies. Regulatory levies present an interesting benchmark as they are not aimed at raising additional tax revenues. Ideally, these levies raise no additional tax revenues, representing the ideal case (i.e. from the point of view of revenue neutrality) in which sub national governments introduce additional environmental levies but raise no additional tax revenues. After an analysis of the possibilities, problems and effects of these levies, the analysis proceeds with an examination of the same aspects for revenue raising environmental levies.

During recent decades, several proposals for the introduction of additional ecological taxes and related levies have been made. As previously indicated in this chapter, in Nentjes \& De Vries (red., 1990), regulatory environmental charges are suggested in relation to such problems as eutrophication, dehydration and the diffusion of chemical pesticides and heavy metals. By introducing regulatory levies on manure substances, cattle fodder, ground water, pesticides and heavy metals, the study shows that an additional amount of tax revenues of approximately 935 to 1285 million guilders could be raised. By introducing these regulatory levies, the problems of eutrophication, dehydration and the diffusion of chemical pesticides and heavy metals could be reduced by $90 \%, 25 \%-50 \%, 70 \%$ and $30 \%$, respectively. Although several of these proposals seem interesting for sub national governments, in Nentjes \& De Vries (red., 1990), the level of government by which these levies should be introduced, is not explicitly taken into account. For sub national governments, interesting options especially include those for which these governments already impose a comparable levy (e.g. on the same substance, activity etc.) or for which these governments already have an environmental policy responsibility. Other interesting options include those that are related to local and regional environmental problems and those for which the imposition of regulatory environmental levies does not result in strong differences (e.g. in taxing capacities) between different sub national governments in this country. Of the proposals suggested, regulatory charges on ground water and those on the diffusion of heavy metals and pesticides within regional ground and surface waters seem the most interesting options for sub national governments. Provinces already impose earmarked charges on ground water, while the diffusion of heavy metals and pesticides is generally considered a regional environmental problem. ${ }^{31}$ Regulatory levies on manure substances and cattle fodder, on the other hand, present less obvious options in this case, merely because comparable levies are already currently imposed by the national government. The consistence with the principle of fiscal equivalence (see chapter 6 of this study), the associated administrative costs, and the costs in terms of changing intergovernmental relationships mainly determine whether these regulatory levies can also actually be introduced by sub national governments in the Netherlands. Although no explicit recognition is made of the government level by which these levies are imposed, it follows from the study by Nentjes \& de Vries (red., 1990), that considerable fiscal effects can be expected from the intro-

${ }^{31}$ See also Paulus (1994f, 1994g). 
duction of regulatory levies on ground water, pesticides and heavy metals. More specifically, the analysis shows that the introduction of regulatory levies on these substances can be expected to be associated with additional tax revenues of 1225 to 910 million guilders. Although these figures can differ, e.g. because of the familiarity with taxes that are imposed on the same substances or within the context of the same environmental problems, once these levies are introduced by sub national governments, the range of fiscal effects is too high to expect a zero additional tax revenue. This implies that either block grants or specific grants have to be reduced by an approximate amount or that particular national or sub national taxes have to be reduced in order to keep the main changes revenue neutral.

In the Netherlands, the reduction of grants in correspondence to the introduction of additional levies and taxes by municipalities and provinces has been further examined by i.a. the Commissie de Kam (1992). Among others, the Commission shows that considerable (re)distributional effects can be expected from shifts in grants and taxes. These effects strongly diverge between different municipalities and provinces. Strong (re)distributional effects can arise because, generally, the division of the reduction in grants differs from the division of the addition of tax means. The addition of tax means depends, among others, on the taxing capacities of different governments. These, however, (can) vary per government body. ${ }^{32}$ Within the context of reducing national government grants in correspondence to extended possibilities for municipalities and provinces to raise revenues by means of own taxation, the same Commission suggested, among others, an inhabitants tax, a municipal tax on building activities and a transfer of environmental user taxes from the central government to sub national governments. Although the introduction of a tax on specific vessels such as pleasure boats ("pleziervaartuigenbelasting") was not explicitly analyzed by the Commission, the possible usefulness of such a tax for provinces with intensive water recreational facilities was acknowledged (p. 61). Within the context of the ecological concerns approaches of ecological taxation (see chapters 4 and 5 of this study), such a tax could be a clear example of a possible source of revenues (pleasure boats as private goods) which is tied to the consumption of a local public good (e.g. the sustainable development of a watershed).

Within the context of the central subject of this section, a transfer of environmental user taxes on ground water and waste substances from the central government to sub national governments in the Netherlands is one of the most interesting proposals of the De Kam Cormmission (Commissie de Kam, 1992, pp. 58-60). A transfer of these taxes to provinces seems especially interesting because they coincide with the policy areas for which these provinces already have clear responsibilities. The Commission, however indicates that, since the taxing capacities for the suggested ground water tax strongly varies for different provinces in the Netherlands, the national go-

${ }^{32}$ For a more detailed analysis of the effects of these shifts, see chapter 6 of the report of the Commissie de Kam (1992). 
vernment, which strongly adheres to the equivalence principle, might object to the transfer of a ground water tax to sub national goverments. It is also stated that, since there are no strong differences in taxing capacities between provinces, a transfer of environmental user taxes on waste substances from the central government to provinces in the Netherlands, can generally be considered to be a more acceptable option. The taxes on waste substances that are suggested by the Commission are those that are imposed on installations that treat waste for instance by burning or dumping waste substances. Certain waste substances are exempted from taxation. The suggested tax rate is set at 14 guilders per ton of waste substances. Tax revenues are expected to amount to 230 million guilders. Since only a few installations are liable for this tax (i.e. only those that burn or dump waste), the administrative costs of this tax are expected to be moderate.

In an article which is largely based on the report by the Commissie Haks (1990), Van der Hoek (1991) examines thirteen broad based general tax proposals by which the revenue raising capacities of provinces in the Netherlands can be increased by 200 million guilders. Several of these tax proposals are also interesting from an environmental point of view as they include proposals for a provincial electricity tax, a surcharge on the water pollution charge, a tax based on the connection to the electricity system, a tax based on the connection to the water system, a provincial tax on pleasure boats and a provincial tax on mopeds. Based on the premise that each provincial government is free in deciding whether or not to implement the tax and free in setting the rates of these taxes, the alternative provincial taxes are evaluated on the basis of several criteria (p. 70). Taxes, for instance, should be general and not specific in the sense that revenues are earmarked. The liability for the (new) provincial tax should also not coincide with the liability for existing sub national government taxes. In addition, taxes should yield a reasonable and stable revenue, be distributed in a acceptable manner over provinces and be structured with a broad tax base. Furthermore, taxes should be workable and the costs of collection should be as low as possible. Tax payers should also be able to explicitly identify the tax as a provincial tax. On the basis of these criteria, van der Hoek concludes that only a provincial tax on the distribution of electricity can, in principle, be considered a feasible policy alternative. The tax, which is suggested to be based on a fixed sum per connection in addition to an amount which increases proportionally with the quantity of electricity delivered per connection, is shown to be relatively simple. The costs of collection are shown to be reasonably low (approximately $2 \%$ of gross revenues).

Based on the same criteria, a surcharge on the water pollution charge is considered to be undesirable. The charge would strongly vary across provinces, while provincial jurisdictions would usually not coincide with the jurisdictions of water boards. A tax which is based on being connected to the electricity system is considered infeasible for different reasons. First, because it can not be expected that many private distributors of electricity will voluntarily co-operate in the collection of the tax. Second, because the markets on which these distributors operate will not always correspond with provincial jurisdictions. In addition, the collection costs of 
this tax are also considered to be unacceptable. A tax which is based on being connected to the water system is also considered infeasible for several of these reasons. An additional difficulty of the latter taxes is comprised by the fact that several connections do not have individual water meters. A provincial tax on mopeds is considered infeasible mainly because of its limited practicability and the presence of high collection costs. A provincial tax on pleasure boats is presented as reasonably practicable, although sensitive to fraud and evasion. Mainly because the tax yield is very unequally distributed over provinces, since more than $70 \%$ of all pleasure boats are used or located within only four provinces, the tax is considered to be infeasible in the Netherlands (p. 76). The infeasibility, in this particular case, is related to the unequal distribution of the tax yield over provinces. In the Netherlands, such an unequal distribution is generally considered to be inconsistent with the equivalence principle. This principle, however, is irrelevant for environmental taxes within the ecological concerns approaches of ecological taxation. Under the latter approaches, taxing authorities are constituted on the basis of ecological circumstances, whether these circumstances are equally distributed over a country or not. In this sense, the introduction of a tax on pleasure boats in only four provinces can be feasible, under this approach, when consistent with relevant ecological circumstances.

Although there are no explicit references to sub national governments, several of the ecological tax options suggested in the review that resulted from action point $A$ 106 of the first NEPP, ${ }^{33}$ are also interesting within the context of this section. They mainly consist of taxes that are suggested in relation to the area of raw materials and resource savings, including taxes on water, primary surface materials, nutrients, pesticides and waste disposal charges (see also NEPP-2). Since minerals are often unevenly distributed throughout the Netherlands, taxes on particular surface minerals, such as shingles or gravel especially constitute an interesting option for sub national governments. They represent particular regional or local circumstances, which also demand a regional or local policy approach. The match between the decision making level and the level at which ecological circumstances occur is central to the ecological concerns approaches of ecological taxation.

It follows that sub national governments and especially provinces in the Netherlands can select from different options when considering the introduction of additional ecologically relevant taxes and levies. Among others, these options enclose environmental user taxes on ground water and waste substances; taxes on the distribution of electricity; taxes on basic substances and/or inputs (e.g. pesticides); regulatory charges on ground water and heavy metals and environmental levies on basic surface materials (e.g. gravel). The introduction of most of these levies, even regulatory levies, can be expected to be accompanied by additional tax revenues, implying that the greater part of the options should preferably be accompanied by correspon-

${ }^{33}$ Tweede Kamer der Staten-Generaal (1992), Financiële instrumenten in thet millieubeleid, 22779 , nrs. $1-2$. 
ding reductions in grants or taxes. This in order to keep the introduction of these options revenue neutral and consistent with existing financial and intergovernmental relationships in the Netherlands.

The previous considerations have also demonstrated that, under the current double dividend approach of ecological taxation, the feasibility of these options in practice, mainly depends on their consistence with the equivalence principle. Due to the strong adherence to this equivalence principle, large differences in the taxing and provision capacities between sub national governments in this country are typically considered undesirable and therefore usually prohibited. As previously argued, the equivalence principle is irrelevant for environmental taxes within the ecological concerns approaches. Under the latter approaches, the feasibility of the presented options mainly depends on the consistence of the taxes with relevant ecological circumstances. In comparison to the options presented within the analytical framework of the first question (section 9.2), the administrative and institutional restrictions for those presented within the framework of the second question are even stricter. Sub national governments in this country are only allowed to impose a restricted and limited set of taxes and levies. The introduction of additional taxes and levies then requires the establishment of new laws and acts or extensive supplementations of relevant existing acts and laws. In this sense, the costs in terms of time, administration and institutional changes are higher than the required changes indicated in section 9.2.

Within the context of the environmental areas and tasks for which sub national governments in the Netherlands are mainly responsible, Table 9.14 shows that in addition to the taxes and levies that are currently used for ecological purposes, and in addition to those which can be restructured via an incorporation of environmental policies into the tax code, sub national governments in the Netherlands can also opt for the introduction of additional environmentally relevant taxes and levies. Interesting options especially include those that are intended to be used in relation to the extraction of ground water, the production of waste, the distribution of electricity and the input or use of several basic substances or inputs (see Table 9.14).

The analysis in this and the previous sections shows that, under the current double dividend approach, the possibilities for different levels of government in the Netherlands to further develop ecological taxation, mainly entail a further internalization of relevant environmental purposes into the existing tax code, e.g. via ecologically differentiated tax rates. In addition, possibilities entail a revenue neutral introduction and use of supplementary environmentally relevant levies, e.g. in relation to those environmental problems for which these governments already bear particular policy responsibilities. Generally, these options indicate potential directions for a further development of ecological taxation alongside the afore mentioned vertical dimension (see chapters 5 and 8 of this study). For different levels of government in this country, the actual introduction of these options depends on the associated costs. The latter include i.a. costs in terms of undesirable economic and income redistribution and the costs that are associated with the assignment or changes of tax laws etc., 
that are necessary to further develop ecological taxation. These costs likely vary for different levels of government. In principle, however, the significance of the role that can be played by sub national governments in the development process of ecological taxation does not drastically differ from the role that can be played by the national government.

\begin{tabular}{|c|c|c|c|c|}
\hline $\begin{array}{l}\text { Proposals } \\
\text { type of tax } \rightarrow\end{array}$ & $\begin{array}{l}\text { Regu- } \\
\text { latory } \\
\text { levy }\end{array}$ & $\begin{array}{l}\text { Revenue } \\
\text { raising } \\
\text { tax }\end{array}$ & $\begin{array}{l}\text { Level of gom } \\
\text { vermment }\end{array}$ & Specifics \\
\hline $\begin{array}{l}\text { Extraction of } \\
\text { ground water }\end{array}$ & 1. X & 2. $\mathrm{X}$ & $\begin{array}{l}\text { 1. provincial or } \\
\text { central govern- } \\
\text { ment } \\
\text { 2. provincial } \\
\text { government }\end{array}$ & $\begin{array}{l}\text { Whether levies on ground water } \\
\text { can be introduced by sub natio- } \\
\text { nal governments mainly } \\
\text { depends on whether or not } \\
\text { differences arise across sub } \\
\text { national govern- } \\
\text { ment bodies due to the impo- } \\
\text { sition of these levies }\end{array}$ \\
\hline Eutrophication & $(x)$ & $(x)$ & $\begin{array}{l}\text { (provinces, } \\
\text { regional author- } \\
\text { ities) }\end{array}$ & $\begin{array}{l}\text { Further research has to indicate } \\
\text { whether or not it is possible for } \\
\text { regional governments in the } \\
\text { Netherlands to use taxes and } \\
\text { levies with regard to manure } \\
\text { substances and pesticides }\end{array}$ \\
\hline Waste & & $\mathrm{X}$ & $\begin{array}{l}\text { prov- } \\
\text { inces/munici- } \\
\text { palities }\end{array}$ & $\begin{array}{l}\text { Levies can be introduced in the } \\
\text { form of environmental user } \\
\text { taxes on waste substances or in } \\
\text { the form of waste disposal } \\
\text { charges }\end{array}$ \\
\hline Miscellaneous & & $\mathrm{X}$ & provinces & $\begin{array}{l}\text { A provincial tax on the } \\
\text { distribution of electricity and } \\
\text { levies on primary surface mine- } \\
\text { rals such as sand and gravel }\end{array}$ \\
\hline $\begin{array}{l}X=\text { moderat } \\
(x)=\text { low to } m\end{array}$ & . & irable & & \\
\hline
\end{tabular}

Table 9.14 Sub national governments: options for the introduction of additional efrvironmental taxes and levies.

The actual role that can be played by sub national governments, under the current double dividend approach, however, is restricted by the existing administrative or intergovernmental structures. These structures are among others marked by a close 
adherence to the equivalence principle. In this sense, although there is a relatively large potential for sub national governments to further develop ecological taxation, the use of this potential is restricted by the current financial and administrative relationships in the Netherlands. Since sub national governments also face disincentives in the sense that central government grants can be reduced once new local or regional (environmental) taxes are introduced, the actual role that can be played by sub national governments in the development of ecological taxation is further restricted under the double dividend approach. Given the theoretical potential but actual restrictions for sub national governments to further develop ecological taxation under the current double dividend approach and status quo structures, it can be questioned whether an ecological concerns approach can offer more opportunities in this respect. Within this context, in the following chapter, the development of ecological taxation on the basis of an ecological concerns approach and relevant policy implications are further analyzed. 


\section{Development of Ecological \\ Taxation: Horizontal \\ Dimension, Feasibility and \\ Policy Implications}

\subsection{Introduction}

When the policy options that were indicated in the previous chapter of this study are actually introduced, they can shift part of (local) taxation in the Netherlands towards the use of the environment. Being embedded into status quo fiscal and administrative structures, a 'various purposes' attribute is commonly ascribed to the ecological taxes that are introduced into these structures. In this sense, these options can be generalized and categorized as policy alternatives that belong to what, in this study, has been designated as the 'double dividend' approach of ecological taxation. A general feature of this approach is the introduction by general purpose decision making units of ecological taxes that are aimed at achieving both fiscal and ecological purposes. In the previous chapter of this study it was shown that, under the current double dividend approach and in relation to current fiscal and administrative structures, there are several restrictions for different levels of government in the Netherlands to further develop ecological taxation. Relevant structures for ecological taxation in this country have so far allowed this type of taxation to be mainly developed along certain stages of the vertical dimension. Only recently, opportunities have been provided to also introduce environmental levies that are aimed at inducing tax avoiding changes in behaviour. For the national government, such opportunities are mainly provided by the extended possibilities to introduce regulatory environmental levies on energy. For sub national governments, opportunities are mainly provided by the possibility to further introduce ecological tax rate differentiations. Generally, however, the existing intergovernmental structures in the Netherlands provide only few opportunities for sub national governments to use or introduce ecologically relevant taxes. The close adherence to the equivalence principle (see chapter 6 of this study) also substantially restricts the opportunities of sub national governments to independently conduct decentralized environmental policies.

Given the restrictions for these governments to further develop ecological taxation under the current double dividend approach, it can be questioned whether an ecological concerns approach can offer more opportunities in this respect. Contrary to double dividend approaches, under EC approaches, only ecological concerns are taken into consideration. The ecological tax unit (ETU) approach constitutes a clear examples of EC approaches. Under an ecological tax unit approach, taxes are imposed by a functional taxing authority, which is constituted on the basis of relevant ecological circumstances (see chapter 4 of this study). In comparison to other approaches, an important difference and advantage of the ecological tax unit approach is the utilization of the relevant ecological system as the starting point for the introduction of 
ecological taxes. In this sense, contrary to other approaches in which taxes are introduced at the level of ruling political jurisdictions, the ETU approach emphasizes the imposition of taxes by units which move beyond the level and boundaries of existing political jurisdictions, if required by relevant ecological circumstances. Since the policy implications that arise from the ETU approach likely differ from those of other approaches, while the vertical dimension of ecological taxation has already been discussed in the previous chapter of this study, in this chapter the possibilities and problems for different levels of government to further develop ecological taxation alongside a horizontal dimension are described. This description is placed within the context of the ETU approach. In addition, in this chapter, the policy implications that result from this analysis are discussed.

After the introduction (section 10.1), the main features and restrictions for different government bodies to further develop ecological taxation alongside the afore mentioned horizontal dimension are described in section 10.2. An outline of the elements that have been identified in this study as being relevant for the feasibility of ecological taxation is provided in section 10.3. In this section also the main policy implications for the development of ecological taxation in general and for the Netherlands in specific are further discussed.

\subsection{Horizontal dimension of ecological taxation: further development stages?}

In previous chapters of this study, it was argued that in order to be feasible, ecologically effective and acceptable, ecological taxes have to be introduced at a level which is cllearly related to relevant ecological circumstances. Accompanied by relevant fiscal structures in which preferably earmarked taxes are levied by functional taxing and decision making units, ecological tax units were presented as ideal representatives of this idea. Within the existing institutional structure for taxation in the Netherlands, only water boards come close to representing the idea of ecological tax units. ${ }^{1}$ A further introduction of ecological tax units in this country would entail large institutional and constitutional changes. These changes include the introduction of particular functional environmental decision making bodies and the assignment of 'the power to tax' to these bodies. Among others, interesting options in this respect involve the introduction of relevant functional boards with regard to soil and ground water protection regions and the assignment of associated taxing powers. Following recent discussions on regional environmental policies with regard to ammonia, the assignment of a so-called Manure Board ("mestschap") presents another interesting option. An example could be a board with taxing powers comparable to those of a water board, but with its main functions connected to manure related environmental problems. Since an immediate introduction of these options would significantly change the current finamcial and intergovernmental relationships in the Netherlands, the indicated options can

1 For a more detailed description of water boards, see Havekes et al. (1991). 
be considered drastic ecological tax policies. Given the current institutional framework for ecological taxation in this country, the question is whether particular starting points and opportunities are provided by this framework to further develop such policies.

Within the context of the ecological tax unit approach, this question can be analyzed by identifying different options by which it is possible to connect the imposition of current (ecological) taxes to relevant ecological circumstances. In the following, a further identification of these options is restricted to the options for sub national governments in the Netherlands. The analysis is restricted to sub national governments, in order to stress a possible role for these governments in the process of developing feasible ecological tax policy options. The identification of particular policy options is also restricted to the provincial and municipal taxes that are currently imposed within the context of the protection and mistreatment of soil and water in the Netherlands. ${ }^{2}$ These taxes constitute an important part of the total set of environmental levies that are currently imposed by sub national governments in this country.

The main taxes that are imposed within the context of soil and water related environmental problems in the Netherlands are the water pollution charge, the ground water tax, the water quantity assessments, the charge for soil protection, municipal sewerage charges and 'precario' dues. The environmental context for the imposition of these levies can perhaps best be illustrated by the following quote from an information brochure of the Dutch Ministry of Physical Planning, Housing and Environment (VROM). "Ground water, the soil, ditches and pools in the Netherlands are heavily polluted with nitrogen, phosphorus and potassium, mainly due to agriculture. The use of nitrous fertilizers has increased almost 20 -fold since 1920 , the use of manure has more than quadrupled. Persistent substances, such as metals, chemical pesticides and other organic compounds, constitute a serious threat to the quality of the soil and ground water. Fertilizers and precipitation are increasingly polluting the soil. The use of pesticides in agriculture has risen to approximately 20 million $\mathrm{kg}$ of active ingredients per year. The intensive use of some pesticides threatens the supply of drinking water. Waste dumping also jeopardizes the quality of the soil and ground water" (VROM ministry, 1992, p. 13).

It follows that soil and water related environmental problems in this country mainly involve soil dehydration as a consequence of the extraction of ground water, pollution of soil and ground water resulting from the diffusion of environmentally hazardous substances and eutrophication as the outcome of the accumulation of nitrogen and phosphorus in soil and in surface and ground water. ${ }^{4}$ All three of these problems are in some sense isolated in particular geographic regions in the Nether-

2 For a more extensive elaboration of this example, see Paulus (1994f and 1994g).

3 VROM-ministry (1992).

4 See also Paulus (1993b). 
lands. For each environmental problem, polluting emissions, activities and the resulting environmental burden (i.e. immission) all occur within a specific region. The problems are thus not necessarily of equal importance for the entire country. ${ }^{5}$ One of the characteristics of the protection of soil and water in the Netherlands is its orientation towards specific regions, i.e. towards regions which are unique from an environmental or ecological point of view. With regard to the environmental protection of soil and water, this orientation is reflected among others in the indication of soil and ground water protection regions by provinces in the Netherlands (see also chapter 6 of this study). Despite the fact that these regions are mainly constituted on the basis of ecological circumstances, it is not these regions but the provinces (in which they are located) which have the authority to use and impose taxes within the context of given ecological circumstances. In this sense, the imposition of ground water charges and the charges for soil protection by provinces indirectly reflects several elements of a structure in which relevant taxing authorities are related to relevant ecological circumstances.

For the creation of institutional structures in which the imposition of ecologically relevant levies can be more closely related to relevant ecological circumstances, therefore further options have to be identified. Within the existing institutional framework in the Netherlands, an important opportunity in this respect is provided by the possibility for different levels of government to introduce intergovernmental cooperation arrangements. To handle a particular problem which goes beyond the boundaries of a particular local government, different municipalities in the Netherlands can, for instance, become part of an intermunicipal co-operation arrangement. On the basis of the Act on Joint Arrangements ("Wet Gemeenschappelijke Regelingen"), ${ }^{6}$ provinces in the Netherlands can indicate co-operation areas, i.e. policy areas in which different municipalities can co-operate in order to achieve a common purpose. By cooperating with other municipalities, these governments can adjust the provision of a specific good ( $e . g$. the environmental quality in a specific region) to the spatial range of the demands for this good. If particular polluting activities within a specific municipality, for instance, have negative environmental consequences for other municipalities, the introduction of an intermunicipal co-operation arrangement can provide an opportunity for the internalization of these effects. The Act on Joint Arrangements allows three types of co-operation arrangements. First, initiating a public body, which

5 For this reason, these environmental problems are often referred to as regional environmental problems reflecting the fact that the diffusion of different substances takes place within the borders of a specific region (See National Institute of Public Health and Environmental Protection in the Netherlands (RIVM), 1988, p. 198).

6. The Act on Joint Arrangements offers possibilities for all kinds of co-operation arrangements between different levels of government. Arrangements are possible between municipalities, between municipalities and water boards, between municipalities and provinces, between municipalities, water boards and provinces, between provinces etc. 
has a general and daily board and a chairman. Second, initiating a joint organization, which has a daily board but which does not have as much authority as a public body. Third, appointing one of the municipalities as the central municipality of the arrangement. In the latter arrangement, the civil servants of the central municipality execute relevant tasks.

The choice of the type of co-operation is important because each type has its own set of authorities or powers to execute its task. Particular taxes and levies, for instance, can only be imposed by a co-operation arrangement in the form of a public body. More specifically, co-operation arrangements in the form of public bodies are allowed to impose municipal charges (e.g. 'precario' dues) and certain earmarked (environmental) taxes which are explicitly laid down in laws or acts (e.g. waste disposal taxes).

From an economic point of view, the opportunities for sub national goverments to become part of interjurisdictional co-operation arrangements, are relevant as they present an opportunity to impose taxes in relation to the range of particular polluting emissions. As long as this range is limited to a particular region (so that there are no transboundary external effects) and the utility which can be derived from this good is also limited to the citizens and others of the particular region in question, the environmental quality of that region can be considered a local public good. Following fiscal federalism theory, to achieve both a complete correspondence with the preferences of citizens and others with regard to this good and a production against minimum costs, the good could best be provided by a decentral level of government. It follows that; despite the fact that only the imposition of ecologically relevant levies by water boards in the Netherlands directly reflects the idea of ecological tax units, there are several opportunities for sub national governments to further develop ecological taxation alongside a horizontal dimension. The opportunities to more closely relate the imposition of ecological taxes to relevant ecological circumstances, are mainly provided by a further development of the institutional context for levies that are imposed within the context of the protection of soil and water. Further opportunities are provided by the introduction of interjurisdictional environmental co-operation arrangements.

Within an international context, these opportunities can also be used as a role model for transnational and international co-operation arrangements, e.g. intergovernmental co-operative environmental policy arrangements between the Netherlands, Germany and/or Belgium. Recently, the assignment of such co-operation arrangements is possible on the basis of a European Framework Arrangement. Under particular restrictions, this arrangement allows governments and authorities of different countries to co-operate with eachother. ${ }^{7}$ For sub national governments in the Netherlands, this

7 See Duchateau and Lok (1993, pp. 293-296). 
arrangement is especially important for the co-operation with Belgian and German counterparts. $^{8}$

For municipalities and provinces in the Netherlands that are willing to cooperate with Belgian authorities or governments, co-operation is possible via the introduction of a public body, via a body that is not (legally) incorporated or via particular administrative arrangements. ${ }^{9}$ Examples include Benego and Scheldemond. Benego is a co-operative arrangement between 34 municipalities in the Netherlands and Belgium. These municipalities are located in the area Antwerpen - Bergen op Zoom - Tilburg - Turnhout. Scheldemond is a co-operative arrangement between one province in the Netherlands ('Zeeland') and two provinces in Belgium ('West Vlaanderen' and 'Oost Vlaanderen'). In the latter arrangement, co-ordinated policies can be conducted in relation to the environmental effects of industries. ${ }^{10}$ For municipalities and provinces in the Netherlands that are willing to co-operate with German authorities or governments, co-operation is possible via the introduction of a public body, via a body which is not (legally) incorporated and via a mutual arrangement and mutual body. "' Examples include the 'Eerns Dollard' region, the 'Euregion', the 'RhineWaal' Region, the 'Rhine Meuse North' region, the 'Euregion Meuse-Rhine' and a co-operative arrangement between particular provinces in the Netherlands and particular cities in Germany. ${ }^{12}$ Most of these arrangements are related to particular watersheds. The different co-operation arrangements that are possible between local and regional governments in the Netherlands and their Belgian and German counterparts, provide important opportunities for sub national governments to more closely relate their environmental policies (including environmental tax policies) to the level of ecological circumstances or relevant environmental problems.

In conclusion it can be stated that a further development of ecological taxation alongside a horizontal dimension, requires institutional and constitutional changes and a further enhancing of the possibilities for different jurisdictions to co-operate with each other. Although, in theory, starting points for the idea of ecological tax units in the Netherlands are provided by the assignment of taxing powers to relevant environmental regions (ground water and soil protection regions) and the assignment of functional environmental boards (e.g. manure boards), the creation and stimulation of co-ordinated intergovernmental environmental policy arrangements seems to present one of the most viable options by which ecological taxation can be further developed

${ }^{8}$ For a more detailed description of the legal intricacies that are involved with these kind of co-operation arrangements, see e.g. Seerden (1993).

9 Duchateau and Lok (1993).

10 See Duchateau and Lok (1993, p. 297 ff.).

11 Ibid.

12 Ibid. 
in the direction of this idea. While the former options require large institutional changes and therefore are costly, the latter options are more coherent with recent policies that aim at changing current institutional structures in the Netherlands. The currently changing intergovernmental relationships in this country, for instance, present an opportunity to more closely relate the development of ecological taxation to relevant local and regional ecological circumstances.

On an international level, the assignment of transnational water boards for particular aquatic ecosystems located in both the Netherlands and Germany presents an interesting option. Up to this point, although the institutional structures in both countries allow the presence of water boards, a transnational water board, which covers particular aquatic ecosystems in both countries, has not yet been introduced. Also in this specific case, the assignment and further enhancing of interjurisdictional co-operation arrangements seems especially relevant for a further development of ecologically effective types of ecological taxation. Since eco-systems commonly do not coincide with political units, such an approach offers the opportunity to minimize on ecological leakages.

For separate jurisdictions, the decision to join or establish a co-operative interjurisdictional agreement, can be made on the basis of the questions formulated in the checklist in chapter 4 of this study. From a constitutional political economic point of view, such a decision making process involves, among others, a determination of the different functions that are fulfilled by the relevant ecological unit and the degree to which these functions are mutually competitive. Further elements of this process involve a determination of the effects of the absence of a relevant decision making or organizational unit and of the possibilities to re-define existing property rights by which relevant externalities can be internalized. In addition, relevant elements of the decision making process include a determination of the willingness of relevant parties to join an associative organizational unit and a determination of the proper sources of revenues for this unit.

Within the context of such a decision making process, with regard to each analytical step, separate jurisdictions can weigh the possibilities and benefits of joining or establishing a co-operative arrangement against the costs involved. In chapter 4 of this study, such an approach has been further described with regard to the river Rhine. For jurisdictions located up or downstream the river Meuse, a comparable approach is conceivable. In all of these cases, what can be stressed is the potential role that can be played by relatively small sized jurisdictions (e.g. sub national governments) in the process of relating organizational structures and taxation to relevant interjurisdictional environmental circumstances. This relationship is extremely significant for the minimization of ecological leakages and thus for the ecological effectiveness and feasibility of this type of taxation. 


\subsection{Feasibility and policy implications}

In the first chapter of this study, feasibility is described as a concept which expresses whether something is viable or workable. In terms of the central research subject of this study, the feasibility concept expresses a bundle of possibilities and intricacies that make ecological taxation a realistic policy option. In recent theory and practice, this type of taxation has been introduced within the context of a double dividend approach. Within this approach, ecological taxation is embedded into or related to current fiscal structures. Examples of such relationships for instance include an incorporation of environmental policy purposes into existing revenue raising taxes. Being part of existing fiscal structures, a 'various purposes" characteristic is usually accredited to these taxes in the sense that they can fulfil both fiscal and ecological purposes. Carried to an extreme, according to this approach, ecological taxation can be used to shift the bulk of taxation away from labour and towards the use of natural resources and the environment. Revenue raising environmental taxes and the concept of ecological tax reform constitute clear elements of this approach. A characteristic feature of this approach is also the imposition of taxes by general purpose decision making units, whose taxing authorities generally do not coincide with relevant ecological circumstances.

Given the general lack of attention, in both theory and practice, for approaches of ecological taxation in which purely ecological concerns or relevant ecological systems are utilized as the starting point for the introduction of ecological taxes, ecological concerns approaches are presented in this study as alternative policy approaches. Central to these alternative approaches of ecological taxation, is the imposition of ecologically relevant taxes by a taxing authority, whose taxing authorities are constituted purely on the basis of ecological circumstances. Another central element of this approach is the use of taxes that are solely designed on the basis of ecological concerns. In an ideal situation, Pigouvian taxes, tax credits, special tax deductions and the taxes that are imposed by ecological tax units represent apparent examples of this approach.

Since both approaches emphasize the use of separate types of ecological taxes, while the institutional and constitutional framework for the imposition of these taxes also differs, the bundle of possibilities and intricacies which determine the feasibility of ecological taxation also diverges under both approaches. Under a double dividend approach, the feasibility of ecological taxation mainly depends on the coherence of ecological taxes with existing fiscal structures and the possibility to balance the possible friction between environmental and other effects and purposes of these taxes (e.g. fiscal purposes). Under an ecological concerns approach, the feasibility of ecological taxation mainly depends on the coherence of ecological taxes with ecological circumstances. In addition, the feasibility of ecological taxation under EC approaches depends on the possibility to make institutional and constitutional changes and on the availability of informational structures that inform relevant actors on possible behavioural changes. Given the afore mentioned set of possibilities and intricacies, 
under both approaches, realistic ecological tax options include those that are accompanied by an accommodating framework in which the elements that further enhance the acceptability and ecological effectiveness of ecological taxes are expressed. Accompanied by such a relevant framework, the viability of ecological taxation under a double dividend approach can be expected to be mainly related to the acceptability of this type of taxation. The acceptability of ecological taxes under this approach depends, among others, on how and for which purposes resulting tax revenues are used. Under an ecological tax unit approach, the viability of ecological taxation can be expected to be mainly related to the ecological effectiveness of this type of taxation. This effectiveness depends, among others, on the possibilities to introduce taxes at a proper level, given relevant ecological circumstances. The relevance of the two approaches differs for different dimensions of the development process in question. Double dividend approaches seem especially rellevant for the gradual development of ecological taxation alongside a vertical dimension. Ecological concerns approaches, on the other hand, seem especially relevant for a more drastic development of this type of taxation alongside a horizontal dimension.

The analysis of the feasibility of ecological taxation in the Netherlands shows that, in the last two decades, within the ruling administrative and financial framework, the development of ecological taxation has followed three consecutive stages:

1) The introduction of several sectoral environmental levies in the period between 1970 and 1988. A distinctive feature of the development of ecological taxation in this period is the introduction of earmarked environmental levies.

2) From 1988 until the beginning of the 1990's, the introduction of a more integrated system of environmental levies. In this stage, the introduction of a broad integrated earmarked fuel charge by the national level of government is one of the main characteristics of this development. At approximately the same time, sub national governments gradually started to increase the rates of several of their environmental levies.

3) From the beginning of the 1990's, a deepening and broadening of ecological taxation, accompanied by the introduction of new ecological taxes. A characteristic feature of this stage is the presentation of ecological tax measures that are aimed at shifting part of the tax burden away from labour and in the direction of pollution and the use of natural resources. The introduction of environmental user taxes on ground water and waste substances in 1995, the intended introduction of a tax on uranium in 1996 and the (intended) introduction of a regulatory tax on energy in 1996 can be seen as the first steps in this direction.

So far, realistic policy options in this country mainly consist of low tax rated earmarked or revenue raising environmental taxes. Although several suggestions for an introduction of Pigouvian or regulatory environmental levies in the Netherlands 
have been made, there is no development towards the introduction of taxes that systematically focus on moments of decisions. It can be expected that in the near future, viable ecological tax policy options for different levels of government in the Netherlands mainly entail those that include a further development alongside the afore mentioned vertical dimension. Such a development mainly includes:

* A gradual abolishment of environmentally unfriendly elements from the existing fiscal structures.

* A further incorporation of environmentally friendly elements within the current tax code.

* A gradual broadening of existing environmental tax bases.

* The introduction of ecologically differentiated tax rates.

* The introduction of new revenue raising environmental taxes.

It follows from the analysis in this study, that the use of an ecological concerns approach, as expressed in, for instance, the assignment of ecological tax unit arrangements, requires considerable institutional and constitutional changes in the Netherlands. For the further development of feasible types of ecological taxes by sub national governments in this country, such changes, however, seem necessary in order to overcome the restrictions and disincentives provided to these government under the current structures and double dividend approach. The recent initiatives and demands for changes in the financial and intergovernmental relationships in the Netherlands, provide increasing opportunities to actually make such changes. The recent demands and initiatives for these changes, mainly emanate from a growing vertical and horizontal interdependence of different levels of government in this country. ${ }^{13}$

Feijtel (1993) argues that a growing vertical interdependence is mainly associated with the aspirations of the national government to decentralize and to introduce broad policy plans such as the NEPP and NEPPP. Both decentralization and the execution of several policy measures that are described in different policy plans, require a more demanding policy role from sub national governments. According to the same author, a growing horizontal interdependence is mainly associated with the re-enforcement of the Act on Joint Arrangements. A growing horizontal interdependence is also associated with the recent reforms of the Municipality and Province Fund and the current changes in the intergovernmental relationships in this country. The latter changes entail the introduction of regional governments and the extended possibilities for sub national government to raise revenues by means of own taxation. All of these developments increase the interdependence of sub national governments and augment the demand for combined policy arrangements. The latter, as was previously argued, comprises one of the central elements of the ecological tax unit approach.

${ }^{13}$ See Feijtel $(1993$, pp. 39-40). 
In the Netherlands, the current imposition of ecologically relevant taxes by sub national governments already contains several elements which closely resemble some of the central features of the idea of ecological tax units. Among others, these elements include the close relationship to particular ecological circumstances, the use of earmarked taxes for ecological purposes and the surveyable level at which these taxes are introduced. The imposition of different environmental levies by water boards in the Netherlands closely reflect these features. In addition, sub national governments play a role in the introduction of intergovernmental co-operation arrangements. These arrangements can be used to create taxing units which coincide with the boundaries of relevant ecological circumstances. Within an international (European) context, an important feature of the taxes that are imposed by sub national governments is also related to their general congruity with the process of European unification and tax harmonization. In relation to this, it can also be noticed that the European Commission, by way of financial inducements, more and more stimulates the assignment of transnational co-operation arrangements.

In conclusion, it can then be stated that, generally, the feasibility of ecological taxation can only be determined on the basis of a case by case approach (see also Paulus, 1994a). This means that the viability of this type of taxation can only be determined, separately, for each decision making unit and for each (type of) ecological tax. For each decision making unit and for separate taxes, the introduction of (additional) realistic ecological tax policy options strongly depends on the current stage of development alongside the vertical and horizontal dimension, and the institutional, administrative and fiscal structures into which these (additional) options have to be embedded. These stages and structures are important elements in the set of determinants of the costs of further designing, introducing and developing feasible ecological tax policy options. With regard to this development process, depending on the stages of development and the presence of relevant structures, different roles can be assigned to different levels of government. Generally, a more demanding role can be detected for relatively small decision making units (e.g. sub national governments) within the process of (further) developing realistic ecological tax policy options alongside the afore mentioned horizontal dimension. In the Netherlands, in the near future, realistic ecological tax policy options entail those that are introduced on a surveyable level, that are related to current fiscal structures and that are embedded into the current process of institutional change. The actual realization of these options, however, requires a particular attention from policy makers. Several implications for actual policy making that arise from the analysis in this study are further described bellow.

\section{Policy implications}

In agreement with other studies on the subject, this study shows that each type of tax, which is intended to be used for ecological and/or other purposes, has its own specific 
bundle of problems and possibilities. In order to be feasible, each type of tax therefore has to be separately designed and be embedded into its own accommodating policy framework (see also Paulus, 1995). The checklist indicated in chapter 3 of this study can be used by policy makers as a policy guide in this respect. In this checklist, it is for instance indicated, that the introduction of Pigouvian taxes should only be considered by policy makers when alternative and more environmentally sound types of behaviour are available and can be conceived as realistic policy options.

Within the current institutional and constitutional structures for ecological taxation and under the current double dividend approach, it can generally be expected that policy makers, however, are unwilling to introduce Pigouvian taxes. Within the current structures, taxes are generally used for revenue raising purposes. In this sense, maintaining the sources of income is inherent to double dividend approaches. When properly designed in the sense that they are directly related to moments of decisions, Pigouvian taxes, however, raise very low or no additional tax revenues. In order to maintain the sources of income, policy makers might therefore be unwilling to introduce such taxes. It is also conceivable that thcy introduce these taxes under the heading of Pigouvian taxes, but at the same time assign clear fiscal purposes to these levies.

For policy makers that are willing to use Pigouvian taxes, difficulties arise as regards the restricted possibilities to properly introduce such taxes under the current structures and approaches. Difficulties are associated with the fact that current taxing authorities are unfamiliar with taxes that are used for other than fiscal purposes. Further difficulties arise with the fact that, mostly, these authorities are constituted on the basis of other than relevant ecological circumstances. Both the inexperiences and the lack of proper institutional structures contribute to the difficulties of obtaining the types of information necessary to design ecologically effective and acceptable taxes. To overcome the difficulties of obtaining these types of information, policy makers can use ecological tax provisions such as tax credits and special tax deductions. Special tax provisions in (business) income taxes can for instance be used by policy makers to induce industries and companies to reveal information on environmentally sound production processes. By revealing this type of information to taxing authorities, these industries etc. can obtain a tax credit or reduce the amount of taxes to be paid. In this sense, tax provisions can be used by policy makers to gather the types of information necessary to induce structural behavioural changes.

Generally, however, the current institutional and fiscal structures provide disincentives for the use of taxes which induce structural behavioural changes or for taxes that are clearly related to relevant ecological circumstances. The introduction of the latter types of taxes generally requires constitutional changes. The checklist in chapter 4 of this study can be used by policy makers and other economic actors to decide whether the costs of such changes outweigh their benefits. The associated costs are mainly related to the processes of formulating, agreeing to and actually implementing the required institutional and constitutional changes. The benefits are mainly related to the expected ecological effectiveness and the acceptability of ecological 
taxes that are embedded into institutional and constitutional structures, that are constituted on the basis of purely ecological concerns. Ideally, these structures are chosen by potential taxpayers/beneficiaries at a constitutional stage. It was argued in chapter 4 of this study that earmarked taxes comprise an important component of the taxes and tax regimes that are chosen at this stage.

Depending on the purpose of the tax and the structures into which the tax is embedded, policy makers can be expected to opt for the introduction of those types of ecological taxes that are consistent with the main principles that underlie these structures. The types of ecological taxes that are chosen by policy makers, also depend on the approach taken. Under the current double dividend approach, which strongly adheres to current fiscal and institutional structures, policy makers can be expected to opt for the introduction of ecological taxes that have a clear fiscal purpose. These include ordinary revenue raising taxes and taxes that are used to fund specific environmental provisions. Under alternative ecological concerns approaches, which strongly adhere to fiscal and institutional structures that are constituted on the basis of purely ecological concerns, policy makers can be expected to opt for the introduction of taxes that have a clear ecological purpose. These include Pigouvian taxes, tax provisions and the taxes that are set by ecological tax units. Where the former approach is marked by a gradual development of ecological taxation, the latter can be considered a more radical approach of ecological taxation. Depending on which of the approaches is generally preferred, different implications arise for the further development of ecological taxation.

To further develop ecological taxation under the current double dividend approach, policy makers have to be aware of the fact that they can only gradually develop ecological taxation and only in close relationship to existing fiscal structures. The development of ecological taxation, under these approaches, likely entails a further incorporation of ecological purposes into the existing tax code. To be able to do this, policy makers have to design and introduce taxes that provide a stable balance between the fiscal and steering effects of these taxes. Given the purpose of finding taxes that provide such a balance, it can be expected that policy makers opt for the introduction of ecological taxes that have a relatively small tax base and/or relatively high tax rates.

To further develop ecological taxation under the alternative ecological concerns approaches, policy makers have to be aware of the drastic changes that have to be made in order to be able to conduct feasible ecological tax policies. After relevant constitutional changes have been made, the development of ecological taxation, under this approach, likely entails a further introduction of earmarked environmental taxes and of taxes that are imposed on the consumption of private goods that are tied to the consumption of the public good in question. To be able to introduce such taxes, policy makers have to design and introduce those types of taxes that entail a clear relationship between the tax payment and the provisions provided by potential tax revenues. In order to constitute such a relationship, it can be expected that policy makers opt for the imposition of earmarked types of taxes on a restricted set of goods 
and a restricted set of the population (e.g. those within an environmental protection region).

In the Netherlands, ecological tax policies have mainly been conducted on the basis of a double dividend approach. Within the context of this approach, ordinary revenue raising taxes and earmarked environmental taxes have been introduced. Several ecological elements have also been incorporated into the taxes that are currently imposed in this country. To further develop ecological taxes within the context of this approach, policy makers in this country have to be aware of the potential role that can be played by sub national governments in the process of introducing and developing feasible ecological tax policy options. In addition, policy makers in the Netherlands have to be aware of the restricted possibilities for these governments to independently introduce, impose and/or use ecologically relevant taxes. To make use of the potential role that can be played by these governments in the process of further developing ecological taxation, policy makers in this country, therefore, either have to extend the afore mentioned possibilities or incorporate these opportunities into currently conducted policies.

Extensions of the afore mentioned possibilities can entail allowing these governments the possibilities to further incorporate environmental policy purposes into their tax codes. In addition, extensions include a further enhancement of the ecological differentiation of tax rates ${ }^{14}$ and the broadening of current tax bases. Extensions can also entail, allowing a revenue neutral introduction of additional ecologically relevant taxes and levies (both revenue raising and regulatory). The latter possibilities are preferably provided for those areas for which sub national governments already bear specific policy responsibilities, e.g. with regard to waste, soil and water. To be able to make use of the roles that can be played by sub national governments in the development of (additional) feasible ecological taxes, policy makers can also use currently conducted policies. Possibilities in this respect include, for instance, the incorporation of the use, imposition and development of ecologically relevant taxes into the currently conducted region oriented environmental policies and the policies that are associated with intergovernmental co-operation arrangements.

The incorporation of ecological tax policies into the policies on interjurisdictional co-operation arrangements can also provide the starting point for ecological tax policies that are conducted on the basis of ecological concerns approaches. If policy

${ }^{1.4}$ Due to the current changes in the municipality fund, municipalities in the Netherlands have recently gained a ligher degree of freedom in setting tax rates. The changes in the municipality fund have also resulted in high increases of these rates. These rates differ considerably for different municipalities in this country (see also Bij, van der, et al., 1994). The differences between municipalities as regards their environmental tax rates reflect that, despite the clear adherence to the equivalence principle, these governments can also offer a different package of taxes and tax rates to local tax payers. This closely reflects several elements of the theory suggested by Tiebout (1956), in which consumer citizens can express their preferences with regard to particular packages of provisions and taxes via "voting with their feet". 
makers aim at introducing ecological taxes that are based on purely ecological concerns, e.g. via an ETU approach, they have to be aware of the institutional and constitutional changes that are associated which such an approach. These changes facilitate the introduction of alternative courses of policy action in which thoroughly and carefully designed are embedded into relevant fiscal, instutional and constitutional structures. Changes can include the assignment of taxing powers to relevant environmental regions (e.g. ground water and soil protection regions), the assignment of functional environmental boards (e.g. manure boards) and the creation of co-ordinated intergovernmental environmental policy arrangements. The latter arrangements can also serve as a role model and starting point in the process of enacting or further enhancing transnational environmental co-operation arrangements.

If policy makers also, i.e. besides using tax credits and special tax deductions, use taxes to stimulate environmentally sound ways of behaviour, they have to act as the provider and gatherer of information on alternative tax avoiding changes in behaviour. Within the process of development, the search for interjurisdictional environmental co-operation arrangements requires policy makers to act as environmental diplomats and co-ordinators. To perform these and other roles, policy makers have to be confronted with a set of proper incentives, such that they (can) also actually conduct their required roles. ${ }^{15}$ In reference to Brennan and Buchanan $(1980,1985)$ and Wicksell (1896), it was argued in chapter 4 of this study, that a framework in which there is a close relationship between those who pay, benefit and have a say in the ecological tax policies of the relevant taxing authority, provides particular incentives for policy makers to act in a particular manner, e.g. on behalf of tax payers or in relation to certain (ecological or revenue raising) purposes. The use of earmarked types of taxes constitutes an important element of this framework.

From the above it follows that, other than in most studies, the analysis of ecological taxation in this study shows that, for the actual development of feasible ecological taxes, policy makers can choose between a gradual or a drastic ecological tax policy approach. Although the types of ecological taxes and their design differ per approach, this study shows that the use of tax provisions and earmarked taxes and the incorporation of ecological tax policies into region oriented policies and policies on interjurisdictional co-operation arrangements, are important elements for the practical feasibility of ecological taxation under both approaches. This study also shows that, generally and in relation to the specific case of the Netherlands, relatively small sized jurisdictions can play a role in the further development of feasible ecological taxes. To stress these and other important aspects of the study, the main elements of the research approach and the research results are summarized in chapter 11 . Several

15 For a more explicit analysis of the different roles that can be played by political entrepreneurs in the political decision making process on environmental issues, see e.g. Mierlo, van \& van Nispen (1991). 
directions for further research on the subject of the feasibility of ecological taxation are also provided in the final chapter. 


\section{Summary, Conclusions and Directions for Further Research}

\subsection{Introduction}

In this final chapter, the main results and conclusions of the research conducted in this study are recapitulated. After the introduction (section 11.1), a summary of the main results and conclusions is provided in section 11.2. Several concluding remarks and directions for further research on the subject of ecological taxation are described in section 11.3.

\subsection{Summary and conclusions}

\section{Background and scope}

In reference to possible divergences that can arise between the marginal social and the marginal private net product, Pigou $(1912 ; 1920)$ suggested to use taxes for the internalization of external effects. Since then, Pigou's suggestions have been further elaborated and incorporated into environmental economics. Within this branch of economics, the concept of externalities is central to the explanation of environmental external effects such as pollution. Following the suggestions of Pigou, taxes can be used for the internalization of these effects, providing a basis for the idea of using taxes for environmental purposes. The latter idea has become increasingly popular in recent years. This popularity can be mainly attributed to increasing environmental problems and the perception that command and control instruments are ineffective.

In chapter 1 of this study it is argued that although Pigou suggested a tax which is purely intended to be used for allocational and not for fiscal purposes, in both theory and practice, ecological taxes have generally been presented under the heading of a 'double dividend' (DD) approach. A general feature of this approach is the 'various purposes" attribute which is commonly ascribed to ecological taxes. Taxes are not only aimed at achieving particular ecological purposes, but, at the same time, also at raising tax revenues and at accomplishing other purposes, e.g. with regard to employment or the redistribution of income. Consequently, in the design of these taxes, also other than environmental issues are taken into consideration. This and an increasing concern for the possible fiscal effects that can be associated with Pigouvian types of taxes, has shifted the attention from both theorists and actual policy makers away from approaches in which taxes are set on the basis of purely ecological concerns. Examples of the latter 'ecological concerns" (EC) approaches include the Pigouvian tax approach, as originally formulated and incorporated into environmental economics, and approaches in which taxes are set in coherence with 
relevant ecological systems. In addition to the afore mentioned shift in attention, the greater part of the existing body of literature on ecological taxation has generally neglected the usual mismatch between the boundaries of current decision making structures and the boundaries of relevant ecological circumstances in practice. In addition, the roles that can be played by small sized decision making units in the process of further developing this type of taxation and the institutional framework into which this type of taxation is embedded, have also commonly been neglected. It can therefore generally be expected that the feasibility of ecological taxes differs under double dividend and ecological concerns approaches of ecological taxation.

\section{Research aim and research approach}

Against this background, the central aim of this study can be described as the analysis of the feasibility of ecological taxation under DD and EC approaches and the derivation of relevant policy implications for the use of this type of taxation in general and in practice. To analyze the feasibility of ecological taxation in practice, the current and expected future imposition of this type of taxation in the Netherlands is used as a case study. To conduct a feasibility analysis of ecological taxation, a feasibility concept is used which refers to the viability of ecological taxation. More specifically, this concept relers to those possibilities and problems that make this type of taxation a realistic and thus imaginable policy option. To be able to conduct a feasibility analysis, it is a priori assumed that it has already been decided that taxes can be considered an appropriate instrument, given particular ecological circumstances. In this sense, it thus assumed that the feasibility of ecological taxation need not be determined on the basis of a comparative analysis, in which the use of taxes has to be compared to that of other environmental policy instruments.

Given these assumptions, the research approach consists of an analysis of the possibilities, problems and elements that make ecological taxation a viable policy option under different approaches of ecological taxation. Since the boundaries of ecological units (e.g. a watershed, a mountain range, a river basin etc.) are generally inconsistent with the boundaries of current political decision making units, part of the feasibility analysis in this study is conducted on the basis of constitutional (environmental) economics. A central feature of this branch of political economy is the inclusion of collective decision and choice making institutions as variables of the analysis.

\section{Theoretical context}

In chapters 2 and 3, ecological taxation is placed within a relevant theoretical context, which is then used to discuss the sources of origin, the main concepts and the design of ecological taxes. The theoretical context, which consists of the theory of environmental policy, environmental economics, modern public finance and specific points of view embedded in the classical theory of taxation, is further described in chapter 2. Within this theoretical context and within the context of the EC and DD approaches 
of ecological taxation, the analysis in chapter 2 shows that; in the original formulation, the Pigouvian tax approach constitutes a clear example of approaches in which taxes are set on the basis of ecological concerns. Under a Pigouvian tax approach, the singular purpose assigned to ecological taxes is the taxation of those types of behaviour which, from an ecological point of view, can be considered inappropriate. In an ideal case, the tax accomplishes this purpose, internalizes external environmental effects and raises no additional tax revenues. In this sense, the only concern is the accomplishment of a particular ecological purpose. The analysis in this chapter however also shows that Pigouvian taxes, in their original formulation, only present a theoretical ideal image, for which only proxies (e.g. regulatory levies and standard and charges approaches) can be formulated in practice. Consequently, the attention for the use of revenue raising taxes for ecological purposes has steadily increased. In this respect, the attention for the use of taxes for ecological purposes has gradually shifted towards an approach in which these taxes are aimed at accomplishing both ecological and revenue raising purposes.

In order to explain and following the growing attention for possible double dividend features of ecological taxation, the main possibilities, problems and the design of ecological taxes are further displayed in chapter 3 . This chapter starts by defining ecological taxes as types of levies (i.e. compulsory contributions or forms of payments) which conform with one or more of the following characteristics:

Taxes are aimed at accomplishing tax avoiding changes in the behaviour of those who are confronted with the taxes, in order to incorporate (part of the) negative external environmental effects into the decision calculus of the externality generator.

Taxes are aimed at raising revenues which can be used for an environmental sector involved in so far as this is necessary to achieve a particular environmental or ecological goal.

There is a relationship between the tax base and the nature and size of environmentally (un)desired aspects, factors and/or activities.

Defined as such, different types of ecological taxes can be distinguished. They include revenue raising, earmarked and regulatory environmental levies. The concept of ecological tax reform, which best reflects the main features of the double dividend approach, incorporates several elements of these different types of levies. The different types of ecological taxes, as defined above, can be distinguished from a broader category of ecologically relevant taxes. The latter also include taxes (initially) introduced for non-environmental. reasons but with a certain impact on the environment. An analysis of the intricacies of using these different types of taxes for ecological and other purposes shows, that the most important problems in this respect are related to the ecological effectiveness of these taxes, the linkage between the tax point, moments of decisions and the point of pollution and the associated administrative and enforcement costs. Further problems are related to the types of information needed to set the 
proper ecological tax rates, the fiscal and steering effects of ecological taxes and the earmarking and use of possible tax revenues. Problems are also rellated to the concordance of ecological taxation with existing national and international tax and legal systems and to the distributional incidence and the (inter)national economic effects of this type of taxation.

Given these problems and possibilities, which differ per type of ecological tax, it is shown in chapter 3 of this study that the use of taxes for ecological purposes comprises several complicated problems. These problems can be solved only if the ecological tax as a policy instrument is placed within a general policy framework. On the one hand this can be achieved by using an ecological tax in the form of a Pigouvian tax as an instrument of environmental policy. In this case it is important to formulate and search for an accommodating policy for behavioural alternatives. Outside the existing tax system, also new earmarked environmental taxes can be introduced. In this case it is important to find a proper relationship between the taxes, tax liable individuals and the provision of an ecologically relevant service. The possibility exists, on the other hand, to reform the entire tax system in order to stimulate an optimal use of natural resources. If ecological taxes of the ordinary revenue raising type are used this in fact opens a political discussion on the entire tax system. From this it follows that ecological taxes are complicated, yet that in principle ecological taxes could be feasible when coherent with certain preconditions. For each type of tax or tax reform, these conditions have been more explicitly indicated by way of a checklist in chapter 3. From the analysis in this chapter it also follows that the elements which determine the viability of ecological taxes under a double dividend approach (e.g. revenue raising and earmarked taxes and ecological tax reform) differ from those that, in principle, are set purely on the basis of ecological concerns (e.g. Pigouvian taxes). The viability of the latter types of levies strongly depends on the incorporation of elements in the design of these taxes which further enhance their allocational function, and the presence of a framework in which information on behavioural alternatives is distributed to relevant actors. The viability of the former types of levies strongly depends on their compatibility with existing fiscal structures and the possibilities to reach agreement on the possible destination of associated tax revenues.

\section{The imposition of ecological taxes and the concept of ecological tax units}

Assuming that, in order to serve a meaningful purpose and be acceptable and feasible, ecological taxes not only have to be accurately designed but also be imposed by a proper taxing authority, on a proper level and within a relevant institutional and fiscal framework, the imposition of ecological taxes and the concept of ecological tax units are further discussed in chapter 4 of study. In this chapter, the discussion of ecological tax issues is placed within the context of the theory of constitutional political economy and constitutional environmental economics. Using different theories, including the theory of fiscal federalism, the theory of clubs, Tiebout's theory of local expenditures, Brennan and Buchanan's theory of taxation and Wicksell's voluntary 
exchange approach, ecological tax units are introduced as the ideal representatives of several of the central elements of the ecological concerns approaches of ecological taxation.

Ecological tax units refer to decision making arrangements in which the range of a political or tax unit corresponds with the range of an ecological unit, i.e. with the range of relevant ecological circumstances. These decision making units have the authority to impose (ecological) taxes and, ideally, represent the idea of club-like functional purpose arrangements. Relevant actors can voluntarily decide to join the club-like arrangement (e.g. via voting with their feet), but agree to pay a club-like fee, when joining the arrangement. The fees or 'taxes', which are necessary to achieve a preset target, are set by representatives who are elected by those who join the arrangement. Formulated as such, these units represent an institutional arrangement by which it is, in theory, possible to impose taxes in close connection with relevant ecological circumstances. This arrangement has an institutional and fiscal structure which is marked by a close relationship between those who pay, have a say and benefit from the ecological tax policies conducted by the taxing authority. Earmarking is thus an important feature of ecological tax units Where the existence of this close relationship is relevant for the acceptability of these taxes, the close connection with relevant ecological circumstances is relevant for the ecological effectiveness of these taxes. In this sense, both these elements of ecological tax units are important for the viability of ecological taxation.

Since it can be expected that existing taxing authorities tend to be political units which most of the times do not fit the description of being clearly related to relevant ecological circumstances (the river Rhine presents a clear example), an analytical framework for the development and creation of ecological tax units is presented in chapter 4 . Consensus building, earmarking and constitutional changes constitute important elements of this framework. From a constitutional political economic point of view, the costs and benefits and the institutional structures that are required to make constitutional changes are formulated by way of a checklist in chapter 4. The checklist shows the practical problems to be solved and the decisions that have to be taken in order to actually make such changes. It follows from the analysis in chapter 4, that the imposition of ecological taxes in close relationship to relevant ecological circumstances is a very intricate matter. In order to arrive at a succesful imposition in practice, it requires an approach of ecological taxation which is more radical than the gradual strategies suggested by the DD approaches.

\section{From theory to practice}

Following the conclusions from the previous chapters, in chapter 5 an analytical framework is formulated that incorporates several elements of the DD and EC approaches of ecological taxation and that can be used to make an application of the theoretical considerations to the actual and intended use of ecological taxes in the Netherlands. A central element of this framework is the development of ecological taxation 
alongside a horizontal and vertical dimension. These dimensions express the development of ecological taxation in the direction of thoroughly and carefully designed taxes (vertical dimension) and in the direction of a proper level of imposition, given ecological circumstances (horizontal dimension). The development of ecological taxation alongside these two dimensions allows this type of taxation to be designed and embedded into institutional, constitutional, fiscal and other relevant structures and changes that facilitate and ensure the ecological effectiveness and acceptability of these taxes.

By placing ecological taxation within a broader process of development, the analysis in this chapter shows that DD and EC approaches not necessarily have to be conceived as two opposite approaches. Within the context of the development process of ecological taxaton, the two approaches present likely approaches in relation to a particular development dimension. If ecological taxation can only be further developed within the status quo structures, either because the costs of institutional or constitutional change outweigh their benefit or because policy makers have developed an interest in maintaing these structures, the DD approach can be used to indicate the relevant elements of design. In this sense, this approach seems the most likely approach for a development of ecological taxation alongside the vertical dimension. If, on the other hand, institutional or constitutional changes, are considered desirable, EC approaches can be used to analyze whether and how such changes are also actually feasible. In this sense, these approaches seem the most likely approaches for a development of ecological taxation alongside the horizontal dimension.

\section{Institutional and other relevant frameworks for ecological taxation in the Netherlands}

Since relevant institutional frameworks and the acceptability of ecological taxes vary from country to country and even from jurisdiction to jurisdiction, the costs of further developing ecological taxation alongside both dimensions can also be expected to vary per country and per jurisdiction. They can therefore only be determined on the basis of a case by case approach. In this sense, the analysis of the feasibility of ecological taxation in this study is applied to the specific case of the Netherlands. To be able to conduct such an analysis, first the institutional, fiscal and environmental policy framework for ecological taxation is described in chapter 6 of this study. In this chapter, an analysis of the division of responsibilities between different governments in the Netherlands with respect to particular environmental tasks and the imposition and use of certain taxes, shows that this framework provides particular inflexibilities and restrictions on the level and/or authority by which these taxes can be imposed, on the design and purpose of these taxes and on the possibilities to differentiate the imposition of ecological taxes throughout the country. Inflexibilities and restrictions are especially faced by sub national governments in this country. To directly respond to relevant local ecological circumstances by way of taxes, requires the general agreement of the central government and the establishment of Special Acts. In recent years, changing financial and intergovernmental relationships in this country, however, have 
also provided several opportunities for sub national governments to introduce and use taxes more closely in relationship to relevant ecological circumstances. Mainly, these opportunities are provided by the introduction of regional governments in the Netherlands, the intention to strengthen the financial independence of sub national governments and the intention to further enhance co-operation arrangements between municipalities in this country. Additionally, in recent years, provinces in the Netherlands have also gained increasing responsibilities for the protection of the environment.

Further opportunities are provided by the existing environmental policy framework in this country. Within this framework, there is a growing interest in region oriented environmental policies. In addition, within this framework, the execution of a significant part of environmental policies is increasingly being delegated to provinces, municipalities and water authorities. It is also recognized, within this framework, that an internalization of environmental externalities within prices constitutes an important element of attaining sustainable growth. Given these opportunities, it can be noted that, in recent years, sub national governments in the Netherlands have played a more significant role with regard to particular environmental policies and tasks. These tasks are mainly related to the decontamination of soil and sound, the prevention and disposal of waste, sewerage, the purification of water, the protection of particular regions, energy savings and environmental education.

Within the context of the afore mentioned restrictive frameworks, opportunities and developments, in chapter 7 the actual use of environmentally relevant taxes in the Netherlands is described and analyzed. In this chapter it is shown that several environmental levies are imposed by different levels of government in this country. For the central government, these include environmental user taxes on fuel, regulatory environmental user taxes on leaded and unleaded oil, a noise charge, a charge on surplus manure, a livestock fodder charge and a water pollution charge for national waters. Sub national governments in the Netherlands impose among others a water pollution charge for regional waters (provinces, municipalities and water authorities), a charge for soil protection (provinces), a waste disposal tax (municipalities), a ground water charge (provinces), refuse collection charges (municipalities), sewerage charges (municipalities) and water quantity assessments (water boards).

The main function of the environmental levies and charges that are imposed by different government bodies in the Netherlands is primarily a fiscal one. Environmentall levies as those suggested by Pigou have hardly been introduced in this country. Environmental levies in the Netherlands are based on products as well as emissions. Studies indicate that the total amount of revenues raised by these environmental levies amount to some 3 billion guilders, which is less than $2,5 \%$ of total tax receipts in this country.

\section{The development of ecological taxation in the Netherlands}

Given the current use of ecologically relevant taxes in the Netherlands, in chapters 810 , the development of ecological taxation in this country is further analyzed. In 
chapter 8 , it is shown that although the use of taxes for ecological purposes in the Netherlands is on average comparable to that of other European OECD Member countries, several specific features of ecological taxation in this country can still be detected. These features mainly include the fact that the greater part of the ecologically relevant levies that are currently used in this country share the characteristic of being relatively small earmarked types of taxes that have relatively low tax rates. The main purpose of these levies is to raise a proper amount of tax revenues, by which relevant environmental expenditures can be financed. From the analysis in the same chapter it follows, that with regard to the imposition of ecologically relevant taxes, only the imposition of ecologically relevant levies by water boards in this country closely reflects the idea of ecological tax units. As regards the development of ecological taxation, it follows from the analysis in this chapter that this kind of taxation in this country is gradually developing, via a stepwise process, from a system in which different sectoral environmental levies are introduced within a relatively unco-ordinated manner towards a more structured system, in which environmental levies are more thoroughly designed and co-ordinated. At the beginning of 1995, this system serves as an important financing scheme for environmental policies and at the same time offers opportunities for the introduction of (additional) ecologically relevant taxes and tax elements that are not primarily intended to be used for revenue raising purposes. For the near future, this financing scheme and the provided opportunities serve as the starting point for a gradual introduction of the idea of ecological tax reform in this country. Since the latter reform constitutes one of the major elements of the double dividend approach of ecological taxation, it can also be concluded that the development of ecological taxation in the Netherlands mainly develops alongside the previously mentioned vertical dimension. Although current institutional, intergovernmental and financial changes create increasing possibilities for the use of an ecological circumstances approach, they do not enhance the development towards a tax system which systematically focuses on moments of decisions or relevant ecollogical units.

Building on the general trends and features of ecological taxation in the Netherlands, which indicate that relevant structures for ecological taxation have so far allowed this type of taxation to be mainly developed along certain stages of the vertical dimension, in chapter 9, several possibilities and problems of moving this type of taxation towards particular and further stages alongside this dimension are further identified. The analysis in this chapter shows that, under the current double dividend approach, the possibilities for different levels of government to further develop ecological taxation, mainly consist of a further internalization of relevant environmental purposes into the existing tax code. More specifically, possibilities entail the ecological differentiation of tax rates, a broadening of tax bases and the inclusion or exemption of particullar tax provisions. In addition, possibilities entail a revenue neutral introduction and use of supplementary environmentally relevant levies, e.g. in relation to those environmental problems for which these governments already bear particular policy responsibilities. For different levels of government in 
this country, the actual introduction of these options depends on the associated costs: The latter include costs in terms of undesirable economic and income redistribution effects and the costs that are associated with the assignment or changes of tax laws that are necessary for a further development of ecological taxation.

The analysis in chapter 9 also shows that although, in principle, the potential for sub national governments to further develop ecological taxation is relatively high, the actual role that can be played by these governments in the process of further developing this type of taxation is restricted. Under the current double dividend approach, restrictions are mainly provided by the existing administrative or intergovernmental structures in this country. These structures are among others marked by a close adherence to the equivalence principle. In addition, sub national governments face particular disincentives under the current structures and approach, in the sense that central government grants can be reduced once new local or regional environmental taxes are introduced.

Given the theoretical potential but actual restrictions for sub national governments to further develop ecological taxation under the current double dividend approach and status quo structures, in chapter 10 , it is analyzed whether an ecological concerns approach can offer more opportunities in this respect. More specifically, in this chapter, several possibilities and problems of further developing ecological taxation alongside the horizontal dimension are analyzed. From the analysis in this chapter it follows that, since only the imposition of water authorities by water boards closely reflects the idea of ecological tax units, the development of ecological taxation towards stages of the afore mentioned horizontal dimension, requires institutional changes and a further enhancing of the possibilities for different jurisdictions to cooperate with each other. Although, in theory, starting points for the idea of ecological tax units in the Netherlands are provided by the adjudication of taxing powers to relevant environmental regions (ground water and soil protection regions) and the establishment of functional environmental boards (e.g. manure boards), the creation and stimulation of co-ordinated intergovernmental environmental policy arrangements seems to present one of the most viable options by which ecological taxation can be further developed in the direction of this idea. From the analysis in chapter 10, it also follows that relatively small sized jurisdictions (e.g. sub national governments) can fullfil a role in the process of relating organizational structures and taxation to relevant interjurisdictional, national and transnational environmental circumstances. The latter, as was previously argued, is extremely significant for the minimization of ecological leakages and thus for the ecological effectiveness and feasibility of this type of taxation.

\section{The feasibility of ecological taxation and policy implications}

In conclusion it can be stated that this study shows that the feasibility of ecological taxation can only be determined on the basis of a case by case approach. This means that the viability of this type of taxation can only be determined, separately, for each 
decision making unit and for each (type of) ecological tax. For each decision making unit and for separate taxes, the introduction of (additional) realistic ecological tax policy options strongly depends on the current stage of development alongside the vertical and horizontal dimension, and on the institutional, administrative and fiscal structures into which these (additional) options are embedded.

Under the current double dividend approach, which strongly adheres to existing institutional structures for ecological taxation, policy makers can be expected to opt for the introduction of ecological taxes that have a clear fiscal purpose. These include ordinary revenue raising taxes and taxes that are used to fund specific environmental expenditures. To further develop ecological taxation under the current double dividend approach, policy makers have to be aware of the fact that they can only gradually develop ecological taxation and only in close relationship to existing fiscal structures. The development of ecological taxation, under this approach, likely entails a further incorporation of ecological purposes into the existing tax code. To be able to do this, policy makers have to design and introduce taxes that provide a stable balance between the fiscal and steering effects of these taxes. Given the purpose of finding taxes that provide such a balance, it can be expected that policy makers opt for the introduction of ecological taxes that have a relatively small tax base and/or relatively high tax rates.

Under alternative ecological concerns approaches, which strongly adhere to fiscal and institutional structures that are constituted on the basis of purely ecological concerns, policy makers can be expected to opt for the introduction of taxes that have a clear ecological purpose. These include Pigouvian taxes, tax provisions and the taxes that are set by ecological tax units. To further develop ecological taxation under the alternative ecological concerns approaches, policy makers have to be aware of the drastic changes that have to be made in order to be able to conduct feasible ecological tax policies. After relevant constitutional changes have been made, the development of ecological taxation, under this approach, likely entails a further introduction of earmarked environmental taxes and of taxes that are imposed on the consumption of private goods that are tied to the consumption of the public good in question. To be able to introduce such taxes, policy makers have to design and introduce those types of taxes that entail a clear relationship between the tax payment and the provisions provided by potential tax revenues. In order to constitute such a relationship, it can be expected that policy makers opt for the imposition of earmarked types of taxes on a restricted set of goods and a restricted set of the population (e.g. those within an environmental protection region).

In the Netherlands, ecological tax policies have mainly been conducted on the basis of a double dividend approach. Within the context of this approach, ordinary revenue raising taxes and earmarked environmental taxes have been introduced. To further develop ecological taxation, policy makers in this country have to be aware of the potential role that can be played by sub national governments. To make use of this role, policy makers have to allow these governments the possibilities to further incorporate environmental policies into their tax code, to broaden existing tax bases 
and to ecologically differentiate tax rates. In addition, to make use of this role, policy makers also have to incorporate these different possibilities into currently conducted policies, preferably region oriented environmental policies and policies that are associated with intergovernmental co-operation arrangements.

In conclusion, it can then be stated that, other than in most studies on the subject, the analysis of ecological taxation in this study shows that, for the actual development of feasible ecological taxes, policy makers can choose between a gradual and a drastic ecological tax policy approach. Although the types of ecological taxes and their design differ per approach, this study also shows that the use of tax provisions and earmarked taxes and the incorporation of ecological tax policies into region oriented policies and policies on interjurisdictional co-operation arrangements, are important elements for the practical feasibility of ecological taxation under both approaches. This study also shows that, generally and in relation to the specific case of the Netherlands, relatively small sized jurisdictions can play a rolle in the further development of feasible ecological taxes.

\subsection{Concluding remarks}

The implications for ecological tax policies that follow from the conclusions and analysis in this study are closely related to the assumptions and the analytical framework employed in the study. One of the main assumptions is the a priori assumption that governments have already decided to use ecological taxes for particular purposes. One of the basic elements of the analytical framework is the qualitative analytical approach of the general research questions.

Those who criticize the a priori assumption that governments have already decided to use ecological taxation for particular purposes, can argue that the relatively intensive use of ordinary command and control instruments for environmental policy in practice does not seem to depict the validity of this assumption. Moreover, it can be argued that, assuming that governments have already decided to employ these instruments, the analysis has assumed away one of the pressing problems in actual environmental policy making, i.e. the choice between different policy instruments. In addition, it can be argued that, under this assumption, the analysis does not take into consideration the possibility that a combination of environmental policy instruments (e.g. tax instruments combined with non tax instruments) can be a more practicable and thus feasible policy option for actual environmental policy making. In response to the first argument it can be stated that, although the actual use of command and control instruments is relatively intensive in comparison to the use of tax instruments, the role of the latter instruments can be expected to become more significant for actual environmental policy making in the near future. This is due, among others, to increasing environmental problems and the recognition that existing command and control instruments seem ineffective. Moreover, it can be stated, in response to this and the second argument, that the current relatively intensive use of command and control instruments does not make the asserted assumption less valid. In fact, it can 
even be stated that this study can provide particular explanations for the fact that, although there is a growing intention to use particular types of taxes and tax reforms for environmental purposes, the actual introduction of these taxes may be restricted if they can not be embedded into the proper institutional, constitutional and fiscal structures. In response to the third argument, it has to be recognized that combinations of different environmental policy instruments have not explicitly been taken into consideration in this study. Implicitly, however, it has been indicated that, under double dividend approaches and alongside the vertical development dimension, the viability of ecological taxes demands them to be closely connected to existing institutional, environmental policy, fiscal and other relevant structures. Within the context of the $\mathrm{EC}$ approaches, the use of ecological tax provisions in current (business) income taxes provides another example of tax instruments that are emphasized in this study and that are combined with particular elements from existing structures. The inclusion of a more explicit comparative analysis of tax and non tax environmental instruments into future feasibility analyses of ecological taxes, however, could provide further information on the relative viability, ecological effectiveness and the acceptability of these taxes.

In this study, the feasibility of ecological taxation has been analyzed by way of a qualitative analysis. Most studies about the feasibility of ecological taxation are set up in quantitative ways. Generally, these studies assess the effects and the possible impact of ecological taxes on the basis of a particular model (e.g. as developed by the Central Planning Bureau) and a given set of data. The latter set generally consists of data on current behaviour as expressed in particular coefficients, elasticities etc. The main problem with these coefficients etc., however, is that they can only indicate the current status quo but can not express structural behavioural or innovative changes. These changes however are intrinsic to ecological taxes that are imposed in close connection to relevant ecological circumstances and to taxes that are connected directly to a point of choice, i.e. a moment of decision (see Buchanan, 1969). Given the problems of assessing these changes under approaches that proceed on the basis of the current set of data, a study about the feasibility of ecological taxes that are apt to change people's behaviour significantly in ways that cannot yet be known, is difficult if not impossible to set up in quantitative ways. Since the current set of data is irrelevant for a feasibility study of ecological taxes that are aimed at stimulating structural behavioural or innovative changes, case studies are generally necessary to provide the relevant data by which it is possible to conduct such an analysis. In this respect, in this study, the feasibility of ecological taxes has been analyzed within the specific case of the Netherlands. An analysis of the development of ecologically relevant taxes by sub national governments in this country has been conducted, in order to illustrate the possibilities and intricacies that are associated with the imposition of taxes that are closely related to ecological units. By further extending approaches by which it is possible to assess the feasibility of structural behavioural and innovative changes that arise from the imposition of ecological taxes, additional information can be gathered on the viability, ecological effectiveness and the acceptability of ecologically relevant 
taxes. Such approaches can also provide further information on the changes in relevant institutional structures that are necessary to introduce feasible types of these taxes in practice. The constitutional political economic approach presented in this study can serve as a starting point for such approaches. 


\section{References}

Aalders, M.V.C., van et al. (red.) (1993/1994), Miliewoorschriften, 's-Gravenhage: Delwel Uitgeverij B.V., 1993/94, Band 3 (le druk: 1981).

Adar, Z. \& J.M. Griffin, (1976), Uncertainty and the Choice of Pollution Control Instruments, Journal of Environmental Economics and Management, 3 (3), October, pp. 178-188 (as published in Oates (red.), 1992, pp. 132-142)

Andersen, M.S. (1993), Governance by Green Taxes. Making Pollution Prevention Pay, paper presented at the conference "Setting, Operating and Enforcement of Environmental Policy Standards", organized by the Institute for Transnational and Legal Research of the University of Limburg (METRO) and the Centre for Law Enforcement and European Integration of the University of Utrecht, Maastricht: December 3-4, 1993.

Andriessen, J.E., S. Miedema, C.J. Oort en W.J. Ridder (1991), De sociaal-economische besturing van Nederland, Groningen: Noordhoff (le druk: 1963).

Backes, C. et al. (1992), Gebiedsgericht milieubeleid, rapport van de werkgroep gebiedsgericht millieubeleid, Vereniging voor milieurecht, Zwolle: W.E.J. Tjeenk Willink.

Backhaus, J.G. \& J.J. Krabbe (1988), Henry George's Theory and an Application to Industrial Siting, International Joumal of Social Economics, 15(3/4), pp. 103-119.

Backhaus, J.G. (1991a), Henry George and the Environment, Joumal of the History of Economic Thought, Spring, pp. 90-98.

Backhaus, J.G. (1991b), "The Eco-Tax" (Umwelt und offentliche Haushalte: Die Umweltsteuer und ihre Alternativen), in: Jürgen Wahl (hrsg.), Stewerpolitik vor newen Aufgaben, Regensburg, 1991, pp. 195-203.

Backhaus, J.G. (1992), The State as a Club: A Perspective for Public Finance in a Prosperous Democracy, Economia delle scelte pubbliche, 1, pp. 3-16.

Backhaus J.G. (1993), In Pursuit of Utopia? The Quest for Ecological Tax Reform, Paper presented at a session on Georgist Perspectives on the Environment during the COPE meetings in Paris, January, 1993.

Backhaus, J.G. (1994), Subsidiarity and Ecologically Based Taxation: Aspirations and Options, Paper, Maastricht: University of Limburg.

Backhaus, J.G. \& A.T.G. Paulus (1991), De ecotax: mogelijk, maar ingewikkeld, Maandschriff Economie, tijdschrift voor algemeen- en sociaal economische vraagstukken, Jaargang 55 , no. 5, pp. 356-370.

Backhaus, J.G. \& A.T.G. Paulus (1993), Ecotaxes as an Instrument for an Effective Environmental Land Use Policy: A View from the Netherlands, in: Leeuw, A. de \& H. Priemus (Eds.), Bodenpolitik und Infrastruktur, Studies of the European Faculty of Land Use and Dewelopment, Bonn, Frankfurt, New York: Lang, Vol. 18, pp. 1-28.

Bakker, L. \& A. Bleijenberg (1991), Brandstofheffing en inkomensverdeling, Delft: Centrum voor Energiebesparing en Schone Technologie. 
Bator, F.M. (1958), The Anatomy of Market Failure, Quarterly Journat of Economics, LXXII (August), pp. 351-379.

Baumol, W.J. \& W.E. Oates (1971), The Use of Standards and Prices for Protection of the Environment, Swedish Journal of Economics, March, pp. 42-54.

Baumol, W.J. \& W.E. Oates (1988), The Theory of Environmental Policy, Cambridge: Cambridge University Press, Second Edition (First Edition: 1975).

Becker, U. (1991), Der Gestaltungsspielraum der EG-Mitgliedstaaten im Spannungsfeld zwischen Umweltschutz und freiem Warenwerkehr, Baden-Baden: Nomos Verlagsgesellschaft.

Belastingwetten: 1994, met een inleiding van Ch.P.A. Geppaart, Kluwers Wetboeken en Wetten, no. 3, Deventer: KJuwer, 25e druk (1e druk: 1969, 23e druk: 1992, 24e druk: 1993).

Benham, F.C. (1934), Notes on the Pure Theory of Public Finance, Economica, Vol. I, pp. 436-458.

Benkert W., J. Bunde \& B. Hansjürgens (1990), Umweltpolitik mit Ökosteuern? Ökologische und finanzpolitische Bedingungen fir neue Umweltabgaben, Marburg: Metropolis.

Bennett, R.J. (1980), The Geography of Public Finance: Welfare under Fiscal Federalism and Local Government Finance, London and New York: Methuen.

Bergmann, E. \& D. Ewringmann (1989), Öko-steuern: Entwicklung, Ansatzpunkte und Bewertung, in: Nutzinger \& Zahrnt (Hrsg.) (1989), Okostewern. Umweltsteuer und-Abgaben in der Diskussion, Karlsruhe: Veriag C.F. Müller, pp، 43-73.

Bij, van der J., C.G.M. van Oosteren \& H. de Groot (1994), Milieuleges voor bedrijven, Den Haag: IOO, Onderzoeksreeks nr. 55.

Boele, J. et al.; E.P.J. Wasch. (eindred.) (1992), Hoofdzaken milieuheffingen, Deventer: FED, tweede gewijzigde druk (le druk: 1990), Fiscale studieserie nr. 27.

Boele, J. et al. (1994), Hoofdzaken milieuheffingen, Deventer: Fed, 3e geheel herz. druk.

Bohm, P. \& C.S. Russell (1985), Comparative Analysis of Alternative Policy Instruments, in: Kneese, A.V. J.L. Sweeney (eds.), Handbook of Natural Resource and Energy Economics, North-Holland: Elseviers Science Publishers B.V., Vol. 1, 1985, pp. 395-460.

Bovenberg, A.L., M.E.T. van den Broek, R.J. Mulder (1991), Instrumentkeuze in het milieubelerd, Den Hilag: Ministerie van Economische Zaken, Directie Algemene Economische Politiek, Discussienota 9102.

Bovenberg, A.L. \& R. de Mooij (1993), Do Environmental Taxes yield a Double Dividend?, Rotterdam: Erasmus University Rotterdam, Research Centre for Economic Policy (OCFEB), Research Memorandum 9302.

Brennan, G. \& J.M Buchanan (1980), The Power to Tax. Analytical Foundations of a Fiscal Constiturion, Cambridge: Cambridge University Press. 
Brennan, G. \& J.M. Buchanan (1985), The Reason of Rules. Constitutional Political Economy, Cambridge: Cambridge University Press.

Bressers, J.Th.A. (1983), Beleidseffektiviteit en waterkwaliteitsbeleid: een bestuwrskundig onderzoek, Enschede: Sneldruk Boulevard (Proefschrift Enschede).

Brooks, M.A. \& B.J. Heijdra (1987), Rent-Seeking and Pollution Taxation: An Extension, Southerm Economic Joumal, 54(2), October, pp. 335-342.

Buchanan, J.M. (1959), Positive Economics, Welfare Economics, and Political Economy, The Joumal of Law and Economics, Voll II, pp. 124-138.

Buchanan, J.M. (1963), The Economics of Earmarked Taxes, Journal of Political Economy, pp. 457469.

Buchanan, J.M. (1965), An Economic Theory of Clubs, Economica, 32, pp. 1-14.

Buchanan, I.M. (1969), Cost and Choice. An Inquiry in Economic Theory, Chicago: University of Chicago Press.

Buchanan, J.M. and G. Tullock (1962), The Calculus of Consent: Logical Foundations of Constitutional Democracy, Ann Arbor, Mich: University of Michigan Press.

Buchanan, J.M. (1975), The Limits of Liberty. Between Anarchy and Leviathan. Chicago: University of Chicago Press.

Burrows, P. (1979), The Economic Theory of Pollution Control, Guildford: Billings and Sons Limited.

BZW/MICON, Brabants-Zeeuwse Werkgeversvereniging (1993), De onzichtbare hand: deel 2, Eindrapportage impactanalyse van milieubelastingen en -retributies wanwege lagere overheden op her bedrijfsleven, MICON milieu-adviesgroep, Oktober 1993.

Cansier, D. (1988), Öffentliche Finanzen im Dienst der Umweltpolitik. Neuere theoretische Ansätze, in: Schmidt, C. (Hrsg.), Offentliche Finanzen und Umweltpolitik 1, Berlin: Duncker \& Humblot, pp. 11.50 .

CBS, Centraal bureau voor de statistiek (1991), Kosten en financiering van het milieubeheer 19871988, Voorburg/Heerlen: CBS.

CBS, Centraal bureau voor de statistiek (1992a), Statistiek der waterschapsfinanciën. Rekeningen 1990, Voorburg/Heerlen: CBS.

CBS, Centraal bureau voor de statistiek (1992b), Kosten en financiering wan het milleubeheer 1989, door E.J. Dietz, Kwartaalbericht milieu, Voorburg/Heerlen: CBS.

Cnossen, S. \& H. Vollebergh (1991). Towards a Global Excise on Carbon, OCFEB: reprint 9201 [also: overdr. uit National Tax Journal, Vol. 45, 1992]. 
Coase, R.H. (1960), The Problem of Sociall Cost, The Journal of Law and Economics, October, pp. $1-44$.

Coase, R.H. (1992), The Institutional Structure of Production, The American Economic Review, Septeriber, pp. 713-719.

Common, M. (1988), Enwironmental and Resource Economics: an Introduction, London: Longman (Longman Economics Series).

Commissie de Kam (1992), Commissie verruiming eigen middelen lagere overheden, voorz.: C.A. de Kam (Commissie-De Kam), Belastingen omladg, rapport van de commissie verruiming eigen middelen van lagere overheden, Den Haag: Ministerie van Binnenlandse Zaken.

Commissie Christiaanse (1983), Commissie tot herziening van het belastinggebied van provincies en gemeenten, voorw. door J.H. Christiaanse (Commissie Christiaanse), Rapport inzake de herziening wan het belastinggebied van provincies en gemeenten, 's-Gravenhage: Ministerie van Binnenlandse Zaken: Staatsuitgeverij.

Commissie Haks (1990), Rapport Werkgroep alternatieve provinciale belastingbronnen, Den Haag: Ministerie van Binnenlandse Zaken.

Comes, R. \& T. Sandler (1986), The Theory of Externalities, Public Goods and Club Goods, Cambridge (etc.): Cambridge University Press.

Cropper, M.L. \& W.E. Oates (1992), Environmental Economies: A Survey, Journal of Economic Literoture, Vol XXX (June), pp. 675-740.

Cullis, J.G. \& P.R. Jones (1994), Public Finance and Public Choice: Analytical Perspectives, London: McGraw Hill.

Delbeke, J. (1993), Het Europese milieubeleid, in: Taselaar, H. R. Wit, P. van Driel (ed.) (1993), Naar een Europese Ecotax. Het voorbeeld van de energieheffing, Amsterdam: Wiardi Beckman Stichting, Anne Vondeling Stichting/PvdA-Eurodelegatie.

Demsetz, H. (1970), The Private Production of Public Goods, The Joumal of Law and Economics, Vol. 13, October, pp. 293-306.

Dewees, D.N. (1983), Instrument Choice in Environmental Policy, Economic Inquiry, Vol. XXI (1), January, pp. $53-71$.

DHV/VROM (1992), Buitenlandse ervaringen met financiele instrumenten in het milieubeleid, Amsterdam: VU; Amersfoort: DHV Milieu en Infrastructuur B.V.

Downing, P.B.(1984), Environmental Economics and Policy, Boston: Little, Brown and Co.

Downing, P.B. \& W.D. Watson, Jr. (1974), The Economics of Enforcing Air Pollution Controls, Journal of Envirommental Economics and Management, 1, (3), November, 219-36 (As published in Oates, 1992, pp. 507-524). 
Dragun, A.K. (1985), Property Rights and Pigovian Taxes, Jowrnal of Economic lssies, Vol. XIX, Number 1, March, pp. 111-122.

Driel, P. van (red.) (1992), Ecotaxaties, eem debat over regulerende heffingen op energie, verslag van een studiedag naar aanleiding van het rapport van de commissie Wolfson d.d. 27 februari 1992.

Drupsteen. Th.G. (1991), Milieurecht, in: Boersema, J.J. (eindred.), J.W. Copius Peereboom \& W.T. de Groot (red.), Basisboek Milieukunde, Meppel: Boom, 4e geheel herziene druk.

Duchateau, N.C. \& K.J. Lok (1993), De gemeente verkend, Leiden etc: Stenfert Kroese, 1993 (le druk, 1986).

Europees Parlement (1990), Ecotax, een inleiding in de Ecotax, Brussel: Europees Parlement, Green Papers 1, 15-16 November, 1990.

Ewringmann, D. (1990), Finanzpolitische Probleme, in: Nutzinger, H. \&. A. Zahrnt (Hrsg.) (1990), Für eine Ökologische Stewerreform. Energiesteuern als Instrumente der Umweltpolitik, Frankfurt am Main: Fischer Taschenbuch Verlages.

Faber, M. \& P. Michaelis (1989), Ändenung der Produktions- und Verbrauchsweise durch Umweltabgaben am Beispiel der Abfall-Wirtschaft, in: Nutzinger, H. \& A. Zahrnt (Hrsg.) (1989), Ökosteuern. Umweltsteuer und -Abgaben in der Diskussion, Karlsruhe: Verlag C.F. Müler.

Feijtel, J. (1993), Samenhang in drievoud, in: Groot, de H. \& J.A.A. Poppelaars (red.), Financiële verhouding in samenhang, Den Haag: 100 , September, Onderzoeksreeks nr. 50.

Frey, B.R. \& R. Eichenberger (1994), A single european market for governments - the idea of FOCI, University of Zurich, preliminary version, April 18, 1994.

Gaines, S.E. \& R.A. Westin (eds.) (1991), Taxation for Environmental Protection, New York etc.: Quorum Books.

Gawel, E. (1991), Umweltpolitik durch gemischten Instrumenteneinsatz. Allokative Effekte instrumen tell diversifizierter Lenkwngsstrategien für Umweltgüter, Berlin: Duncker \& Humblot.

George, H. (1879), Progress and Poverty, An Inquiry into the Cause of Industrial Depressions and Increase of Want with Increase of Wealth......The Remedy, San Fransisco, (Author's Proof edition); New York: Appleton (1880); New York: Schalkenbach Foundation (1979) (Centennial Edition).

Gieskes, J.G.E. (1993), Precariorechten en reclamebelasting, Serie Belastingminiaturen 3, Deventer: FED.

Goulder, L.H (1994), Environmental Taxation and the "Double Dividend:" A Reader's Guide, Cambridge Massachusetts: NBER, Working Paper No. 4896.

Groen Links (1990), Grenzen aan de chloor, met een chloortax op weg naar een duurzame chemic, November, Den Haag: Tweede-Kamerfractie Groen Links. 
Groen Links (1991), Op weg naar een groene belastingheffing. Een voorstel om een begin te maken met ecologische belastingheffing ten gunste van milieu en werkgelegenheid, Oktober, Den Haag: Tweede-Kamerfractie Groen Links.

Groen Links (1992), Op weg naar een groene belastingheffing II. Een eerste stap op weg naar ecologisering wan de Belasting Toegevoegde Waarde (BTW) ten gumste van miliew en werkgelegenheid, Oktober, Den Haag: Tweede-Kamerfractie Groen Links.

Groot, de H. \& J.A.A. Poppelaars (red.) (1993), Financiële verhouding in samenhang, Den Haag: 100, September, Onderzoeksreeks nr. 50 .

Hagem, C. (1994), Cost-effective climate policy in a small country, Oslo (Norway): CICERO, Center for Climate and Energy Research (Forthcoming in the Energy Joumal).

Hahn, R.W. (1989), Economic Prescriptions for Enwironmental Problems: How the Patient Followed the Doctor's Orders, Joumal of Economic Perspectives, Volume 3, Number 2, Spring 1989, pp. 95114 (as published in Oates; 1992, p. 279-298)

Hamilton, J.H., E. Sheshinski \& S.M. Slutsky (1989), Production Externalities and Long-run Equilibria: Bargaining and Pigovian Taxation, Economic Inquiry, Vol. XXVII, July, pp. 453-471.

Hansjürgens, B. (1992), Umweltabgaben im Steuersystem. Zu den Möglichkeiten einer Einführung van Unwweltabgaben in das Steuer- und Abgabensystem der Bundesrepwblik Deutschland, BadenBaden: Nomos Verlaggesellschaft.

Harford, J.D. (1978), Firm Behavior Under Imperfectly Enforceable Pollution Standards and Taxes, Journal of Environmental Economics and Management, 5 (1), March, 26-43 (as published in Oates, 1992, pp. 525-542)

Harrington, W. (1988), Enforcement Leverage When Penalties Are Restricted, Journal of Public Economics, 37, October, 29-53 (as published in Oates, 1992 pp. 543-567).

Havekes, H.J.M. et al. (1991), Het waterschap in kort bestek, uitgegeven in samenwerking met de Unie van Waterschappen, 1991/1992, 's-Gravenhage: VUGA Uitgeverij, 3e druk (1e druk, 1987).

Hayek, F.A. (1945), The Use of Knowledge in Society, American Economic Review, XXXV, No. 4 (September), pp. $519-530$

Heaps, T. \& J.F. Helliwel (1985), The Taxation of Natural Resources, in: A.J. Auerbach \& M. Feldstein (eds.), Handbook of Public Economics, Volume 1, North Holland: Elseviers Science Publishers B.V, 1985, pp. 421-472.

Hoek, van der M.P. (1991), Local Taxation in the Netherlands, Public Budgeting and Finance, Spring, Volume 11, Number 1, pp. 66-79.

Hoel, M. (1992), The Role and Design of a Carbon Tax in an International Climate Agreement, in: OECD Documents (1992), Climate Change: Designing a Practical Tax System, Paris: OECD, pp. 101-116. 
Hueting, R. (1974), Nieuwe schaarste en economische groei. Meer welwaart door minder produktie?, Amsterdam Brussel: Agon Elsevier.

Hueting, R., P. Bosch \& B. de Boer (1992), Methodology for the calculation of sustainable national income, statistische onderzoekingen, M44, Voorburg: CBS.

Huppes G., E. van der Voet, W. van der Naald, P. Maxson, G. Vonkeman (1992), New Market Oriented Instruments for Environmental Policies, European Communities, Environmental Policy Series, London: Graham and Totman Limited.

lerland, E.C. van (1993), Macroeconomic analysis of environmental policy, Amsterdam: Elsevier.

Ilsink, J.W. (1990), Belastingen en milieu, in: Simons, A.L.C. (1990), Belastingen en milheu, Serie Belastingconsulentendagen, nr. 35 Deventer: FED.

Ilsink, J.W. \& J. Schuurman (1991), Schematisch overzicht van de Nederlandse belastingen, Deventer: Kluwer, $25 \mathrm{e}$ druk.

Imman, R.P. (1987), "Markets, Governments, and the "New" Political Economy", in: Auerbach, A.J. \& M. Feldstein (eds.), Handbook of Public Economics, Volume II, North-Holland: Elseviers Science Publishers BV, pp. 647-777.

Intentieprogramma Bodembescherming Limburg (1991), Maastricht: Provincie Limburg, 2 dln.

Jaeger, F. (1993), Natur and Wirtschaft. Ökonomische Grundlagen einer Politik des qualitativen Wachstums, Chur/Zürich: Verlag Rüegger AG.

Kemper, M. (1989), Das Umweltproblem in der Marktwirtschaft. Wirtschaftstheoretische Grundlagen und vergleichende Analyse umweltpolitischer Instrumente in der Luftreinhalte- und Gewässerschutzpolitik, Vollkswirtschaftliche Schriften, Heft 390, Berlin: Duncker \& Humblot, Zweite, unveränd. Aufl.

Kntippel, H. (1989), Umweltpolitische Instrumente. Analyse der Bewertungskriterien und Aspekte einer Bewertung, Friedrich-Naumann-Stiftung, Wissenschaftliche Reihe, Baden-Baden: Nomos Verlaggesellschaft.

Koopmans, L., A.H.E.M. Wellink, H.J. Woltjer \& C.A. de Kam (1991), Overheidsfinanciën, Leiden (etc.): Stenfert Kroese, 7e geheel herz. druk.

Korff, A.J. (1993), Maatschappelijke samenhang en de financiëlle verhouding, in: Groot, de H. \& J.A.A. Poppelaars (red.), Financiele verhouding in samenhang, Den Haag: IOO, September, Onderzoeksreeks nr. 50 .

Krabbe, J.J. and W.J.M. Heijman (1986), Economische theorie van het miliew, Assen: van Grorcum.

Lee, D.R. (1985), Rent-Seeking and its Implications for Pollution Taxation, Southern Economic Journal, 51 (3), January, pp. 731-744.

LMO (1988), Milieu, incl. BTW, Utrecht: Uitgave Landelijk Milieu-overleg. 
Luhmann, H.-J. (1994), Okologusche Stewerreform auf dem Weg zur Wirklichkeit. Zwei Fliegen mit einer Klappe schlagen, Wuppertal: Wuppertal Institute, August (Forthcoming in: "Das Parlament").

Man, G. de et al (1987), Economie wan de collectieve sector 1. Cursusdl. 6: Blok 6: De financién van de lagere overheden: leereenheden 33-40 (A..). Modderkolk), Heerlen.: Open Universiteit.

Marshall, A. (1969), Principles of Economics, London: MacMillan, 8th Edition (First Edition: 1890).

Mauch, S.P., R. Iten, E.U. von Weizsaicker \& J. Jesinghaus (1992), Okologische Steuerreform, Europäische Ebene und Fallbeispiel Schweiz, Chur/Zürich: Verlag Rüegger.

Meadows, D.L. (1972), The Limits to Growth, a Report for the Chub of Rome Project on the Predicament of Mankind, New York: Universe Books.

Meadows, D.L. \& D. Meadows \& J. Randers (1992), De Grenzen Voorbij - Een wereldwijde cata* strofe of een duwrzame wereld, Spectrum/Aula.

Mercuro, N. (1992), Ecology, Law and Economics: The Simple Analytics of Environmental Economics, University of New Orleans: draft paper.

Mierlo, J.G.A. van \& F.K.M. Nispen (1991), Mirror, Mirror on the Wall. Who is the Fairest of them All or Why so Many Public Policies designed to tackle Environmental Problems have failed so far, in: Kraan, D.J. \& R.J. in 't Veld (eds.), Environmental Protection: Public or Private Choice, Dordrecht: Kluwer Academic Publishers, pp. 207-219.

Mishan, E.J. (1968), The Costs of Economic Growth, London: Staple Press, 2nd Edition (First Edition: 1967).

Morgenstern, R.D. (1991), Toward a Comprehensive Approach to Global Climate Change Mitigation, American Economic Review, AEA Papers and Proceedings, Vol. 81 No 2, May, pp. 140-145.

Mueller, D.C. (1989), Public Choice II, Cambridge (etc.): Cambridge University Press, rev, ed.

Mueller, D.C. (1990), James M, Buchanan: Economist cum Contractarian, Constitutional Political Economy, Vol. 1, No. 2, pp. 169-196.

Musgrave, P.B. \& R. Musgrave (1984), Public Finance in Theory and Practice, New York: McGraw Hill, 4th ed. (First Edition: 1973).

Musgrave, R.A. (1985), A Brief History of Fiscal Doctrine in: Auerbach, A.J. \& M. Feldstein (eds.), Handbook of Public Economics, Vol. I, North-Holland: Elseviers Science Publishers B.V., pp. 1-59.

Musgrave, R.A. \& A.T. Peacock (eds.) (1958), Classics in the Theory of Public Finance, London: Macmillan.

Nentjes, A. \& J.L. de Vries (red.) (1990), Financiele instrumenten voor het Nederlandse milieubeleid, Utrecht: LMO. 
Nutzinger, H. \& A. Zahmt (Hrsg.) (1989), Okostewerm. Umweltstewer wnd-Abgaben in der Diskussion, Karlsruhe: Verlag C.F. Müller.

Nutzinger, H. \& A. Zahrnt (Hrsg) (1990), Fü eine Okologische Stewerreform. Energiesteuern als Instrwnente der Umweltpolitik, Frankfurt am Main: Fischer Taschenbuch Verlages.

Oakland, W.H. (1987), Theory of Public Goods, in: A.J. Auerbach \& M. Feldstein, Handbook of Public Economics, Volume 2, North-Holland: Elseviers Science Publishers B.V., 1987, pp. 485-535.

Oates, W.E. (1972). Fiscal Federalism, New York: Harcourt, Brace \& Co.

Oates, W.E. (ed.) (1992), The Economics of the Environment, Aldershot: Edward Elgar Publishing Limited (An Elgar Reference Collection)

Oates, W.E. (1994), Environment and Taxation: The Case of the United States, in: OECD Documents, Environment and Taxation: The Cases of the Netherlands, Sweden and the United States, Paris: OECD.

Oates, W.E. \& R.M. Schwab (1988), Economic Competition Among Jurisdictions: Efficiency Enhancing or Distortion Inducing?, Joumal of Public Economics, 35, April, pp. 333-354.

OECD (1993a), Taxation and the Environment. Complementary Policies, Paris: Cedex.

OECD (1993b), Group on economic and environmental policy integration, Integrating environment and economics, Paris: drafted: 24 May 1993.

OECD Documents (1992), Climate Change: Designing a Practical Tax System, Paris: OECD.

Oosterhuis, F.H. and A.F. de Savornin Lohman (1994), Environment and Taxation: The Case of the Netherlands, in: OECD Documents, Environment and Taxation: The Cases of the Netherlands, Sweden and the Unired States, OECD: Paris, 1994, pp. 7-50.

Opschoor, J.B. \& B.V. Vos (1989), The Application of Economic Instruments for Environmental Protection in OECD Member Countries, OECD: Paris.

Paulus, A.T.G. (1993a), Environmental Policy, Environmental Policy Instruments and Ecological Tax Reform, Mastricht: University of Limburg, Working Paper, nr. 93.003.

Paulus, A.T.G. (1993b), Passibilities of Using Taxes for Environmental Policy Purposes, Maastricht: University of Limburg, Research Memorandum, nr. 93-063.

Paulus, A.T.G. (1993c), Ecological Taxes and Ecological Tax Refom, Change, Research and Policy Newsletter on Global Change from the Netherlands, 16, October 1993, pp. 16 17.

Paulus, A.T.G. (1994a), Ecological Taxation, Concept End Report of NOP research project 850151 $E$ : "The Feasibility of Ecological Taxation in the Netherlands", Maastricht: University of Limburg.

Paulus, A.T.G. (1994b), Ecological Taxation in the Netherlands, Maastricht: University of Limburg, Research Memorandum 0/94-052. 
Paulus, A.T.G. (1994c), The Imposition of Ecological Taxation: The Concept of Ecological Tax Units, Maastricht: University of Limburg. Research Memorandum 0/94-053.

Paulus, A.T.G. (1994d), Ecological Taxation and Global Climate Change: an Mustrative Example, Maastricht" University of Limburg, Working Paper 0/94-009.

Paulus, A.T.G. (1994e), The Institutional, Fiscal and Environmental Policy Framework for Ecological Towation in the Netherlands, Maastricht: University of Limburg: Working Paper 0/94-010.

Paulus, A.T.G. (1994f), Ecological Toxation by Sub National Government Bodies in the Netherlands: Policy Recommendations, Possibilities and Complexities, Maastricht: University of Limburg. Working Paper 0/94011.

Paulus, A.T.G. (1994g), Possibilities of Using Taxes for Ecological Purposes, in: Faure M., J. Vervaele and A. Weale (eds.), Environmental Standards in the European Union in an Interdisciplinary Framework, Antwerpen/Apeldoorn: MAKLU, pp. 155-182.

Paulus, A.T.G. (1995), The Feasibility of Ecological Taxation, in: Climate Change Research: Evaluation and Policy Implications, Proceedings of an International Conference, Maastricht, 6-9 December, 1994 (forthcoming).

Pearce, D. (1991), The Role of Carbon Taxes in Adjusting to Global Warming, The Economic Joumal, July, Vol. 101, no. 407, pp. 938-948.

Pigou, A.C. (1912), Wealth and Welfare, London: Macmilian and Company.

Pigou, A.C. (1946), The Economics of Welfare, London: Macmillan \& Company, 4th Edition (First Edition: 1920).

Pigou, A.C. (1947), Socialism versus Capitalism, London: Macmillan \& Company.

Plante-Faile, M. (1993), Toeristenbelasting, Serie Belastingminiaturen, nr. 7, Deventer: FED.

Poterba, J.M. (1991), Tax Policy to Combat Global Warming: On Designing a Carbon Tax, Cambridge, Massachusetts: National Bureau of Economic Research, Inc. (NBER), Working Paper Series, Working Paper no. 3649.

Poterba, J.M. (1993), Global Warming Policy: A Public Finance Perspective, The Journal of Economic Perspectives, Fall, Volume 7, nr. 4, pp. 47-63.

Raad voor de Gemeentefinanciën (1986), Na een collier de misère: Gelijkwaardigheid. Een zilveren raad over gowden koorden, Publicatie ter gelegenheid van het vijfentwintigjarig bestaan van de Raad voor de Gemeentefinanciên, 's-Gravenhage: Uitgeveriji van de Vereniging van Nederlandse Gemeenten.

RIVM (1988), Zorgen voor morgen. Nationale miliewverkenning 1985-2010, Alphen aan den Rijn: Samson; Zwolle: H.D. Tjeenk Willink. 
Samuelson, P.A. (1954), The Pure Theory of Public Expenditures, Review of Economics and Statistics, $36,387-389$.

Savornin Lohman, A. de (1994), Incentive Charges in Environmental Policies: Why are they White Ravens?, in: Faure M., J. Vervaele and A. Weale (eds.), Environmental Stondards in the European Union in an Interdisciplinary Framework, Antwerpen/Apeldoorn: MAKLU, pp. 117-133.

Schoof, D.J.W. (1991), Concepten en thema's in het milieubeleid, in: Boersema, J.J. (eindred.), J.W. Copius Peereboom \& W.T. de Groot (red.), Basisboek Milieukunde, Meppel: Boom, 4e geheel herziene druk, pp. 456-484.

Schuddeboom, J. (1990), Milieubeleid in de praktijk, Enschede: Universiteit Twente (CBOO).

Schumpeter, J.A. (1953), Die Krise des Steuerstaates, originally in Zeitfragen aus dem Gebiet der Soziologie, 4. Heft. 1918; reprinted in Aufsätze zur Sociology, Tübingen: Mohr/Siebeck, 1953.

Schumpeter, J.A. (1954), History of Economic Analysis, New York: Oxford University Press.

Schuurman, J. (1988). De prijs van water. Een onderzoek naar de aard en omvang van de regwlerende nevenwerking van de verontreinigingsheffing oppervlaktewateren, Arnhem: Gouda Quint B.V.

Schuurman, J. (1990), Ecologische belastingheffing, in: Opstellen aangeboden aan Prof. Mr. J.F.M. Giele, Giele Bundel, Deventer: Kluwer, pp. 603-619.

Schuurman, J. (1992), Milieuheffingen, TMA, L, pp. 1-9.

Second Chamber of the States General (1988/1989), National Environmental Policy Plan (NEPP), Session $1988-1989,21137$, nos. 1-2.

Seerden, R. (1993), Publiekrechtelijke grensoverschrijdende samenwerking tussen decentrale overheden: juridische aspecten van publiekrechtelijke afspraken tussen Nederlandse decentrale overheden en hun "counterparts' in Belgie en Duitsland, Antwerpen/Apeldoorn: Maklu, Baden: Nomos.

SER, Sociaal-Economische Raad (1989a), 'Our Common Furure', Advies, Den Hag: SER, Publicatie nir. 6 .

SER, Sociaal-Economische Raad (1989b), Nationaal Miliewbeleidsplan, Advies, Den Haag: SER, Publicatie nr. 17.

SER, Sociaal-Economische Raad (1990), Nationaal Milieubeleidsplan Plus, Advies, Den Haag: SER, Publicatie nr. 17.

SER, Sociaal-Economische Raad (1991), Economile en Milieu, 's-Gravenhage: SER, rapport 91/18, September 11 .

SERV, Sociaal-Economische Raad van Vlaanderen (1992), Het economisch instrumentarium inzake milieubeleid, studierapport, 30 September, Brussel: SERV. 
Simons, A.L.C. (1990), Serie Belastingconsulentendagen, nr. 35, Belastingen en milieu, Deventer: FED.

Sio, B. (1991), Gemeentelijke belastingen voor bedrijwen, Kluwer: Deventer.

Smith, A. (1971), The Wealth of Nations, London: Dent, I.M. \& Sons Ltd., Volume Two (First Edition: 1776).

Smith, S. \& H. Vollebergh (1993), The European Carbon Excise Proposal: a 'Green' Tax takes Shape, Rotterdam: Erasmus University Rotterdam, OCFEB, Research Centre for Economic Policy, Research Memorandum: 9305 .

Staatscourant (1994), Rijnoeverstaten willen breder Rijnwerdrag, December 9, nr. 238.

Stevens, L.G.M. (1993), Fiscale aspecten van het decentralisatiebeleid, in: Groot, de H. \& J.A.A. Poppelaars (red.), Financiele verhouding in samenhang, September, Onderzoeksreeks nr. 50, Den Haag: 100 .

Stiglitz, J.E. (1986), Economics of the Public Sector, New York: Norton.

Stuurgroep Regulerende Energieheffingen (1992), Een onderzoek war de effecten op energiebesparing en de economie, Eindrapportage, Februari, Den Haag.

Taselaar, H., R. Wit, P. van Driel (red.) (1993), Naar een Europese Ecotcax. Het voorbeeld van de energieheffing, Amsterdam: Whardi Beckman Stichting, Anne Vondeling Stichting/PvdA-Eurodelegatie.

Teufel, D. (1989), Der UPI-Vorschlag für eine ökologische Stenerreform, in: Nutzinger H. \& A. Zahrnt (Hrsg.) (1989), Ökosteuern. Umweltstetuer und-Abgaben in der Diskussion, Karlsruhe: Verlag C.F. Müller.

Tiebout, C.M. (1956), A Pure Theory of Local Expenditures, Joumal of Political Economy, 64, pp. $416-424$.

Tietenberg, T. (1992), Enwirommental and Notural Resource Economics, Glenview: Scott Foresman and Company, 3d Edition (First Edition: 1984).

Tollison, R.D. (1972), Consumption Sharing and Non Exclusion Rules, Economica, August, Vol. 39, pp. 276-291.

Tweede Kamer der Staten Generaal (1974/75), Nota instrumenten milieuhygienisch beleid, heffingen en fysieke reguleringen, Bijlage bij Kamerstukken II 1974/75, Den Haag: nr. 13 100, hoofdstuk XVII, nr. 2.

Tweede Kamer der Staten-Generaal (1979), Nota Milieuheffingen, Bijlage bij de Handelingen, zitting 1978/1979, nr. 15 658, nrs: 1-2, Den Haag: Staatsuitgeverij (Pub1. van het Ministerie van Volksgezondheid en Millieuhygiène). 
Tweede Kamer der Staten Generaal (1984/85), Notitie alrematieve fincuicieringsstelsels, Den Haag: Kamerstukken II, 1984/85, UCV 107.

Tweede Kamer der Staten-Generaal (1989), Nationaal Milieubeleidsplan: kiezen of verliezen (Nationall Environmental Policy Plan), Den Haag: 21 137, nrs. 1-2.

Tweede Kamer der Staten-Generaal (1989/1990), Derde Nota Waterhuishouding: Water voor nu en later: regeringsbeslissing, vergaderjaar 1989/1990, 21 250, nrs. 1-2 (1989), nr. 3 (1990), 's-Gravenhage: SDU Uitgeverij.

Tweede Kamer der Staten-Generaal (1990), Nationaal Milieubeleidsplan-plus (National Environmental Policy Plan-Plus), Den Haag: 21 137, nrs, 20-21.

Tweede Kamer der Staten-Generaal (1990), Actieplan gebiedsgericht miliewbeleid, Den Haag: 21 896, nrs. 1-2.

Tweede Kamer der Staten-Generaal (1992), Financiele Instrumenten in het Miliewbeleid, Den Haag: 22.779 , nr. 1., 4 September 1992.

Tweede Kamer der Staten-Generaal (1993), Nationaal Milieubeleidsplan 2: Milieu als maatstaf (National Environmental Policy Plan 2); Den Haag: 23 560, nrs. 1-2.

Tweede Kamer der Staten-Generaal (1993), Milieuprogramma 1994-1997, Den Haag: 23 405, nrs. 12, 21 September 1993.

Tweede Kamer der Staten-Generaal (1993), Vervolgnota Energiebesparing, vergaderjaar 1993-1994, 23561, 's-Gravenhage: SDU Uitgeverij Plantijnstraat, publ. Ministerie van Economische Zaken, nrs. $1-2$.

Umwelt- und Prognose Institut Heidelberg E.V. (UPI) (1988), Okostewern als marktwirtschaftiches Instruments im Umweltschutz. Vorschläge fiur eine okologische Steuerreform, Oktober, Heidelberg: UPI, 2. ergänzte Auflage.

Vereniging Maastrichtse Juristen voor Milieubehoud/Werkgroep Limburgse Milieuproblematiek (1989), Stand van het Limburgse Leefmiliew, 1989. Proeve van een inventarisatie, beschrinting en juridische analyse van milieuknelpunten in de provincie Limburg, Maastricht: uitg. door Vereniging Maastrichtse Juristen voor Milieubehoud/Werkgroep Limburgse Milieuproblematiek.

Vollebergh, H. (1990), De vervwiler betaalt als bekostigingsbeginsel, Rotterdam: Erasmus University/ Institute for Economic Research: Discussion Paper Series $9007 \mathrm{G} / \mathrm{P}$

Vollebergh, H. (1992a), Energieke energieheffingen gezocht, in. P. van Driel (red.), Ecotaxaties. Een debat over regulerende heffingen op energie, Verslag van een studiedag naar aanleiding van het rapport van de commissie-Wolfson op 27 februari 1992.

Vollebergh, H. (1992b), Het beginsel de verwuiler betaalt en publieke heffingen, Erasmus Universiteit Rotterdam: Onderzoekcentrum voor Financieel Economisch Beleid en Vakgroep Economische Politiek. 
Vollebergh, H.R.J. \& J.L. de Vries (1990), Financiële instrumenten wan het milieubeleid, ESB, September 26, pp. 888-891.

Vollebergh, H., \& J.L. de Vries (1993), Financiele gevolgen wan een regulerend miliewheffingenpakket, Rotterdam: OCFEB [also: reprint Erasmus Universiteit Rotterdam: 9208, overdr. uit Tijdschrift voor politieke economie, Vol. 15, n. 2, 1992].

VROM-ministry, Ministry of Physical Planning, Housing and the Environment, (1992), Nederlands Millewbeleid", "Sravenhage: VROM.

VROM (1992), Ministerie van Volkshuiswesting, Ruimtelijke Ordening en Milieubeheer, DirectoraatGeneraal Milieubeheer, Financiele instrumenten in het afvalstoffenbeleid: ervaringen en mogelijkheden, nr. 1992/6 (Publikatiereeks afvalstoffen).

VROM (1993), Ministerie wan Volkshuisvesting, Ruimtelijke Ordening en Milieubeheer, DirectoraatGeneraal Milieubeheer, Differentiatie van tarieven voor inzameling van huishoudelijk afval, Eindrapport, nr. 1993/9 (Publicatiereeks afvalstoffen).

Wasch, E.P.J. (1979), Het belaste milieu, Fiscale Studieserie, Deventer: FED.

Wasch, E.P.J. (1983), Het belaste milleu. Miliewheffingen in praktijk, Deventer: FED. (Supplement bij le druk van 1979).

Wasch, E.P.J. (red.) (1990), Milieuheffingen, algemeen, in: Boele, J. et al., Hoofdzaken milieuheffingen, Fiscale Studieserie nr. 27, Deventer: FED, hoofdstuk 1.

WCED, World Commission on Environment and Development (1987), Our Common Future, OxfordNew York: Oxford University Press.

Weizsäcker, E.U. von (1988), Some Preliminary Thoughts on an Ecological Tax Reform, Bonn, March 22 (not for publication).

Weizsucker, E.U. von (1989), Ökologische Steuerreform als europaïsches Thema - Wo stehen die EG-Partner und wie lässt sich die ökologische Steuerreform im Binnenmarkt verwirklichen? in: Nutzinger, H.G. \& A. Zahmt (Hrsg.) (1989), Okosteuerm. Umweltstewer und-Abgaben in der Diskussion, Karlsruhe: Verlag C.F. Müller.

Weizsäcker, E.U. von \& J. Jesinghaus (1992), Ecological Tax Reform. A Policy Proposal for Sustainable Development, London, New Jersey: Zed Books.

Wilhelm, S. (1990), Okosteuern, Marktwirtschaft und Umweltschutz, München: Beck'sche Reihe 423.

Wicksell, K. (1896), Ein Neues Prinzip der gerechten Besteuerung in: Finanztheoretische Unterswchungen, Jena.

Wicksell, K. (1958), A new Principle of just Taxation in: Musgrave, R.A. \& A.T. Peacock (eds.) (1958), Classics in the Theory of Public Finance, London: Macmillan. 
Wiersma, D. (1989), De efficiëntie van een marktconform milieubeleid: een uitwerking van de 502 emissiebestrijding van de Nederlandse electriciteitssector, Proefschrift Rijksuniversiteit Groningen, s.l., s.n.

Williamson, O.E. (1993), Transaction Cost Economics and Organization Theory, Berkeley: University of California, unpublished manuscript (February 1993).

Wit, de W. (1993), Actuele ontwikkelingen op het gebied van de milieuheffingen, in: Acht, van $\mathbb{R} . J . J$. \& R. Uylenburg (red.), Financiële instrumenten in het milieurecht, Zwolle: W.E.J. Tjeenk Willink, pp. 49-64.

Wit, de W. (1994), Europese aspecten van milieuheffingen, in: Boele, J. et al. (1994), Hoofdzaken milieuheffingen, Deventer: Fed, 3e geheel herz. druk, pp. 39-60.

Wolfson, D.J. (1988), Publieke sector en economische orde, Groningen: Wolters-Noordhoff.

WRR, Wetenschappelijke Raad voor Regeringsbeleid (1992), Milieubeleid" strategie, instrumenten en handhaafbaarheid, 's-Gravenhage: SDU Uitgeverij, Rapporten aan de regering, nr. 41.

Yandle, B. (1989), Taxation, Political Action, and Superfund, Cato Journal, Vol. 8, No. 3 (Winter), pp. $751-764$. 


\section{Author index}

Aalders, M.V.C., van, 142,145, 151

Adar, Z., 32

Andersen, M.S., 8

Andriessen, J.E., 128

Backes, C., 138

Backhaus, J.G., 37,38,60,61,77,87,91,97, $98,144,159$

Bakker, L, 230

Bator, F.M., 18

Baumol, W.J., 3,18,24,26,27,28,29,32, 34,87

Becker, U., 64,65

Benham, F.C., 36

Benkert W., 3,8,9,44,64,68,71

Bennett, R.J., 80

Bergmann, E., 58,70

Bij, van der J., 252

Bleijenberg, A., 230

Boele, J., 8,48,150-155,157-159,162,167

Bohm, P., 144

Bovenberg, A.L., 23,68,69,230

Brennan, G., 8,77,88,89,90,91,92,100,253

Bressers, J.Th.A., 8

Brooks, M.A., 7

Buchanan, J.M., 7,8,10,11,34,61,78,82,88, $89,90,93,100,111,115,253,266$

Bunde, J., 8,9

Burrows, P., 20,21,28

Cansier, D., 4

Christiaanse, J.H., 125

Cnossen, S., 230

Coase, R.H., 3,19,20,21,33

Common, M., 15,20

Cornes, R. 78,79,91

Cropper, M.L., 20

Cullis, J.G., 88

Delbeke, J., 64

Demsetz, H., 78

Dewees, D.N., 23

Downing, P.B., 23,32,33

Dragun, A.K., 60

Driel, P. van, 42,187

Drupsteen. Th.G., 144,145

Duchateau, N.C., $117,119,123,124,128,200$, $205,206,212,243$

Eichenberger, R., 94,95

Ewringmann, D., 49,58,70
Faber, M., 71

Feijtel, J, 248

Frey, B.R., 94,95

Gaines, S.E., 42,43

Gawel, E., 30

George, H., 37,38,39

Gieskes, J.G.E., 203

Griffin, J.M., 32

Groot, H. de, 126,127

Hagem, C., 8

Hahn, R.W. 25,32,33

Hamilton, J.H., 60

Hansjürgens, $B, 5,8,9,17,28,44,58,59,64,65$,

$69,70,85,109$

Harford, J.D., 33

Harrington, W., 33

Havekes, H.J.M., 163, 164, 183, 184,240

Hayek, F.A., 31

Heaps, T., 52

Heijdra, B.J., 7

Heijman, W.J.M., 79

Helliwel, J.F., 52

Hoek, van der M.P., 234

Hoel, M. 8, 101

Hueting, R., 136

Huppes, G., 22,52

lerland, E.C. van, 8,230

Ilsink, J.W., 203

Inman, R.P., 1

Jaeger, $F “, 25,27,28$

Jesinghaus, J., $46,51,54,67,68,70$

Jones, P.R., 88

Kam, C.A. de $125,127,201,209,233$

Kemper, M., 17,18

Knüppel, H., 23,66

Koopmans, L., 121,128,231

Korff, A.J., 124

Krabbe, J.J., 37,79

Lee, D.R., 7

Lok, K.J., 117,119,123,124,128,200,205,206, 212,243

Luhmann, H.-J., 51

Man, G. de, 129

Marshall, A., 2,18

Mauch, S.P., 8

Meadows, D., 134

Meadows, D.L, 134 
Mercuro, N., 16

Michaelis, $P$, 71

Mierlo, J.G.A. van, 253

Mishan, E.J., 20,83

Mooif, R. de, 230

Morgenstern, R.D., 61

Mueller, D.C., 7,84,100,102

Musgrave, P.B., $4,17,18,35$

Musgrave, R.A., $1,2,4,6,17,18,34,35$

Nentjes, A., 23,225,228,229,230,232

Nispen, F.K.M., 253

Nutzinger, $\mathrm{H}_{\mathrm{s}}, 3,8,71$

Oakland, W.H., 6

Oates, W.E., $3,15,18,20,24,26,27,28,29,32,34$ * $80,81,84,86,87$

OECD $, 9,17,24,41,42,43,49,50,53,55,56,58,62$, $66,71,108,109,164,167,171,173-179$

Oosterhuis, $\mathbb{F}^{2} \mathrm{H}, 9,9,166,167,168,223,224$

Opschoor, J.B., $9,23,24,43,62,144,152,164$, $171-173,175,180,185$

Paulus, A.T.G., 17,47,50,61,77,100,115,117, $149,159,232,241,249,250$

Peacock, A.T., 34

Pearce, D., 8

Pigou, A.C., 2,3,4,6,7,18,25,26,28,30,34,38, $44,60,255$

Plante-Failé, M., 205,207

Poterba, J.M., 8

RIVM, 242

Russell, C.S., 144

Samuelson, P.A., 6,78

Sandler, T., 78,79,91

Savornin Lohman, A.F. de, 9,166,167,168, $223,224,230$

Schoof, D.J.W, 138

Schuddeboom, J., 155, 162

Schumpeter, J.A., 37,115

Schuurman, J., 8,43,52,53,54,157,230

Scliwab, R.M., 87

Seerden, R., 244

SER, $20,22,26,46,134,135,136$

SERV, $23,25,27,42,52,68,69,134,135$

Sheshinski, E., 60

Simons, A.L.C., 8

Sio, B., 129,130,131,200,203,204,207,208

Slutsky, S.M., 60

Smith, A., 34,35

Smith, S., 230

Stevens, L.G.M., 1. 17, 120,121,122,126,204

Stiglitz, J.E., 35,36
Taselaar, H., 42,44

Teufel, D., 4,67,68

Tiebout, C.M., 77,83,252

Tietenberg, $T, 3,15,16,19,20,21,24,144$

Tollison, R.D., 82

Tullock, G., 7

Vollebergh, H., 8,230

Vos, B.V., $9,23,24,43,62,144,152,164,171$ $173,175,180,185$

Vries, J.L. de, $23,225,228,229,230,232$

VROM, 136, 175,214-219,241.

Wasch, E.P.J., 8,42,50,64,223,225

Watson, W.D. Jr., 32,33

WCED, $8,51,135$

Weizsäcker, E.U. von, 8,46,50,51,54,64,66, $67,68,70$

Westin, R.A., 42,43

Wilhelm, S., 3,65,70,71

Wicksell, K., 2,7,34,59,77,88,90,92,93,253

Wiersma, D., 9,230

Williamson, O.E., 77,117

Wit, $\mathbb{R}_{\text {, }} 42$

Wit, de W., 43,226

Wolfson, D.J., $80,81,85$

WRR, $4,21,22,23,24,27,36,37,42,47,52,66,86$, 101,135

Yandle, B., 60

Zahrnt, A., 3,8,71 


\section{Subject index}

accelerated depreciation, $49,50,112,166,167$, $168,188,189,222,228$

acidification, 136,229

act on chemical wastes, $145,151,193$

act on chemical waste substances, 145

act on environmentally hazardous substances, 145

act on financial relationships 1984,119

act on fuel user taxes with an environmental tax base, 155

act on joint arrangements, $124,242,248$

act on noise nuisance, 145,151

act on nuclear energy, 145

act on waste substances, 145,151

administrative charges, $53,122,132,133,156$, $161,171,173,179,199,206,207$

administrative/intergovernmental relationships, $101,117,120,123,124,126,128$, $134,146,147,212,231,232,236,240$, $245,248,263,264$

advertising tax, $129,199,203,204,210$, 224

air pollution act, $145,151,193$

air traffic act, 155

benefit $\operatorname{tax}, 122,131,132,199-203,210$

block grants, $119-123,125,126,133,231,233$

building site $\operatorname{tax}, 122,129,131,132,199-203$, 210

charge for soil protection, $149,150,158,159$, $193,198,210,241,261$

charge on surplus manure, $149,150,162,163$, $168,193,261$

checklist, $12,71,72,76,102,103,104,245,250$, 258,259

club, $13,17,77,79,82,84,91-94,258,259$

co-government, 120,158

commuter tax, $199,204,205,206,210,224$

compliance, $24,32,33,48,68$

constitutional changes, $100,101-105,111,112$, $115,240,244,246,248,250,251,253$, $259,260,264$

constitutional environmental economics, 8,13 , $77,97,256,258$

constitutional political economy, $7,8,13,77$,

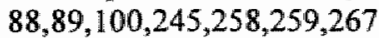

continental approach, $1,2,6$

control region, $133,155,156,163,183$

council for municipal finance, 123

D(cuble) D(ividend) approach, 9-13,37,38, $39,41,56,77,105,107,110,112,114,115$, $192,194,226,230,236,236,238,239$, $246,250,251,252,255-258$ 。 262-264

decentralized unitary state, 117 decree, $129,141,142,150,158,159,162,212$ dehydration, $136-139,141,142,197,229,232,241$ dimension

-horizontal, 112-1 16,191-193,239, $240,243,244,247,249,260,263,264$ -vertical, 112-116,191-193,195,196, $223,236,237,239,240,247,248,249$, $260,262,264,266$

disposal charges, 193

dog tax, 122,129,132,160,203

earmarked $\operatorname{tax}(\mathrm{es}), \quad 44-47,50,61,62,69,70$, $71,73,87,90,104,108,151,152,154$, $155,157,159,162,166,175,181$, $183,190-193,240,247,249,251$, $253,257,258,265$

E(cological) C(oncerns) approach, 9-14,39, $76,77,94,102,105,107,108,110,111$, $112,115,233,235,236,237-239,245$, $246,247,248,251-253,255-259,263,264$ ecological effectiveness, $10,13,56,57,60,69,78$, $86,99,104,107,110,111,117,172$, $195,245,247,251,257,259,260,263,266$ ecological level, $78,79,85,86,112,147$ ecological tax reform, $13,15,37,41,44,47,50$ $53,55,56,62-64,66-71,74,75,115,182$, $184,190,192,194,195,223,226,227$, $228,230,231,246,257,258,262$

ecological tax units, $8,77,78,91,92,93,95,97$, $98,99,101,103,104,110,111,182,183$, $192,239,240,241,243,244,246,247$. $248,249,251,258,259,263$

ecologically relevant taxes, $10,41,48,49,61$, $109,116,146,149,171,180,183,194$, $226,239,242,243,246,249,252,257$, $261,262,266$ 
econonic level, $86,147,194$

energy, $8,16,41,51,53,54,55,60,74,100,109$, $139,141,145,154,155,185-87,189-193$, $197,198,200,202,203,204,210,211$, $225,227-230,239,247,261$

enforcement, $23,24,32,33,53,56,87,90,94,95$, $96,104,108,123,139,141,143,145,218$, $221,231,248,257$

entertainment charges, 130,207

environmental charge on fuels, 168,189,191, 193

environmental hygiene law, 144,145

envirotumental policy, $3,4,5,6,8,11,13,14,15$, $17,21-25,27,28,30,31,33,37,38,41,45$ $47,50,51,56,58,59,61,63,65,70,73,75$, $87,88,97,101,107,117,124,134,147$, $149,152,153,154,155,159,166,168$, $175,180,182,183,185,187-189,194$ $198,201,208,209,211,227,228$, $230,232,239,240,243-246,252$, $253,256,258,260,261,263-266$

environmental protection act, 133,138,140, $141,143,144,145,150,151,159,161$ environmental protection regions, $159,252,264$ environmental protection law, 144 environmental user taxes, $149,151,155,166$, $167,182,184,188,191,233-236,247,261$

equalization grant, 128

eutrophication, $136,138,139,197,198,211,229$, $232,237,241$

externalities $1-3,6,7,15,17-20,25-31,34,36,38$, $41,44,60,78,80-83,92,94,110,111$, $115,147,243,245,255,261$

Ceasibility, $1,9-14,24,31,71,78,79,86,97,99$, $105,107,108,110,113,116,117,125$, $212,218,219,235,236,239,240,245$, $246,247,249,253,254,256,260,263$, 265,266

fees, $42,43,53,79,91,129,156,209,224$

fertilizers act, 162,163

financial relationships, $70,83,117,119,126,128$, $146,147,212,226,231,232,236,237$, $240,248,260$

fiscal effects $5,9,39,56,58,60,61,69,70,175$, $177,178,179,213,232,233,251,258,264$

fiscal federalism, $13,77,79,80,82,83,83,85$, $93,94,243,258$

foci, 94,95 framework act for changing administrative relationships, 124

fuel charge, $151,152,154,155,165,191,193,247$

general tax service, 150

government faillure, $1,6,10,24,88$

ground water act, $145,159,162$

ground water charge, $122,128,129$, $149,150,162,167,168,192,193$, $198,199,208,210,213,242,261$

ground water protection region, $139,158,159$, $185,240,242,263$

installations, $32,50,53,128,130,131,151,153$, $154,156,160,162,199,207,234$

intermunicipal co-operation arrangement, 124 , $141,156,242,243,(252)$

legal charges, 129,172

levies, $8,11,42,43,45,47,48,49,50,61,64,65$, $69,76,77,86,92,105,121-126,128-130$, $132,133,143,145,147,149-155,160$, $163-166,168,169,171,172,179-189$, $191-194,239,241-243,247-250,252$, $257,258,261,262$

licence, 156

livestock fodder charge, 149,163

local council, 150,212

lubricating oil, 151,152

lump sum tax, $4,35,36,45,48,89$

manure agency, 162

manure board, $240,244,253,263$

market charges, $122,130,132$

market failure, $1,17,21$

memorandum, $152,153,154,157$

mining act 1903,145

ministry of public housing, physical planning and environment, $136,218,241$

municipality, 118,119,121-133,139-143,147, $149,156,160,161,163,165-167,180$, $181,182,196,197,198,203-220,224$, $241-244,261$

municipality act, $127,128-130,150,161,199$, $200,201,212$

municipality fund, $119,120,123,124,252$

national environmental policy plan, 136 $142,185,188,189,190,225$ 
national institute of public health and environmental protection, 242

nature protection act, 144,159

Netherlands scientific council for government policy, $4,21,23$

noise charge (on civil aviation), 149,150, $155,165-\rrbracket 68,173,174,192,193,261$

OECD $, 9,17,24,41-43,49,50,53,55,56,58,62$, $66,71,108,109,134,164,167,17 \llbracket-180$, $185-187,262$

order(s) in council, $158,159,162$

parking tax, $127,128,199,206,209,210$, 211,224

physical planning and constructions act, 144 , 145

Pigouvian taxes, 4-7,9,25-31,37,38,39,44。 $45,47,49,52,58-61,64,66,68,69,72$, $73,75,77,108,111,112,120,144,167$, $169,192,246,250,251,255,257$, 258,264

pollitical unit, $8,78,92,94,95,99,100,245,259$ polluter pays principle, $46,66,68,69,134,153$, $154,157,159,172,182,202,203,216,220$ precario dues, $122,128,130-133,167,199,203$, $204,209,210,211,241,243$

principal amount of the $\operatorname{tax}, 128,209,210$ province, $93,95,98,118,119,121,122,124-128$, $133,139-142,147,149,155,156,158,159$, $162,163,165,166,180,181,182,196$ $198,208,209,212,232-237,242,244,261$ province act, $119,127,1.29,199,212$ province fund $119,120,248$ provincial executive, 150,212 public choice, $7,60,88$ public industrial organization, 122,123 public or collective good, $1,2,6,15,17,18,36$, $78,79-84,90,91,98,121,147,233$, $243,252,264$

quid pro quo reductions, $23 \|$ quid pro quo relationship, $4,34,44-46,73,130$, $132,160,200,203,204,207$

real estate taxes, $122,125,129-132,163,166$, $190,199-203,205,208,210,211,213$ refuse collection charges/rates, 122,130,131, $133,149,150,160,161,167,168,185$, $191,193,198,207,208,216,220,261$ region oriented environmental polioy, 138 , $252,261,265$

regulation (local governments), $118,124,130$, $141,143,145,150,151,158,162,185,212$

regulatory charges, $29,34,38,39,44,45,48$, $50,68,69,149,150,151,154,219,220$, $229,230,232,233,235,239,247,252$

revenue raising taxes, $6,9,11,34,37,38,39,41$, $42,44-47,50-52,58,60,61,64,69,71,73-$ $76,89,108,125,126,130,131,152,160$, $164,166,182,192,200,203,229,237,246$ $248,251,252,257,264$

Rhine, $78,95,96,98,99,243,244,245,259$

service or user charges, $98,130,150,151,155$, $160,161,199,207,208-211,219,222$ sewerage charges, $122,130,131,149,150,161$, $165,174,175,185,191,193,198,207$. $208,213,241,261$

sewage treatment plant, 156 silence region, 139 single tax, $37,38,50$ socio-economic council, 20,135 soil protection act, $₫ 45,151,158,159,185,192$ soil protection region, $139,158,244,253,263$ special acts, $128,129,133,146,161,199$ specific grants, $119,120,121,124,125,231,233$ state council 187 steering effects, $51,54,56,58-61,63,64,67,69$, $70,157,168,175,177-182,185,213,214$, $215,230,251,258,264$

sub national government bodies, $9,12,99,100$, $101,117-126,128,134,139,140,142,146$, $147,149,150,155,156,157,164,166$, $169,181,182,185,190,191,195-199$, $208-214,211-214,220,223,226,230$ $237,239,241,243-245,247-249,252$, $260,261,263,264,266$

sufferance dues, 122,130

surcharges, $122,125-129,189,190,199,209$, $210,225,234$

surface waters polllution act, $133,134,142,144$, 145,155

sustainable (development), $8,41,46,51,96$, $98,99,101,135,136,138,143,147,196$, $198,211,233,261$

tax allowance schemes for environmental investments, $50,68,112,188$

tax credit, $30,31,43,50,111,112,144,182,220$, 
tax differentiation, $109,112,160,167,168,171$, $172,173,175,179,181,185,188-191,193$, $201,203,204,206-208,213-217,220$, $224,225,226,228,239,252,262$

tax provisions, $48,49,149,166,167,181,185$, $190,192,193,196,199,210,213,214$, $224,225,226,250,253,262,264$, 265,266

tourist taxes, $122,129,131,199,204-206,209$, 210

transfer taxes, $127,166,220,224$

tradeable permits, $15,22,30-32,229$

transaction costs, $19,20,21,28,33,88$

user charges, $46,53,98,130,150,151,155,160$, $\llbracket 61,164,166,171-175,179,184,199$, $207,219,222$

voluntary exchange, $2,7,77,90,258 / 259$

wabm act, $145,150,152,154,159$

waste, $16,41,51,98,100,126-127,131-133$, $136,137,139,141,142,147,15], 152$, $155,156,158,159,160,162,164,166-$ $169,172-175,177,180-182,184,185$. $188,190-193,197,198,207,208,211$, $212,214-220,229,231,233-237,241$, $243,247,252,261$

water board, $85,93,95,118,122,128,131,133$, $134,139-142,147,149,150,155-157$, $163,164,165-167,181,182,183,191$, $196-199,209,212,234,240,242,245$, $249,261-263$

water board act, 199,212

water pollution charge, $122,128,129,132-134$, $149,150,155-158,163,164,165$, $167,182,184,1185191,193,198$, $199,201,208,210,211,213,234,241,261$

water quantity assessments, $133,134,149,163$, $164,167,182,184,191,193,198,199$, $201,208,210,211,241,261$

waste (disposal) tax, 131-133,149,150, $160,161,168,185,191,193,198$, $208,213,216,220,235,237,243,261$ 


\section{Samenvatting}

\section{Achtergrond}

In een verwijzing naar de mogelijke verschillen die kunnen optreden tussen het marginale sociale en het marginale private netto produkt, stelde Pigou $(1912,1920)$ voor om belastingen te gebruiken voor de internalisering van externe effecten. Met deze suggestie bood Pigou in feite een nieuw perspectief voor de tot op dat moment bestaande opvattingen over de rol van de markt en de overheid. Sindsdien is Pigous suggestie verder uitgewerkt en opgenomen binnen de milieu-economie. Binnen deze tak van de economie staat het concept van externe effecten centraal bij de verklaring van milieu-externaliteiten (bijvoorbeeld milieuvervuiling). Volgens Pigous suggesties, kunnen belastingen worden gebruikt voor de internalisering van deze milieu-externaliteiten. Het opnemen en verder uitwerken van de suggestie van Pigou binnen de milieu-economie kan dan ook worden gezien als een van de belangrijkste grondslagen van het idee om belastingen voor milieudoeleinden te gebruiken. Dit idee is de laatste jaren steeds populairder geworden. Dit hangt samen met een toename van het aantal milieuproblemen en de algemene opvatting dat de instrumenten die momenteel voor het milieubeleid worden gebruikt (bijvoorbeeld directe reguleringen), niet effectief zijn.

In hoofdstuk I van dit onderzoek wordt beargumenteerd, dat alhoewel ecologische belastingen in de zin van Pigou alleen een allocatief en niet een fiscaal doel dienen, deze belastingen steeds meer worden gepresenteerd onder de noemer van de zogenaamde "double dividend" (DD) benadering. Een centraal uitgangspunt van deze benadering is het toekennen van meerdere doelen aan ecologische belastingen. Heffingen kunnen in die zin, naast een ecologisch doel, ook een fiscaal doel hebben of gericht zijn op het verwezenlijken van een aantal doeleinden ten aanzien van de herverdeling van inkomen of de werkgelegenheid. Als gevolg hiervan worden in deze benadering dan ook andere dan louter ecologische overwegingen meegenomen in het ontwerp van ecologische belastingen. De nadruk op deze benadering en de toenemende belangstelling voor de mogelijke fiscale effecten van belastingen in de zin van Pigou, heeft bijgedragen tot een verminderende aandacht, zowel in theorie als in de praktijk, voor heffingen die enkel gebaseerd zijn op ecologische overwegingen. Voorbeelden van benaderingen waarin deze laatste heffingen centraal staan, zijn onder meer de benadering via Pigouviaanse heffingen en benaderingen waarin ecologische belastingen worden ontworpen en opgelegd in nauwe samenhang met relevante ecolo-

1 Met dank aan Lea Wijnands woor haar correcties en suggesties ten aanzien van de Nederlandse tekst van deze samenvatting. 
gische omstandigheden. In dit proefschrift worden de benaderingen waarin heffingen louter gebaseerd zijn op ecologische overwegingen, gepresenteerd onder de noemer van de zogenaamde "ecological concerns" (EC) benaderingen.

Naast de bovengenoemde verminderende aandacht voor EC-benaderingen, is er in de bestaande literatuur over ecologische belastingheffing weinig aandacht voor het institutionele kader waarbinnen dit type belastingheffing moet worden ingekaderd. Daarnaast wordt er in de bestaande literatuur vaak weinig aandacht geschonken aan de rol van lagere overheden bij het verder ontwikkelen van ecologische belastingheffing. Het verwaarlozen van deze aspecten en de magere belangstelling voor het feit, dat in het algemeen, het bereik van bestaande beslissingsstructuren niet overeenkomt met het bereik van relevante ecologische omstandigheden, doet vermoeden dat de ecologische belastingen die haalbaar zijn onder DD-benaderingen verschillen van die belastingen die haalbaar zijn onder EC-benaderingen.

\section{Doel van het onderzoek en onderzoeksbenadering}

Tegen deze achtergrond is het centrale doel van het onderhavige onderzoek in hoofdstuk I omschreven als het analyseren van de realiseerbaarheid ('feasibility') van ecologische belastingheffing en het afleiden van relevante beleidsimplicaties voor het gebruiken van dit type heffing in het algemeen en in de beleidspraktijk in het bijzonder. In die zin betreft deze studie een theoretische haalbaarheidsanalyse, die vervolgens wordt toegepast op een bepaalde casus. In dit onderzoek wordt het benutten van belastingen en heffingen voor ecologische en andere doeleinden in Nederland als casus gebruikt. Het haalbaarheidsconcept dat in deze studie wordt gehanteerd, verwijst naar een bundel van mogelijkheden en problemen die van ecologische belastingheffing een realistische en dus denkbare beleidsoptie maken. Om de bovengenoemde haalbaarheidsanalyse uit te voeren, wordt in deze studie a priori aangenomen dat al bepaald is dat deze instrumenten geschikt zijn om, gegeven de geldende ecologische omstandigheden, gebruikt te worden voor (in)directe ecologische doeleinden. Er wordt dus aangenomen, dat de haalbaarheid van ecologische belastingen afhankelijk is van de relevante elementen van enkel dit instrument en niet bepaald hoeft te worden op basis van een vergelijkende analyse waarin het gebruiken van deze belastingen moet worden afgewogen tegen het gebruik van andere milieubeleidsinstrumenten.

Gegeven deze aanname bestaat de haalbaarheidsanalyse uit een analyse van de mogelijkheden, problemen en elementen die van ecologische belastingheffing, onder de genoemde benaderingen, een realistische beleidsoptie maken. Omdat het bereik van ecologische omstandigheden in het algemeen niet overeenkomt met het bereik van bestaande politieke beslissingseenheden (denk bijvoorbeeld aan de rivier de Maas), wordt een gedeelte van de haalbaarheidsanalyse uitgevoerd op basis van een constitutionele politiek-economische benadering. Een centraal element van de constitutionele politieke economie is dat collectieve besluitvormingsstructuren zelf als variabele in de uit te voeren analyses worden opgenomen. Het gebruiken van een dergelijke benadering is met name relevant ten aanzien van bepaalde problemen die zich binnen ecolo- 
gische eenheden afspelen. In het algemeen valt het bereik van deze ecologische eenheden (zoals het stroomgebied van een rivier of een bergketen) niet samen met het bereik van bestaande politieke eenheden. De laatste eenheden zijn gewoonlijk beslissingseenheden die niet of nauwelijks op basis van ecologische omstandigheden zijn afgebakend.

\section{Theoretische context}

In de hoofdstukken 2 en 3 van deze haalbaarheidsstudie wordt ecologische belastingheffing geplaatst binnen een relevante theoretische context. Deze context wordt vervolgens gebruikt om de grondslagen, belangrijkste concepten en het ontwerp van dit type heffing te bepalen. Deze theoretische context, die onder meer bestaat uit de economische theorie van het milieubeleid, de economische benadering van milieuproblemen en de theorie der openbare financiën, wordt verder uitgewerkt in hoofdstuk 2. Uit de analyse van ecologische belastingen in dit hoofdstuk volgt onder meer, dat onder een benadering waarin Pigouviaanse heffingen centraal staan, het enige doel van deze heffingen het belasten van ecologisch ongewenst gedrag is. In het ideale geval wordt een internalisering van alle relevante milieu-externaliteiten bereikt, zonder dat er additionele fiscale opbrengsten voor de staat aan zijn verbonden. In dit bijzondere geval zijn het dan louter ecologische overwegingen die een rol spelen bij het opleggen van deze heffingen. De analyse in hoofdstuk 2 toont echter ook aan dat de Pigouviaanse heffingen, zoals oorspronkelijk geformuleerd, slechts een theoretisch ideaalbeeld vormen. Dit ideaalbeeld kan in de praktijk alleen worden benaderd. Regulerende heffingen, het gebruiken van belastingfaciliteiten (bijv. belastingkredieten) en de door Baumol en Oates voorgestelde combinatie van een milieustandaard met heffingen, vormen bekende voorbeelden van dergelijke benaderingen. Het feit dat er met dergelijke benaderingen ook fiscale effecten kunnen zijn gemoeid, heeft ertoe geleid dat de aandacht voor het gebruiken van belastingen voor ecologische doeleinden geleidelijk is verschoven in de richting van benaderingen waarin het bereiken van zowel ecologische als fiscale doeleinden centraal staat.

In hoofdstuk 3 worden de belangrijkste mogelijkheden, problemen en het ontwerp van ecologische belastingen verder geanalyseerd. Dit hoofdstuk begint met een definitie van ecologische belastingen, waarin deze worden gedefinieerd als typen heffingen (zijnde gedwongen bijdragen of overdrachten) die voldoen aan een of meer van de karakteristieken die hieronder beschreven zijn.

Heffingen zijn gericht op het verwezenlijken van belastingontwijkende gedragsveranderingen bij diegenen die met deze heffingen worden geconfronteerd. Het doel is daarbij om relevante externaliteiten geheel of gedeeltelijk in de beslissingen van deze actoren te internaliseren.

Heffingen zijn gericht op het verwerven van opbrengsten die gebruikt kunnen worden voor een bepaalde milieusector voor zover dit noodzakelijk is voor het verwezenlijken van een bepaald ecologisch doel. 
- Er is sprake van een relatie tussen de heffingsgrondslag en de aard en omvang van bepaalde gewenste of ongewenste ecologische aspecten, factoren en/of activiteiten.

Gegeven deze karakteristieken, kunnen drie belangrijke typen van ecologische belastingen en heffingen worden onderscheiden, te weten Pigouviaanse of regulerende heffingen, milieubestemmingsheffingen en (opbrengstverwervende) milieubelastingen. Deze belastingen kunnen worden onderscheiden van een bredere categorie van ecologisch relevante belastingen, waarin ook zijn opgenomen de belastingen en heffingen die, alhoewel voor andere dan milieudoeleinden bedoeld, ook een gewenste of ongewenste impact op het milieu hebben. In het algemeen kunnen nu de volgende mogelijkheden voor ecologische belastingheffing worden onderscheiden.

- De introductie van nieuwe heffingen die gericht zijn op het verwerven van opbrengsten die kunnen worden gebruikt voor de financiering van bepaalde milieu-uitgaven. Kortom, de introductie van nieuwe milieubestemmingsheffingen.

Het supplementeren van het bestaande systeem van belastingen en heffingen met Pigouviaanse heffingen.

Het opnemen van bepaalde milieubeleidsdoelstellingen in bepaalde belastingen en heffingen, bijw. via het heroriënteren van bestaande belastingaftrekken of belastingtarieven.

Het vervangen van bestaande belastingen en heffingen (bijvoorbeeld die op arbeid) door ecologische belastingen en heffingen. Kortom, de introductie van ecologische belastinghervorming.

De problemen die met het ontwerpen en introduceren van deze beleidsopties samenhangen, verschillen per mogelijkheid. In het algemeen hangen deze problemen vooral samen met het ontwerpen van belastingen en heffingen die ecologisch effectief zijn en met het bepalen van de relatie tussen de belastinggrondslag, het milieuvervuilende gedrag en het moment waarop besloten wordt tot gebruik van milieuvriendelijke technieken over te gaan. Verdere problemen doen zich voor ten aanzien van de hieraan gerelateerde administratieve kosten en het soort en de hoeveelheid informatie die nodig is om de juiste heffing of belasting op te leggen. Daarnaast kunnen er zich problemen voordoen ten aanzien van de fiscale, regulerende, economische en inkomens(her)verdelingseffecten van deze heffingen en het oormerken van bepaalde heffingsopbrengsten. Problemen doen zich tevens voor ten aanzien van het inkaderen van ecologische belastingheffing binnen bestaande nationale en internationale juridische en belastingsystemen. Gegeven deze problemen wordt er in hoofdstuk 3 geconcludeerd, dat ecologische belastingheffing complex maar mogelijk is, mits ieder type heffing dat bedoeld is om voor bepaalde ecologische en/of andere doeleinden te worden gebruikt ook zorgvuldig wordt ontworpen. Voor ieder type ecologische belasting worden de belangrijkste aspecten van een dergelijk ontwerp in een checklist 
aangegeven. De analyse in hoofdstuk 3 toont tevens aan dat de elementen die bepalend zijn voor de haalbaarheid van ecologische belastingen verschillen onder DD- en ECbenaderingen. De haalbaarheid van heffingen die behoren tot de EC-benaderingen, zoals de Pigouviaanse heffingen, wordt vooral bepaald door de aanwezigheid van een raamwerk waarbinnen informatie kan worden verstrekt over belastingontwijkende gedragsveranderingen. De aanwezigheid van relevante informatie over de mogelijkheden tot het realiseren van deze veranderingen komt de allocatieve functie van deze heffingen ten goede. De haalbaarheid van heffingen die vallen onder DD-benaderingen, zoals bijvoorbeeld milieubelastingen, milieubestemmingsheffingen en ecologische belastinghervorming, hangt vooral samen met de compatibiliteit van deze beleidsopties met bestaande fiscale structuren. Verder hangt de haalbaarheid van de laatstgenoemde beleidsopties samen met de mogelijkheden om consensus te bereiken over de bestemming van mogelijke belastingopbrengsten.

\section{Ecologische belastingheffing en het concept van ecologische belastingeenheden}

In hoofdstuk 4 van dit proefschrift wordt een beschouwing gegeven van het concept van ecologische belastingeenheden. Centraal staat de vraag op welk schaalniveau, door welke belastingheffende instantie en binnen welke institutionele en fiscale kaders ecologische belastingen het beste kunnen worden opgelegd, willen ze acceptabel en haalbaar zijn en een rol van betekenis kunnen spelen. In hoofdstuk 4 wordt de discussie hierover geplaatst binnen het kader van de constitutionele milieu-economie en de theorie der politieke economie. Gebruikmakend van diverse elementen van o.a. de 'fiscal federalism' theorie, de clubtheorie, Tiebouts theorie over lokale uitgaven en bepaalde uitgangspunten van Buchanan en Wicksell, worden ecologische belastingeenheden gepresenteerd als de vertegenwoordigers van EC-benaderingen in ideale zin. Kenmerkend voor deze eenheden is dat ecologische belastingen en heffingen worden opgelegd door een autoriteit waarvan de belastingheffende bevoegdheden zijn afgebakend op basis van relevante ecologische omstandigheden. Tevens bestaat er binnen deze eenheden een nauwe band tussen degenen die de heffing in kwestie moeten betalen, degenen die van het beleid van de autoriteit profiteren en degenen die het bestuur van deze autoriteit kiezen. Ecologische belastingeenheden zijn niet alleen functioneel afgebakend, maar worden ook gekenmerkt door een structuur waarbinnen de acceptatie van belastingen door degenen die ermee geconfronteerd worden, een belangrijke rol speelt. Waar het eerste belangrijk is voor de ecologische effectiviteit van deze heffingen, speelt het laatste een belangrijke rol bij de uiteindelijke acceptatie van deze heffingen. Het concept van ecologische belastingeenheden omvat dan ook een aantal elementen die significant zijn voor de haalbaarheid van ecologische belastingheffing.

Omdat mag worden verwacht dat het bereik van bestaande belastingautoriteiten niet of slechts gedeeltelijk zal overeenstemmen met het bereik van ecologische belastingeenheden (denk bijvoorbeeld aan de rivier de Rijn), wordt er in hoofdstuk 4 tevens een analytisch kader gepresenteerd voor de verdere ontwikkeling van deze eenheden. Het vormen van consensus, het oormerken van belastingopbrengsten en het doorvoe- 
ren van constitutionele veranderingen, vormen belangrijke elementen van dit analytische kader. Vanuit constitutioneel politiek economisch oogpunt is er in hoofdstuk 4 ook een checklist opgesteld. In de checklist zijn onder meer de institutionele wijzigingen die nodig zijn om constitutionele veranderingen tot stand te brengen en de hiermee samenhangende kosten en baten aangegeven. De beslissingen en de praktische problemen die moeten worden opgelost om daadwerkelijk tot deze veranderingen te komen, worden ook in deze checklist aangegeven. Uit de analyse in dit hoofdstuk volgt dat het opleggen van ecologische belastingheffing in nauwe samenhang met relevante ecologische omstandigheden, een benadering vereist die radicaler is dan de geleidelijke strategieên die onder DD-benaderingen worden voorgesteld.

\section{Van theorie naar praktijk}

In navolging van de conclusies uit eerdere hoofdstukken, wordt in hoofdstuk 5 een analytisch kader geformuleerd waarin een aantal verschillende elementen van de DDen EC-benaderingen zijn opgenomen. Met behulp van dit kader is het mogelijk om de theoretische overwegingen die in het proefschrift gemaakt zijn, vervolgens toe te passen op de praktijk van ecologische belastingheffing in Nederland. Een centraal element van dit kader is de ontwikkeling van ecologische belastingheffing langs een horizontale en verticale dimensie. Deze dimensies drukken de verdere ontwikkeling uit van ecologische belastingheffing in de richting van heffingen die voldoen aan de in hoofdstuk 3 genoemde eisen (verticale dimensie) en die, gegeven ecologische omstandigheden, worden opgelegd in nauwe relatie tot deze omstandigheden (horizontale dimensie). De ontwikkeling van ecologische belastingheffing langs deze twee dimensies maakt mogelijk dat dit type belastingheffing wordt ontworpen en ingekaderd in institutionele, constitutionele, fiscale en andere relevante kaders, die de effectiviteit en acceptatie van deze belastingheffing vergemakkelijken en verzekeren.

In hoofdstuk 5 wordt aangetoond dat EC- en DD-benaderingen niet noodzakelijkerwijs twee tegenover elkaar staande benaderingen van ecologische belastingheffing behoeven te zijn. Binnen de context van het geschetste ontwikkelingsproces vertegenwoordigen zij de meest geschikte benadering voor een bepaalde dimensie van ecologische belastingheffing. Wanneer ecologische belastingheffing alleen verder kan worden ontwikkeld binnen de huidige status-quo structuren, ofwel omdat de kosten van het maken en doorvoeren van constitutionele veranderingen niet opwegen tegen de baten ervan ofwel omdat beleidsmakers een duidelijk belang hebben ontwikkeld bij het behouden van de huidige structuren, kunnen DD-benaderingen worden gebruikt voor het verdere ontwerp van deze belastingheffing. Deze benadering is, met andere woorden, in het bijzonder relevant voor de verdere ontwikkeling van ecologische belastingheffing langs de eerder aangegeven verticale dimensie. Wanneer er echter wel een voorkeur is voor het maken van institutionele en constitutionele veranderingen, dan kunnen EC-benaderingen worden gebruikt voor het analyseren van de mogelijkheden en de wijze waarop deze veranderingen daadwerkelijk kunnen worden doorgevoerd. EC-benaderingen zijn dan ook vooral relevant voor de verdere ontwik- 
keling van ecologische belastingheffing langs de eerder genoemde horizontale dimensie.

Institutionele en andere relevante kaders voor ecologische belastingheffing in Nederland

Aangezien de relevante institutionele kaders voor ecologische belastingheffing evenals de acceptatie daarvan variëren per land en per jurisdictie, kan verwacht worden dat de kosten van het verder ontwikkelen van ecologische belastingheffing langs beide dimensies ook verschillen per land en per jurisdictie. Deze kosten kunnen dan ook alleen worden bepaald op basis van een "case by case"-benadering. In de verdere hoofdstukken van dit proefschrift wordt de haalbaarheid van ecologische belastingheffing dan ook geanalyseerd binnen het kader van een bepaalde casus, te weten ecologische belastingheffing in Nederland. In hoofdstuk 6 wordt daartoe eerst het institutionele, financiële, fiscale en milieubeleidskader voor ecologische belastingheffing in Nederland nader omschreven. Een analyse van de bestaande verantwoordelijkheden van verschillende overheden voor bepaalde fiscalle taken en milieutaken laat onder meer zien dat de bestaande institutionele en financiële verhoudingen tussen verschillende overheden in Nederland bepaalde beperkingen aan ecologische belastingheffing opleggen. Beperkingen zijn er vooral ten aanzien van het schaalniveau waarop en de belastingheffende instantie waardoor ecologische belastingen kunnen worden opgelegd, ten aanzien van het ontwerp en doel van deze belastingen en ten aanzien van het regionaal kunnen differentiëren van ecologische belastingheffing. Zo zijn er, binnen de huidige institutionele context, weinig mogelijkheden voor lagere overheden in Nederland om zelfstandig tot (nieuwe) belastingheffing over te gaan of om over te gaan tot het heffen van belastingen, die voor andere dan fiscale doeleinden zijn bestemd. Tegelijkertijd echter, bieden het bestaande milieubeleidskader en recente veranderingen in de bestaande financiële en bestuurlijke verhoudingen tussen overheden, een toenemend aantal mogelijkheden voor lagere overheden om ecologische belastingheffing meer direct te relateren aan relevante ecologische omstandigheden. Deze mogelijkheden betreffen in het bijzonder de introductie van regionale overheden, de uitbreiding van het lokale belastinggebied en het toenemende besef van het belang van een gebiedsgericht milieubeleid. Daarnaast is er een toenemend besef voor het gebruiken van belastingen voor het internaliseren van milieu-externaliteiten.

Voortbouwend op de in hoofdstuk 6 geschetste problemen en de mogelijkheden voor ecologische belastingheffing door verschillende overheden in Nederland, wordt er in hoofdstuk 7 een overzicht gegeven van de belangrijkste milieuheffingen en ecologisch relevante belastingen die momenteel in dit land worden opgelegd. Een nadere bestudering van deze heffingen en belastingen laat zien dat de bestaande ecologische belastingheffing in Nederland vooral wordt gekenmerkt door het type en het doel van de heffing en het overheidsniveau waardoor deze heffing wordt opgelegd. Met betrekking tot het type heffing dat voor ecologische doeleinden wordt gebruikt is opvallend, dat eigenlijk met uitzondering van de bestaande milieuver- 
bruiksbelastingen; alle overige heffingen, milieubestemmingsheffingen zijn. Het doel van het overgrote deel van de bestaande ecologische belastingen en heffingen is daarom dan ook een fiscaal doel. Regulerende effecten worden met de bestaande heffingen en belastingen nauwelijks nagestreefd. Dit blijkt tevens uit de relatief lage belastingtarieven. In totaal vormen de opbrengsten die door middel van milieuheffingen in Nederland worden opgehaald nog geen $3 \%$ van de totale belastingopbrengsten. Wat betreft het overheidsniveau is opvallend dat lagere overheden (provincies, gemeenten en waterschappen) een belangrijke rol spelen bij een groot deel van de in Nederland opgelegde milieuheffingen.

\section{De (verdere) ontwikkeling van ecologische belastingheffing in Nederland}

Op basis van het in de vorige hoofdstukken geschetste huidige gebruik van belastingen en heffingen voor ecologische en andere doeleinden in Nederland, worden in de hoofdstukken 8 tot en met 10 een aantal mogelijkheden en problemen van een verdere ontwikkeling van ecologische belastingheffing in dit land nader geanalyseerd. Alhoewel het bestaande gebruik van ecologische belastingen en heffingen in Nederland vergelijkbaar is met dat van andere Westeuropese OECD landen en met dat van de Skandinavische landen, blijkt uit hoofdstuk 8 dat ecologische belastingheffing in Nederland gekenmerkt wordt door een aantal trends en specifieke karakteristieken. Uit de in dit hoofdstuk uitgevoerde analyse en evaluatie volgt, dat ecologische belastingheffing in Nederland zich langzaam en geleidelijk ontwikkelt van een systeem waarin verschillende sectorale milieuheffingen op een relatief ongecoördineerde manier werden ingevoerd, tot een meer gestructureerd systeem waarbinnen milieuheffingen langzaam gekoppeld worden aan relevante ecologische omstandigheden. Bovendien worden er tegelijkertijd, en eveneens geleidelijk, mogelijkheden geschapen voor de introductie van ecologisch relevante belastingen en heffingen die ook voor niet fiscale doeleinden kunnen worden gebruikt. Zowel het bestaande financieringssysteem van het milieubeleid als de geboden mogelijkheden voor de verdere ontwikkeling van ecologische belastingheffing die niet primair gericht is op fiscale doeleinden, kunnen als een belangrijk beginpunt worden gezien voor een geleidelijke introductie van het idee van ecologische belastinghervorming in dit land. Omdat ecologische belastinghervorming een belangrijk element vormt van DD-benaderingen, kan tevens geconcludeerd worden dat de ontwikkeling van dit type belastingheffing zich in Nederland met name langs een verticale dimensie verder ontwikkelt. Alhoewel recente veranderingen in de bestaande bestuurlijke en financiële verhoudingen de mogelijkheden vergroten voor het toepassen van EC-benaderingen, stimuleren zij (nog) niet een ontwikkeling in de richting van een belastingsysteem dat zich systematisch richt op keuzemomenten of ecologische omstandigheden.

Voortbouwend op de conclusies in hoofdstuk 8, worden in hoofdstuk 9 een aantal mogelijkheden en problemen die samenhangen met een verdere ontwikkeling van ecologische belastingheffing langs de genoemde verticale dimensie verder beschouwd. Uit de in hoofdstuk 9 gehouden analyse volgt dat onder de huidige DD- 
benadering perspectieven voor een verdere ontwikkeling van ecologische belastingheffing vooral worden geboden door een verdere internalisering van relevante milieudoeleinden in bestaande belastingen en heffingen. Voorbeelden zijn o.a. een verhoging of differentiatie van bestaande tarieven op basis van ecologische overwegingen. Verdere perspectieven worden geboden door een invoering van additionele milieuheffingen die opbrengsten-neutraal zijn en die samenhangen met die milieuproblemen en die gebieden waarvoor de verschillende overheden in dit land reeds beleidsverantwoording dragen. De daadwerkelijke introductie van deze heffingen door verschillende overheden in Nederland is afhankelijk van de hieraan gerelateerde kosten. Deze kosten hangen onder meer samen met mogelijke ongewenste economische en inkomensherverdelingseffecten en met het wijzigen of invoeren van bepaalde belastingwetten die nodig zijn om over te gaan tot een verdere ontwikkelingsfase. De analyse in hoofdstuk 9 toont ook aan, dat allhoewel er in principe een relatief groot potentieel is voor lagere overheden om ecologische belastingheffing verder te ontwikkelen, er restricties door het institutionele systeem worden opgelegd die verhinderen dat deze overheden ook daadwerkelijk van dit potentieel gebruik kunnen maken. Onder de huidige DD-benadering worden deze restricties vooral opgelegd door de bestaande bestuurlijke en financiële verhoudingen. Kenmerkend voor deze verhoudingen is het vasthouden aan het equivalentie-principe, op basis waarvan er weinig verschillen in belastingen en provisies tussen lagere overheden in Nederland worden toegelaten. Bovendien worden lagere overheden in dit land, binnen de huidige structuren en benadering, ontmoedigd om nieuwe (ecologische) belastingen in te voeren. Het gevaar bestaat namelijk dat de algemene en specifieke uitkeringen die door de centrale overheid aan lagere overheden worden uitgekeerd, worden gekort als reactie op de introductie van nieuwe lokale of regionale belastingen.

Gegeven het theoretische potentieel maar de in de praktijk bestaande restricties voor de ontwikkeling van ecologische belastingheffing door lagere overheden onder de huidige benadering en structuren, wordt in hoofdstuk 10 nader geanalyseerd of een EC-benadering meer perspectieven kan bieden. Meer specifiek worden in dit hoofdstuk een aantal mogelijkheden en problemen voor het verder ontwikkelen van ecologische belastingheffing langs een horizontale dimensie bezien. De analyse in dit hoofdstuk toont aan, dat omdat alleen waterschappen min of meer het concept van ecologische belastingeenheden vertegenwoordigen, een verdere ontwikkeling van ecologische belastingheffing in de richting van deze dimensie, institutionele en constitutionele veranderingen vergt. Zo zouden in principe, in theorie, belastingheffende bevoegdheden kunnen worden toegekend aan bepaalde milieubeschermingsgebieden. Ook zou kunnen worden overgegaan tot de oprichting van verdere functionele milieu-overheden zoals bijvoorbeeld mestschappen. Aangezien dit alles echter aanzienlijke veranderingen in het bestaande institutionele, financiële, constitutionele en fiscale kader in Nederland met zich mee zal brengen, lijkt het bevorderen van samenwerking op het gebied van millieu tussen verschillende overheden in Nederland goed te passen binnen de huidige discussies over wijzigingen in de bestaande bestuurlijke en financiële verhoudingen in dit land. Deze ontwikkelingen bieden niet alleen een belangrijk 
aanknopingspunt voor het vastleggen van een aantal kenmerken van het concept van ecologische belastingeenheden binnen de bestaande institutionele structuren in Nederland, maar kunnen bovendien een belangrijke voorbeeldfunctie vervullen ten aanzien van ecologische belastingheffing door transnationale of internationale beslissingseenheden. Uit hoofdstuk 10 volgt ook dat het stimuleren van verdere interjurisdictionele samenwerkingsverbanden op het gebied van milieu, de meest haalbare optie is voor een verdere ontwikkeling van ecologische belastingheffing in de richting van de hiervoor aangegeven horizontale dimensie. De analyse in hoofdstuk 10 toont ook aan dat relatief kleine beslissingseenheden (bijvoorbeeld lagere overheden) een rol kunnen spelen in de verdere ontwikkeling van ecologisch effectieve en acceptabele vormen van ecologische belastingheffing.

De realiseerbaarheid van ecologische belastingheffing en hieruitvolgende beleidsimplicaties

Als conclusie kan worden gesteld dat het bepalen van de haalbaarheid van ecologische belastingheffing een "case by case"-benadering vergt, waarbij de haalbaarheid van dit type heffing wordt bepaald voor iedere afzonderlijke beslissingseenheid en voor iedere afzonderlijke belasting en heffing. De haalbaarheidsanalyse van ecologische belastingheffing in dit proefschrift toont aan, dat in het algemeen, de haalbaarheid van dit type heffing in grote mate wordt bepaald door de huidige ontwikkelingsfasen en het institutionele, bestuurlijke en fiscale kader waarbinnen dit type moet worden vastgelegd. De ontwikkelingsfasen en het inkaderen in relevante structuren zijn belangrijke determinanten van de kosten van het verder ontwerpen, introduceren en ontwikkelen van ecologische belastingen als realistische beleidsopties.

Onder de huidige DD-benaderingen, waarin sterk wordt vastgehouden aan de bestaande institutionele en constitutionele structuren voor ecologische belastingheffing, kan worden verwacht dat beleidsmakers in het bijzonder belangstelling zullen hebben voor het introduceren van ecologische belastingen die een duidelijk fiscaal doel hebben. De typen belastingen die aan dit doel voldoen, zijn onder meer milieubelastingen en milieubestemmingsheffingen. Onder alternatieve EC-benaderingen, waarin de afbakening van fiscale en institutionele structuren op basis van relevante ecologische omstandigheden centraal staat, kan verwacht worden dat beleidsmakers in het bijzonder geinteresseerd zullen zijn in het introduceren van heffingen die zijn gebaseerd op puur ecologische overwegingen. Dit zijn onder meer Pigouviaanse heffingen, belastingfaciliteiten en de belastingen die worden opgelegd door ecologische belastingeenheden. Waar DD-benaderingen worden gekenmerkt door hun geleidelijke ontwikkeling van ecologische belastingheffing, worden EC-benaderingen vooral gekenmerkt door hun meer radicale benadering van dit type belastingheffing. Afhankelijk van de vraag aan welke van de twee benaderingen in het algemeen de voorkeur wordt gegeven, doen zich verschillende implicaties voor ten aanzien van de verdere ontwikkeling van ecologische belastingheffing. 
Voor de verdere ontwikkeling van ecologische belastingheffing onder de huidige DD-benaderingen, moeten beleidsmakers er rekening mee houden dat zij dit type belastingheffing alleen geleidelijk en in nauwe samenhang met bestaande fiscale structuren kunnen ontwikkelen. De verdere ontwikkeling van ecologische belastingheffing, onder deze benadering zal naar alle waarschijnlijkheid bestaan uit het verder inkaderen van ecologische doeleinden in bestaande belastingen. Voor het succesvol kunnen inkaderen van deze doeleinden, moeten beleidsmakers die belastingen kunnen ontwerpen en introduceren, waarmee een stabiele balans tussen de regulerende en fiscale effecten van deze belastingen kan worden verwezenlijjkt. Aannemende dat beleidsmakers een dergelijke balans nastreven, kan worden verwacht dat zij in het bijzonder zullen kiezen voor de introductie van ecologische belastingen die gekenmerkt worden door een relatief smalle belastinggrondslag en/of relatief hoge belastingtarieven. Om ecologische belastingheffing verder te ontwikkelen onder de alternatieve EC-benaderingen, moeten beleidsmakers bedacht zijn op de structurele veranderingen die dit met zich meebrengt. Nadat constitutionele veranderingen zijn doorgevoerd of tijdens het veranderingsproces, kan verwacht worden dat de verdere ontwikkeling van ecologische belastingheffing onder deze benadering vooral bestaat uit het introduceren van milieubestemmingsheffingen en van heffingen op private consumptiegoederen die gerelateerd kunnen worden aan de consumptie van het publieke goed in kwestie. Om zulke heffingen te kunnen introduceren, moeten beleidsmakers die heffingen kunnen ontwerpen en introduceren die een nauwe samenhang vertonen tussen de betaling en het profijt van de heffing. Om een dergelijke samenhang te verwezenlijken, kan verwacht worden dat beleidsmakers kiezen voor het opleggen van bestemmingsheffingen of belastingen op een beperkte groep goederen en/of op een beperkt deel van de bevolking (bijvoorbeeld diegenen die binnen de grenzen van een milieubeschermingsgebied wonen).

In Nederland is het beleid met betrekking tot ecologische belastingheffing met name uitgevoerd op basis van DD-benaderingen. Binnen de context van deze benaderingen zijn vooral milieubelastingen en bepaalde milieubestemmingsheffingen ingevoerd. Voor de verdere ontwikkeling van ecologische belastingheffing in dit land, moeten beleidsmakers rekening houden met de potentiële rol van lagere overheden. Om van die rol gebruik te kunnen maken, moeten beleidsmakers verdere mogelijkheden voor deze overheden creëren om een ecologische belastingpolitiek te kunnen voeren. Mogelijkheden in deze zin bestaan uit het uitbreiden van de mogelijkheden om milieubeleid in lokale en regionale belastingen in te bouwen, om relevante belastinggrondslagen te verbreden en om een (verdere) ecologische differentiatie van belastingtarieven tot stand te brengen. Beleidsmakers moeten daarnaast deze mogelijkheden ook inkaderen in het huidige gebiedsgerichte milieubeleid en binnen het beleid dat gericht is op het verwezenlijken van interjurisdictionele samenwerking.

Concluderend kan worden gesteld dat deze studie, anders dan de meeste studies over dit onderwerp, aantoont dat beleidsmakers voor de daadwerkelijke ontwikkeling van haalbare ecologische belastingen, kunnen kiezen tussen een geleidelijk of een meer drastisch beleid. Alhoewel het type, het ontwerp en de structuur van haalbare 
ecologische belastingen onder beide beleidsopties verschillen, toont de studie ook aan dat beide benaderingen een aantal gemeenschappelijke elementen bezitten die mede bepalend zijn voor de haalbaarheid van ecologische belastingen. Het gebruiken van bestemmingsheffingen, belastingfaciliteiten en het inkaderen van het beleid met betrekking tot ecologische belastingheffing in het huidige gebiedsgerichte milieubeleid en in het beleid gericht op samenwerking tussen overheden, vormen de belangrijkste gemeenschappelijke elementen. De studie toont ook aan dat in het algemeen, en met betrekking tot Nederland in het bijzonder, relatief kleine beslissingseenheden (bijvoorbeeld gemeenten, provincies, waterschappen) een rol kunnen vervullen in de verdere ontwikkeling van haalbare ecologische belastingen. 


\section{Curriculum Vitae (English)}

Aggie Paulus was born in Maastricht on July 22, 1967. From 1979 to 1985 she attented secondary school (VWO/Atheneum) at the Sint Maartens College in Maastricht. From September 1985 to May 1990, she studied General Economics at the Faculty of Economics and Business Administration at the University of Limburg in Maastricht. In May 1990 she received her Master's degree (Cum laude). For her master's thesis on the feasibility of a negative income tax in the Netherlands, she received the first Wall Street Journal Europe Student Achievement Award (September, 17, 1990). From August 1990 to August 1991, she worked as a teaching assistant professor at the Quantitative Economics Department of the University of Limburg. From August 1991 to August 1995, she worked as a research assistant (AiO) at the General Economics Department of the same university.

\section{Curriculum Vitae (Dutch)}

Aggie Paulus werd geboren in Maastricht op 22 juli 1967. Van 1979 tot en met 1985 volgde zij een VWO/Atheneum opleiding aan het Sint Maartenscollege te Maastricht. Vanaf September 1985 tot en met Mei 1990 studeerde zij algemene economie aan de Faculteit der Economische Wetenschappen van de Rijksuniversiteit Limburg in Maastricht. In mei 1990 studeerde ze cum laude af. Voor haar doctoraalscriptie over de haalbaarheid van een systeem van negatieve inkomstenbelasting in Nederland, ontving zij de eerste Wall Street Journal Europe Student Achievement Award (17 September, 1990). Van augustus 1990 tot augustus 1991 was zij werkzaam als toegevoegd docent bij de vakgroep Kwantitatieve Economie van de Rijksuniversiteit Limburg. Van augustus 1991 tot augustus 1995 was zij als AiO verbonden aan de vakgroep Algemene Economie van diezelfde universiteit. 